\title{
Integrated Development and Testing Plan for the Plutonium Immobilization Project
}

July 1998

Lawrence Livermore National Laboratory Westinghouse Savannah River Company Argonne National Laboratory

Pacific Northwest National Laboratory 


\section{DISCLAIMER}

This document was prepared as an account of work sponsored by an agency of the United States Government. Neither the United States Government nor the University of California nor any of the employees, makes any warranty, express or implied, or assumes any legal liability or responsibility for the accuracy, completeness, or usefulness of any information, apparatus, product, or process disclosed, or represents that its use would not infringe privately owned rights. Reference herein to any specific commercial product, process, or service by trade name, trademark, manufacturer, or otherwise, does not necessarily constitute or imply its endorsement, recommendation, or favoring by the United States Government or the University of California. The views and opinions of authors expressed herein do not necessarily state or reflect those of the United States Government or the University of California, and shall not be used for advertising or product endorsement purposes.

This report has been reproduced directly from the best available copy.

Available to DOE and DOE contractors from the

Office of Scientific and Technical Information

P.O. Box 62, Oak Ridge, TN 37831

Prices available from (423) 576-8401

Available to the public from the National Technical Information Service

U.S. Department of Commerce 5285 Port Royal Rd., Springfield, VA 22161 


\section{Integrated Development and Testing Plan for the Plutonium Immobilization Project}

July 1998

Lawrence Livermore National Laboratory Westinghouse Savannah River Company

Argonne National Laboratory

Pacific Northwest National Laboratory 



\section{Table of Contents}

\section{OVERVIEW}

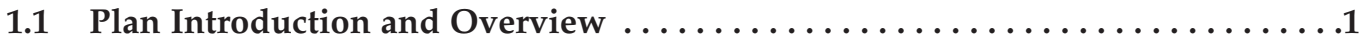

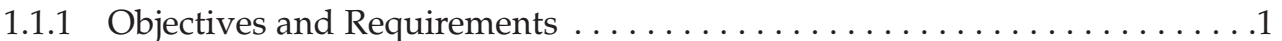

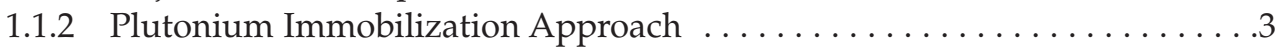

1.1.3 Development and Testing Approach and Overview ..............4

1.1.4 Summary of Development and Testing Activities $\ldots \ldots \ldots \ldots \ldots$

1.1.5 Organization of Plan . . . . . . . . . . . . . . . . . . . . . . . 13

1.1.6 Major Milestones . . . . . . . . . . . . . . . . . . . . . . . . . . . . . . . . . . 14

1.1.7 Development and Testing Program Budgets . . . . . . . . . . . 16

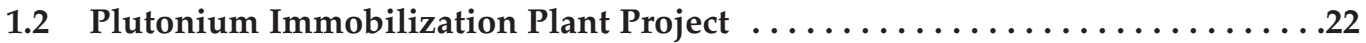

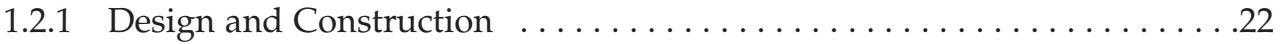

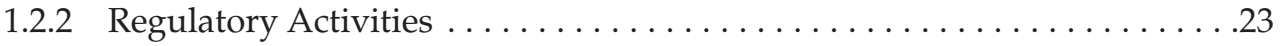

1.2.3 Facility Commissioning, Startup, and Operations $\ldots \ldots \ldots \ldots \ldots .23$

1.2.4 Plant Technical Support $\ldots \ldots \ldots \ldots \ldots \ldots \ldots \ldots \ldots \ldots \ldots \ldots \ldots \ldots \ldots \ldots \ldots \ldots .23$

1.3 Immobilized Waste Form Licensing and Qualification $\ldots \ldots \ldots \ldots \ldots \ldots .25$

1.3.1 Office of Civilian Radioactive Waste Management Plan to Incorporate Plutonium Waste Form in Repository . . . . . . . . . . . . . . . . 25

1.3.2 Immobilization Project Activities Supporting Licensing and Qualification for Repository Disposal $\ldots \ldots \ldots \ldots \ldots \ldots \ldots \ldots \ldots$

\section{DEVELOPMENT AND TESTING ACTIVITY PLANS}

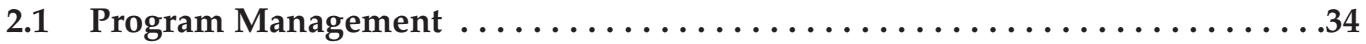

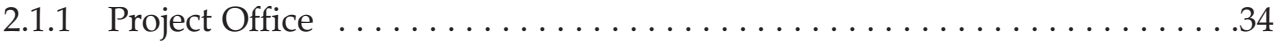

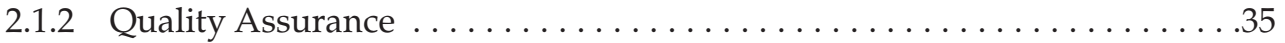

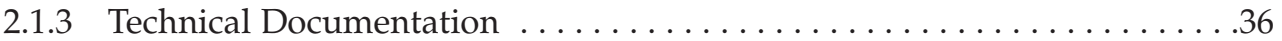

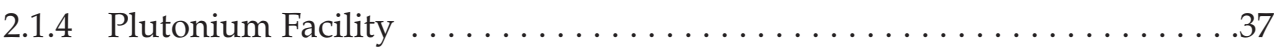

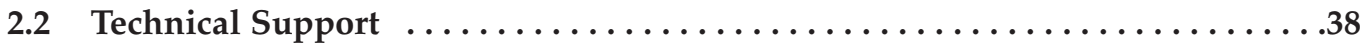

2.2.1 Feed Materials Characterization and Blending $\ldots \ldots \ldots \ldots \ldots \ldots$

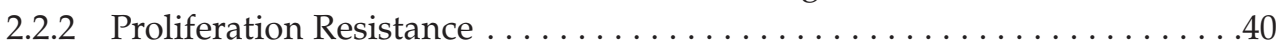

2.2.3 System Integration and Cross-Cutting Functions $\ldots \ldots \ldots \ldots \ldots \ldots . \ldots$ 


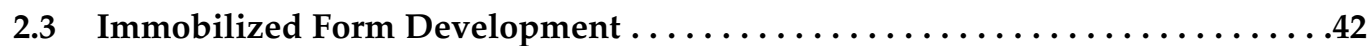

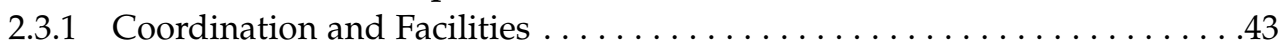

2.3.2 Basic Formulation and Process Parameters . . . . . . . . . . . . . . 45

2.3.3 Form Qualification Samples and Data . . . . . . . . . . . . . .47

2.3.4 Product Control Model Development ......................50

2.4 Performance Testing and Qualification for Repository $\ldots \ldots \ldots \ldots \ldots \ldots 5$

2.4.1 Form Performance Testing and Dissolution Modeling ..............56

2.4.1.1 Radiation-Damaged Sample Synthesis . . . . . . . . . . . . . . .56

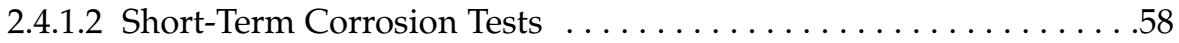

2.4.1.3 Long-Term Corrosion Tests . .......................59

2.4.1.4 Integrated Corrosion Tests ......................61

2.4.1.5 Single-Pass Flow-Through Tests $\ldots \ldots \ldots \ldots \ldots \ldots \ldots . \ldots 63$

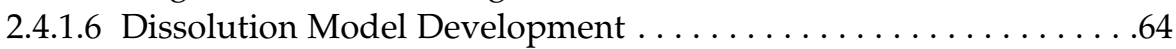

2.4.1.7 Physical Property Measurements $\ldots \ldots \ldots \ldots \ldots \ldots \ldots \ldots . \ldots \ldots$

2.4.2 Thermodynamic Data Determination and Validation . . . . . . . . . .66

2.4.2.1 Aqueous Solubility/Speciation Measurements .............66

2.4.2.2 Solid-Phase Enthalpy and Entropy Measurements ...........68

2.4.3 Form Qualification and Repository Interactions . . . . . . . . . . . . . 69

2.5 Plutonium Conversion Process/Equipment Development .............72

2.5.1 Material Receipt and Storage . . . . . . . . . . . . . . . . . . .74

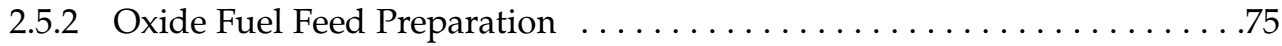

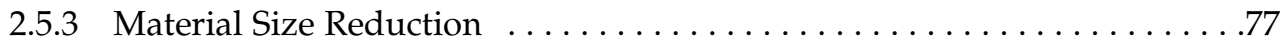

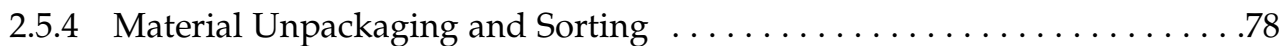

2.5.5 Metal Fuel Feed Preparation . . . . . . . . . . . . . . . . . . . . . 80

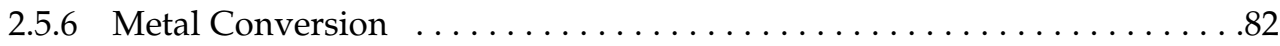

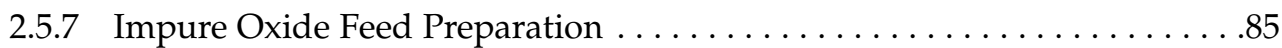

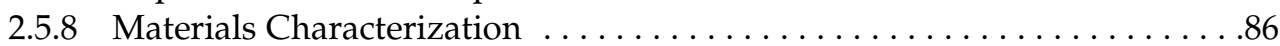

2.5.9 Material Control and Accountability $\ldots \ldots \ldots \ldots \ldots \ldots \ldots \ldots \ldots \ldots \ldots$

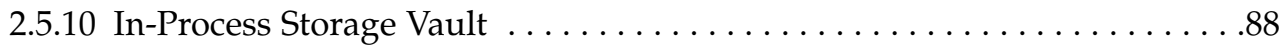

2.6 First-Stage Immobilization Process/Equipment Development $\ldots \ldots \ldots \ldots \ldots 90$

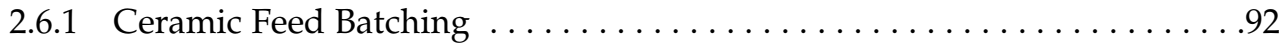

2.6.2 Ceramification Subsystem Development and Testing $\ldots \ldots \ldots \ldots \ldots 93$

2.6.2.1 Ceramification Process Development ..................94

2.6.2.2 Ceramification Equipment Development . . . . . . . . . . .96

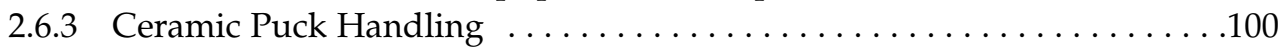

2.6.4 Puck NDE for Process Control . . . . . . . . . . . . . . . . . . . . . . . . . . 102

2.6.5 SNM Material Accountability . . . . . . . . . . . . . . . . . . . . 104

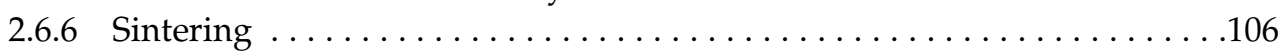

2.6.7 Recycle of Unacceptable Materials . . . . . . . . . . . . . . . . 108

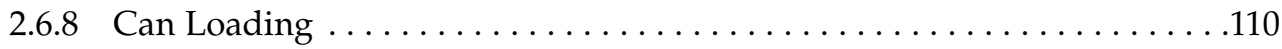

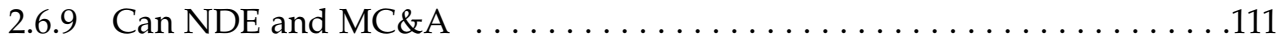

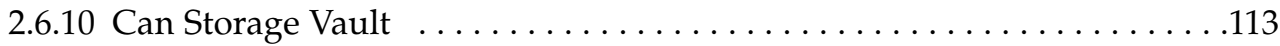


2.7 Second-Stage Immobilization Process/Equipment Development . . . . . . . 114

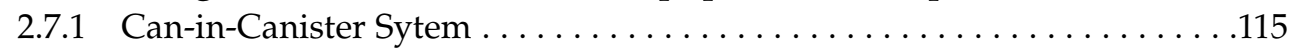

2.7.1.1 Can-in-Canister Design and Assembly . . . . . . . . . . . . . . . 115

2.7.1.2 Canister Pour Analysis and Testing . . . . . . . . . . . . . . . . .117

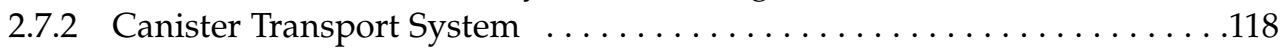

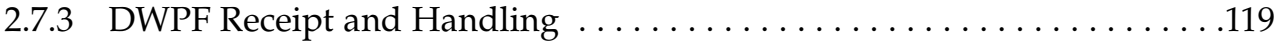

2.8 Plant Equipment Testing and Demonstrations $\ldots \ldots \ldots \ldots \ldots \ldots \ldots \ldots \ldots . \ldots \ldots$

2.8 .1 Ceramic Process Test Facility . . . . . . . . . . . . . . . . . . . . 121

2.8.2 Plutonium Process Support Laboratory . . . . . . . . . . . . . . 123

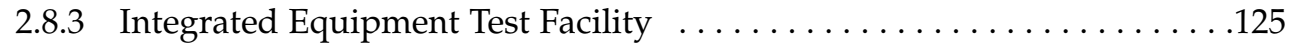

2.9 National Environmental Policy Act Support ..........................

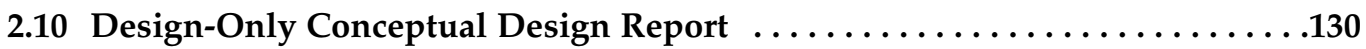

APPENDIX A

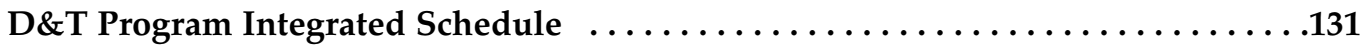

APPENDIX B

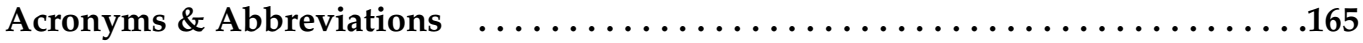




\section{LIST OF ILLUSTRATIONS}

\section{LIST OF FIGURES}

\section{OVERVIEW}

Figure 1-1 Ceramic Can-in-Canister Concept $\ldots \ldots \ldots \ldots \ldots \ldots \ldots$

Figure 1-2 Plutonium Immobilization Process $\ldots \ldots \ldots \ldots \ldots \ldots \ldots \ldots$

Figure 1-3 Integrated Plutonium Immobilization Process Flow Diagram . . . . . .4

Figure 1-4 Immobilization Project Top Level Schedule . . . . . . . . . . . . . . . 5

Figure 1-5 Immobilization Project Development Logic and Linkages . . . . . . . . 5

Figure 1-6 Immobilization D\&T Program Organization . . . . . . . . . . . . . .

Figure 1-7 Immobilization D\&T Work Breakdown Structure . . . . . . . . . . . . 9

Figure 1-8 Repository Licensing Schedule . . . . . . . . . . . . . . . .25

Figure 1-9 Logic Diagram for Repository Licensing Process . . . . . . . . . 26

Figure 1-10 Timeline Showing the Relationship Between the Repository Licensing Schedule and Major Immobilization Project Deliverables Related to Repository Licensing and Qualification ...........32

Figure 1-11 Linkages of Activities and Data for Qualifying the Immobilized Waste Form for Repository Disposal . . . . . . . . 33

\section{DEVELOPMENT AND TESTING ACTIVITY PLANS}

Figure 2-1 Baseline Ceramic Composition Showing the Major

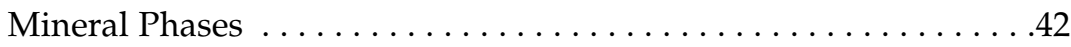

Figure 2-2 Sample Series Relationship to the Form Development Tasks . . . . . 44

Figure 2-3 Process Flow Diagram ........................73

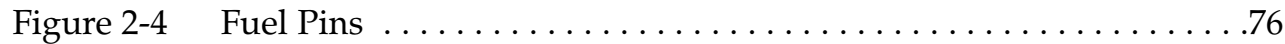

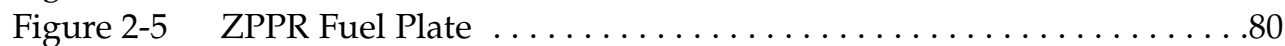

Figure 2-6 The Hydriding-Nitriding Stage of the HYDOX Concept for

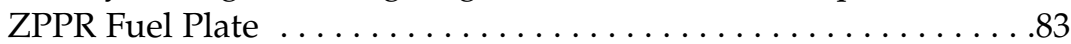

Figure 2-7 First-Stage Immobilization Process Flow Diagram . . . . . . . . . .91

Figure 2-8 Ceramification Subsystem Testing Configuration . . . . . . . . . . . 97

Figure 2-9 Second-Stage Immobilization Process Flow Diagram . . . . . . . . . 114

Figure 2-10 Can-in-Canister Assembly . . . . . . . . . . . . . . . . . . . . . 115 


\section{LIST OF TABLES}

\section{OVERVIEW}

Table 1-1 Assumptions and Requirements for the Immobilization Project . . . .2

Table 1-2 Data Needs for Repository Licensing Analyses . . . . . . . . . . . . .27

\section{DEVELOPMENT AND TESTING ACTIVITY PLANS}

Table 2-1

Table 2-2
Preliminary Baseline Composition and Feed Specifications . . . . . .46

Sample Types, Test Types, and Approximate Numbers of

Samples to Be Tested .56 


\section{Overview}

\subsection{PLAN INTRODUCTION AND OVERVIEW}

This integrated plan for the DOE Office of Fissile Materials Disposition (MD) describes the technology development and major project activities necessary to support the deployment of the immobilization approach for disposition of surplus weapons-usable plutonium. The plan describes details of the development and testing (D\&T) tasks needed to provide technical data for design and operation of a plutonium immobilization plant based on the ceramic can-in-canister technology (Immobilization Fissile Material Disposition Program Final Immobilization Form Assessment and Recommendation, UCRL-ID-128705, October 3, 1997). The plan also presents tasks for characterization and performance testing of the immobilization form to support a repository licensing application and to develop the basis for repository acceptance of the plutonium form. Essential elements of the plant project (design, construction, facility activation, etc.) are described, but not developed in detail, to indicate how the D\&T results tie into the overall plant project. Given the importance of repository acceptance, specific activities to be conducted by the Office of Civilian Radioactive Waste Management (RW) to incorporate the plutonium form in the repository licensing application are provided in this document, together with a summary of how immobilization D\&T activities provide input to the license activity.

\subsubsection{Objectives and Requirements}

The ultimate goal of the Immobilization Project is to develop, construct, and operate facilities that will immobilize from about 18 to 50 tonnes (MT) of U.S. surplus weaponsusable plutonium materials in a manner that meets the "spent fuel" standard (Fissile Materials Storage and Disposition Programmatic Environmental Impact Statement Record of Decision, Storage and Disposition Final PEIS, issued January 14, 1997, 62 Federal Register 3014) and is acceptable for disposal in a geologic repository. In the can-in-canister technology, this is accomplished by encapsulating the plutonium-containing ceramic forms within large canisters of high level waste (HLW) glass. Deployment of the immobilization capability should occur by 2006 and be completed within 10 years. In support of this ultimate goal, the principal objective of the D\&T program is:

To establish the technical basis for the design, construction, and operation of the U.S. capability to immobilize surplus weapons-usable plutonium in a suitable and costeffective manner.

Specific D\&T objectives include:

- Development of an immobilization form that: meets nonproliferation objectives for plutonium disposition; meets repository acceptance standards; and effectively incorporates desired concentrations of plutonium, neutron absorbers, and expected impurities (especially uranium).

- Development of necessary and sufficient technical data on the immobilization processes and processing equipment to support the design of a cost-effective immobilization plant and the acceptance of the waste form product. 
- Provision for an efficient and effective technology transfer from the multiple laboratory development effort to production plant site organization.

- Demonstration and validation of the can-in-canister technology at the immobilization site well in advance of plant startup to facilitate technology transfer and institutional processes necessary to implement immobilization.

Key programmatic requirements and assumptions are listed in Table 1-1.

Table 1-1. Assumptions and requirements for the Immobilization Project.

\section{Goal}

- Immobilize between 18 to 50 MT of surplus plutonium

- 32 MT from pits

- $18 \mathrm{MT}$ from other sources (source of minimum case)

\section{Feed Materials Conversion}

- Form of incoming material

- Oxide from pit disassembly and conversion

- Other oxides

- Fast Flux Test Facility (FFTF) fuel

- Metals and alloys, including Zero Power Plutonium Reactor (ZPPR) fuel

- Specifications on incoming material

- Conform to stabilization requirements of the Environmental Management (EM) Stabilization Program or feed acceptance specifications agreed to between the Immobilization Project and feed providers

- Converted feed materials will be blended to levelize both the plutonium and uranium elemental and isotopic concentrations, and the impurity concentrations

- The conversion process for non-pit plutonium will be co-located with first-stage immobilization

\section{Immobilization}

- Baseline site and facilities

- Can-in-canister at the Savannah River Site (SRS)

- 221-F Canyon building or new facility to produce canned plutonium forms

- DWPF will supply the HLW glass and fill canisters containing plutonium forms

- Backup: Hanford's Fuels and Materials Examination Facility (FMEF) and planned HLW Vitrification Plant

- Radiation barrier

- Can-in-canister package meets the spent fuel standard

- HLW glass composition sufficient to produce an at least $100 \mathrm{rem} / \mathrm{hr}$ radiation field 1 meter from the accessible surface (without intervening shielding) measured at the mid-plane 30 years after fabrication

- Start date and completion schedule

- First production HLW glass pour into plutonium loaded canister in 2006

- Nominal campaign completed within 10 years

- Defense Waste Processing Facility (DWPF) assumptions

- Just-in-time delivery of canisters to DWPF

- DWPF operations will span completion of MD mission

- Safeguards and security will be upgraded as appropriate

- Additional MD canisters will not significantly extend or otherwise impact DWPF operations

\section{Repository Interface}

- Canisters will be stored at SRS until custody transfer to RW

- Repository qualification of the plutonium form to be part of D\&T program 


\subsubsection{Plutonium Immobilization Approach}

The can-in-canister, or external radiation barrier, approach is the baseline technology for the Immobilization Project (Gray and Gould, Immobilization Technology Down-Selection Radiation Barrier Approach, UCRL-ID-127320, May 23, 1997). In the two-part can-in-canister process, plutonium would be immobilized at a nominal $10 \mathrm{wt} \%$ concentration within titanate-based ceramic forms that are placed within metallic cans. Multiple cans of the plutonium forms containing about $28 \mathrm{~kg}$ plutonium would be encapsulated subsequently in HLW glass within a large canister, such as that currently being produced at the SRS's DWPF. The HLW glass provides the desired radiation barrier to enhance proliferation resistance of the immobilized plutonium. The can-in-canister concept is illustrated in Figure 1-1.

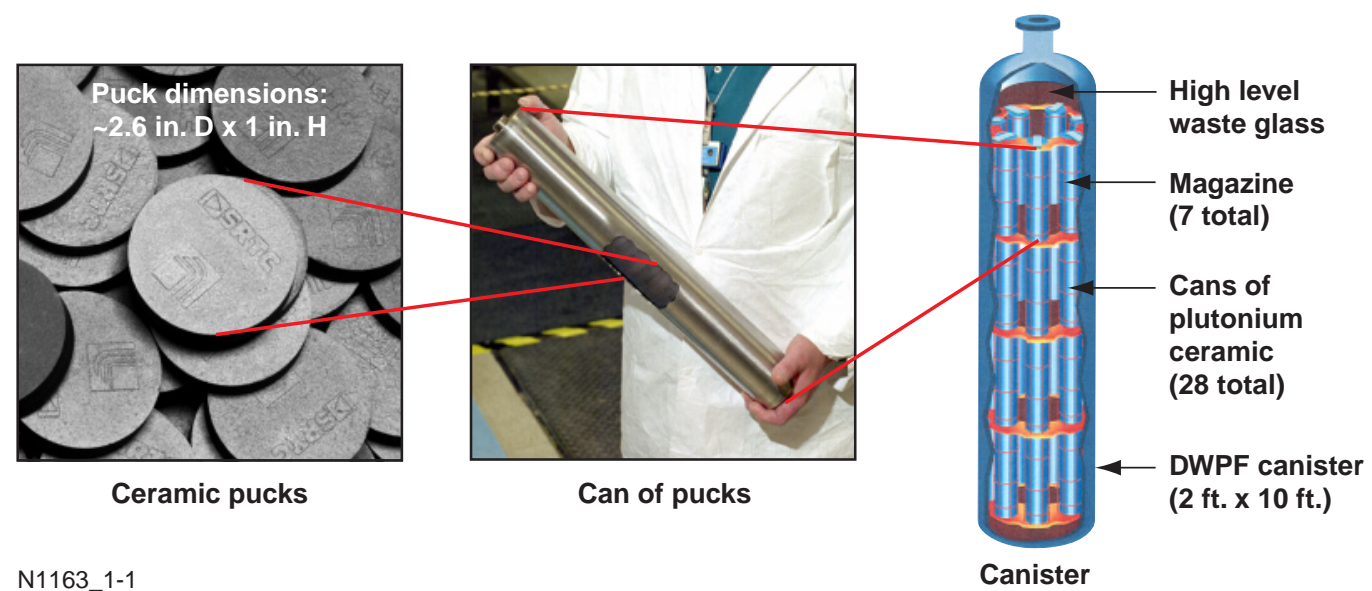

Figure 1-1. Ceramic can-in-canister concept.

Figures 1-2 and 1-3 show the key steps in the processes for making the ceramic can-incanister forms. As shown in Figure 1-2, the processes can be grouped into three major stages:

- Plutonium conversion, where the surplus plutonium-bearing materials are converted to an acceptable oxide feed.

- First-stage immobilization, where the plutonium oxide feed is blended, mixed with ceramic precursor materials, and subsequently solidified into ceramic forms.

- Second-stage immobilization, where the DWPF canisters containing several of the canned plutonium forms are assembled and then filled with HLW glass and sealed.

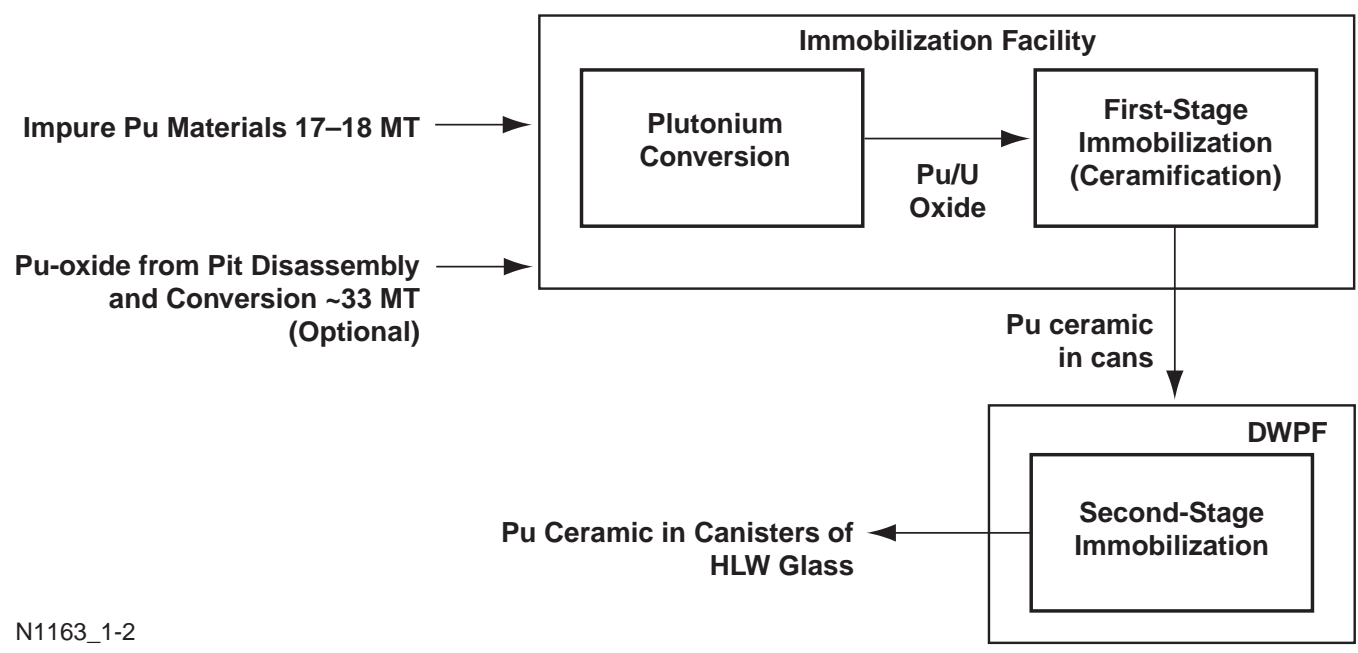

Figure 1-2. Plutonium immobilization process. 


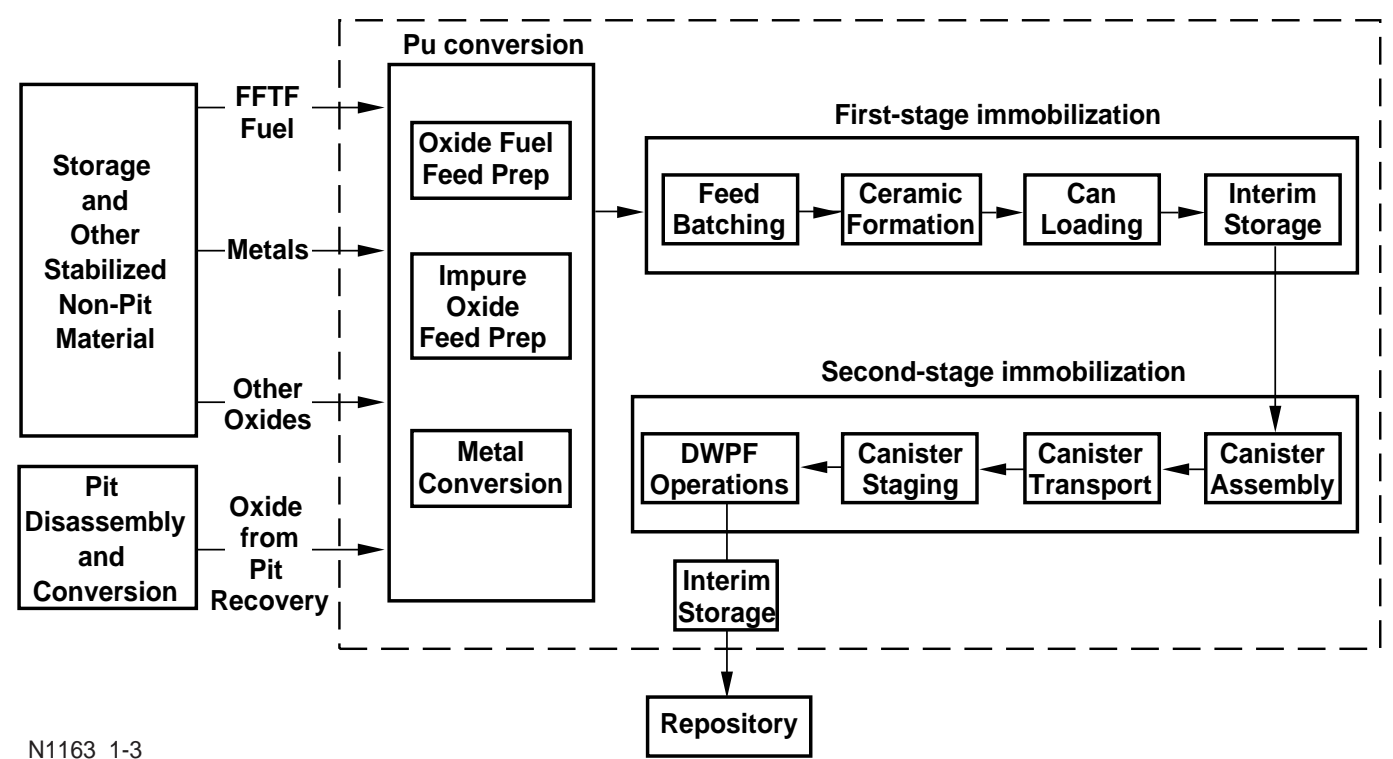

Figure 1-3. Integrated plutonium immobilization process flow diagram.

Key aspects of the technologies for plutonium materials conversion to oxide (e.g., for metals and impure, plutonium-bearing materials) and the immobilization of plutonium into ceramic are in preliminary (or laboratory-scale) stages of development. The D\&T activities described herein are intended to develop necessary and sufficient technical data for the design, construction, and operation of an immobilization plant as expeditiously as possible, and to provide the necessary data for a repository licensing application.

The D\&T program described in this plan supports: development of the plutonium ceramic form; development of technical data for plutonium conversion and first-stage immobilization; design of added capabilities to support the second-stage HLW immobilization step; and development of data for predicting performance of the immobilized plutonium HLW canisters in a federal repository.

\subsubsection{Development and Testing Approach and Overview}

The principal driver of the Immobilization Project is the concern about proliferation of surplus plutonium, which needs to be urgently addressed. This plan supports having a can-in-canister immobilization capability available by 2006 . The D\&T program described in this plan has been tailored to provide timely technical data needed for the design, construction, and operation of the immobilization plant, and to support the development and submission of a repository licensing application in 2002.

Figure 1-4 shows a schedule depicting the major D\&T elements, and their linkages to the Immobilization Plant Project and the DOE integrated qualification process for the immobilized plutonium-HLW form involving MD, EM, and RW. Key project dates are indicated in the figure. Figure 1-5 is a logic chart that provides information on the linkages and the information flow between the key program elements. To support a June 2006 "hot" startup of the immobilization plant, the D\&T program must provide data on processing conditions, equipment specifications, and functional design requirements by September 2000. Actual designs of special, first-of-kind equipment will be provided to the project by the D\&T team during FY01. Additionally, technical data on the plutonium immobilization form's performance characteristics in the repository environment must be developed and evaluated to qualify the form for disposal in the Federal Waste Management System. This 
Immobilization Project Schedule

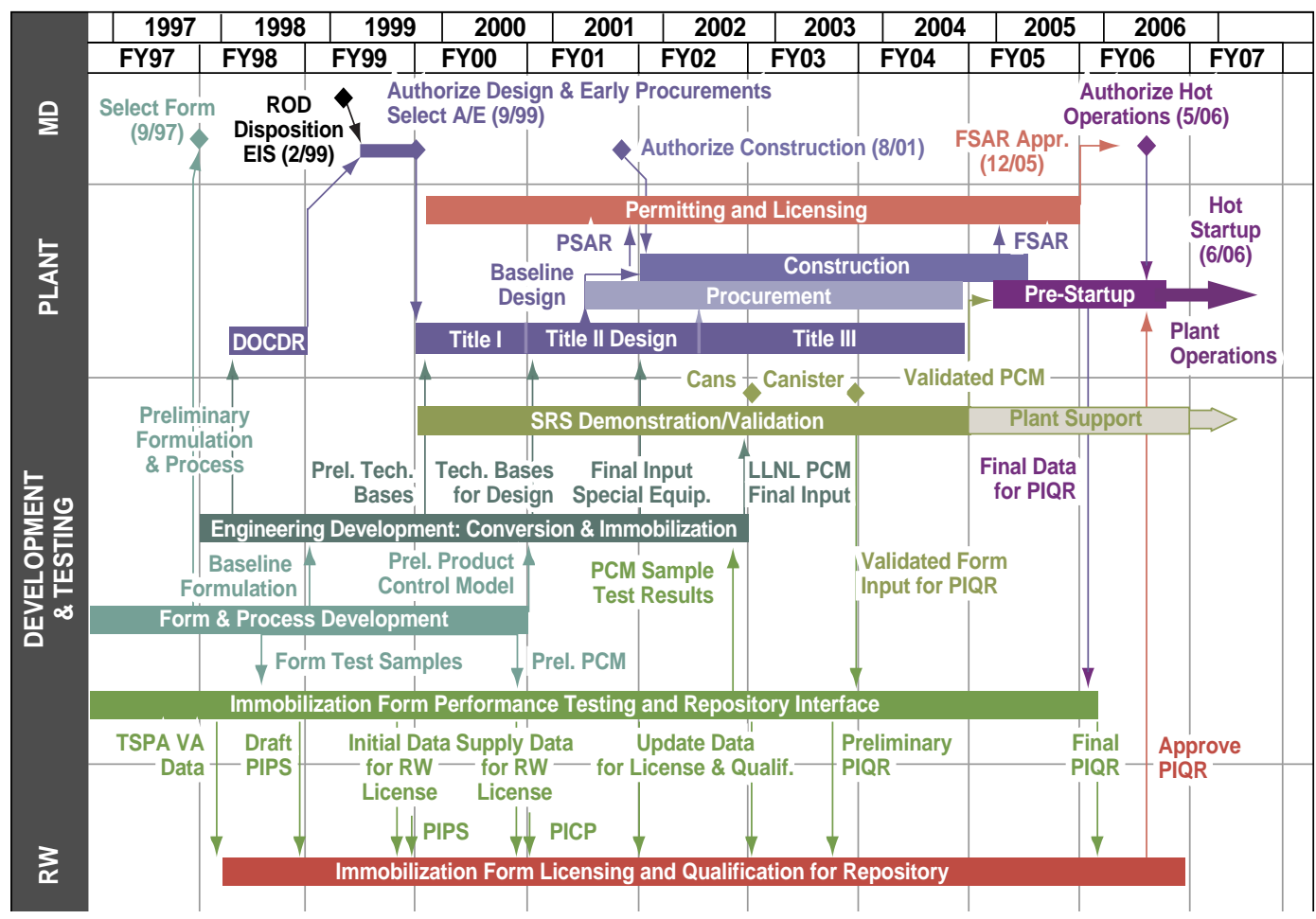

Figure 1-4. Immobilization Project top level schedule.

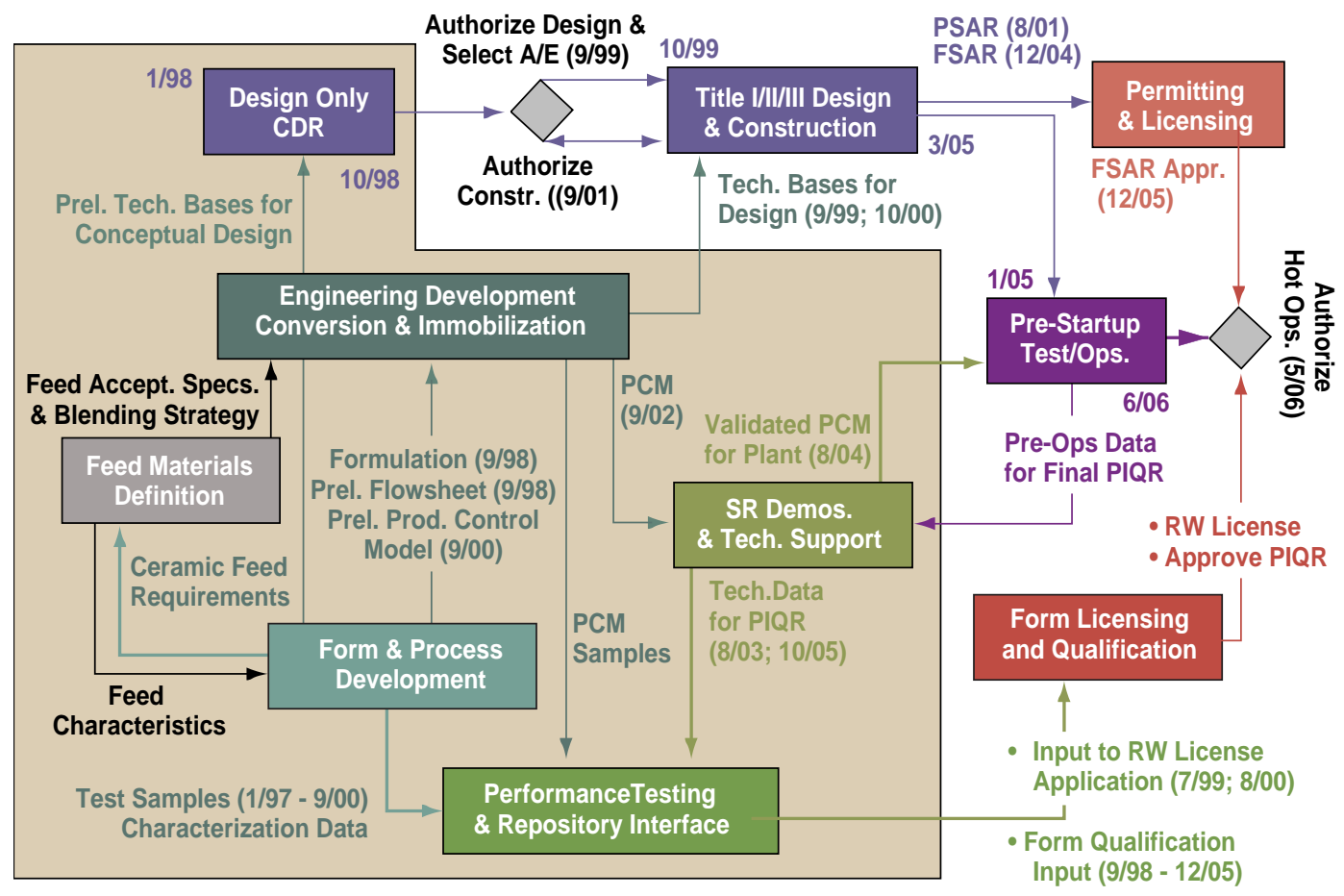

Figure 1-5. Immobilization Project development logic and linkages. 
section summarizes the overall D\&T approach for providing these data, identifies the organizations involved, and discusses how organizational roles evolve as the program is implemented. Details of the D\&T approach are contained in Chapter 2 of this document.

\section{Elements of the D\&T Program}

The following core technology elements of the D\&T program are described in this plan:

- Immobilized form development, which involves formulation of the composition, configuration of the plutonium ceramic product, and development of the product control model (PCM).

- Performance testing and repository qualification, which involves development of data and models for behavior of the immobilized form in the repository, testing of the performance characteristics of the ceramic forms under simulated repository conditions, testing of the ceramic forms for product consistency, and working with RW to qualify the plutonium waste form for repository disposal.

- Plutonium conversion, which involves process and equipment development and testing for the front end processing system to convert the incoming feed materials into a suitable oxide for immobilization.

- First-stage immobilization, which involves process and equipment D\&T for the processing system to condition the plutonium feed oxides with ceramic precursor oxides and neutron absorbers and to fabricate the canned plutonium ceramic forms.

- Second-stage immobilization, which involves D\&T of equipment and systems for those operations associated with the canister and the pouring of HLW glass.

- Demonstration of the can-in-canister technology at the immobilization site to validate process conditions and to facilitate institutional processes, stakeholder support, U.S. nonproliferation objectives, and technology transfer.

Cross-cutting these major task areas are activities grouped under the category of technical support. These tasks include feed materials characterization and blending, proliferation resistance, and cross-cutting systems integration activities (such as materials control and accountability [MC\&A] and dose assessment). In addition, separate activities provide support for the experimental impact statement (EIS) and the design-only conceptual design report (DOCDR).

As illustrated in Figures 1-4 and 1-5, the D\&T activities will be coordinated with and linked to the Immobilization Plant Project, which is discussed briefly in Section 1.2 of this plan. The first steps in the project will be to conduct preconceptual engineering studies to develop facility data for the site EIS (9/98), and to develop sufficient conceptual design information (DOCDR, 9/98) to support funding in FY00 for a design-only project. Subsequently, the project will execute the preliminary and detailed designs beginning 10/99. A key deliverable of the D\&T program will be a final technical data report (TDR) for design of the immobilization plant in the fourth quarter of 2000. The TDR will define feed specifications, process parameters, equipment requirements, and functional design criteria for the plant project and product specifications for the repository licensing and plant operations. Members of the D\&T team will provide technical support and liaison to the plant project team during the design, construction, and activation of the immobilization plant as required.

Successful deployment of immobilization on the aggressive schedule described in this plan will require strong cooperation and close coordination among the D\&T team, the architect-engineer (A/E) team, the plant operations team, and the DOE team (MD, EM, and RW). The overall program will evolve from a D\&T focus (during FY98-00), to design (during FY00-02), to construction (during FY02 through FY05), and finally, to operations 
(beginning in FY06). Each of the teams must be involved during these successive stages of deployment, with the leadership shifting from the D\&T team to the project/operations team. Specific roles and responsibilities will be defined in a project management plan and in memoranda of understanding among the teams.

\section{Participating Organizations}

The organization of the immobilization D\&T team is shown in Figure 1-6. Lawrence Livermore National Laboratory (LLNL) is the DOE technical lead laboratory for the Immobilization Project. It has overall technical responsibility for the D\&T program. The preferred site for plutonium immobilization is the Savannah River Site, because use of the DWPF would allow startup to proceed on the aggressive 2006 schedule and would utilize the site's existing plutonium infrastructure. Consequently, this plan involves the Westinghouse Savannah River Company's Technology Center (SRTC) and plant organization in the development of the immobilization technology.

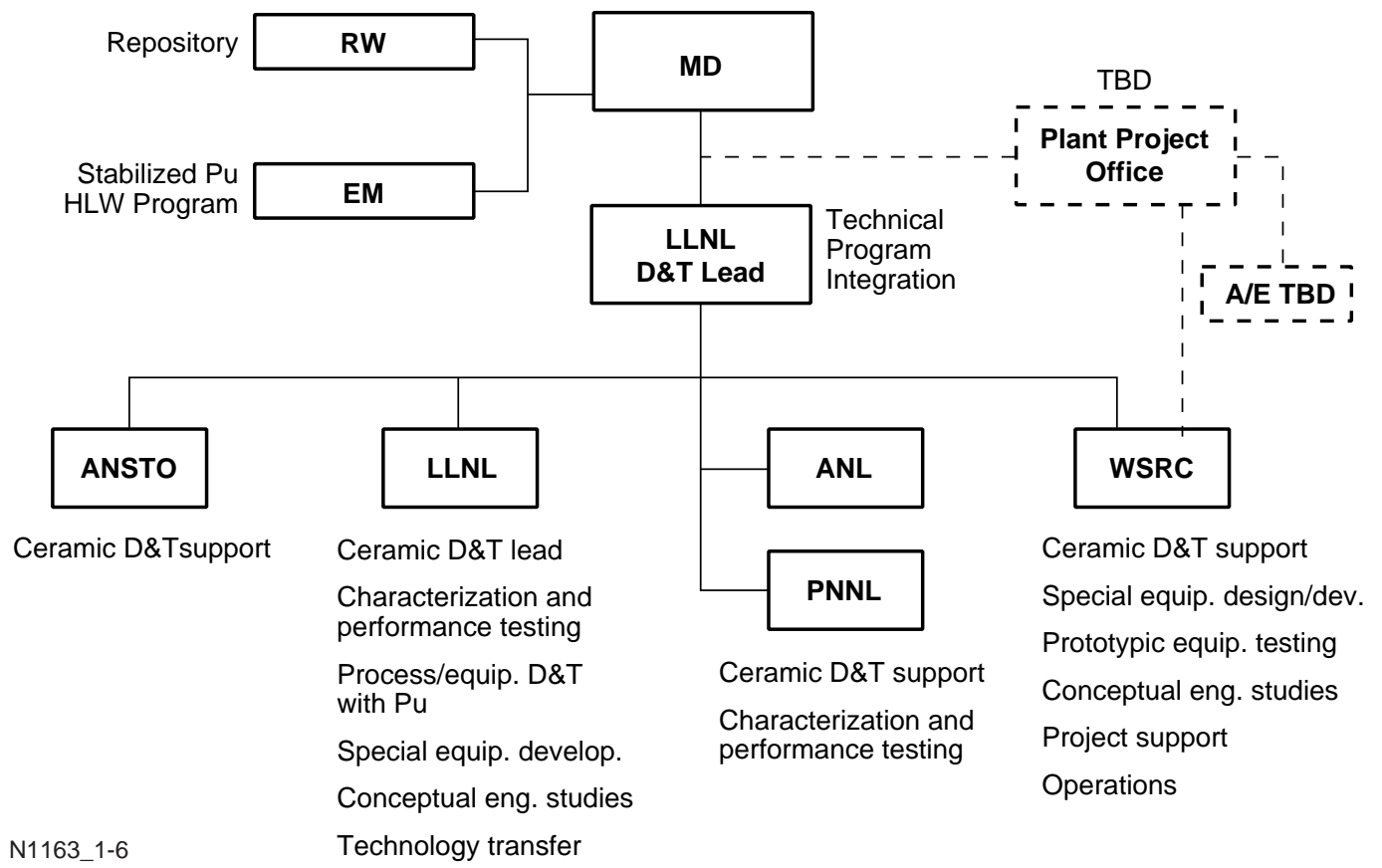

Figure 1-6. Immobilization D\&T program organization.

The main participants in the immobilization D\&T program and their primary responsibilities are listed below. A number of responsibilities are shared among the participating organizations.

- LLNL-Program technical lead, form characterization and qualification, ceramic form development lead, process/equipment development with plutonium, and process systems testing and validation for both conversion and immobilization.

- Westinghouse Savannah River Company (WSRC) - Partner with LLNL in form qualification and repository interface, form development, process/equipment development activities, process/product validation testing with plutonium, and technology transfer to the plant, and full-scale cold canister pour experiments. (Full-scale canister pours will be done at Clemson.)

- Australian National Science and Technology Organization (ANSTO)—Ceramic formulation development and characterization testing.

- Argonne National Laboratory (ANL)-Properties/characterization of immobilization forms, and performance testing. 
- Pacific Northwest National Laboratory (PNNL)—Properties/characterization of immobilization forms, and performance testing.

- RW and its subcontractors-Repository performance assessments, criticality analysis, and oversight of waste form acceptance process.

- EM-Interface issues related to feed materials to plutonium conversion.

- EM and vitrification plant operator-Second-stage immobilization interface issue resolution and waste form acceptance.

A number of subcontractors are, or will be, supporting specific task areas. They include: Bechtel Corporation (pre-conceptual engineering studies); Los Alamos National Laboratory (materials accountability measurements); Lawrence Berkeley National Laboratory (chemical valence state measurements); Massachusetts Institute of Technology (thermodynamic properties of neutron absorbers); University of California at Davis (thermodynamic properties of constituents in titanate ceramic); and Clemson University (ceramic development support).

\subsubsection{Summary of Development and Testing Activities}

A brief summary of each of the programmatic activity areas is given in this section. Figure 1-7 shows the Immobilization D\&T work breakdown structure (WBS). The detailed plans for these activities are described in Chapter 2, which is organized according to the WBS.

\section{Program Management}

Program management consists of four functions:

1. Project management provides the oversight necessary to manage and control cost, schedule, and technical output of the Immobilization Project in a manner acceptable to the customers (MD, RW, EM, and the plant project).

2. The quality assurance (QA) activity involves the establishment and implementation of a QA Program for the Immobilization Project and the development of a QA plan and procedures. QA provides the plans, procedures, and controls consistent with RW Quality Assurance Requirements and Description (QARD) 0333P that are required for repository acceptance of the immobilized plutonium form and the immobilization plant licensing and design activities.

3. Technical documentation creates and maintains a document tracking and control system for the immobilization program. This task also coordinates the development of the TDRs, which serve as the major deliverable from the D\&T program to the Immobilization Plant Project repository licensing and plant operations.

4. The plutonium facility task provides funding for the plutonium facility infrastructure that supports the D\&T activities and manages the conduct of work in the facility.

\section{Technical Support}

Technical support activity encompasses program tasks that serve as integration functions across the core technical program elements. The major elements in this program area are:

- Feed materials characterization and blending

- Proliferation resistance

- System integration and cross-cutting functions. 


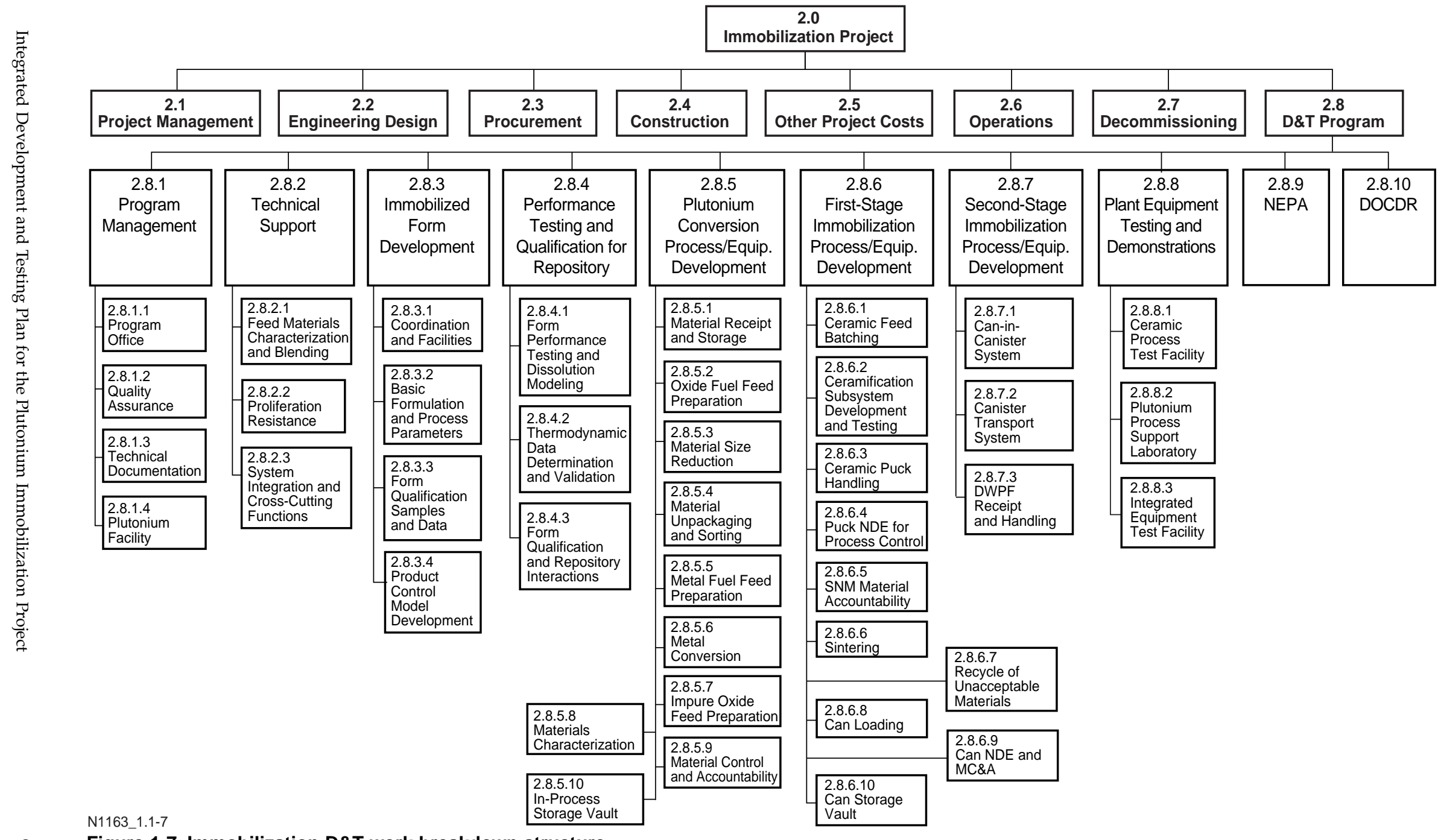


Immobilized Form Development

This element of the D\&T program will provide:

- Compositions of the ceramic immobilization form that accommodate the range of plutonium feed materials expected

- The related processing parameters for fabricating the plutonium forms

- Important physical and chemical properties of the final form needed for process/equipment development, production, and waste form qualification

- A preliminary product control model (PCM) that establishes acceptable ranges for feed compositions and processing parameters.

These development activities involve: lab-scale experiments with plutonium, uranium, desired neutron absorber elements, and the other materials contained in the expected feed; non-radioactive experiments with surrogate materials; and analysis of data related to the feed materials and the physical chemistry of the ceramic form.

As illustrated in Figure 1-5 above, data provided by form/process development support equipment development, conceptual design of the immobilization plant, and form performance testing and qualification.

\section{Performance Testing and Qualification for Repository}

The plutonium ceramic form in the HLW glass canister must be tested, assessed, and qualified for acceptance in the federal geologic repository in advance of the immobilization plant's operation. The performance testing and qualification process involves interactions among the Immobilization Project team and the MD, RW, and EM organizations of DOE. This process, which is addressed Section 1.3, involves the following general activities:

- Characterization of the performance of the plutonium forms made in the D\&T program under simulated repository conditions (MD).

- Performance testing and assessment of the plutonium can-in-canister waste package in the repository environment (RW).

- Development of analytical models and required data for the calculation of the long-term, in-repository behavior of the plutonium-bearing forms (MD, RW).

- Development and approval of immobilized form acceptance specifications and documentation (MD, RW, EM).

- Development of pertinent process and product data from the validation tests in the D\&T program and from trial runs in the production facilities prior to actual startup (MD).

\section{Plutonium Conversion Process/ Equipment Development}

The plutonium conversion processes consist of several unique mechanical and chemical operations that will require D\&T of prototypic equipment* with either actual plutonium materials or non-radioactive surrogate materials. The high radiation levels of the plutonium feed materials, especially the fuel-grade plutonium, will require D\&T of remotely operated equipment and material transfer systems. The work with plutonium will be performed in the plutonium facilities at LLNL with WSRC participation. Development

*The terms "prototypic equipment," "prototype," or "prototypical" used in this plan denote experimental equipment having features similar, but not necessarily identical, to those expected for the plant; however, function and product should be the same. In some cases, prototypes will be plant-scale; in others, subscale prototypes will be tested. 
and testing with surrogate materials will be performed at SRS. (See sidebar, following page, for discussion of the overall strategy for development and validation testing of equipment for immobilization.)

\section{First-Stage Immobilization Process/ Equipment Development}

First-stage plutonium immobilization utilizes processes and equipment that are generally similar to those used in mixed oxide (MOX) fuel manufacturing. Thus, the equipment concepts needed can be adapted, to some extent, from existing industrial applications. Nevertheless, key process steps and equipment need to be developed and tested for the specific ceramic formulation with actual plutonium feed materials in an integrated system that is functionally prototypical, albeit at a reduced scale, of the eventual plant system. This will involve the feed (powder) preparation subsystem or module coupled to the ceramic formation operations. These modules will be tested with plutonium for product quality, radiation dose control, and plutonium MC\&A. This integrated subsystem test, which will be coupled to the plutonium conversion test system at LLNL, will be prepared and performed during FY98-FY01, and will involve both LLNL and WSRC personnel. Nondestructive evaluation (NDE) and MC\&A techniques for the ceramic product will be demonstrated in conjunction with the ceramic system tests. Material handling and transfer equipment, feed materials blending, and the ceramic canning module will be developed and tested with full-scale prototype equipment at SRS using surrogate materials.

\section{Second-Stage Immobilization Process/ Equipment Development}

Second-stage immobilization consists of operations that assemble the canisters containing the cans of plutonium ceramic forms, transport the canisters to the DWPF, and fill them with HLW glass. The major development tasks in this area involve design of the immobilization canister package, cold glass pour testing of prototype canisters, and D\&T of the canister loading module.

\section{Plant Equipment Testing and Demonstrations}

The final stages of process/equipment testing are planned to be performed by WSRC personnel in SRS facilities or at nearby Clemson University. In accordance with the development strategy described in the sidebar (following page), three different testing capabilities will be established for purposes of technology transfer, validation of equipment operability and maintainability, and plutonium "waste" form qualification.

A ceramic process test facility using plant-scale and plant-configured equipment will be established at Clemson University beginning in FY00 to perform full-scale testing of the critical ceramic powder operations using surrogate materials and uranium. These tests will evaluate processing parameters, oxide powder flow, and equipment operability and maintainability in a simulated plant equipment configuration. The Clemson tests will validate, at plant scale and configuration, the processing results from the ceramic system tests performed at LLNL (see First-Stage Immobilization Process/Equipment Development, above) with actual plutonium materials using somewhat smaller-scale equipment.

In conjunction with the Clemson facility, a smaller-scale ceramic testing line will be installed in a glove box facility at the SRTC during FY00-01 as part of its Plutonium Process Support Laboratory (PPSL). This facility will have functionally prototypic equipment that will be able to fabricate full-size plutonium ceramic forms (pucks) and also will be able to load the pucks into cans for subsequent emplacement in a can-in-canister assembly. The early focus of work in the PPSL (FY01-04) will be to transfer the ceramic fabrication technology from LLNL, validate the ceramic product chemistry over a wide range of feed impurities, and finalize the product control model for subsequent 


\section{Process and Equipment Development and Testing Strategy}

The planned plutonium immobilization facility has several important features that drive the development approach to establish the production process and define plant equipment systems. These features are:

- Glovebox confinement system for all plutonium material operations, many requiring special features to control dusting from plutonium oxide powder operations

- Automation and remote operation of equipment to achieve acceptably low radiation exposure to workers

- Many first-of-kind and mostly one-of-kind equipment items - many requiring iterative development, integration with other equipment, and testing to support design.

As a consequence of these unique features, many special equipment systems for the immobilization plant will be developed and designed by the D\&T team working with the operating contractor, the $\mathrm{A} / \mathrm{E}$, and commercial vendors who produce similar equipment systems. Where possible, commercially available equipment will be modified to be adaptable to the special applications associated with the immobilization process.

The process and equipment development approaches being used for the immobilization project account for the uniqueness, complexity, state of knowledge, and physical nature of the processing steps. Depending on which of these features apply, development of the processes and equipment systems for plutonium immobilization follows some combination of the following steps:

- Alternative evaluation and concept definition

- Feasibility testing

- Development of processing parameters using lab-scale equipment

- Engineering evaluation and design of prototypes for testing

- Testing of unit operations equipment with surrogate materials
- Testing integrated equipment systems with surrogate materials

- Testing unit operations and integrated equipment systems with plutonium.

The extent and nature of equipment testing needed to support design, construction, and acceptance for operations is dependent on equipment scaling features, sensitivity of the ceramic product, and complexity of the equipment, including its operability/maintainability in a plutonium environment. Four different engineering development approaches are being used for the various immobilization equipment modules (subsystems):

1. D\&T of plant-scale prototypic equipment with surrogate (non-plutonium) materials for systems involved in mechanical operations that are not product sensitive.

2. D\&T of plant-scale prototypic equipment with plutonium for systems involving or affecting chemical reactions that are material sensitive.

3. D\&T of subscale, functionally prototypic equipment with plutonium for product-sensitive (ceramic form) equipment in conjunction with testing plant-scale equipment with surrogates and uranium. (This combination of subscale testing with plutonium and plant scale testing using surrogate materials reduces costs and conserves plutonium materials and waste during the development phase.)

4. Engineering (analytical) evaluation and definition of functional/performance specifications for equipment systems not requiring one of the above development approaches (e.g., because of low complexity, easily adaptable commercial equipment, and/or use in non-plutonium environment).

The fact that the conversion and first-stage immobilization processes require relatively moderate batch sizes makes development/testing with fullsize equipment financially feasible. 
plant use. During this period, cans of ceramic forms may be generated as part of an integrated demonstration of the can-in-canister technology that would involve a full HLW glass pour into a can-in-canister in the DWPF well in advance of start-up of the immobilization plant.

A third equipment testing capability will be established at SRS in an existing plant building (246-F) for the purpose of integrating and testing automated equipment systems that perform the numerous plutonium material handling functions throughout the immobilization process. These tests, to be performed with surrogate materials (non-radioactive), will evaluate and validate the operational and maintenance aspects of the equipment systems and provide valuable input to the plant project.

\section{NEPA Support}

The National Environmental Policy Act (NEPA) EIS process requires the development of six site-specific data call reports to provide the facility and process data for the proposed Immobilization Plant located in new or existing facilities at either the Savannah River Site or the Hanford Reservation. Nine rough order of magnitude (ROM) cost estimates based on the EIS data will be developed to assist in MD's decision process.

\section{Design-Only Conceptual Design Report}

In order to support the budget planning process and the selection of the A/E, a DOCDR will provide a conceptual design of the immobilization plant and cost estimates for the preliminary and final design phases of the plant project. An ROM estimate of the capital and operating costs for the plant will also be developed.

\subsubsection{Organization of Plan}

This D\&T plan is organized into two chapters and an appendix. The remainder of this first chapter contains a brief description of:

- The Immobilization Project, which summarizes the engineering, design, and construction activities

- Repository qualification and licensing.

The second chapter is organized according to the D\&T WBS and contains detailed descriptions of the following plan activity elements:

- Program management

- Technical support

- Immobilized form development

- Performance testing and qualification for repository

- Plutonium conversion process/equipment development

- First-stage immobilization process/equipment development

- Second-stage immobilization process/equipment development

- Plant equipment testing and demonstrations

- NEPA Support

- DOCDR 
Finally, Appendix A contains a detailed, integrated schedule for all the activity elements and their linkages leading to the construction and activation of the production plant.

This plan is intended to be a "living document" and will be updated periodically as the experimental program and plant project progress.

\subsubsection{Major Milestones}

The major program milestones are indicated in the tables below.

\section{Program Management: Milestones}

\begin{tabular}{lccccc} 
Milestone & Date & LLNL & WSRC & ANL & PNNL \\
\hline Provide draft D\&T plan & $11 / 97$ & $\bullet$ & 0 & 0 & 0 \\
\hline Provide draft QA procedures & $9 / 98$ & 0 & $\bullet$ & & \\
\hline Provide draft project management plan & $10 / 98$ & $\bullet$ & 0 & & \\
\hline Provide D\&T plan & $8 / 98$ & $\bullet$ & 0 & 0 & 0 \\
\hline Update D\&T plan & $8 / 99$ & $\bullet$ & 0 & 0 & 0 \\
\hline Provide preliminary TDR & $10 / 99$ & $\bullet$ & 0 & & \\
\hline Provide TDR & $10 / 00$ & $\bullet$ & 0 & &
\end{tabular}

- Primary Responsibility

O Support Responsibility

Technical Support: Milestones

\begin{tabular}{lccccc} 
Milestone & Date & LLNL & WSRC & ANL & PNNL \\
\hline Provide feed material specification report & $7 / 98$ & $\bullet$ & 0 & & \\
\hline
\end{tabular}

\section{Immobilized Form Development: Milestones}

\begin{tabular}{|c|c|c|c|c|c|}
\hline Milestone & Date & LLNL & WSRC & ANL & PNNL \\
\hline Provide final baseline ceramic formulation & $9 / 98$ & ? & $\mathrm{O}$ & $\mathrm{O}$ & \\
\hline $\begin{array}{l}\text { Provide form summary report for repository license } \\
\text { application and preliminary TDR }\end{array}$ & $6 / 99$ & - & $\mathrm{O}$ & O & \\
\hline Provide preliminary PCM & $9 / 00$ & 0 & 0 & & \\
\hline
\end{tabular}


Performance Testing and Qualification for Repository: Milestones

\begin{tabular}{|c|c|c|c|c|c|}
\hline Milestone & Date & LLNL & WSRC & ANL & PNNL \\
\hline $\begin{array}{l}\text { Provide data input to RW for repository total system } \\
\text { performance assessment, viability assessment (TSPA-VA) }\end{array}$ & $11 / 97$ & $\bullet$ & & O & O \\
\hline Complete fabrication of samples for radiation damage studies & $7 / 98$ & & O & & $\bullet$ \\
\hline $\begin{array}{l}\text { Issue draft plutonium immobilization } \\
\text { product specification (PIPS) }\end{array}$ & $8 / 98$ & O & ○ & O & O \\
\hline $\begin{array}{l}\text { Issue preliminary integrated data report for } \\
\text { repository licensing application }\end{array}$ & $7 / 99$ & $\bullet$ & O & O & O \\
\hline Provide final PIPS & $8 / 99$ & O & $\bullet$ & O & O \\
\hline Provide final PICP & $8 / 00$ & O & • & 0 & 0 \\
\hline $\begin{array}{l}\text { Issue updated integrated data report for repository } \\
\text { licensing application }\end{array}$ & $8 / 00$ & $\bullet$ & 0 & 0 & 0 \\
\hline $\begin{array}{l}\text { Issue updated integrated data report for repository } \\
\text { licensing application }\end{array}$ & $8 / 01$ & $\bullet$ & 0 & & \\
\hline $\begin{array}{l}\text { Issue updated integrated data report for repository } \\
\text { licensing application }\end{array}$ & $9 / 02$ & - & 0 & & \\
\hline Provide preliminary PIQR & $8 / 03$ & 0 & $\bullet$ & & \\
\hline
\end{tabular}

\section{Plutonium Conversion Process/Equipment Development: Milestones}

\begin{tabular}{|c|c|c|c|c|c|}
\hline Milestone & Date & LLNL & WSRC & ANL & PNNL \\
\hline $\begin{array}{l}\text { Complete cold tests of metal feed prep and metal } \\
\text { conversion systems }\end{array}$ & $6 / 99$ & $\bullet$ & & & \\
\hline $\begin{array}{l}\text { Complete hot tests of metal feed prep and metal } \\
\text { conversion systems }\end{array}$ & $8 / 00$ & - & & & \\
\hline $\begin{array}{l}\text { Complete cold tests of oxide fuel feed prep } \\
\text { and material unpackaging and sorting }\end{array}$ & $9 / 00$ & & ○ & & \\
\hline Provide TDR for all plutonium conversion modules & $9 / 00$ & ○ & 0 & & \\
\hline $\begin{array}{l}\text { Provide final design package for metal feed prep } \\
\text { and conversion modules for supplemental TDR }\end{array}$ & $6 / 01$ & 0 & 0 & & \\
\hline $\begin{array}{l}\text { Provide final design package for oxide fuel feed prep, } \\
\text { material unpackaging and sorting, and material handling } \\
\text { systems for supplemental TDR }\end{array}$ & $6 / 01$ & & ○ & & \\
\hline
\end{tabular}

\section{First-Stage Immobilization Process/Equipment Development: Milestones}

\begin{tabular}{|c|c|c|c|c|c|}
\hline Milestone & Date & LLNL & WSRC & ANL & PNNL \\
\hline Complete evaluation of test feed batching system & $7 / 99$ & & $\bullet$ & & \\
\hline Provide process design criteria for TDR & $6 / 00$ & • & O & & \\
\hline Verify ceramic formation subsystem performance & $8 / 00$ & $\bullet$ & O & & \\
\hline Provide first-stage immobilization TDR & $9 / 00$ & $\bullet$ & O & & \\
\hline Provide supplemental TDR & $6 / 01$ & - & O & & \\
\hline $\begin{array}{l}\text { Provide design package for blending, material handling, } \\
\text { and puck loading modules for supplemental TDR }\end{array}$ & $6 / 01$ & $\mathrm{O}$ & $\bullet$ & & \\
\hline Provide PCM/report to SRS & $9 / 02$ & 0 & $\mathrm{O}$ & & \\
\hline
\end{tabular}


Second-Stage Immobilization Process/Equipment Development: Milestones

\begin{tabular}{|c|c|c|c|c|c|}
\hline Milestone & Date & LLNL & WSRC & ANL & PNNL \\
\hline $\begin{array}{l}\text { Provide design and plans for cold full-scale } \\
\text { canister experiments }\end{array}$ & $7 / 98$ & $\bullet$ & O & & \\
\hline Provide analysis of canister system for preliminary TDR & $9 / 99$ & & $\bullet$ & & $\bullet$ \\
\hline $\begin{array}{l}\text { Complete specifications and initial equipment } \\
\text { procurement for canister loading and assembly }\end{array}$ & $9 / 98$ & & $\bullet$ & & \\
\hline $\begin{array}{l}\text { Complete integration of canister receipt and handling } \\
\text { operations at DWPF and provide input for TDR }\end{array}$ & $6 / 00$ & & $\bullet$ & & \\
\hline
\end{tabular}

National Environmental Policy Act Support: Milestones

\begin{tabular}{lccccc} 
Milestone & Date & LLNL & WSRC & ANL & PNNL \\
\hline Complete EIS cost estimates & $1 / 98$ & $\bullet$ & 0 & &
\end{tabular}

Design-Only Conceptual Design Report: Milestones

\begin{tabular}{lccccc} 
Milestone & Date & LLNL & WSRC & ANL & PNNL \\
\hline Complete draft DOCDR & $7 / 98$ & $\bullet$ & 0 & & \\
\hline
\end{tabular}

\subsubsection{Development and Testing Program Budgets}

Summary funding requirements for the D\&T program and for the individual sites are given in the tables below.

Immobilization D\&T Program: Total Budget (\$K)

\begin{tabular}{lrrrrrrrr} 
D\&T Activity & FY98 & FY99 & FY00 & FY01 & FY02 & FY03 & FY04 & Total \\
\hline Program management & 4990 & 6030 & 5430 & 3735 & 2835 & 2340 & 2240 & 27600 \\
\hline Technical support & 895 & 900 & 700 & 550 & 350 & 0 & 0 & 3395 \\
\hline Form development & 3068 & 3105 & 1950 & 130 & 105 & 0 & 0 & 8358 \\
\hline Performance testing and qualification & 5400 & 5070 & 4930 & 3920 & 3320 & 2660 & 2770 & 28070 \\
\hline Plutonium conversion & 4545 & 7750 & 3770 & 1460 & 235 & 0 & 0 & 17760 \\
\hline First-stage immobilization & 8507 & 11250 & 8190 & 2820 & 1815 & 0 & 0 & 32582 \\
\hline Second-stage immobilization & 1215 & 2050 & 1945 & 925 & 0 & 0 & 0 & 6135 \\
\hline Plant equipment testing and demos. & 780 & 150 & 9200 & 10000 & 8800 & 3300 & 4400 & 36630 \\
\hline NEPA & 375 & 0 & 0 & 0 & 0 & 0 & 0 & 375 \\
\hline DOCDR & 1225 & 400 & 0 & 0 & 0 & 0 & 0 & 1625 \\
\hline Total & $\mathbf{3 1 0 0 0}$ & $\mathbf{3 6 7 0 5}$ & $\mathbf{3 6 1 1 5}$ & $\mathbf{2 3 5 4 0}$ & $\mathbf{1 7 4 6 0}$ & $\mathbf{8 3 0 0}$ & $\mathbf{9 4 1 0}$ & $\mathbf{1 6 2 5 3 0}$ \\
\hline
\end{tabular}


Immobilization D\&T Program: Equipment Budget (included above)

\begin{tabular}{lrrrrrrrr} 
D\&T Activity & FY98 & FY99 & FY00 & FY01 & FY02 & FY03 & FY04 & TOTAL \\
\hline Program management & 0 & 0 & 0 & 0 & 0 & 0 & 0 & 0 \\
\hline Technical support & 0 & 0 & 0 & 0 & 0 & 0 & 0 & 0 \\
\hline Form development & 0 & 0 & 0 & 0 & 0 & 0 & 0 & 0 \\
\hline Performance testing and qualification & 150 & 125 & 0 & 0 & 0 & 0 & 0 & 275 \\
\hline Plutonium conversion & 1400 & 1650 & 400 & 0 & 0 & 0 & 0 & 3450 \\
\hline First-stage immobilization & 2595 & 3595 & 650 & 0 & 0 & 0 & 0 & 6840 \\
\hline Second-stage immobilization & 200 & 340 & 1000 & 0 & 0 & 0 & 0 & 1540 \\
\hline Plant equipment testing and demos. & 0 & 0 & 4300 & 3600 & 2600 & 900 & 2500 & 13900 \\
\hline NEPA & 0 & 0 & 0 & 0 & 0 & 0 & 0 & 0 \\
\hline DOCDR & 0 & 0 & 0 & 0 & 0 & 0 & 0 & 0 \\
\hline TOTAL & $\mathbf{4 3 4 5}$ & $\mathbf{5 7 1 0}$ & $\mathbf{6 3 5 0}$ & $\mathbf{3 6 0 0}$ & $\mathbf{2 6 0 0}$ & $\mathbf{9 0 0}$ & $\mathbf{2 5 0 0}$ & $\mathbf{2 6 0 0 5}$ \\
\hline
\end{tabular}

Immobilization D\&T Program by Site: Total Budget (\$K)

\begin{tabular}{lrrrrrrrr} 
Site/Yr & FY98 & FY99 & FY00 & FY01 & FY02 & FY03 & FY04 & TOTAL \\
\hline LLNL & 19397 & 21485 & 13445 & 5595 & 3365 & 1145 & 1100 & 65532 \\
\hline WSRC & 7470 & 11175 & 18470 & 14475 & 11160 & 4520 & 5570 & 72840 \\
\hline ANL & 1978 & 1885 & 2025 & 1695 & 1765 & 1845 & 1925 & 13118 \\
\hline PNNL & 2105 & 2110 & 2045 & 1775 & 1170 & 790 & 815 & 10810 \\
\hline LANL & 0 & 0 & 80 & 0 & 0 & 0 & 0 & 80 \\
\hline Rocky Flats Environmental & & & & & & & & \\
Testing Site (RFETS) & 50 & 50 & 50 & 0 & 0 & 0 & 0 & 150 \\
\hline Total & $\mathbf{3 1 0 0 0}$ & $\mathbf{3 6 7 0 5}$ & $\mathbf{3 6 1 1 5}$ & $\mathbf{2 3 5 4 0}$ & $\mathbf{1 7 4 6 0}$ & $\mathbf{8 3 0 0}$ & $\mathbf{9 4 1 0}$ & $\mathbf{1 6 2 5 3 0}$ \\
\hline
\end{tabular}

Immobilization D\&T Program by Site: Equipment Budget (included above)

\begin{tabular}{lrrrrrrrr} 
Site/Yr & FY98 & FY99 & FY00 & FY01 & FY02 & FY03 & FY04 & TOTAL \\
\hline LLNL & 3500 & 2750 & 0 & 0 & 0 & 0 & 0 & 6250 \\
\hline WSRC & 695 & 2835 & 6350 & 3600 & 2600 & 900 & 2500 & 19480 \\
\hline ANL & 150 & 125 & 0 & 0 & 0 & 0 & 0 & 275 \\
\hline PNNL & 0 & 0 & 0 & 0 & 0 & 0 & 0 & 0 \\
\hline LANL & 0 & 0 & 0 & 0 & 0 & 0 & 0 & 0 \\
\hline Total & $\mathbf{4 3 4 5}$ & $\mathbf{5 7 1 0}$ & $\mathbf{6 3 5 0}$ & $\mathbf{3 6 0 0}$ & $\mathbf{2 6 0 0}$ & $\mathbf{9 0 0}$ & $\mathbf{2 5 0 0}$ & $\mathbf{2 6 0 0 5}$ \\
\hline
\end{tabular}


Program Management: Total Budget (\$K)

\begin{tabular}{lrrrrrrrr} 
Site/Yr & FY98 & FY99 & FY00 & FY01 & FY02 & FY03 & FY04 & TOTAL \\
\hline LLNL & 3915 & 4600 & 3800 & 2100 & 1250 & 850 & 800 & 17315 \\
\hline WSRC & 625 & 900 & 1100 & 1100 & 1050 & 950 & 900 & 6625 \\
\hline ANL & 225 & 255 & 255 & 260 & 260 & 265 & 265 & 1785 \\
\hline PNNL & 225 & 275 & 275 & 275 & 275 & 275 & 275 & 1875 \\
\hline LANL & 0 & 0 & 0 & 0 & 0 & 0 & 0 & 0 \\
\hline Total & 4990 & $\mathbf{6 0 3 0}$ & $\mathbf{5 4 3 0}$ & $\mathbf{3 7 3 5}$ & $\mathbf{2 8 3 5}$ & $\mathbf{2 3 4 0}$ & $\mathbf{2 2 4 0}$ & $\mathbf{2 7 6 0 0}$ \\
\hline
\end{tabular}

Technical Support: Total Budget (\$K)

\begin{tabular}{lrrrrrrrr} 
Site/Yr & FY98 & FY99 & FY00 & FY01 & FY02 & FY03 & FY04 & TOTAL \\
\hline LLNL & 805 & 700 & 500 & 400 & 200 & 0 & 0 & 2605 \\
\hline WSRC & 40 & 150 & 150 & 150 & 150 & 0 & 0 & 640 \\
\hline ANL & 0 & 0 & 0 & 0 & 0 & 0 & 0 & 0 \\
\hline PNNL & 0 & 0 & 0 & 0 & 0 & 0 & 0 & 0 \\
\hline RFETS & 50 & 50 & 50 & 0 & 0 & 0 & 0 & 150 \\
\hline LANL & 0 & 0 & 0 & 0 & 0 & 0 & 0 & 0 \\
\hline Total & $\mathbf{8 9 5}$ & $\mathbf{9 0 0}$ & $\mathbf{7 0 0}$ & $\mathbf{5 5 0}$ & $\mathbf{3 5 0}$ & $\mathbf{0}$ & $\mathbf{0}$ & $\mathbf{3 3 9 5}$ \\
\hline
\end{tabular}

Immobilized Form Development: Total Budget (\$K)

\begin{tabular}{lrrrrrrrr} 
Site/Yr & FY98 & FY99 & FY00 & FY01 & FY02 & FY03 & FY04 & TOTAL \\
\hline LLNL & 1945 & 1935 & 1050 & 50 & 50 & 0 & 0 & 5030 \\
\hline WSRC & 770 & 920 & 790 & 80 & 55 & 0 & 0 & 2615 \\
\hline ANL & 353 & 250 & 110 & 0 & 0 & 0 & 0 & 713 \\
\hline PNNL & 0 & 0 & 0 & 0 & 0 & 0 & 0 & 0 \\
\hline LANL & 0 & 0 & 0 & 0 & 0 & 0 & 0 & 0 \\
\hline Total & $\mathbf{3 0 6 8}$ & $\mathbf{3 1 0 5}$ & $\mathbf{1 9 5 0}$ & $\mathbf{1 3 0}$ & $\mathbf{1 0 5}$ & $\mathbf{0}$ & $\mathbf{0}$ & $\mathbf{8 3 5 8}$ \\
\hline
\end{tabular}

\section{Performance Testing and Qualification: Total Budget (\$K)}

\begin{tabular}{lrrrrrrrr} 
Site/Yr & FY98 & FY99 & FY00 & FY01 & FY02 & FY03 & FY04 & TOTAL \\
\hline LLNL & 1820 & 1455 & 1225 & 710 & 650 & 295 & 300 & 6455 \\
\hline WSRC & 300 & 450 & 300 & 300 & 270 & 270 & 270 & 2160 \\
\hline ANL & 1400 & 1380 & 1660 & 1435 & 1505 & 1580 & 1660 & 10620 \\
\hline PNNL & 1880 & 1785 & 1745 & 1475 & 895 & 515 & 540 & 8835 \\
\hline LANL & 0 & 0 & 0 & 0 & 0 & 0 & 0 & 0 \\
\hline Total & $\mathbf{5 4 0 0}$ & $\mathbf{5 0 7 0}$ & $\mathbf{4 9 3 0}$ & $\mathbf{3 9 2 0}$ & $\mathbf{3 3 2 0}$ & $\mathbf{2 6 6 0}$ & $\mathbf{2 7 7 0}$ & $\mathbf{2 8 0 7 0}$ \\
\hline
\end{tabular}


Performance Testing and Qualification: Equipment Budget (included above)

\begin{tabular}{lrrrrrrrr} 
Site/Yr & FY98 & FY99 & FY00 & FY01 & FY02 & FY03 & FY04 & TOTAL \\
\hline LLNL & 0 & 0 & 0 & 0 & 0 & 0 & 0 & 0 \\
\hline WSRC & 0 & 0 & 0 & 0 & 0 & 0 & 0 & 0 \\
\hline ANL & 150 & 125 & 0 & 0 & 0 & 0 & 0 & 275 \\
\hline PNNL & 0 & 0 & 0 & 0 & 0 & 0 & 0 & 0 \\
\hline LANL & 0 & 0 & 0 & 0 & 0 & 0 & 0 & 0 \\
\hline Total & $\mathbf{1 5 0}$ & $\mathbf{1 2 5}$ & $\mathbf{0}$ & $\mathbf{0}$ & $\mathbf{0}$ & $\mathbf{0}$ & $\mathbf{0}$ & $\mathbf{2 7 5}$ \\
\hline
\end{tabular}

Plutonium Conversion Process/Equipment Development: Total Budget (\$K)

\begin{tabular}{lrrrrrrrr} 
Site/Yr & FY98 & FY99 & FY00 & FY01 & FY02 & FY03 & FY04 & TOTAL \\
\hline LLNL & 4095 & 5475 & 2220 & 685 & 115 & 0 & 0 & 12590 \\
\hline WSRC & 450 & 2275 & 1470 & 775 & 120 & 0 & 0 & 5090 \\
\hline ANL & 0 & 0 & 0 & 0 & 0 & 0 & 0 & 0 \\
\hline PNNL & 0 & 0 & 0 & 0 & 0 & 0 & 0 & 0 \\
\hline LANL & 0 & 0 & 80 & 0 & 0 & 0 & 0 & 80 \\
\hline Total & $\mathbf{4 5 4 5}$ & $\mathbf{7 7 5 0}$ & $\mathbf{3 7 7 0}$ & $\mathbf{1 4 6 0}$ & $\mathbf{2 3 5}$ & $\mathbf{0}$ & $\mathbf{0}$ & $\mathbf{1 7 7 6 0}$ \\
\hline
\end{tabular}

Plutonium Conversion Process/Equipment Development:

\section{Equipment Budget (included above)}

\begin{tabular}{lrrrrrrrr} 
Site/Yr & FY98 & FY99 & FY00 & FY01 & FY02 & FY03 & FY04 & TOTAL \\
\hline LLNL & 1400 & 600 & 0 & 0 & 0 & 0 & 0 & 2000 \\
\hline WSRC & 0 & 1050 & 400 & 0 & 0 & 0 & 0 & 1450 \\
\hline ANL & 0 & 0 & 0 & 0 & 0 & 0 & 0 & 0 \\
\hline PNNL & 0 & 0 & 0 & 0 & 0 & 0 & 0 & 0 \\
\hline LANL & 0 & 0 & 0 & 0 & 0 & 0 & 0 & 0 \\
\hline Total & $\mathbf{1 4 0 0}$ & $\mathbf{1 6 5 0}$ & $\mathbf{4 0 0}$ & $\mathbf{0}$ & $\mathbf{0}$ & $\mathbf{0}$ & $\mathbf{0}$ & $\mathbf{3 4 5 0}$ \\
\hline
\end{tabular}

First-Stage Immobilization Process/Equipment Development: Total Budget (\$K)

\begin{tabular}{lrrrrrrrr} 
Site/Yr & FY98 & FY99 & FY00 & FY01 & FY02 & FY03 & FY04 & TOTAL \\
\hline LLNL & 5547 & 6920 & 4550 & 1550 & 1100 & 0 & 0 & 19667 \\
\hline WSRC & 2960 & 4330 & 3640 & 1270 & 715 & 0 & 0 & 12915 \\
\hline ANL & 0 & 0 & 0 & 0 & 0 & 0 & 0 & 0 \\
\hline PNNL & 0 & 0 & 0 & 0 & 0 & 0 & 0 & 0 \\
\hline LANL & 0 & 0 & 0 & 0 & 0 & 0 & 0 & 0 \\
\hline Total & $\mathbf{8 5 0 7}$ & $\mathbf{1 1 2 5 0}$ & $\mathbf{8 1 9 0}$ & $\mathbf{2 8 2 0}$ & $\mathbf{1 8 1 5}$ & $\mathbf{0}$ & $\mathbf{0}$ & $\mathbf{3 2 5 8 2}$ \\
\hline
\end{tabular}


First-Stage Immobilization Process/Equipment Development:

Equipment Budget (Included above)

\begin{tabular}{lrrrrrrrr} 
Site/Yr & FY98 & FY99 & FY00 & FY01 & FY02 & FY03 & FY04 & TOTAL \\
\hline LLNL & 2100 & 2150 & 0 & 0 & 0 & 0 & 0 & 4250 \\
\hline WSRC & 495 & 1445 & 650 & 0 & 0 & 0 & 0 & 2590 \\
\hline ANL & 0 & 0 & 0 & 0 & 0 & 0 & 0 & 0 \\
\hline PNNL & 0 & 0 & 0 & 0 & 0 & 0 & 0 & 0 \\
\hline LANL & 0 & 0 & 0 & 0 & 0 & 0 & 0 & 0 \\
\hline Total & 2595 & 3595 & 650 & 0 & 0 & 0 & 0 & 6840 \\
\hline
\end{tabular}

Second-Stage Immobilization Process/Equipment Development: Total Budget (\$K)

\begin{tabular}{lrrrrrrrr} 
Site/Yr & FY98 & FY99 & FY00 & FY01 & FY02 & FY03 & FY04 & TOTAL \\
\hline LLNL & 195 & 200 & 100 & 100 & 0 & 0 & 0 & 595 \\
\hline WSRC & 1020 & 1800 & 1820 & 800 & 0 & 0 & 0 & 5440 \\
\hline ANL & 0 & 0 & 0 & 0 & 0 & 0 & 0 & 0 \\
\hline PNNL & 0 & 50 & 25 & 25 & 0 & 0 & 0 & 100 \\
\hline LANL & 0 & 0 & 0 & 0 & 0 & 0 & 0 & 0 \\
\hline Total & $\mathbf{1 2 1 5}$ & $\mathbf{2 0 5 0}$ & $\mathbf{1 9 4 5}$ & $\mathbf{9 2 5}$ & $\mathbf{0}$ & $\mathbf{0}$ & $\mathbf{0}$ & $\mathbf{6 1 3 5}$ \\
\hline
\end{tabular}

Second-Stage Immobilization Process/Equipment Development: Equipment Budget (included above)

\begin{tabular}{lrrrrrrrr} 
Site/Yr & FY98 & FY99 & FY00 & FY01 & FY02 & FY03 & FY04 & TOTAL \\
\hline LLNL & 0 & 0 & 0 & 0 & 0 & 0 & 0 & 0 \\
\hline WSRC & 200 & 340 & 1000 & 0 & 0 & 0 & 0 & 1540 \\
\hline ANL & 0 & 0 & 0 & 0 & 0 & 0 & 0 & 0 \\
\hline PNNL & 0 & 0 & 0 & 0 & 0 & 0 & 0 & 0 \\
\hline LANL & 0 & 0 & 0 & 0 & 0 & 0 & 0 & 0 \\
\hline Total & $\mathbf{2 0 0}$ & $\mathbf{3 4 0}$ & $\mathbf{1 0 0 0}$ & $\mathbf{0}$ & $\mathbf{0}$ & $\mathbf{0}$ & $\mathbf{0}$ & $\mathbf{1 5 4 0}$ \\
\hline
\end{tabular}

Plant Equipment Testing and Demonstrations: Total Budget (\$K)

\begin{tabular}{lrrrrrrrr} 
Site/Yr & FY98 & FY99 & FY00 & FY01 & FY02 & FY03 & FY04 & TOTAL \\
\hline LLNL & 0 & 0 & 0 & 0 & 0 & 0 & 0 & 0 \\
\hline WSRC & 780 & 150 & 9200 & 10000 & 8800 & 3300 & 4400 & 36630 \\
\hline ANL & 0 & 0 & 0 & 0 & 0 & 0 & 0 & 0 \\
\hline PNNL & 0 & 0 & 0 & 0 & 0 & 0 & 0 & 0 \\
\hline LANL & 0 & 0 & 0 & 0 & 0 & 0 & 0 & 0 \\
\hline Total & $\mathbf{7 8 0}$ & $\mathbf{1 5 0}$ & $\mathbf{9 2 0 0}$ & $\mathbf{1 0 0 0 0}$ & $\mathbf{8 8 0 0}$ & $\mathbf{3 3 0 0}$ & $\mathbf{4 4 0 0}$ & $\mathbf{3 6 6 3 0}$ \\
\hline
\end{tabular}


Plant Equipment Testing and Demonstrations:

Equipment Budget (included above)

\begin{tabular}{lrrrrrrrr} 
Site/Yr & FY98 & FY99 & FY00 & FY01 & FY02 & FY03 & FY04 & TOTAL \\
\hline LLNL & 0 & 0 & 0 & 0 & 0 & 0 & 0 & 0 \\
\hline WSRC & 0 & 0 & 4300 & 3600 & 2600 & 900 & 2500 & 13900 \\
\hline ANL & 0 & 0 & 0 & 0 & 0 & 0 & 0 & 0 \\
\hline PNNL & 0 & 0 & 0 & 0 & 0 & 0 & 0 & 0 \\
\hline LANL & 0 & 0 & 0 & 0 & 0 & 0 & 0 & 0 \\
\hline Total & 0 & 0 & $\mathbf{4 3 0 0}$ & $\mathbf{3 6 0 0}$ & $\mathbf{2 6 0 0}$ & $\mathbf{9 0 0}$ & $\mathbf{2 5 0 0}$ & $\mathbf{1 3 9 0 0}$ \\
\hline
\end{tabular}

National Environmental Policy Act Support: Total Budget (\$K)

\begin{tabular}{lrrrrrrrr} 
Site/Yr & FY98 & FY99 & FY00 & FY01 & FY02 & FY03 & FY04 & TOTAL \\
\hline LLNL & 350 & 0 & 0 & 0 & 0 & 0 & 0 & 350 \\
\hline WSRC & 25 & 0 & 0 & 0 & 0 & 0 & 0 & 25 \\
\hline ANL & 0 & 0 & 0 & 0 & 0 & 0 & 0 & 0 \\
\hline PNNL & 0 & 0 & 0 & 0 & 0 & 0 & 0 & 0 \\
\hline LANL & 0 & 0 & 0 & 0 & 0 & 0 & 0 & 0 \\
\hline Total & $\mathbf{3 7 5}$ & $\mathbf{0}$ & $\mathbf{0}$ & $\mathbf{0}$ & $\mathbf{0}$ & $\mathbf{0}$ & $\mathbf{0}$ & $\mathbf{3 7 5}$ \\
\hline
\end{tabular}

Design-Only Conceptual Design Report: Total Budget (\$K)

\begin{tabular}{lrrrrrrrr} 
Site/Yr & FY98 & FY99 & FY00 & FY01 & FY02 & FY03 & FY04 & TOTAL \\
\hline LLNL & 725 & 200 & 0 & 0 & 0 & 0 & 0 & 925 \\
\hline WSRC & 500 & 200 & 0 & 0 & 0 & 0 & 0 & 700 \\
\hline ANL & 0 & 0 & 0 & 0 & 0 & 0 & 0 & 0 \\
\hline PNNL & 0 & 0 & 0 & 0 & 0 & 0 & 0 & 0 \\
\hline LANL & 0 & 0 & 0 & 0 & 0 & 0 & 0 & 0 \\
\hline Total & $\mathbf{1 2 2 5}$ & $\mathbf{4 0 0}$ & $\mathbf{0}$ & $\mathbf{0}$ & $\mathbf{0}$ & $\mathbf{0}$ & $\mathbf{0}$ & $\mathbf{1 6 2 5}$ \\
\hline
\end{tabular}




\subsection{PLUTONIUM IMMOBILIZATION PLANT PROJECT}

The Immobilization Plant Project encompasses the design, construction, commissioning, activation, and operation of a production plant sized to immobilize either 50 or $17 \mathrm{MT}$ of weapons surplus plutonium in a nominal 10-year time period.* The plant, whose key functions have been shown schematically in Figure 1-3, will immobilize various plutonium feed materials from the MD pit disassembly and conversion (PD\&C) program and/or from the EM and Nuclear Energy (NE) programs. The feed materials from EM and $\mathrm{NE}$ are first converted in the plutonium conversion front end into a suitable oxide. This oxide and any plutonium oxide from the MD PD\&C program are then processed in first-stage immobilization into plutonium-containing ceramic forms, which are placed within metal cans. In second-stage immobilization, these cans are placed inside DWPF canisters, the canisters are transported to the DWPF, and they are filled with HLW glass. The filled canister is sealed and decontaminated, and then placed into interim storage prior to its shipment to a federal waste repository. The plutonium immobilization plant is planned to begin hot operation in 6/06, produce its first canister with plutonium and HLW in 11/06, and complete its mission in about 2016. The current schedule for the plant project and key linkages to D\&T activities have been depicted in Figure 1-4.

\subsubsection{Design and Construction}

The precursor activity to the start of the Immobilization Plant Project (preliminary and detailed design) is the DOCDR, which is described in Section 2.2.1. The DOCDR provides budget quality costs of the preliminary and final design phases of the plant project and also provides an ROM estimate of the capital and operating costs for the plant.

Following conceptual design and selection of the A/E contractor, design of the plant proceeds through preliminary and detailed design phases. In these successive design stages, plant equipment and facility concepts become more detailed and precise as more detailed definitions of process parameters and equipment are provided by the D\&T program.

Preliminary design, which begins about 10/99, provides a basis to obtain construction funding. Although changes can be incorporated during detailed design, the system configuration must essentially be determined at the end of preliminary design. At this time, a baseline estimate for the complete project will be prepared and submitted to DOE to obtain funding authorization. Detailed design, scheduled to begin 11/00, will involve

${ }^{*}$ The $50 \mathrm{MT}$ and $17 \mathrm{MT}$ figures refer only to the amount of plutonium in the feed. The total heavy metal content in the feed is higher because uranium is also a feed constituent, and in addition the ceramic process adds additional uranium as part of the precursor material to achieve the desired final product composition. 
design of the overall plant and its support systems by the A/E as well as design of special equipment by the technical team with the A/E's assistance. Special equipment design teams will be established early during the D\&T phase to ensure timely availability of design specifications for special equipment. Site representatives are expected to play key roles in all design phase activities and provide technical guidance during construction and startup. Authorization to proceed with construction is expected to occur before final design completion.

Plant construction activities, such as site and facility preparation and procurement of long lead items, overlap the latter stage of detailed design. The actual construction of the plant is projected to take roughly three and a half years.

\subsubsection{Regulatory Activities}

The plant project will be executed subject to DOE orders and federal uniform building code standards. A major requirement to satisfy these regulations is the safety analysis of the facility. This task requires, among other things, the generation of two reports: the preliminary safety analysis report (PSAR) and the final safety analysis report (FSAR). The PSAR must be completed before start of construction, and the FSAR is required before start of operations. In addition to the safety analysis, a safety review by the Defense Nuclear Facilities Safety Board (DNFSB) or by the Nuclear Regulatory Commission (NRC) must occur prior to start of operations to verify that the safety requirements indicated in the reports have actually been implemented in a satisfactory manner.

\subsubsection{Facility Commissioning, Startup, and Operations}

Commissioning and cold activation (pre-startup) of the plant is planned to begin in 1/05 and last for roughly 16 months. Commissioning of equipment, phased integration of subsystems, preoperational testing, and final operator training will be performed. The 16-month cold activation period will also involve the final demonstration phase of integrated process performance and the resulting immobilized product. This activity is required to complete the plutonium waste form qualification process for the repository. This cold activation period culminates in the operational readiness review (ORR) for start of hot operations. Initiation of hot operation $(6 / 06)$ leads to the production of the first canister containing plutonium and HLW in 11/06.

\subsubsection{Plant Technical Support}

The D\&T program will support the plant project in two major areas. First and foremost, the D\&T program will document the technical basis for plant design and operation. The first part of the technical basis will be a series of TDRs that will be consistent with the plutonium immobilization top-level requirements and which will contain the detailed technical information needed by the A/E to execute the plant design. The data reports will contain the following elements:

- Design criteria

- Site specifications

- Governing regulations 
- Conceptual drawings

- Feed characteristics

- Process descriptions

- Preliminary product characteristics and specifications

- Unit operation detailed descriptions/specifications

- Interface specifications

- Material handling and storage requirements

- Operational parameters

- Maintenance requirements

- Safety assessments

For some specialized equipment, the deliverable to the project could be in the form of actual detailed engineering drawings for building the equipment. A second major deliverable from the D\&T program will be a final report describing the product specifications and processing controls required for the immobilization plant to produce acceptable product.

Because it is not possible to define and convey the totality of design information in the data package, a certain core element of the D\&T program personnel is expected to be retained as technical liaison to the project. The function of this group is to interpret, advise, and consult with the project during the detailed design, construction, and activation phases to ensure that the plant meets its performance goals. 


\subsection{IMMOBILIZED WASTE FORM LICENSING AND QUALIFICATION}

\subsubsection{Office of Civilian Radioactive Waste Management Plan to Incorporate Plutonium Waste Form in Repository}

The activities described in this section are consistent with licensing application planning for the potential repository. The TSPA, criticality, and design basis event (DBE) tasks all provide direct input into licensing documents. The remaining tasks-304L corrosion, updates to geochemistry models, leach tests, criticality benchmarking, and chemical assay testing-provide important supporting data and analyses that form the technical bases to be used in these licensing documents. The TSPA task will use information provided by the model update and the leach tests. The criticality task will use information provided by the $304 \mathrm{~L}$ corrosion, model update, criticality benchmarking and chemical assay tasks. The Office of Civilian Radioactive Waste Management plans to continue its performance confirmation program, collecting site and performance data beyond the licensing application submission date of FY02. This approach is factored into the long-range plan. Figure 1-8 is a time line showing the major milestones for the repository licensing process. The Immobilization Project must conform to these milestones.

\begin{tabular}{|c|c|c|c|c|c|c|c|c|c|c|c|c|}
\hline Task Name & 97 & 98 & 99 & 00 & 01 & 02 & 03 & 04 & 05 & 06 & 07 & 08 \\
\hline TSPAYA & & 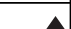 & & & & & & & & & & \\
\hline TSPA-VA & & $\nabla$ & & & & & & & & & & \\
\hline EIS & & & & $\diamond$ & & & & & & & & \\
\hline Construction LA to NRC & & & & & & $\diamond$ & & & & & & \\
\hline Conf. period updates & & & & & & - & & & & & $\rightarrow$ & \\
\hline Approval to construct & & & & & & & & & $\diamond$ & & & \\
\hline Repository construction & & & & & & & & & & & & $\diamond$ \\
\hline Possession LA to NRC & & & & & & & & & & & & $\checkmark$ \\
\hline
\end{tabular}

N1163_1.3.1

Open symbols are used for the Confirmation Period milestones to indicate that these dates are not yet established, and are only shown schematically.

Figure 1-8. Repository licensing schedule.

The logical connections and data flow between the various tasks and models that will be used in the safety analysis of the repository are shown in Figure 1-9. This figure shows how data and models that are generated by the Immobilization Project (the large shaded area) will be combined with other data specific to the repository to perform criticality analyses, TSPAs, and DBE analyses. The results of these analyses form the technical basis for the safety analysis report (SAR) required in a repository licensing application. Specifically, the Immobilization Project will need to provide the Repository Program with information on the general characteristics of the immobilized plutonium; thermo- 


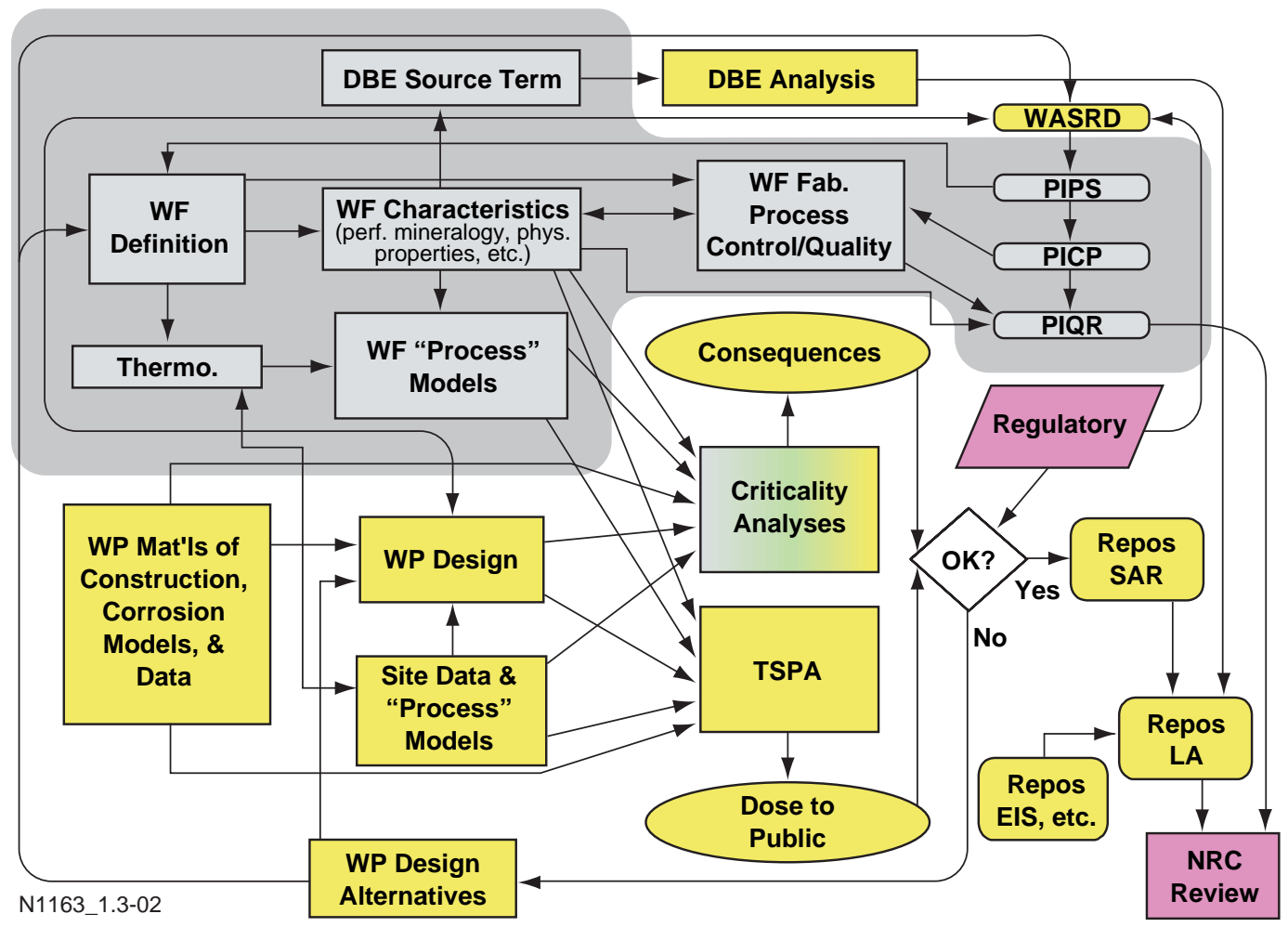

Figure 1-9. Logic diagram for repository licensing process. Shaded area encompasses tasks, data, and models that the Immobilization Project is responsible for providing. Other activities and data are to be provided by the Repository Program.

dynamic data for chemical elements and compounds that are unique to the plutonium waste form; "process models" that quantitatively describe how the waste form degrades in the repository environment; and information on the particulate source term for DBE analyses. (A complete list of information needed is given in Table 1-2.) The Repository Program will combine this information with corresponding data, designs, and models for the waste package and geologic setting of the repository, and analyze a range of possible scenarios and time histories for the immobilized plutonium as emplaced in the repository. As shown in the figure, the outputs of the various analyses are a series of quantitative statements of projected consequences. These projections are then compared to regulatory standards. If the results of the analyses show that the consequences are within acceptable regulatory limits, then the analyses become part of the Repository SAR and are included in the Repository LA. If the consequences are deemed unacceptable, then changes must be made to some combination of the waste form, waste package, or repository design. In fact, the Immobilization Project has already changed the formulation and preferred number of plutonium-bearing canisters per waste package as a result of the first round of criticality analyses, which suggested a possible long-term criticality problem under certain unlikely scenarios.

Once an acceptable disposal system (which includes not only the immobilized form, but also the repository system) has been arrived at, the characteristics of the immobilized form that are important to meeting the repository goals are codified in the Repository's Waste Acceptance Systems Requirements Document (WASRD). Also included in this document are the administrative criteria needed for acceptance of the immobilized plutonium waste form. A waste form that meets these requirements would be "qualified" 
for disposal in the repository. Based on these requirements, the Immobilization Project will prepare a series of documents (the PIPS, PICP, and PIQR in Figure 1-9) that describe how the requirements of the WASRD will be met, and that ultimately document the fact that the requirements were met. These documents, together with the production records for the actual material, constitute the paperwork to demonstrate that a production waste form is actually acceptable for repository disposal. These acceptance documents are described more fully in Sections 1.3.2 and 2.4.3 of this plan.

Table 1-2. Data needs for repository licensing analyses.

\begin{tabular}{|c|c|c|}
\hline & Data Need & Data Source \\
\hline Can & $\begin{array}{l}\text { Dimensions } \\
\text { Materials of construction } \\
\text { Number of cans ( } 17 \text { MT \& } 50 \text { MT cases) }\end{array}$ & $\begin{array}{l}\text { 1st stage immobilization } \\
\text { 1st stage immobilization } \\
\text { 1st stage immobilization }\end{array}$ \\
\hline Canister & $\begin{array}{l}\text { Dimensions } \\
\text { Weight } \\
\text { Line drawings and geometry } \\
\text { Materials of construction } \\
\text { Number of canisters }\end{array}$ & $\begin{array}{l}\text { Existing DWPF data } \\
\text { 2nd stage immobilization } \\
\text { 2nd stage immobilization } \\
\text { 2nd stage immobilization } \\
\text { and existing DWPF data } \\
\text { 2nd stage immobilization }\end{array}$ \\
\hline $\begin{array}{l}\text { Ceramic } \\
\text { physical and } \\
\text { chemical data }\end{array}$ & $\begin{array}{l}\text { Phase and chemical composition } \\
\text { (average and max.) } \\
\text { Radionuclide inventory (to } 0.05 \% \\
\text { of total inventory) } \\
\text { Pu/U loading } \\
\text { Size of form } \\
\text { Number per can } \\
\text { Properties for DBE analysis drop test } \\
\text { particle size distribution, etc. } \\
\text { Leachable surface area } \\
\text { Porosity/permeability }\end{array}$ & $\begin{array}{l}\text { Form development } \\
\text { Form development \& feed } \\
\text { materials characterization } \\
\text { 1st stage immobilization } \\
\text { 1st stage immobilization } \\
\text { 1st stage immobilization } \\
\text { 1st stage immobilization } \\
\text { Performance testing } \\
\text { Performance testing } \\
\text { Performance testing }\end{array}$ \\
\hline DWPF glass & As above for ceramic & Existing DWPF data \\
\hline $\begin{array}{l}\text { Ceramic } \\
\text { leaching and } \\
\text { alteration data }\end{array}$ & $\begin{array}{l}\text { Degradation model(s) } \\
\text { Rate law for dissolution of each phase } \\
\text { Secondary solid phases produced } \\
\text { Key release rates (Pu, U, Am, Gd, Hf.....) } \\
\text { Colloid generation/release data (at temp. } \\
\text { the percent in colloids versus in solids) } \\
\text { Effects of radiation damage }\end{array}$ & $\begin{array}{l}\text { Performance testing } \\
\text { Performance testing } \\
\text { Performance testing } \\
\text { Performance testing } \\
\text { Performance testing } \\
\text { Performance testing }\end{array}$ \\
\hline $\begin{array}{l}\text { Thermo- } \\
\text { dynamic data }\end{array}$ & $\begin{array}{l}\mathrm{Pu}, \mathrm{U}, \mathrm{Am}, \mathrm{Gd}, \mathrm{Hf}, \mathrm{Ti} \text { solubility \& } \\
\text { stability constants: oxides, hydroxides, } \\
\text { silicates, carbonates, phosphates, } \\
\text { chlorides, fluorides } \\
\text { Entropy and enthalpy of primary } \\
\text { solid phases }\end{array}$ & Performance testing \\
\hline
\end{tabular}


For the D\&T Plan the following assumptions are made:

- No new waste package design will be necessary for the immobilized form waste package because DWPF canisters will be used.

- The period of performance starts in FY98 and continues to FY02. Activities beyond FY02 are identified, but not budgeted.

The basis for all work conducted for the licensing application will be under an approved QA Plan. Input data (waste form [WF] characteristics, dissolution, thermodynamics, etc.) to support the RW analyses will be provided by MD for the immobilized forms (see Section 1.3.2 below).

The D\&T-related work activities in the Repository Program required for licensing and qualification are discussed below.

Total System Performance Assessments

Starting in FY99, TSPAs based on the specific characteristics of plutonium immobilized in a ceramic matrix must be conducted. These analyses will be conducted in conjunction with the TSPAs for commercial spent nuclear fuel (CSNF) and HLW, using the accepted methodology, models, and scenarios for the LA. This includes using process models such as flow and transport for the site, degradation models for materials of construction, dissolution and alteration models for each waste form, and geochemical models for waste form/water/materials of construction/site mineralogy interactions. Furthermore, biosphere models or scenarios used for CSNF and HLW waste will also be applied to the plutonium waste forms. Based on these considerations, the impacts of plutonium waste forms on repository performance will be evaluated. The TSPA section input for inclusion in the SAR of the licensing application will be prepared. These analyses will be conducted utilizing the RW QA procedures.

\section{Criticality}

Intact, degraded, and external criticality analyses will be conducted for the immobilized ceramic waste form in support of the LA. These analyses will be conducted using the methodology, models, and scenarios consistent with those used for commercial SNF and HLW, which comprise the bulk of the repository inventory. In other words, the immobilized plutonium waste form (and all other waste forms in the repository) will be analyzed in a manner consistent with CSNF and HLW. Because these analyses input the LA, all input data must have an approved QA pedigree. Specific criticality activities are discussed below.

Intact Configuration Criticality. Based on the characteristics of the waste forms, waste package (WP) design configurations (e.g., 4 or 5 canisters of immobilized plutonium in a waste package or co-disposal of plutonium with HLW) must be developed. Thermal outputs, structural integrity of the WP, shielding requirements for the WP and the transporter, and intact criticality assuming flooded conditions must be calculated. The final design configuration must meet the design thermal and structural limits, not exceed the NRC criticality target, and provide radiation shielding requirements for canister/ waste package/transporter/ transportation overpack handling.

Degraded Mode Criticality. Based on the intact configuration design, degradation modes of the WP and WF will be developed in a repository environment, and criticality potential for these degraded modes calculated. This will be done by developing degradation scenarios and then analyzing consequences of the scenarios. 
To develop degradation scenarios, environmental parameters (temperature, infiltration rates, water chemistry, etc.) that directly affect possible degradation scenarios for the waste package and the waste form must be determined. Physical and chemical degradation modes will be postulated. These analyses will be based on the corrosion characteristics of the canister/waste package materials of construction, dissolution rates of the waste form, expected surface areas of the waste forms (initially and when degraded), thermodynamic data for the mineral complexes formed due to interactions between the waters with the package and waste forms, the repository temperature, solubility of solids, precipitation and partitioning between fissile materials and neutron absorbers, solution $\mathrm{pH}$, etc. Thermodynamic models (such as EQ3/6 and AREST-C) will be used to develop expected scenarios, solubilities, and partitioning.

For each scenario developed, a range of concentrations must be calculated. These include calculations of neutronically active species in the degraded configuration as a function of time in several material phases remaining in the intact waste form, in solution, and in the precipitates (clay or sludge). Using the code MCNP, the reactivity $\left(\mathrm{k}_{\text {eff }}\right)$ for each representative concentration of the neutronically active species must be calculated. A set of piecewise linear regressions for $\mathrm{k}_{\text {eff }}$ as a function of the concentration of the neutronically active species must be developed and the moderator effect in each of the phases produced. These regressions must be incorporated to track the concentration of each specie in the various phases throughout the period of isolation. The range of possible criticality configurations will be screened, sensitivity analyses performed, and the results evaluated to determine the appropriate maximum fissile loading depending on the criticality control methods selected.

External Criticality. Outputs of the degraded scenarios form the source terms for the external criticality calculations. The source terms will be a function of time (using the chemistry of the solution and equilibrium thermodynamic models to estimate mobilization rates and maintain mass balance). Initial mobilization of the fissile material based on dissolution and secondary mobilization of fissile material from clay or precipitates will be calculated. Flow and transport of the fissile material to the near-field (area of the invert) and far-field will be estimated for flow rates expected in the repository.

Estimates will be made of reconcentration of the fissile material due to: existence and capacity of reducing zones; existence and capacity of zeolite zones; sorption on fracture surfaces; effect of changes in solution chemistry (e.g., pH); modeling of the dynamic processes to account for both removal from solution and remobilization; expected shape and distribution of fissile mass. A range of concentrations of neutronically active species will be estimated for the calculation of $\mathrm{k}_{\text {eff }}$.

The occurrence of criticality events will be estimated by evaluating the effects of varying moderator concentrations (water, silica, and carbon) and other sensitive parameters, and developing a regression for $\mathrm{k}_{\text {eff }}$ as a function of neutronically active species. Probabilities associated with the occurrence of a criticality event will be estimated and consequence analyses performed. The release of radioactive species will be calculated together with the thermal output from any event that caused this release.

\section{Design Basis Events}

To conform to the requirements of 10CFR60, analyses of DBEs are being conducted for the program as an integral part of the LA. Releases (particulate and gaseous) that could occur at specified distances from the site boundary as a result of off-normal occurrences are governed by the specific characteristics of the waste form and the nature of the accident analyzed. Consequently, DBE analyses are being conducted for every different type of waste 
(CSNF, HLW, SNF, MOX, immobilized plutonium) to determine the consequences expected from each waste type, and to develop design options to mitigate against such releases. For the suite of accident scenarios (for both the surface and subsurface facilities) that will be considered, the isotopic characteristics of the waste form and the particulate fraction and its size distribution must be specified as input to the analysis.

It is anticipated that the DBE analyses will be conducted in two stages. The first will be a scoping analysis to determine whether HLW or SNF bounds the immobilized waste form. Then, if differences are detected, a more systematic and rigorous analysis will need to be conducted to define the extent of the problem and to develop mitigating options. (Note that although the characteristics of the HLW glass and the plutonium loaded ceramic are different in their disintegration and isotopic characteristics, the impact of this difference is unknown.) Based on the findings of this task, the DBE section input will be prepared for inclusion in the SAR of the LA.

\section{Model Updates}

To support the long-term performance analyses, the thermodynamic model must be augmented to simulate the repository environment. This requires modeling all the species associated with the plutonium waste forms at varying $\mathrm{pH}$ and flow conditions.

Thermodynamic data for the suite of species specific to the special characteristics of plutonium waste forms will be loaded. Models in support of the TSPA and criticality analyses will be executed. Updates to the model must be conducted in compliance with the RW QA procedures. The MD program is developing the thermodynamic data set needed for use with these models for conducting TSPA and criticality analyses (Section 4). It will be necessary to acquire or qualify such data using NRC-approved QA procedures (see Section 2.5.2).

\section{L Corrosion Testing and Analysis}

Scoping, short-term service condition tests that attempt to bound the conditions anticipated at a repository must be conducted to determine formation of chromates, oxides, and other species in aqueous solutions, and the effect of such complexes on solution $\mathrm{pH}$. These results will confirm or invalidate scenarios predicted by modeling. Existing experimental setups will be used by the RW Program to conduct these tests. Chemical and other analyses will be performed to obtain the data, and a letter report will be prepared. These tests will be conducted under RW QA procedures.

\section{Criticality Benchmark Experiments}

The criticality portion of the licensing application will require conservative values of those cross sections that are poorly known, and benchmark criticality experiments to approximate the materials in the likely critical configuration. Any deficiency in the benchmark experimental configuration will have to be compensated for by greater conservatism in the cross section estimates. This may produce an estimate of an unacceptably high criticality risk. Of the noncommercial waste forms, MOX is probably sufficiently covered by benchmark criticality experiments being conducted for CSNF, but the immobilized plutonium form is not. The area of uncertainty requiring the greatest attention is the neutron absorption cross section in the intermediate energy range (from 0.1 to 100 electron volts) for the fissile elements and principal neutron absorbers (gadolinium and hafnium). The intermediate energy range is important in calculations of the potential for criticality when there is insufficient moderating water to produce a thermal neutron spectrum. This is particularly true when a significant fraction of the moderation is provided by silicon, because the neutron spectrum of a silicon-moderated system lies mostly in this uncertain intermediate region. These experiments will be piggybacked on the experiments already being conducted for CSNF using procedures that are already in place. 


\section{Performance Confirmation Period}

Site and performance data for TSPA and criticality analyses will continue to be generated during the performance confirmation period following the licensing application (FY02) and up until the license to receive and possess waste packages is submitted in FY08. These new data will be used to update the SAR, and the updated performance analyses will be presented to the NRC. Long-term leach data will continue to be generated during this period, and during the repository operating and monitoring period.

\subsubsection{Immobilization Project Activities Supporting Licensing and Qualification for Repository Disposal}

The criticality, performance, and DBE analyses discussed in the previous section will require a variety of input data and models. Some of the required information deals with repository-specific processes, conditions, and designs, but much of the required data will need to be provided by the Immobilization Project. Though the required information will be generated throughout the project, the majority of it will come from form development and performance testing activities. Thus, the need to provide this information to the Repository Program motivates much of the R\&D work described in the form development and performance testing sections of this plan (Sections 2.3 and 2.4). Table 1-2 lists the information needs of the Repository Program, and identifies the portion of the Immobilization D\&T Program that is responsible for generating the required information. Figure 1-10 shows the timing of the major deliverables to the Repository Program from the Immobilization Project in relation to the repository-licensing schedule.

\section{Documentation}

The Immobilization Project will develop technical reports covering details of the immobilized form's physical properties, its measured performance under simulated repository conditions, and an analytical model of its expected degradation in the repository environment. These reports, shown in Figure 1-10, will provide essential input to the Repository Program for the TSPA-VA, EIS, and licensing application.

As part of the waste form acceptance process, the Immobilization Project will develop a set of documents that demonstrate conformance of the immobilized plutonium waste form to the characteristics of the waste form that has been analyzed and deemed acceptable in a geologic repository. This documentation will be necessary to comply with the acceptance criteria for disposal, and to provide the backup data to the NRC demonstrating this compliance.

As discussed above, the Repository WASRD contains the disposability criteria and the administrative criteria needed for acceptance of the immobilized plutonium waste form. Based on these requirements, the Immobilization Project will develop the PIPS (Figure 1-10) that defines the specific, derived requirements levied on the waste form and are necessary to comply with the WASRD. The PIPS also defines the requirements for documentation such that all necessary supporting data and analyses are properly captured. The Office of Civilian Radioactive Waste Management will show acceptance of this document through a formal concurrence process.

Based on the PIPS, the Immobilization Project will develop the PICP that documents the strategy for compliance with the PIPS. For example, the PICP will document whether compliance will be demonstrated by testing, analyses, examination, demonstration, or some combination thereof. The Office of Civilian Radioactive Waste Management will also have concurrence responsibility for this document. 


\begin{tabular}{|c|c|c|c|c|c|c|c|c|c|c|c|c|c|c|}
\hline Task Name & 97 & 98 & 99 & 00 & 01 & 02 & 03 & 04 & 05 & 06 & 07 & 08 & 09 & 10 \\
\hline Repository Tasks & & & & & & & & & & & & & & \\
\hline TSPA-VA & & & & & & & & & & & & & & \\
\hline Repos. \& WP designs & & & $\rightarrow$ & & & & & & & & & & & \\
\hline EIS and ROD & & $\longrightarrow$ & & & & & & & & & & & & \\
\hline Construction LA to NRC & & & & & & $\star$ & & & & & & & & \\
\hline Conf. period updates & & & & & & & & & & & & & & \\
\hline Approval to construct & & & & & & & & & $\star$ & & & & & \\
\hline Repository construction & & & & & & & & & & & & & & \\
\hline Possession LA to NRC & & & & & & & & & & & & $\diamond$ & & \\
\hline Receive \& Possess & & & & & & & & & & & & & & $\star$ \\
\hline Immobilization Tasks & & & & & & & & & & & & & & \\
\hline Input to TSPA-VA & 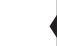 & & & & & & & & & & & & & \\
\hline Integrated EIS & & $J$ & & & & & & & & & & & & \\
\hline Preliminary input to LA & & & $\phi$ & & & & & & & & & & & \\
\hline Undated input to LA & & & & $\phi$ & & & & & & & & & & \\
\hline Confirmation Update & & & & & $\gamma$ & & & & & & & & & \\
\hline Confirmation Update & & & & & & 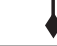 & & & & & & & & \\
\hline Confirmation Update & & & & & & & 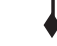 & & & & & & & \\
\hline Confirmation Update & & & & & & & & 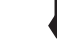 & & & & & & \\
\hline PIPS complete & & & $\diamond$ & & & & & & & & & & & \\
\hline PICP complete & & & & $\diamond$ & & & & & & & & & & \\
\hline PIQR complete & & & & & & & & & $\gamma$ & & & & & \\
\hline Plant startup & & & & & & & & & & $\star$ & & & & \\
\hline
\end{tabular}

Figure 1-10. Timeline showing the relationship between the repository licensing schedule and major Immobilization Project deliverables related to repository licensing and qualification.

Finally, the Immobilization Project will prepare the PIQR to document the testing and analyses conducted as part of the qualification/acceptance activity. This document will contain all the information necessary to demonstrate to the NRC and the Repository Program that the controls on the production and packaging of the immobilized plutonium put forward in the PICP are, indeed, adequate to ensure that the waste form meets the requirements of the WASRD. In addition, the Immobilization Project will be required to develop and maintain production, storage, and shipping records for each batch of immobilized plutonium. The PIQR and the relevant records for each batch of immobilized plutonium constitute the documentation necessary to make that batch of material acceptable for disposal in the repository.

\section{Form Qualification Logic}

The strategy for form qualification along with the logical connections and data flow between the various tasks is depicted in Figure 1-11. Data on the immobilized form and its production process required for qualifying the form for repository disposal will be generated in three phases: 


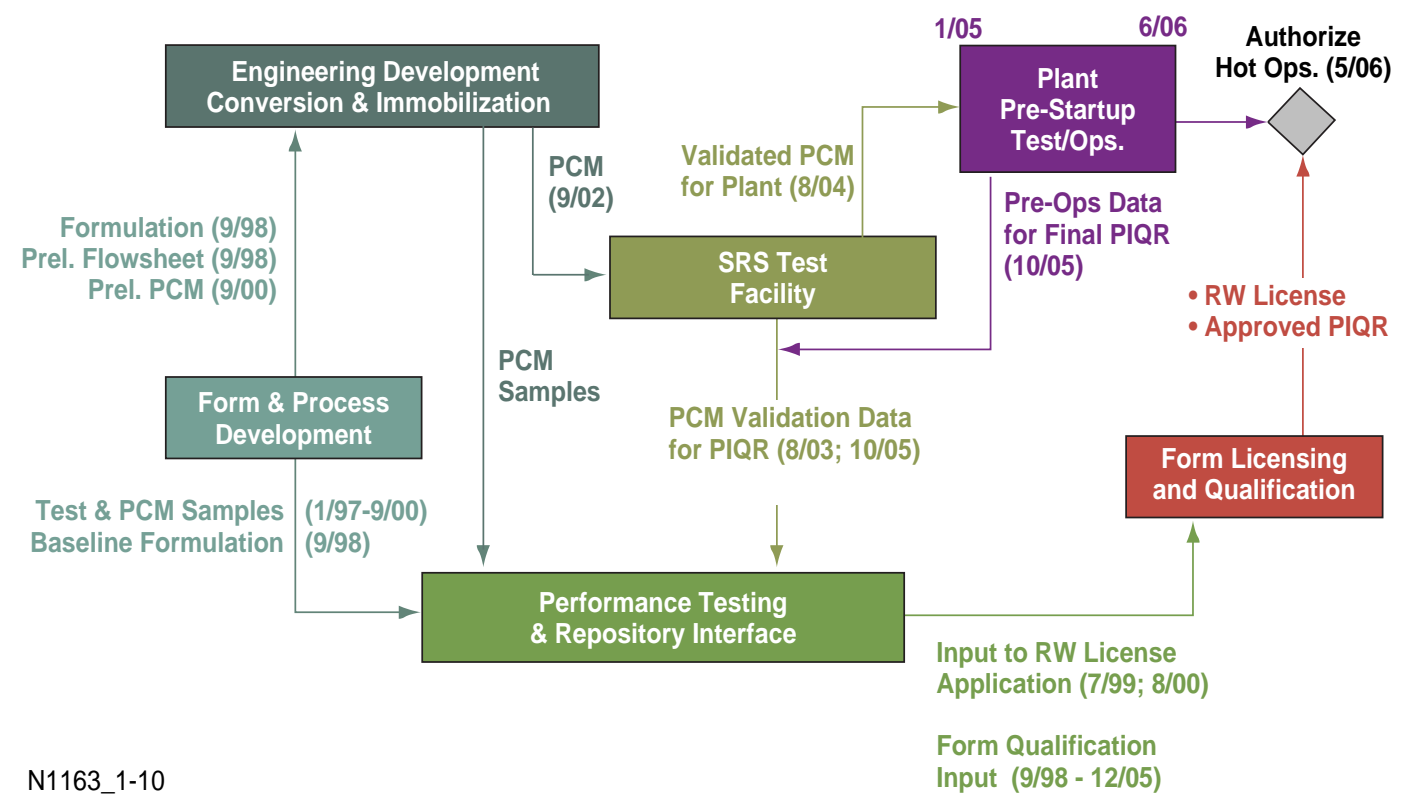

Figure 1-11. Linkages of activities and data for qualifying the immobilized waste form for repository disposal.

1. Development phase (under Immobilized Form Development Activity), involving testing with lab-scale equipment.

2. Testing and refinement phase (under the Plutonium Conversion and First-Stage Immobilization Process/Equipment Development Activities), involving testing with larger-scale equipment at LLNL.

3. Validation phase (under Plant Equipment Testing and Demonstrations), involving testing with functionally prototypic equipment at the Immobilization Plant site, SRS.

The Form Development tasks will provide the fundamental data leading to qualification. Basic data packages developed by these tasks include the baseline formulation, the process flowsheet, and the preliminary PCM. The PCM will establish the ranges for feed compositions and process parameters that will ensure an acceptable immobilized form (product). These basic data and test samples serve as input to the performance testing and repository activity and to the engineering development activities for conversion and first-stage immobilization. The former provides form performance input to the license application and to the form qualification. The engineering development activities define the process conditions, the process limits, and the equipment specifications. These tasks also test and refine the preliminary PCM.

In the final phase, product-size ceramic forms (pucks) will be produced using functionally prototypic equipment in the PPSL at SRS for a variety of feed material compositions to validate the PCM and to provide data for the PIQR. 


\section{Development and Testing Activity Plans}

\subsection{PROGRAM MANAGEMENT}

The program management activity consists of task management in four areas:

- The project office

- Quality assurance

- Technical documentation

- The plutonium facility.

\subsubsection{Project Office}

The project office ensures that all program activities and tasks are completed on schedule and within budget and that milestones and deliverables support the program technical requirements.

The project office function includes developing and controlling program budgets, costs, technical tasks, deliverables, milestones, and schedules, as well as coordinating the work among the four participating DOE sites. It also develops and updates this D\&T plan. The project office also prepares a program management plan that governs the interface of the program with MD, RW, and the plant project and that develops and maintains a work breakdown structure and dictionary that provides the framework for the budget, schedule, and technical control necessary for the successful execution of the project.

Project Office: Milestones

\begin{tabular}{llccccc}
\multicolumn{2}{l}{ Milestone } & Date & LLNL & WRSC & ANL & PNNL \\
\hline FY98 & Provide draft D\&T plan & $11 / 97$ & $\bullet$ & 0 & 0 & 0 \\
\hline & Provide D\&T plan & $8 / 98$ & $\bullet$ & 0 & 0 & 0 \\
\hline & Complete draft project management plan & $9 / 98$ & $\bullet$ & 0 & & \\
\hline FY99 & Update D\&T plan & $8 / 99$ & $\bullet$ & 0 & 0 & 0 \\
\hline FY00 & Update D\&T plan & $8 / 00$ & $\bullet$ & 0 & 0 & 0 \\
\hline
\end{tabular}

- Primary Responsibility

O Support Responsibility 
Project Office: Total Budget (\$K)

\begin{tabular}{lrrrrrrrr} 
Site/Yr & FY98 & FY99 & FY00 & FY01 & FY02 & FY03 & FY04 & Total \\
\hline LLNL & 1555 & 1750 & 1755 & 1040 & 480 & 490 & 490 & 7560 \\
\hline WSRC & 400 & 500 & 600 & 600 & 600 & 600 & 600 & 3900 \\
\hline ANL & 50 & 55 & 55 & 60 & 60 & 65 & 65 & 410 \\
\hline PNNL & 75 & 75 & 75 & 75 & 75 & 75 & 75 & 525 \\
\hline LANL & 0 & 0 & 0 & 0 & 0 & 0 & 0 & 0 \\
\hline Total & $\mathbf{2 0 8 0}$ & $\mathbf{2 3 8 0}$ & $\mathbf{2 4 8 5}$ & $\mathbf{1 7 7 5}$ & $\mathbf{1 2 1 5}$ & $\mathbf{1 2 3 0}$ & $\mathbf{1 2 3 0}$ & $\mathbf{1 2 3 9 5}$ \\
\hline
\end{tabular}

\subsubsection{Quality Assurance}

The QA activity involves establishment and implementation of a QA program for the immobilization project as well as development of a QA plan and procedures. Quality assurance provides the plans, procedures, and controls that are required for repository acceptance of the immobilized plutonium form and the immobilization plant licensing and design activities. The QA plan is based on the DOE QARD document (DOE/RW-0333P). Consequently, as the QARD is revised, this program plan will be revised to be consistent with the latest revision of the QARD.

The QA plan consists of a top level plan specifying the overall QA requirements for the entire immobilization project. Each participating site will also write and follow individual QA plans that comply with overall program requirements but are tailored for its specific work scope. The plans will address specific requirements, procedures, training, and methods to ensure compliance. Quality Assurance procedures for Immobilization D\&T activities will be written and implemented in accordance with the Immobilization Project QA Plan. The QA program will be established in FY98. Detailed outyear scope and milestones are still being developed.

\section{Quality Assurance: Milestones}

\begin{tabular}{|c|c|c|c|c|c|c|}
\hline \multicolumn{2}{|c|}{ Milestone } & \multirow{2}{*}{$\frac{\text { Date }}{3 / 98}$} & \multirow{2}{*}{$\frac{\text { LLNL }}{0}$} & \multirow{2}{*}{$\frac{\text { WSRC }}{\bullet}$} & \multirow[t]{2}{*}{ ANL } & \multirow[t]{2}{*}{ PNNL } \\
\hline FY98 & Complete QA plan & & & & & \\
\hline & Draft QA procedures & 9/98 & 0 & - & & \\
\hline
\end{tabular}

\section{Quality Assurance: Total Budget (\$K)}

\begin{tabular}{lrrrrrrrr} 
Site/Yr & FY98 & FY99 & FY00 & FY01 & FY02 & FY03 & FY04 & TOTAL \\
\hline LLNL & 200 & 300 & 300 & 300 & 300 & 200 & 200 & 1800 \\
\hline WSRC & 200 & 300 & 300 & 300 & 300 & 300 & 300 & 2000 \\
\hline ANL & 175 & 200 & 200 & 200 & 200 & 200 & 200 & 1375 \\
\hline PNNL & 150 & 200 & 200 & 200 & 200 & 200 & 200 & 1350 \\
\hline LANL & 0 & 0 & 0 & 0 & 0 & 0 & 0 & 0 \\
\hline Total & $\mathbf{7 2 5}$ & $\mathbf{1 0 0 0}$ & $\mathbf{1 0 0 0}$ & $\mathbf{1 0 0 0}$ & $\mathbf{1 0 0 0}$ & $\mathbf{9 0 0}$ & $\mathbf{9 0 0}$ & $\mathbf{6 5 2 5}$ \\
\hline
\end{tabular}




\subsubsection{Technical Documentation}

In FY98, a computerized documentation and document tracking system for the immobilization program is being established and will become operational. The document control activity provides plans and procedures for the retention and distribution of D\&T program reports, calculations, experimental data, specifications, drawings, plans, and procedures. In future years, this activity also coordinates the development and production of the TDRs, which serve as major deliverables from the D\&T program to the plant project. These documents serve as the major reference upon which the plant preliminary and detailed designs and the operating technical specifications will be based. They will contain some or all of the following as appropriate:

- Process descriptions

- Process specifications

- Feed specifications

- Functional design requirements

- Flowsheets and material balances

- Equipment lists

- Equipment dimensions and capacities

- Operating and maintenance requirements

- Conceptual layout drawings

- Utility requirements

- Special studies or requirements

- Waste form production records

- Interface to other systems or unit operations.

In addition to the TDR series that inputs the plant project, the D\&T program will generate a number of technical documents related to the licensing and qualification of the immobilized waste form for repository disposal. As described in Section 1.3.2, these reports include the PIPS, PICP, PICS, WCP, and PIQR.

Technical Documentation: Milestones

\begin{tabular}{|c|c|c|c|c|c|c|}
\hline \multicolumn{2}{|c|}{ Milestone } & \multirow{2}{*}{$\begin{array}{c}\text { Date } \\
6 / 98\end{array}$} & \multirow{2}{*}{$\frac{\text { LLNL }}{\bullet}$} & \multirow[t]{2}{*}{ WSRC } & \multirow[t]{2}{*}{ ANL } & \multirow[t]{2}{*}{ PNNL } \\
\hline FY98 & Complete document control center & & & & & \\
\hline FY00 & Provide preliminary TDR & $10 / 99$ & $\bullet$ & O & & \\
\hline FY01 & Provide TDR & $10 / 00$ & 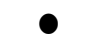 & O & & \\
\hline FY02 & $\begin{array}{l}\text { Provide supplemental TDR for } \\
\text { special process equipment }\end{array}$ & $10 / 01$ & 0 & 0 & & \\
\hline
\end{tabular}


Technical Documentation: Total Budget (K\$)

\begin{tabular}{lrrrrrrrr} 
Site/Yr & FY98 & FY99 & FY00 & FY01 & FY02 & FY03 & FY04 & TOTAL \\
\hline LLNL & 200 & 400 & 400 & 200 & 150 & 50 & 0 & 1400 \\
\hline WSRC & 25 & 100 & 200 & 200 & 150 & 50 & 0 & 725 \\
\hline ANL & 0 & 0 & 0 & 0 & 0 & 0 & 0 & 0 \\
\hline PNNL & 0 & 0 & 0 & 0 & 0 & 0 & 0 & 0 \\
\hline LANL & 0 & 0 & 0 & 0 & 0 & 0 & 0 & 0 \\
\hline Total & $\mathbf{2 2 5}$ & $\mathbf{5 0 0}$ & $\mathbf{6 0 0}$ & $\mathbf{4 0 0}$ & $\mathbf{3 0 0}$ & $\mathbf{1 0 0}$ & $\mathbf{0}$ & $\mathbf{2 1 2 5}$ \\
\hline
\end{tabular}

\subsubsection{Plutonium Facility}

The plutonium facility task provides funding for the plutonium facility infrastructure that supports the D\&T activities and manages the conduct of work in the facility.

\section{Plutonium Facility: Total Budget (\$K)}

\begin{tabular}{lrrrrrrrr} 
Site/Yr & FY98 & FY99 & FY00 & FY01 & FY02 & FY03 & FY04 & TOTAL \\
\hline LLNL & 1960 & 2150 & 1345 & 560 & 320 & 110 & 110 & 6555 \\
\hline WSRC & 0 & 0 & 0 & 0 & 0 & 0 & 0 & 0 \\
\hline ANL & 0 & 0 & 0 & 0 & 0 & 0 & 0 & 0 \\
\hline PNNL & 0 & 0 & 0 & 0 & 0 & 0 & 0 & 0 \\
\hline LANL & 0 & 0 & 0 & 0 & 0 & 0 & 0 & 0 \\
\hline Total & $\mathbf{1 9 6 0}$ & $\mathbf{2 1 5 0}$ & $\mathbf{1 3 4 5}$ & $\mathbf{5 6 0}$ & $\mathbf{3 2 0}$ & $\mathbf{1 1 0}$ & $\mathbf{1 1 0}$ & $\mathbf{6 5 5 5}$ \\
\hline
\end{tabular}




\subsection{TECHNICAL SUPPORT}

The technical support activity area encompasses program tasks that either directly support the plant project activity or serve as integration functions across the other core program elements. The major tasks in this activity area are:

- Feed materials characterization and definition

- Proliferation resistance

- Systems integration and cross-cutting functions.

\subsubsection{Feed Materials Characterization and Blending}

This task provides and maintains data and analyses on the physical, chemical, and radiation characteristics of the non-pit plutonium feed materials expected to be sent for immobilization. Assessments of uncertainty associated with data quality and material specifications for material transfer to MD will be performed.

In FY98, feed material data will be compiled and compared with ceramification process requirements. Molar ratios of specific elements in the expected feed materials will be estimated from their current weight percent values and from knowledge or assumptions about their processing history. Limits on concentrations of non-actinide elements in the feed to the ceramification process will be developed in terms of molar ratios (Section 2.3). Feed material acceptance specifications for incoming materials will be developed based on these limits in combination with the plant's strategy for blending feed materials to meet these limits (below).

In addition, this effort will identify the timing of material availability for transfer to MD, based in part on EM stabilization schedules being complete by the year 2002. Data produced from this effort will support development of a feed material blending strategy.

A discrete event simulation model is being developed to evaluate alternative blending strategies that will:

- Levelize uranium concentration

- Blend for plutonium isotopics

- Mitigate the impact of high-impurity feed streams.

This information will be used to establish feed material requirements that take into account a blending campaign to provide design input for in-line storage and material handling facilities, and to evaluate the need for additional statistical sampling of feed materials. A statistical sampling plan will be developed where needed to support process design decisions. 
In FY99, the feed material database will be updated as more data become available. A decision support system for the production facility will be developed to support blending operations in real-time. Performance of the system will be evaluated using the updated feed materials database. Statistical sampling of specific feed material streams will be undertaken as needed. Any sampling of the specific feed material streams, currently expected only to be some of the RFETS streams, will be coordinated with the site for the development of an appropriate sampling plan.

In remaining years, the materials database, process simulation, and blending decision support system will be updated as needed.

This task also provides the primary interface and point of contact between the immobilization program and the EM 94-1 activities. Joint planning of the transfer of EM and NE materials to MD will be performed.

Feed Materials Characterization and Blending: Milestones

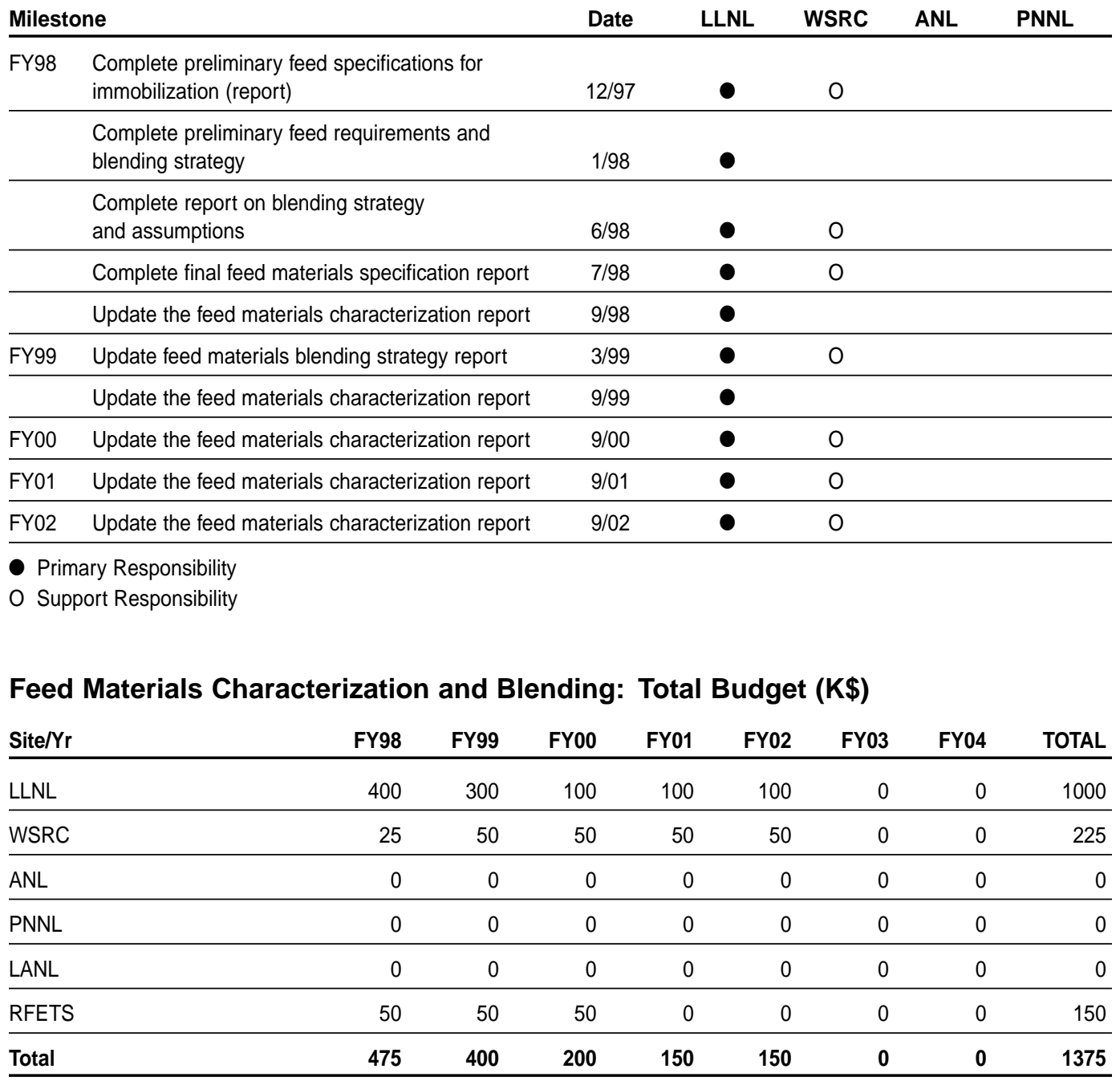




\subsubsection{Proliferation Resistance}

A study of the proliferation resistance of the can-in-canister form relative to spent fuel has been documented in a detailed classified report (White Team report). An unclassified summary report will be prepared and issued.

Proliferation Resistance: Milestones

\begin{tabular}{llccccc}
\multicolumn{2}{l}{ Milestone } & Date & LLNL & WSRC & ANL & PNNL \\
\hline FY98 & $\begin{array}{l}\text { Complete White Team report on proliferation } \\
\text { resistance of can-in-canister design approach }\end{array}$ & $1 / 98$ & - & 0 & 0 & 0 \\
\hline $\begin{array}{l}\text { Complete unclassified report on proliferation } \\
\text { resistance of can-in-canister design approach }\end{array}$ & $7 / 98$ & - & 0 & & \\
\hline
\end{tabular}

Proliferation Resistance: Total Budget (K\$)

\begin{tabular}{lrrrrrrrr} 
Site/Yr & FY98 & FY99 & FY00 & FY01 & FY02 & FY03 & FY04 & TOTAL \\
\hline LLNL & 10 & 0 & 0 & 0 & 0 & 0 & 0 & 10 \\
\hline WSRC & 15 & 0 & 0 & 0 & 0 & 0 & 0 & 15 \\
\hline ANL & 0 & 0 & 0 & 0 & 0 & 0 & 0 & 0 \\
\hline PNNL & 0 & 0 & 0 & 0 & 0 & 0 & 0 & 0 \\
\hline LANL & 0 & 0 & 0 & 0 & 0 & 0 & 0 & 0 \\
\hline Total & $\mathbf{2 5}$ & $\mathbf{0}$ & $\mathbf{0}$ & $\mathbf{0}$ & $\mathbf{0}$ & $\mathbf{0}$ & $\mathbf{0}$ & $\mathbf{2 5}$ \\
\hline
\end{tabular}

\subsubsection{System Integration and Cross-Cutting Functions}

This task serves two functions. First, it coordinates the separate tasks within technical support. In this capacity, it serves as the major technical interface between these support activities and the core program elements, including critical path scheduling. Second, this task is responsible for a systems engineering approach for integrating, coordinating, and developing the common requirements and approaches for dose assessment, MC\&A, $\mathrm{NDE}$, and automation as they apply across the entire immobilization flowsheet (plutonium conversion, first-stage immobilization, and second-stage immobilization). The detailed scope of this latter activity will be further developed this year, but a two-person-year per year effort is assumed for purposes of budget planning.

\section{System Integration and Cross-Cutting Functions: Milestones}

\begin{tabular}{|c|c|c|c|c|c|c|}
\hline Milest & & Date & LLNL & WSRC & ANL & PNNL \\
\hline FY98 & Draft critical path schedule & $7 / 98$ & - & & & \\
\hline & Draft systems approach to evaluate dose, MC\&A, etc. & $7 / 98$ & - & O & & \\
\hline FY99 & $\begin{array}{l}\text { Provide integrated system reports as } \\
\text { input for preliminary TDR }\end{array}$ & 9/99 & - & O & & \\
\hline FY00 & Provide integrated system reports as input for TDR & $9 / 00$ & $\bullet$ & 0 & & \\
\hline
\end{tabular}


System Integration and Cross-Cutting Functions: Total Budget (K\$)

\begin{tabular}{lrrrrrrrr} 
Site/Yr & FY98 & FY99 & FY00 & FY01 & FY02 & FY03 & FY04 & TOTAL \\
\hline LLNL & 395 & 400 & 400 & 300 & 100 & 0 & 0 & 1595 \\
\hline WSRC & 0 & 100 & 100 & 100 & 100 & 0 & 0 & 400 \\
\hline ANL & 0 & 0 & 0 & 0 & 0 & 0 & 0 & 0 \\
\hline PNNL & 0 & 0 & 0 & 0 & 0 & 0 & 0 & 0 \\
\hline LANL & 0 & 0 & 0 & 0 & 0 & 0 & 0 & 0 \\
\hline Total & $\mathbf{3 9 5}$ & $\mathbf{5 0 0}$ & $\mathbf{5 0 0}$ & $\mathbf{4 0 0}$ & $\mathbf{2 0 0}$ & $\mathbf{0}$ & $\mathbf{0}$ & $\mathbf{1 9 9 5}$ \\
\hline
\end{tabular}




\subsection{IMMOBILIZED FORM DEVELOPMENT}

The ceramic that will immobilize the plutonium for disposition is a titanate-based multiphase crystalline mineral composed predominantly of the mineral pyrochlore with minor amounts of the minerals brannerite and rutile. The mineral zirconolite also forms in significant amounts depending on impurity content of the plutonium oxide feed material. Trace minor phases, such as the silicates, will also be present due to certain impurities in the plutonium feed. The principle mineral phases can be seen in the scanning electron microscope (SEM) image shown in Figure 2-1. The final ceramic form incorporating the plutonium is fabricated in the form of a cylindrical puck with a diameter of roughly 2.6 inches, and a height of about 1 inch. Each ceramic puck contains roughly 50 grams of plutonium.

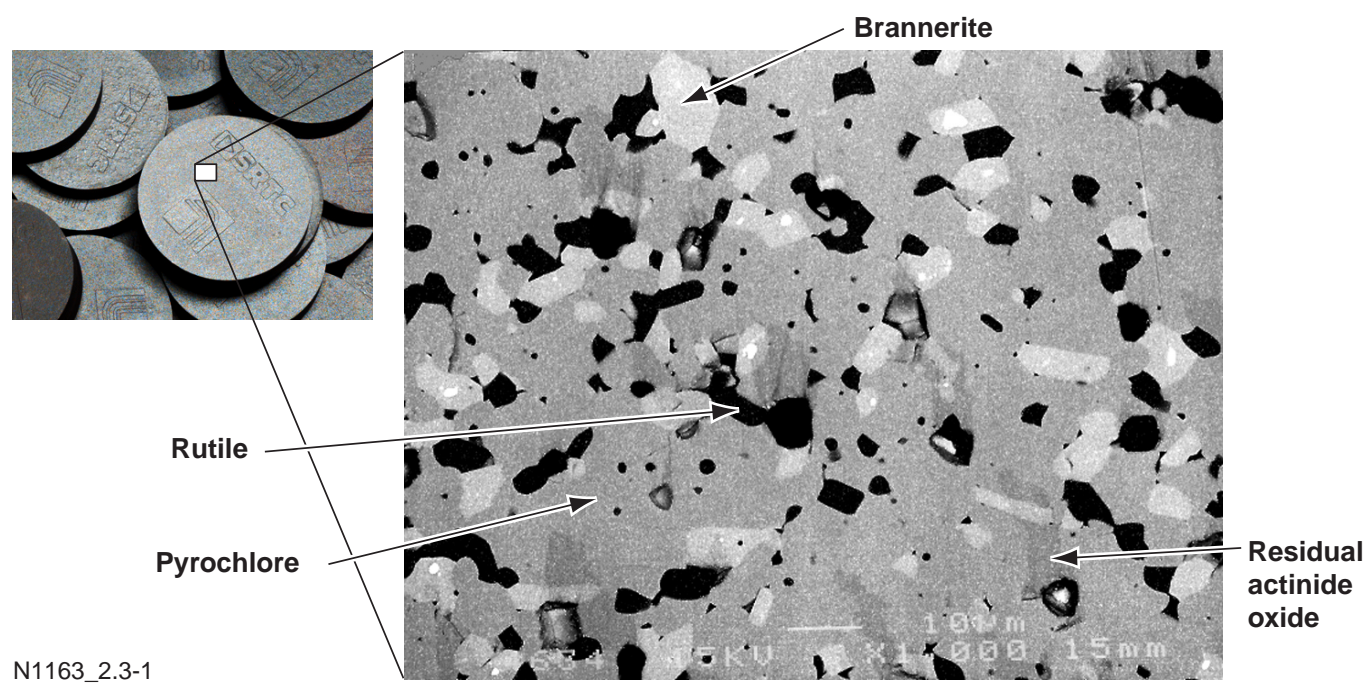

Figure 2-1. Baseline ceramic composition $(\mathrm{Hf} / \mathrm{Pu} / \mathrm{U})$ showing the major mineral phases.

Development of the ceramic form involves:

- Determination of the baseline formulation and acceptable ranges for the ceramic mineralogy and composition

- Definition of the basic processing conditions for making the forms

- Determination of the key physical and chemical properties of the forms

- Preparation of the necessary samples for the characterization of the plutonium feed materials

- Fabrication of the necessary samples for repository characterization and durability measurements 
- Development of a product control model that relates feed composition and processing conditions to product properties affecting durability in a repository.

This activity provides the repository testing and qualification activity (Section 2.4) with durability testing samples and with characterization data for various ceramic form compositions expected to be produced in the immobilization facility. It also supports firststage immobilization process and equipment development (Section 2.6) by providing processing concepts and process parameters.

The form development effort is composed of four integrated tasks that will develop a suitable form to meet all the requirements (present and future) of the plutonium disposition program. These four tasks, described in this section, are as follows:

1. Sample planning, coordination, and preparation of the facilities needed to conduct the form development activities

2. Development of the basic ceramic formulation and processing parameters

3. Fabrication of samples for repository qualification and characterization of the ceramic form

4. Development of a product control model, which will be used in the operating plant to ensure that the product is acceptable for the repository.

In performing these tasks, a series of ceramic samples will be fabricated to provide essential data for form development and repository licensing and qualification. In many cases, the samples will provide data for more than one task area. The planned sample series includes:

- Near-equilibrium processing conditions test samples

- Single-phase samples

- Process and compositional extreme samples

- Impurity samples

- Equilibrium-phase diagram samples.

The relationship between the sample series and the primary and secondary tasks that are supported is indicated in Figure 2-2. Primary dependency between task and sample series is indicated by solid line connections, and secondary dependence by dashed lines. Although each sample series (listed above) except the last provides data to multiple tasks, the description of a given sample series is covered under the appropriate "primary" task.

\subsubsection{Coordination and Facilities}

The objective of this task is to plan the form development sample series and measurement assignments and to prepare necessary facilities to conduct the development work.

The first step in coordinating the form development work is to define the objective measurements and samples needed to provide the necessary data. The sample-task relationships shown in Figure 2-2 identify the major sample categories and the primary tasks which are supported. Detailed planning is required to specify needed sample parameters and to assign the sample preparation and analysis to the participating laboratories (LLNL, WSRC, ANSTO, and ANL). The first deliverable of this task is the definition of the sample test matrices and sample fabrication and analysis assignments. 


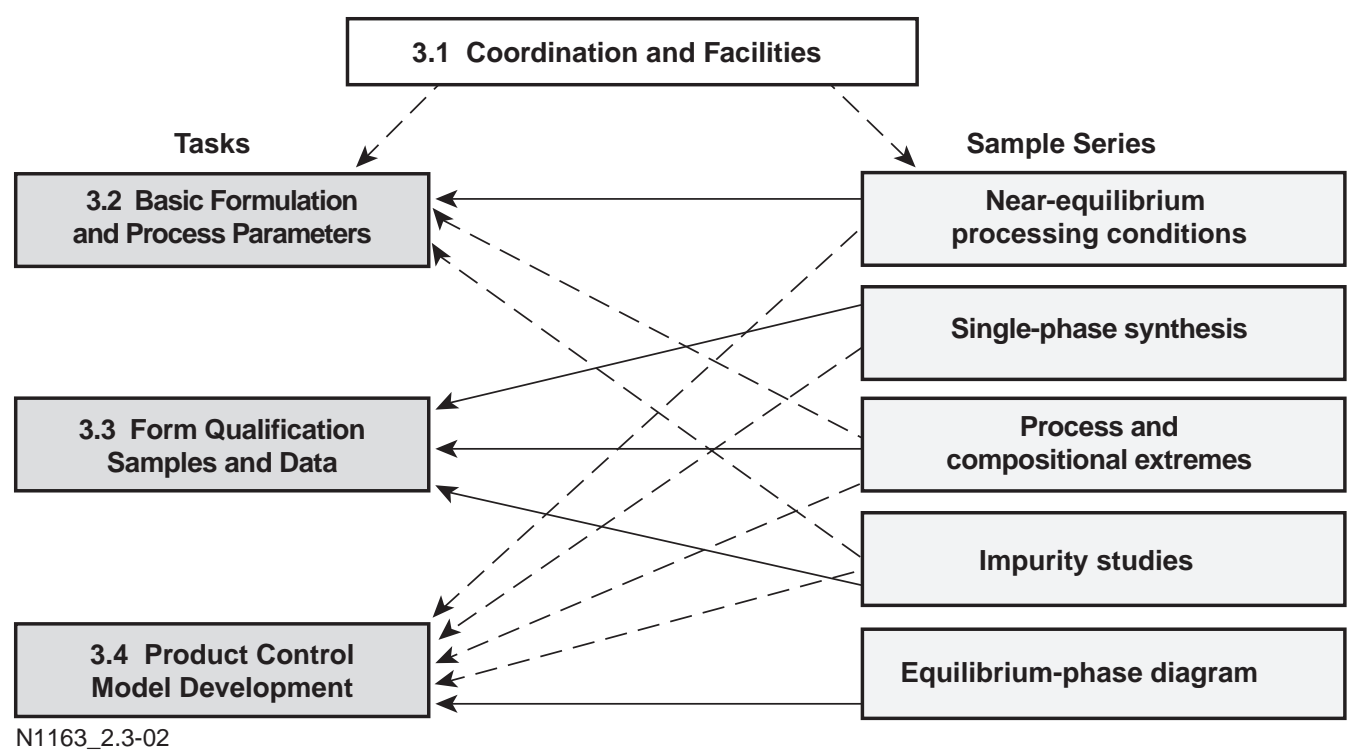

Figure 2-2. Sample series relationship to the form development tasks.

Facilities capable of handling uranium and/or plutonium are required to prepare the various samples needed to characterize and evaluate the ceramic forms. Facilities are required for both fabrication of ceramic test forms using surrogates (cerium and thorium) and plutonium. Screening tests will be performed with surrogate materials due to the lower cost and quicker turn-around time associated with test of these materials. However, actual plutonium materials with their associated range of impurities are expected to alter the mineral forms. Therefore, it is essential to fabricate and evaluate the ceramic forms using plutonium. Since much understanding of the ceramic minerology will be gained from surrogates, tests with plutonium will be limited and will be used primarily for confirmation.

Existing ceramic fabrication facilities for form development with surrogate materials are available at LLNL, ANSTO, and WRSC. In addition, LLNL and ANSTO have the capability to fabricate and characterize plutonium-bearing ceramic samples. Argonne National Laboratory also has the capability to characterize such samples. To carry out the planned development test series on schedule, additional capabilities are needed at WSRC and ANL to produce small ceramic test samples with plutonium. These capabilities will consist of simple milling equipment, presses, and furnaces installed in existing glove boxes. They will be established and brought into operation early in FY98.

\section{Coordination and Facilities: Milestones}

\begin{tabular}{llcccc}
\multicolumn{2}{l}{ Milestone } & Date & $\begin{array}{c}\text { LLNL\& } \\
\text { ANSTO }\end{array}$ & WSRC & ANL \\
\hline FY97 & $\begin{array}{l}\text { Establish plutonium/uranium pellet fabrication } \\
\text { capability at SRS }\end{array}$ & $12 / 97$ & 0 & $\boldsymbol{0}$ & \\
\hline FY98 & Define initial sample matrix and assignments & $1 / 98$ & $\boldsymbol{0}$ & 0 & 0 \\
\hline & Establish plutonium pellet fabrication capability at ANL & $3 / 98$ & 0 & & 0 \\
\hline & Develop follow-on test sample plan & $10 / 98$ & $\bullet$ & 0 & 0 \\
\hline
\end{tabular}

- Primary Responsibility

O Support Responsibility 
Coordination and Facilities: Total Budget (K\$)

\begin{tabular}{lrrrrrrrr} 
Site/Yr & FY98 & FY99 & FY00 & FY01 & FY02 & FY03 & FY04 & TOTAL \\
\hline LLNL & 40 & 0 & 0 & 0 & 0 & 0 & 0 & 40 \\
\hline WSRC & 150 & 0 & 0 & 0 & 0 & 0 & 0 & 150 \\
\hline ANL & 50 & 0 & 0 & 0 & 0 & 0 & 0 & 50 \\
\hline PNNL & 0 & 0 & 0 & 0 & 0 & 0 & 0 & 0 \\
\hline LANL & 0 & 0 & 0 & 0 & 0 & 0 & 0 & 0 \\
\hline Total & $\mathbf{2 4 0}$ & $\mathbf{0}$ & $\mathbf{0}$ & $\mathbf{0}$ & $\mathbf{0}$ & $\mathbf{0}$ & $\mathbf{0}$ & $\mathbf{2 4 0}$ \\
\hline
\end{tabular}

\subsubsection{Basic Formulation and Process Parameters}

The objective of this task is to finalize the chemical formulation of the ceramic immobilization form for the range of expected plutonium feed materials. In addition, this task will develop chemical feed preparation procedures and specifications and determine the essential processing parameters for the ceramic formulation. The results of this task will support conceptual design, plant process and equipment development, plant preliminary design, and final design.

Work under this task falls into two primary areas:

- Development of the baseline ceramic formulation and feed specifications

- Evaluation of the near-equilibrium processing approaches to establish the operating limits, which will produce an acceptable product for the expected range of feed materials.

Development of Baseline Ceramic Formulation and Feed Specifications

A preliminary baseline ceramic formulation has been developed during the form selection process. The current baseline composition, feed specifications, and product mineralogy of the ceramic form are listed in Table 2-1. The baseline compositions (exclusive of impurites in the plutonium feed materials) shown in the table are not expected to change significantly, but they have not yet been finalized. Finalizing the baseline formulation is a main element of this task and is expected to be completed by the end of FY98. Data for defining the final formulation and for verifying the baseline formulation over the range of feed compositions will be provided by the sample test series described in Sections 2.3.3 and 2.3.4.

A second part to this task is to define the feed specifications, which include physical form, particle size, and impurity content in the precursor materials and in the plutonium and uranium oxide feed materials. The feed impurity specifications are developed largely from the impurity tests (discussed in Section 2.3.4). Final feed specifications for ceramic fabrication will be defined and documented in the third quarter of FY99.

\section{Near-Equilibrium Processing Requirements}

The purpose of the near-equilibrium series of samples is to compare the products obtained by plant-like fabrication processes to those obtained at equilibrium processing conditions. If the samples prepared by the plant-like fabrication processes are deter- 
mined to be at or near equilibrium, the product control model will be greatly simplified because kinetic factors would be eliminated from the model. Key processing parameters, such as particle size, pressing pressure, and sintering temperature and atmosphere, will be determined.

Table 2-1. Preliminary baseline composition and feed specifications.

\begin{tabular}{|c|c|c|c|c|}
\hline \multicolumn{2}{|c|}{ Baseline Composition* } & \multicolumn{3}{|c|}{ Baseline Feed Specifications } \\
\hline Oxide & Baseline (wt \%) & Oxide & Form & Particle Size \\
\hline $\mathrm{CaO}$ & 10.0 & $\mathrm{CaO}$ & $\mathrm{Ca}(\mathrm{OH})_{2}$ & not important \\
\hline $\mathrm{HfO}_{2}$ & 10.6 & $\mathrm{HfO}_{2}$ & $\mathrm{HfO}_{2}$ & micron sized \\
\hline $\mathrm{UO}_{2}$ & 23.7 & $\mathrm{UO}_{2}^{2}$ & $\mathrm{UO}_{2}$ or $\mathrm{U}_{3} \mathrm{O}_{8}$ & $<20$ microns \\
\hline $\mathrm{PuO}_{2}$ & 11.9 & $\mathrm{PuO}_{2}$ & $\mathrm{PuO}_{2}$ & $<20$ microns \\
\hline $\mathrm{Gd}_{2} \mathrm{O}_{3}$ & 7.9 & $\mathrm{Gd}_{2} \mathrm{O}_{3}$ & $\mathrm{Gd}_{2} \mathrm{O}_{3}$ & $<325$ mesh \\
\hline $\mathrm{TiO}_{2}$ & 35.9 & $\mathrm{TiO}_{2}$ & $\mathrm{TiO}_{2}$ (anatase) & micron sized \\
\hline
\end{tabular}

\section{Product Composition and Mineralogy ${ }^{\dagger}$ \\ Baseline \\ (vol \%)}

Pyrochlore $\quad 80$

Brannerite 12

Zirconolite $\quad 0$

Rutile

Actinide Oxide

Other Minor Phases

\section{o}

Observed Range

( $\mathrm{vol} \%$ )

$62-90$

$0-22$

$0-25$

$0-16$

$0.04-0.6$

$0-6$

\section{Acceptable Range}

(vol \%)

$>50$

$0-50$

$0-50$

$0-20$

$0-1$

$0-10$

* Excludes impurities in plutonium feed.

t Given the above chemical compositions and specifications, the observed product mineralogy is given by the first column. If impurities in the PuO2 feeds are considered, the observed minerals in the product vary approximately within the range given in the second column. The acceptable range has not yet been determined, but is expected to be about as given in the third column.

Each sample composition to be tested will be fabricated by at least the following processing routes:

- Nitrate/alkoxide fabrication route (equilibrium conditions)

- Oxide fabrication route-dry milling/blending

- Oxide fabrication route-wet blending.

Standardized processing steps and procedures will be used by the sites participating in this sample series to make the samples. Samples will generally be fabricated first with thorium as a surrogate for plutonium. A subset of tests performed with thorium will be repeated with plutonium. As a minimum, samples will be examined by SEM, qualitative energy dispersive spectrometry (EDS), and x-ray diffraction analysis. Quantitative EDS or microprobe analysis will be performed on selected samples.

Based on consensus between LLNL and the other participating sites, additional sample compositions will be identified and samples fabricated for evaluation. 
Basic Formulation and Process Parameters: Milestones

\begin{tabular}{|c|c|c|c|c|c|}
\hline \multicolumn{2}{|c|}{ Milestone } & \multirow{2}{*}{$\begin{array}{l}\text { Date } \\
12 / 97\end{array}$} & \multirow{2}{*}{$\begin{array}{c}\text { LLNL\& } \\
\text { ANSTO } \\
\bullet\end{array}$} & \multirow[t]{2}{*}{ WSRC } & \multirow[t]{2}{*}{ ANL } \\
\hline FY98 & $\begin{array}{l}\text { Provide draft baseline ceramic formulation } \\
\text { and feed specifications }\end{array}$ & & & & \\
\hline & Provide final baseline ceramic formulation & $9 / 98$ & $\bullet$ & 0 & 0 \\
\hline \multirow[t]{3}{*}{ FY99 } & $\begin{array}{l}\text { Complete near-equilibrium processing } \\
\text { conditions sample fabrications }\end{array}$ & $5 / 99$ & $\bullet$ & 0 & O \\
\hline & Provide final feed specifications & $7 / 99$ & $\bullet$ & $\mathrm{O}$ & O \\
\hline & $\begin{array}{l}\text { Provide technical basis for plant as input to } \\
\text { preliminary TDR }\end{array}$ & $8 / 99$ & $\bullet$ & $\mathrm{O}$ & O \\
\hline FY00 & Provide input for TDR & $9 / 00$ & ○ & $\mathrm{O}$ & $\mathrm{O}$ \\
\hline
\end{tabular}

\section{Basic Formulation and Process Parameters: Total Budget (K\$)}

\begin{tabular}{lrrrrrrrr} 
Site/Yr & FY98 & FY99 & FY00 & FY01 & FY02 & FY03 & FY04 & TOTAL \\
\hline LLNL & 325 & 350 & 150 & 0 & 0 & 0 & 0 & 825 \\
\hline WSRC & 250 & 220 & 250 & 0 & 0 & 0 & 0 & 720 \\
\hline ANL & 0 & 0 & 0 & 0 & 0 & 0 & 0 & 0 \\
\hline PNNL & 0 & 0 & 0 & 0 & 0 & 0 & 0 & 0 \\
\hline LANL & 0 & 0 & 0 & 0 & 0 & 0 & 0 & 0 \\
\hline Total & $\mathbf{5 7 5}$ & $\mathbf{5 7 0}$ & $\mathbf{4 0 0}$ & $\mathbf{0}$ & $\mathbf{0}$ & $\mathbf{0}$ & $\mathbf{0}$ & $\mathbf{1 5 4 5}$ \\
\hline
\end{tabular}

\subsubsection{Form Qualification Samples and Data}

This task provides essential samples and data for evaluation of the process control model and for the repository characterization and durability studies. It also provides key form characteristics needed for the repository licensing application that must be submitted July 1999. Form chemical behavior and physical characteristics must be determined in the following categories:

- Mineralogical and compositional product characteristics

- Product physical characteristics such as hardness, fracture toughness, heat capacity, and thermal conductivity.

In addition, essential samples for durability testing (described in Section 2.4.3.) will be fabricated as part of this task.

Two sample series will be made under this task:

- Single-phase synthesis samples

- Process and compositional extreme samples.

These sample series are discussed below. 


\section{Single-Phase Synthesis Samples}

Samples of the individual minerals that make up the composite ceramic (pyrochlore, zirconolite, and brannerite) are needed for dissolution tests, calorimetric measurements, and solubility determinations. Information on the single-phase materials is needed to interpret dissolution data for the ceramic (i.e., to determine whether the concentration of an element in solution is dissolution-rate-controlled or is solubility-limited). The singlephase samples are also valuable for obtaining crystallographic data, which is useful in quantitative x-ray diffraction (XRD) analysis. Such analysis is planned for use in the plant to determine the mineralogical content of the ceramic products. Single-phase materials will also be used in radiation damage experiments. Preparation of the radiation damage samples is covered in another task (Section 2.4.1.1), but the procedures developed in this task will be used in the radiation damage sample preparation.

Pyrochlore, zirconolite, and brannerite will be synthesized. These are the uranium and plutonium host minerals in the ceramic form. Single-phase or near-single-phase endmembers will be made with the following compositions:

$$
\begin{aligned}
& \text { Pyrochlore: } \mathrm{CaCeTi}_{2} \mathrm{O}_{7}, \mathrm{GdGdTi}_{2} \mathrm{O}_{7}, \mathrm{CaUTi}_{2} \mathrm{O}_{7}, \mathrm{CaPuTi}_{2} \mathrm{O}_{7} \\
& \text { Zirconolite: } \mathrm{CaHfTi}_{2} \mathrm{O}_{7} \\
& \text { Brannerite: } \mathrm{CeTi}_{2} \mathrm{O}_{6}, \mathrm{UTi}_{2} \mathrm{O}_{6}, \mathrm{PuTi}_{2} \mathrm{O}_{6}
\end{aligned}
$$

Some single phase minerals with mixed metallic elements will also be made-e.g., $(\mathrm{Ca}, \mathrm{Gd})(\mathrm{Pu}, \mathrm{U}, \mathrm{Hf}) \mathrm{Ti}_{2} \mathrm{O}_{7}$-for calorimetric and dissolution-rate tests. The results of these tests can be used to evaluate solid-solution models based on thermodynamic properties of the end-members, and to test dissolution rate models of the multimetal phases based on dissolution tests of the end-members.

Available information will be used to develop the synthesis methods. The fabrication methods will include routine cold press and sinter processes, but may also include other methods such as nitrate alkoxide methods. Redox control may also be necessary in some synthesis, in particular those with cerium and/or uranium present. These techniques are not always routine, and significant effort may be required to develop the methods needed to make the desired phases. Cold work using cerium as a plutonium surrogate will be used to develop techniques that can then be used with plutonium. Mineral samples will be characterized and analyzed with standard $\mathrm{x}$-ray, electron microprobe, SEM-EDS and/or ICP/MS analysis techniques.

The use of a tracer element incorporated into the ceramic at low concentration levels will be investigated for monitoring ceramic reactivity during dissolution tests. All the elements in the current ceramic formulation are relatively insoluble. Measuring their concentrations in solution during leach tests will not necessarily reflect the extent of reaction of the ceramic. If successful, the "marker" element would fit into the structures of the existing minerals, but during reaction in aqueous solutions, would be released as a soluble species and therefore serve as an indicator of reaction progress.

The single phase materials produced in this task will be used in dissolution rate measurements, calorimetric work, and solubility measurements (see Sections 2.4.1 and 2.4.2)—tasks that depend upon timely completion of the single phase sample task. 


\section{Process and Compositional Extreme Samples}

To produce an acceptable product, an acceptable processing range must be defined. This includes a baseline composition and processing approach to define the target product as well as compositional and processing extremes to define the acceptable processing range. The processing range defined then becomes the boundary that all products must fall within. Any products falling outside the boundary must be recycled in the process. The product control model (discussed later) becomes the means of ensuring that the products produced will fall within the range of acceptable product. These samples will also be used to help define the product control model and will be useful in development of the product consistency specifications.

A trial range of acceptable compositions will first be defined, and then samples will be prepared at each of the extremes and tested for durability. If the durability measurements exceed the requirements, the range can be extended. If the durability is less than the requirements, then the range must be reduced. Samples are made and tested until the acceptable range is defined.

In the case of the ceramic form, the compositional extremes are currently defined as follows:

- Approximately $50 \mathrm{vol} \%$ zirconolite with balance primarily pyrochlore

- Approximately $50 \mathrm{vol} \%$ brannerite with balance primarily pyrochlore

- More than $90 \mathrm{vol} \%$ pyrochlore with reduced neutron absorbers concentrations

- Approximately 90 vol\% pyrochlore with approximately 10 vol\% glass.

Other extremes will be identified as needed. The compositions identified will be fabricated and tested for durability. It is expected that their durabilities will exceed the requirements. Note that the range is sufficiently wide for plutonium disposition needs such that it is not likely that the tests will need to be repeated to find the maximum range that produces products with acceptable durabilities.

For each of the compositions mentioned above, the processing parameters of the ceramic fabrication process will be varied within the range desired for the fabrication approach of interest. The ranges so defined will be important in the design and/or procurement of the processing equipment.

Most of the samples will be prepared first with cerium, which is used as a surrogate for plutonium. For these tests, it is important that most, if not all, samples be repeated with actual plutonium.

Samples will be analyzed using SEM-EDS and/or x-ray diffraction analysis techniques. Some samples will be analyzed using quantitative EDS or microprobe analysis, SEM image analysis, and/or quantitative XRD analysis techniques. 
Form Qualification Samples and Data: Milestones

\begin{tabular}{|c|c|c|c|c|c|}
\hline \multicolumn{2}{|c|}{ Milestone } & \multirow{2}{*}{$\begin{array}{c}\text { Date } \\
3 / 98\end{array}$} & \multirow{2}{*}{$\begin{array}{c}\text { LLNL\& } \\
\text { ANSTO } \\
\bullet\end{array}$} & \multirow[t]{2}{*}{ WSRC } & \multirow{2}{*}{$\frac{\text { ANL }}{0}$} \\
\hline FY98 & Ship A-series samples from LLNL to ANL for durability testing & & & & \\
\hline \multirow[t]{4}{*}{ FY99 } & Complete single-phase "end-member" sample fabrications & $11 / 98$ & $\bullet$ & O & O \\
\hline & $\begin{array}{l}\text { Complete process and compositional extreme } \\
\text { sample fabrications }\end{array}$ & $11 / 98$ & ○ & O & O \\
\hline & $\begin{array}{l}\text { Provide form summary report for repository licensing } \\
\text { application and preliminary TDR }\end{array}$ & $6 / 99$ & $\bullet$ & O & 0 \\
\hline & $\begin{array}{l}\text { Complete single-phase "mixed } \\
\text { composition" sample fabrications }\end{array}$ & $9 / 99$ & & & \\
\hline FY00 & $\begin{array}{l}\text { Provide supplementary data for licensing } \\
\text { application and TDR }\end{array}$ & $10 / 00$ & 0 & 0 & $\mathrm{O}$ \\
\hline
\end{tabular}

Form Qualification Samples and Data: Total Budget (K\$)

\begin{tabular}{lrrrrrrrr} 
Site/Yr & FY98 & FY99 & FY00 & FY01 & FY02 & FY03 & FY04 & TOTAL \\
\hline LLNL & 800 & 300 & 100 & 0 & 0 & 0 & 0 & 1200 \\
\hline WSRC & 300 & 400 & 100 & 0 & 0 & 0 & 0 & 800 \\
\hline ANL & 203 & 150 & 0 & 0 & 0 & 0 & 0 & 353 \\
\hline PNNL & 0 & 0 & 0 & 0 & 0 & 0 & 0 & 0 \\
\hline LANL & 0 & 0 & 0 & 0 & 0 & 0 & 0 & 0 \\
\hline Total & $\mathbf{1 3 0 3}$ & $\mathbf{8 5 0}$ & $\mathbf{2 0 0}$ & $\mathbf{0}$ & $\mathbf{0}$ & $\mathbf{0}$ & $\mathbf{0}$ & $\mathbf{2 3 5 3}$ \\
\hline
\end{tabular}

\subsubsection{Product Control Model Development}

The main focus of the PCM development task will be to develop an accurate model for quantitatively relating output mineralogy, composition, grain size, and porosity as a function of input composition and processing conditions. This model will be used to define compositional and process control envelopes for product control. These parametric envelopes will be integrated with the product consistency protocol for form qualification.

A PCM is essential to:

- Provide adequate process control for the plant

- Provide adequate quality assurance of the ceramic product

- Allow a mapping of expected repository performance to the measured processing parameters and feed characteristics

- Provide an essential element in the waste form process qualification to satisfy repository licensing and acceptability requirements.

To develop and implement a PCM suitable for plant operations, three phases of development are planned: development, testing and refinement, and validation. The development phase is part of this form development task and is discussed in the paragraphs that follow. This first phase is performed primarily with small-scale equipment and smallsize samples. Testing and refinement is a scale-up phase where larger scale equipment is 
used and the samples are full-size ceramic forms (pucks). This second phase is part of First-Stage Immobilization Process/Equipment Development Activity (see Section 2.6.2). Validation is the third and final phase of this effort. This work will be performed in the SRS PPSL with full-size samples to validate and optimize the PCM (see Section 2.8.2). Successful validation of the PCM at SRS will generate the technical specifications and qualify the process for use in the plant.

The various sample series in the development phase are discussed below. These samples, combined with those described in the preceding tasks, provide the basic data needed to develop the preliminary PCM.

\section{Impurity Studies Samples}

A series of samples will be made to further understand the effects of impurities on the characteristics of the ceramic product. These samples will be tailored to determine partitioning coefficients of the impurities in the major phases and to determine cumulative or combined effects of impurities on stabilizing major, minor, and trace phases in the ceramic.

The impurity tests are divided into three basic areas:

- Demonstration of impurity equivalence or near equivalence

- Saturation of impurities to form minor constituent phases

- Effect of volatile impurities.

ANSTO, LLNL, and WSRC will each focus their impurity tests on one of these three areas.

The primary goal for the impurity tests performed at ANSTO will be to categorize impurities into categories of equivalence or near equivalence. For example, can aluminum, gallium, iron, chromium, and vanadium all be treated as a single impurity in the formulation where the sum of the molar quantities of the impurities determines the product properties? These tests on impurities will be divided into three basic areas:

- Zirconolite stabilizers

- Pyrochlore stabilizers

- Glass stabilizers.

The primary goal for the impurity tests performed at LLNL will be to determine the maximum level of each impurity or impurity combination that can be accommodated into the ceramic form before excessive minor phases are stabilized. These tests are divided according to the type of minor phase that is stabilized if too much of the impurity is added. These minor phases include, but are not necessarily limited to, the following:

- Glass: silica-based

- Glass: phosphorous-based

- Nepheline

- Spinel

- Perovskite

- Fluorite

- Hollandite

- Magnetoplumbite

- Alkali molybdates and/or tungstates. 
The primary goal for the impurity tests performed at SRS will be to determine the maximum level of volatile impurities that can be accommodated into the ceramic form without significantly affecting product properties or reducing product density. Volatiles come in three basic categories:

- Oxides (e.g., $\mathrm{Na}_{2} \mathrm{O}, \mathrm{K}_{2} \mathrm{O}$, and $\mathrm{ZnO}$ )

- Chlorides (e.g., $\mathrm{NaCl}, \mathrm{KCl}$, and $\mathrm{CaCl}_{2}$ )

- Fluorides (e.g., $\mathrm{CaF}_{2}$ and $\mathrm{MgF}_{2}$ )

These impurity studies will first be performed with cerium as a surrogate for plutonium, where cerium is substituted for plutonium on a 1-to-1 molar basis. A few tests with thorium as a plutonium surrogate will also be performed.

A subset of the sample compositions will be repeated with plutonium to verify the conclusions observed in the cerium or the thorium surrogate samples.

Most samples will be sintered at $1350^{\circ} \mathrm{C}$ for 4 hours in argon atmosphere. A few samples in each category will be fired at different temperatures to determine any significant effect of temperature. Samples will be prepared using a cold press and sinter process that is known to produce equilibrium or near-equilibrium products. This process is assumed to be the nitrate/alkoxide fabrication process, but could be the wet oxide fabrication process if the particle sizes of the feed oxides are sufficiently small.

A selected set of the sintered samples will be ground into powders and annealed on a chemically compatible surface, such as platinum foil, in different atmospheres. Examples of the different atmospheres are air, $5 \% \mathrm{CO} / \mathrm{CO}_{2}$, and $4 \% \mathrm{H}_{2} / \mathrm{Ar}$.

\section{Equilibrium-Phase Diagram Samples}

An important sample series to be used in developing the process control model will be the equilibrium-phase diagram series. All other sample series used in the previous form development tasks will also provide secondary data for process control model development. A primary additional source of data for the model development will be the data obtained from durability testing as described in Section 2.4.

Samples for the equilibrium phase diagram series (described below) will be fabricated by the nitrate/alkoxide fabrication method using standard materials and procedures. Samples of each composition will be sintered at 1300,1350 , or $1400^{\circ} \mathrm{C}$ for 4 hours or longer in argon atmosphere.

A select set of the sintered samples will be ground into powders and annealed on a chemically compatible surface such as platinum foil in different atmospheres. Examples of the different atmospheres are air, $5 \% \mathrm{CO} / \mathrm{CO}_{2}$, and $4 \% \mathrm{H}_{2} / \mathrm{Ar}$. All samples will be examined by quantitative EDS or microprobe analysis.

Unless the durability of a particular sample is determined to be of interest, these samples will not be subjected to any of the durability tests discussed in Section 2.4. 
The phase diagrams that will be determined include but are not necessarily limited to the following:

- The $\mathrm{CaTiO}_{3}-\mathrm{UTi}_{2} \mathrm{O}_{6}-\mathrm{HfTiO}_{4}$ ternary system with excess $\mathrm{TiO}_{2}$

- The $\mathrm{CaTiO}_{3}-\mathrm{CeTi}_{2} \mathrm{O}_{6}-\mathrm{HfTiO}_{4}$ ternary system with excess $\mathrm{TiO}_{2}$

- The $\mathrm{CaTiO}_{3}-\mathrm{PuTi}_{2} \mathrm{O}_{6}-\mathrm{HfTiO}_{4}$ ternary system with excess $\mathrm{TiO}_{2}$

- The CaHfTi ${ }_{2} \mathrm{O}_{7}-\mathrm{Gd}_{2} \mathrm{Ti}_{2} \mathrm{O}_{7}$ binary system with excess $\mathrm{HfTiO}_{4}$ and $\mathrm{TiO}_{2}$

- The $\mathrm{CaHfTi}_{2} \mathrm{O}_{7}-\mathrm{CaCeTi}_{2} \mathrm{O}_{7}-\mathrm{Gd}_{2} \mathrm{Ti}_{2} \mathrm{O}_{7}$ ternary system with excess $\mathrm{CeTi}_{2} \mathrm{O}_{6}$ and $\mathrm{TiO}_{2}$

- The $\mathrm{CaHfTi}_{2} \mathrm{O}_{7}-\mathrm{CaUTi}_{2} \mathrm{O}_{7}-\mathrm{Gd}_{2} \mathrm{Ti}_{2} \mathrm{O}_{7}$ ternary system with excess $\mathrm{UTi}_{2} \mathrm{O}_{6}$ and $\mathrm{TiO}_{2}$

- The $\mathrm{CaHfTi}_{2} \mathrm{O}_{7}-\mathrm{CaPuTi}_{2} \mathrm{O}_{7}-\mathrm{Gd}_{2} \mathrm{Ti}_{2} \mathrm{O}_{7}$ ternary system with excess $\mathrm{PuTi}_{2} \mathrm{O}_{6}$ and $\mathrm{TiO}_{2}$

- The $\mathrm{CaO}-\mathrm{HfO}_{2}-\mathrm{TiO}_{2}$ ternary system with excess $\mathrm{TiO}_{2}$ and / or $\mathrm{HfO}_{2}$

- The $\mathrm{CaO}-\mathrm{CeO}_{2}-\mathrm{TiO}_{2}$ binary system with excess $\mathrm{TiO}_{2}$ and / or $\mathrm{CeO}_{2}$

- The $\mathrm{CaO}-\mathrm{UO}_{2}-\mathrm{TiO}_{2}$ binary system with excess $\mathrm{TiO}_{2}$ and / or $\mathrm{UO}_{2}$

- The $\mathrm{CaO}-\mathrm{PuO}_{2}-\mathrm{TiO}_{2}$ binary with excess $\mathrm{TiO}_{2}$ and/or $\mathrm{PuO}_{2}$.

The equilibrium-phase diagram tests will be performed almost entirely at LLNL and/or ANSTO. Some tests and detailed characterizations will be performed at ANL.

\section{Control Model Testing and Refinement Samples}

Following the initial sample series described above, an additional test matrix will be developed to explore compositional and processing variables of interest identified in the first year's work. The ceramic form will be pushed to its compositional and processing limits to define the extreme compositional and processing boundaries. This test matrix will be aided by statistical design to ensure adequate coverage of possible compositional scenarios without the proliferation of excessive samples. A number of samples will also be prepared using actual feed materials planned for the immobilization plant. All samples will be analyzed for mineral abundance, composition of constituent minerals, average grain size, and density. These data will be compiled and related to the input compositions and the relevant processing conditions. The process control model, which includes the extreme compositional and processing boundaries, will be completed to support the repository licensing application.

After the initial process control model is developed, processing conditions will be optimized to support design considerations for the final design input. Both uranium/plutonium and uranium/cerium samples will continue to be prepared at LLNL, SRS, and ANSTO to verify the process control model and add to the database that relates input composition and processing conditions to product properties. Formalism of the model will not be changed, but model parameters, such as impurity partitioning coefficients, will be updated as additional data becomes available.

In the outyears, a smaller effort will continue at SRS and LLNL to support form qualification. The product control model, based on input composition and process conditions, will be tested to verify that acceptable products can be produced. 
Product Control Model Development: Milestones

\begin{tabular}{llllll} 
Milestone & Date & $\begin{array}{c}\text { LLNL\& } \\
\text { ANSTO }\end{array}$ & WSRC & ANL \\
\hline FY98 & & & & \\
\hline FY99 & Complete equilibrium phase diagram sample fabrications & $6 / 99$ & $\bullet$ & 0 & 0 \\
\hline & Complete impurity studies sample fabrications & $6 / 99$ & $\bullet$ & 0 & 0 \\
\hline & $\begin{array}{l}\text { Provide summary report for repository } \\
\text { licensing application and preliminary TDR }\end{array}$ & $6 / 99$ & $\bullet$ & 0 & 0 \\
\hline & Propose preliminary PCM & $9 / 99$ & $\bullet$ & 0 & \\
\hline FY00 & Begin PCM testing sample fabrications & $10 / 99$ & $\bullet$ & 0 & 0 \\
\hline & Complete PCM testing sample fabrications & $8 / 00$ & $\bullet$ & 0 & 0 \\
\hline & Provide preliminary PCM & $9 / 00$ & $\bullet$ & 0 & \\
\hline
\end{tabular}

Product Control Model Development: Total Budget (K\$)

\begin{tabular}{lrrrrrrrr} 
Site/Yr & FY98 & FY99 & FY00 & FY01 & FY02 & FY03 & FY04 & TOTAL \\
\hline LLNL & 780 & 1285 & 800 & 50 & 50 & 0 & 0 & 2965 \\
\hline WSRC & 70 & 300 & 440 & 80 & 55 & 0 & 0 & 945 \\
\hline ANL & 100 & 100 & 110 & 0 & 0 & 0 & 0 & 310 \\
\hline PNNL & 0 & 0 & 0 & 0 & 0 & 0 & 0 & 0 \\
\hline LANL & 0 & 0 & 0 & 0 & 0 & 0 & 0 & 0 \\
\hline Total & $\mathbf{9 5 0}$ & $\mathbf{1 6 8 5}$ & $\mathbf{1 3 5 0}$ & $\mathbf{1 3 0}$ & $\mathbf{1 0 5}$ & $\mathbf{0}$ & $\mathbf{0}$ & $\mathbf{4 2 2 0}$ \\
\hline
\end{tabular}




\subsection{PERFORMANCE TESTING AND QUALIFICATION FOR REPOSITORY}

The plutonium form in the HLW glass canister must be assessed and qualified for acceptance in the federal geologic repository in advance of plant operation. The assessment and qualification process involves interactions among the immobilization program team and the MD, RW, and EM organizations of DOE. This process involves the following general activities:

- Characterization of the performance of the plutonium-bearing forms made in the RD\&T program under simulated repository conditions (MD)

- Performance assessment of the plutonium HLW waste package in the repository environment (RW) (see Section 1.3.1)

- Development of models and required data for the calculation of the long-term, in-repository behavior of the plutonium-bearing forms (MD, RW)

- Development and approval of waste acceptance specifications and documentation (MD, RW, and EM)

- Development of pertinent process and product data from the validation tests in the D\&T program and from trial runs in the production facilities prior to actual startup (MD).

The objectives of this activity are to:

- Conduct the performance testing and model development necessary to support the qualification of the immobilized form for repository disposition

- Provide the basis for safety arguments made in the repository licensing application

- Develop the documentation necessary to qualify the immobilization form for acceptance into the Civilian Radioactive Waste Management system.

The work in this activity area (and this chapter) has been subdivided into the following three tasks and associated subtasks:

\section{- Form performance testing and dissolution modeling}

- Radiation-damaged sample synthesis

- Short-term corrosion tests

- Long-term corrosion tests

- Integrated corrosion tests

- Single-pass flow-through tests

- Dissolution model development

- Physical property measurements 
- Thermodynamic data determination and validation

- Aqueous solubility/speciation measurements

- Solid-phase enthalpy and entropy measurements

- Form qualification and repository interactions

\subsubsection{Form Performance Testing and Dissolution Modeling}

Experience with performance testing of HLW glass and spent nuclear fuel has shown that there is no single test that can completely characterize the degradation behavior of a waste form. Hence, the immobilization project will conduct a variety of tests on ceramic materials, basing the testing program on what has been learned from other waste forms. These tests range from short-term (a few days) to long-term (years). The test specimens will include ceramics containing nonradioactive surrogates for plutonium, plutoniumbearing ceramics, single-phase minerals, and radiation-damaged ceramics and single phase minerals. Each test type provides information on a different aspect of the waste form's behavior, or is intended to provide specific information needed for degradation model development and eventual use of those models in performance calculations. The rationale for each test type is described more fully in the following subsections. Table 2-2 summarizes the planned work in the form of a matrix of test types versus. sample types with an estimate of the approximate number of samples that will be tested over the duration of the R\&D program.

Table 2-2. Sample types, test types, and approximate numbers of samples to be tested.

\begin{tabular}{|l|c|c|c|c|c|c|c|c|c|}
\hline \multicolumn{9}{|c|}{ Test Type } \\
\hline & \multicolumn{2}{|c|}{ Short Term Tests } & \multicolumn{2}{c|}{ Long Term Tests } & \multicolumn{3}{c|}{ Other Tests } \\
\hline $\begin{array}{l}\text { Sample } \\
\text { Source }\end{array}$ & MCC-1 & PCT-A & pH-stat* & PCT-B & VHT & Drip & PUFT & SPFT* $^{*}$ & Thermo $^{\dagger}$ \\
\hline $\begin{array}{l}\text { Radiation } \\
\text { damage }\end{array}$ & $\begin{array}{c}15 \\
\text { (plus } \\
\text { repeats) }\end{array}$ & & & & $\begin{array}{c}1-2 \\
\text { if material } \\
\text { is available }\end{array}$ & & $\begin{array}{c}1-2 \\
\text { if material } \\
\text { is available }\end{array}$ & 8 & 8 \\
\hline $\begin{array}{l}\text { Single-phase } \\
\text { samples }\end{array}$ & & & 20 & & & & & 10 & 8 \\
\hline $\begin{array}{l}\text { Form } \\
\text { development }\end{array}$ & $>100$ & $>100$ & & 15 & 15 & 15 & 3 & 6 & \\
\hline $\begin{array}{l}\text { Integrated } \\
\text { systems } \\
\text { tests/demos }\end{array}$ & dozens & dozens & & 12 & 9 & 9 & & 3 & \\
\hline $\begin{array}{l}\text { Plant qual. } \\
\text { runs }\end{array}$ & TBD & TBD & & TBD & & TBD & & & \\
\hline
\end{tabular}

* $\mathrm{pH}$-stat and SPFT both involve tests at multiple $\mathrm{pHs}$ on the same sample. SPFT also involves tests at least 3 test temperatures.

† Thermodynamic data (enthalpy of formation-heat capacity, and absolute entropy).

\subsubsection{Radiation-Damaged Sample Synthesis}

Radiation damage due to the alpha decay of plutonium will change the physical and chemical properties of the ceramic immobilization form. Saturation of this damage is thought to occur after complete metamictization, taking on the order of several hundred to a thousand 
years. To study the impact of radiation damage on the performance of the ceramic, the damage must be accelerated using techniques such as ${ }^{238} \mathrm{Pu}$ doping and ion irradiation. The properties and repository performance of metamict ceramics will be studied to supply input for repository licensing application, can design, and ceramic formulation.

This task covers the fabrication, accelerated damaging, and property testing of ceramic samples. Also covered by this task will be the interpretation of the property data produced on radiation-damaged samples in this program and others. Phase pure minerals (i.e., pyrochlore, zirconolite, and brannerite) and baseline plus other multiphase ceramic mixtures will be fabricated with ${ }^{238} \mathrm{Pu}$; additional samples will be fabricated with ${ }^{239} \mathrm{Pu}$ as undamaged reference materials. Nonradioactive samples containing cerium as a surrogate for plutonium will be fabricated for ion irradiation studies. Samples will be characterized and tested on a regular basis to determine amorphous fraction and density. After saturation of the radiation damage, selected samples will be tested for physical and/or chemical properties including:

- Durability by single pass flow through (SPFT) tests (tested under subsection 2.4.1.5), MCC-1, intermittent drip (tested under subsection 2.4.1.3), and pressurized unsaturated flow through (PUFT) tests (funded under separate tasks)

- Stored energy by calorimetry (funded under separate tasks)

- Cracking/surface area by optical and electron microscopy

- Structure by x-ray absorption spectroscopy and analytical electron microscopy.

Ion irradiation has the advantage that very high doses, which simulate alpha and alpha recoil radiation damage, can be implanted in ceramic samples in very short times. For example, radiation-damage saturation can be achieved in a few minutes using an ion beam. Much higher doses are achievable on a laboratory time scale than are possible with ${ }^{238} \mathrm{Pu}$ testing. Samples simulating the plutonium ceramic form will be prepared and irradiated at a national laboratory with ion beams of appropriate masses and energies to simulate the alpha/alpha recoil radiation damage. Doses simulating up to a million years of storage can be easily achieved. This type of radiation is considered to be a worst case test of alpha/alpha recoil damage because the dose rates are very high.

Consequently, the irradiation times are so short that relaxation processes do not become a factor in annealing any damage caused. The effect of this radiation on the durability will be assessed.

This task interfaces with the ceramic formulation task in terms of setting requirements for the composition and phase assemblage of test samples and possibly for the final form composition. Data developed under this task will be supplied to RW for use in licensing application of the federal repository. Additionally, information on ceramic form swelling will impact can design for the first-stage immobilization process.

This task will also interface with the Environmental Management Science Program (EMSP) project on radiation damage in materials. Partial funding for the task is expected from the EMSP project to perform basic structural and kinetic studies.

In FY98, ${ }^{238} \mathrm{Pu}$ samples (and ${ }^{239} \mathrm{Pu}$ reference samples) will be fabricated. Basic characterization of these samples will be performed. Samples will be stored until saturation of radiation damage is achieved, expected within 3 to 5 years depending on the sample and storage temperature. Cerium-bearing simulant materials will be ion-irradiated and tested for durability by MCC-1. In FY99, storage of ${ }^{238} \mathrm{Pu}$ samples and intermittent characterization will 
continue. The ion irradiation study will be completed in FY99. Radiation damage in the ${ }^{238} \mathrm{Pu}$ samples is expected to saturate between FY01 and FY03. Samples will be fully characterized and tested starting in FY00 and continuing through FY01 and beyond.

Radiation-Damage Sample Synthesis: Milestones

\begin{tabular}{|c|c|c|c|c|c|c|}
\hline \multicolumn{2}{|c|}{ Milestone } & \multirow{2}{*}{$\begin{array}{l}\text { Date } \\
8 / 98\end{array}$} & \multirow[t]{2}{*}{ LLNL } & \multirow[t]{2}{*}{ WSRC } & \multirow[t]{2}{*}{ ANL } & \multirow{2}{*}{$\begin{array}{c}\text { PNNL } \\
\bullet\end{array}$} \\
\hline FY98 & Fabricate ${ }^{238} \mathrm{Pu}$ and cerium ceramic samples & & & & & \\
\hline FY99 & $\begin{array}{l}\text { Complete ion irradiation study and issue } \\
\text { data package to support licensing application }\end{array}$ & $6 / 99$ & & $\bullet$ & & \\
\hline \multicolumn{7}{|l|}{ FY00 } \\
\hline FY01 & Issue report on impacts of radiation damage & $9 / 01$ & & & & - \\
\hline FY02 & Issue data package to RW for repository acceptance & $9 / 02$ & & & & - \\
\hline
\end{tabular}

Primary Responsibility

O Support Responsibility

Radiation-Damage Sample Synthesis: Total Budget $(\$ K)^{\star}$

\begin{tabular}{lrrrrrrrr} 
Site/Yr & FY98 & FY99 & FY00 & FY01 & FY02 & FY03 & FY04 & TOTAL \\
\hline LLNL & 0 & 0 & 0 & 0 & 0 & 0 & 0 & 0 \\
\hline WSRC & 200 & 100 & 50 & 50 & 20 & 0 & 0 & 420 \\
\hline ANL & 0 & 0 & 0 & 0 & 0 & 0 & 0 & 0 \\
\hline PNNL & 520 & 340 & 520 & 510 & 70 & 0 & 0 & 1960 \\
\hline LANL & 0 & 0 & 0 & 0 & 0 & 0 & 0 & 0 \\
\hline Total & $\mathbf{7 2 0}$ & $\mathbf{4 4 0}$ & $\mathbf{5 7 0}$ & $\mathbf{5 6 0}$ & $\mathbf{9 0}$ & $\mathbf{0}$ & $\mathbf{0}$ & $\mathbf{2 3 8 0}$ \\
\hline
\end{tabular}

*Includes contract to ANSTO

\subsubsection{Short-Term Corrosion Tests}

Product consistency will be established by ensuring that density, phase assemblage, and composition are within specifications. The function of these specifications is to show that the product being produced is the same from process run to process run within statistical uncertainty. A short-term corrosion test is needed against a benchmark to tie the product consistency specifications to a performance measure. The product consistency test (PCT) was developed to serve this purpose for HLW glasses at SRS and West Valley. Because the ceramic waste form is much different than HLW glasses, there is a need to determine if this test or one of several other tests should be used for this purpose on the MD ceramic. Thus, the corrosion behavior of ceramic formulations that span the range of possible compositions of the MD ceramic needs to be measured with several test methods, including MCC-1, PCT-A, and pH-stat. By necessity, these tests need to be of short duration to provide confirmation data in a timely manner. Insight gained from testing will also be utilized to provide input to modeling efforts and to the ceramic form formulation activities.

The standard MCC-1 procedure will be performed. The duration will typically be three days at $90^{\circ} \mathrm{C}$. As data are collected and analyzed, longer test durations may be required. The PCT-A will be performed following the ASTM C-1285-94 procedure. This test is completed in demineralized water in triplicate at $90^{\circ} \mathrm{C}$ at $2000 \mathrm{~m}^{-1}$. As with the MCC-1, a full suite of elements will be analyzed. It is anticipated that the $\mathrm{pH}$ stat tests will be relatively short in duration and cover a range of $\mathrm{pH}$ values. 
Ceramic material used in the short-term corrosion tests will be provided by LLNL, ANL, and WSRC. This material is required on a timely basis so that these short-term tests can be initiated. In addition to the baseline ceramic compositions, short-term tests with ceramic containing various impurities will be tested.

In FY98, three sets of tests will be initiated. In early FY98, an abbreviated test matrix will be completed with the pyrochlore-based impurity samples previously prepared at LLNL. Later in FY98, a full test matrix will be completed with a pyrochlore-based sample to be prepared by LLNL. The third series of tests will be initiated with samples containing impurities. These samples will be prepared at LLNL or WSRC.

In FY99, once the compositional envelope has been defined, a number of ceramic samples that cover this operational envelope will be fabricated by LLNL (and/or WSRC) and shipped to ANL for testing.

In FY00 and beyond, testing will focus more on samples that have been prepared by pilot and plant-prototypic equipment. Only a limited number of tests are planned to support form development.

\section{Short-Term Corrosion Tests: Milestones}

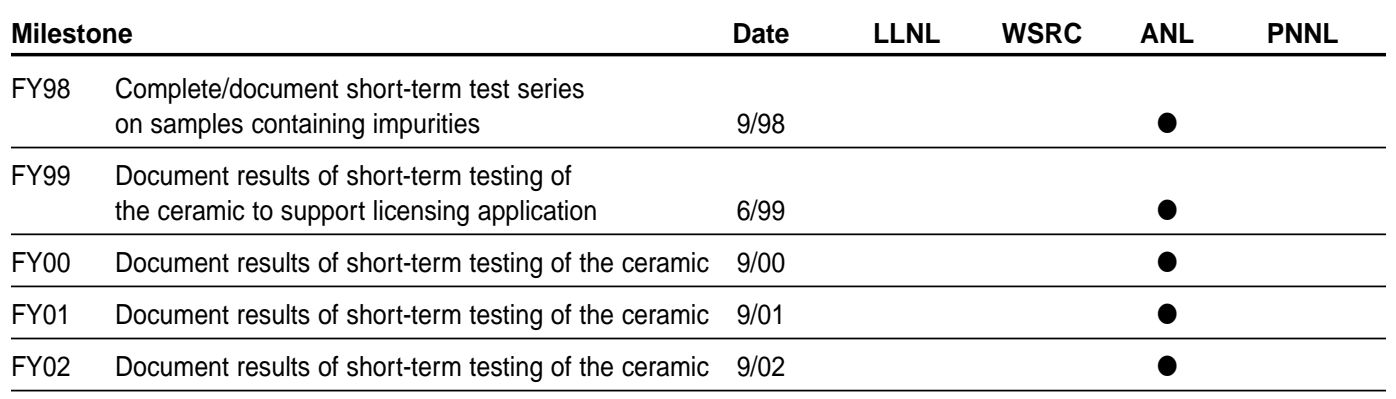

Short-Term Corrosion Tests: Total Budget (\$K)

\begin{tabular}{lrrrrrrrr} 
Site/Yr & FY98 & FY99 & FY00 & FY01 & FY02 & FY03 & FY04 & TOTAL \\
\hline LLNL & 0 & 0 & 0 & 0 & 0 & 0 & 0 & 0 \\
\hline WSRC & 0 & 0 & 0 & 0 & 0 & 0 & 0 & 0 \\
\hline ANL & 570 & 275 & 500 & 325 & 340 & 355 & 375 & 2740 \\
\hline PNNL & 0 & 0 & 0 & 0 & 0 & 0 & 0 & 0 \\
\hline LANL & 0 & 0 & 0 & 0 & 0 & 0 & 0 & 0 \\
\hline Total & $\mathbf{5 7 0}$ & $\mathbf{2 7 5}$ & $\mathbf{5 0 0}$ & $\mathbf{3 2 5}$ & $\mathbf{3 4 0}$ & $\mathbf{3 5 5}$ & $\mathbf{3 7 5}$ & $\mathbf{2 7 4 0}$ \\
\hline
\end{tabular}

\subsubsection{Long-Term Corrosion Tests}

The objective of this task is to characterize the long-term corrosion behavior of the ceramic waste form by use of the PCT, vapor hydration test (VHT), and drip methods. Long-term PCTs are used to describe the behavior of a material as a function of time. The VHT and drip test methods are used to determine the behavior of the MD ceramic in potential repository conditions. These tests were designed specifically to provide input to the performance assessment activities at Yucca Mountain. Insight gained from testing will be utilized to provide input to the waste form optimization and to evaluate the behavior of the plutoniumloaded ceramic under potential repository disposal conditions. 
The PCT-B performed in duplicate at $90^{\circ} \mathrm{C}$ for particle size with surface/volume ratio of $20,000 \mathrm{~m}^{-1}$ is to be terminated at time intervals commensurate with past testing of ceramic materials and extending through four or more years. Several tests with TBD durations will be included in the matrix. The tests will be performed with J-13 water that has been equilibrated with tuff (a reference water used in Yucca Mountain Project testing). Full analyses will be performed on the solutions and the waste forms.

Ceramic materials used in the long-term corrosion tests are provided by LLNL and WSRC. This material is required on a timely basis so that these long-term tests can be initiated. Results from the corrosion of this material are provided to the model development task and to RW.

In FY98, the long-term (PCT-B) tests initiated last year with the zirconolite-based ceramics continue. Tests will also be initiated with a sample of the pyrochlore-based ceramic to be provided by LLNL in mid-year. By the end of FY98, tests with a pyrochlore formulation containing impurities will be initiated.

Tests with the baseline ceramic formulation will be initiated in late FY99, once the compositional envelope has been defined. In addition, a number of ceramic samples that cover the expected operational envelope will be tested.

In FY00 and beyond, testing will focus more on samples that have been prepared with pilot and plant-prototypic equipment. Only a limited number of tests are planned to support form development.

\section{Long-Term Corrosion Tests: Milestones}

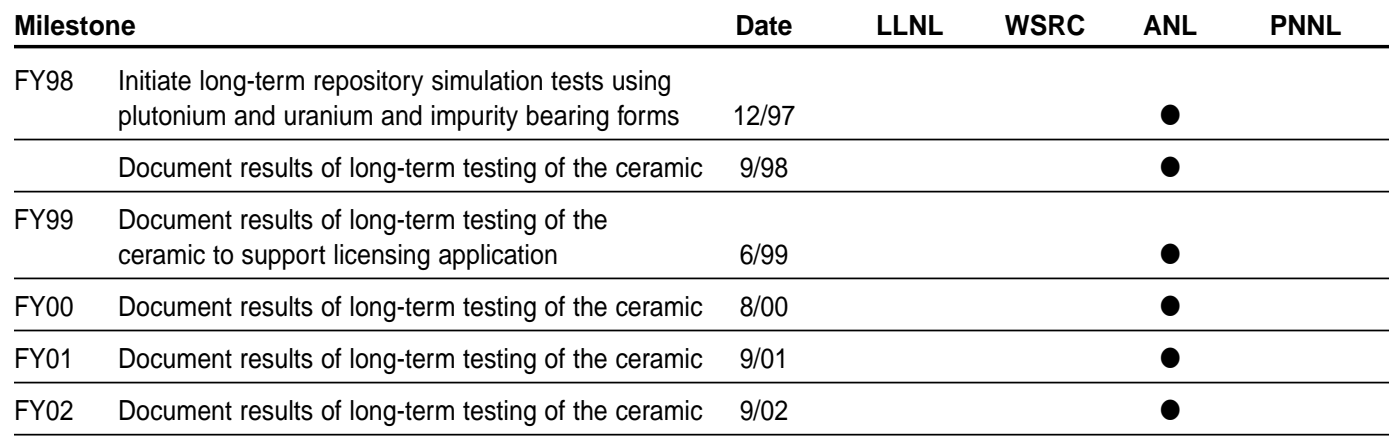

\section{Long-Term Corrosion Tests: Total Budget (\$K)}

\begin{tabular}{lrrrrrrrr} 
Site/Yr & FY98 & FY99 & FY00 & FY01 & FY02 & FY03 & FY04 & TOTAL \\
\hline LLNL & 0 & 0 & 0 & 0 & 0 & 0 & 0 & 0 \\
\hline WSRC & 0 & 0 & 0 & 0 & 0 & 0 & 0 & 0 \\
\hline ANL & 350 & 450 & 470 & 385 & 405 & 425 & 445 & 2930 \\
\hline PNNL & 0 & 0 & 0 & 0 & 0 & 0 & 0 & 0 \\
\hline LANL & 0 & 0 & 0 & 0 & 0 & 0 & 0 & 0 \\
\hline Total & $\mathbf{3 5 0}$ & $\mathbf{4 5 0}$ & $\mathbf{4 7 0}$ & $\mathbf{3 8 5}$ & $\mathbf{4 0 5}$ & $\mathbf{4 2 5}$ & $\mathbf{4 4 5}$ & $\mathbf{2 9 3 0}$ \\
\hline
\end{tabular}


Long-Term Corrosion Tests: Equipment Budget (included above)

\begin{tabular}{lrrrrrrrr} 
Site/Yr & FY98 & FY99 & FY00 & FY01 & FY02 & FY03 & FY04 & TOTAL \\
\hline LLNL & 0 & 0 & 0 & 0 & 0 & 0 & 0 & 0 \\
\hline WSRC & 0 & 0 & 0 & 0 & 0 & 0 & 0 & 0 \\
\hline ANL & 150 & 125 & 0 & 0 & 0 & 0 & 0 & 275 \\
\hline PNNL & 0 & 0 & 0 & 0 & 0 & 0 & 0 & 0 \\
\hline LANL & 0 & 0 & 0 & 0 & 0 & 0 & 0 & 0 \\
\hline Total & $\mathbf{1 5 0}$ & $\mathbf{1 2 5}$ & $\mathbf{0}$ & $\mathbf{0}$ & $\mathbf{0}$ & $\mathbf{0}$ & $\mathbf{0}$ & $\mathbf{2 7 5}$ \\
\hline
\end{tabular}

\subsubsection{Integrated Corrosion Tests}

In the can-in-canister configuration, small cans of the plutonium-loaded ceramic are located inside a DWPF canister filled with HLW glass. Water contacting the ceramic form will have passed through the host rock-and most likely through the surrounding DWPF canister-and interacted chemically with the HLW glass. Consequently, accelerated tests are needed to evaluate the release of the fissile elements and neutron absorbers under conditions that take this into account.

The VHT is a monolith test of variable duration with a $200^{\circ} \mathrm{C}$ steam environment. In this test, a monolith of the ceramic is fixed to a DWPF glass sample. VHTs are conducted to quickly generate alteration products.

An abbreviated matrix of drip tests will be performed at ANL with as-produced and vapor-aged waste forms. The tests will be done at $90^{\circ} \mathrm{C}$ in duplicate. The leachant will be representative of water having reacted with DWPF glass. The solutions will be analyzed periodically, and the test components will be analyzed at the completion of the test. This is an in-service-condition test that provides bounding information insofar as the flow past the waste form is not restricted and air is in contact with the waste form. This test also examines potential synergistic effects that may not otherwise be observed in other tests. The test will be used to evaluate the plutonium/uranium/gadolinium distribution in an in-service environment.

The PUFT system at PNNL provides a unique means to study the corrosion behavior of waste forms under hydraulically unsaturated, open-system conditions. The PUFT experiments will involve creating a "sandwich" of crushed DWPF glass, multiphase ceramic form, and in some tests, other WP materials in a packed column. Fluid is pumped through the column at elevated temperatures, under conditions of less-than-complete fluid saturation. The effluent fluid composition, volumetric water content, temperature, and pressure are monitored continuously during the test. Radioactive and nonradioactive tracers will be injected periodically during the tests to evaluate changes in transport properties of the plutonium, uranium, and neutron absorbers. X-ray microtomography will also be performed periodically to evaluate changes in moisture distribution in the column, and any macroscopic changes in the pore structure as a result of secondary phase formation. After reaction has progressed, the column is dismantled, and the altered material examined to determine the nature of the secondary phases formed. 
The PUFT experiments are designed to evaluate:

- Compatibility between DWPF glass and the ceramic form

- Stability of the ceramic (and DWPF glass) with respect to the formation of secondary phases

- Alteration of unsaturated flow hydraulic properties due to waste form corrosion and secondary phase precipitation

- Adsorption of fissile materials and neutron absorbers on the DWPF waste form surface layers

- Transport of colloidal forms of fissile materials and neutron absorbers.

Data developed under this task are also reviewed, assembled, and transmitted to RW through the waste quality and repository interactions task.

In early FY98, an abbreviated vapor hydration test matrix will be completed with the pyrochlore-based impurity samples previously prepared at LLNL. Later in FY98, a full test matrix will be completed with a pyrochlore-based sample to be prepared by LLNL. Tests are expected to continue through plant start-up.

In FY98, analysis of solution and solid samples from the ongoing PUFT test with a zirconolite-based ceramic will be completed (once this test is terminated, only solid samples will be analyzed). Two additional experiments will be started in FY98: one involving the current baseline ceramic, where pyrochlore is the dominant phase, and the other a ceramic form containing a conservative level of impurities. An additional experiment with a baseline ceramic form doped with ${ }^{238} \mathrm{Pu}$ will be started, likely late in FY98. This test will be continued into FY99 (and possibly longer) to provide data for comparison with a PUFT test that will be started with a fully metamict form in FY00. Additional testing of radiation-damaged samples and ceramics containing important impurities are expected to continue throughout the duration of the project.

\section{Integrated Corrosion Tests: Milestones}

\begin{tabular}{|c|c|c|c|c|c|c|}
\hline \multicolumn{2}{|c|}{ Milestone } & \multirow{2}{*}{$\begin{array}{l}\text { Date } \\
10 / 97 \\
\end{array}$} & \multirow[t]{2}{*}{ LLNL } & \multirow[t]{2}{*}{ WSRC } & \multirow[t]{2}{*}{ ANL } & \multirow{2}{*}{$\frac{\text { PNNL }}{\bullet}$} \\
\hline FY98 & Issue data package on PUFT results for TSPA-VA & & & & & \\
\hline & $\begin{array}{l}\text { Complete/document vapor hydration tests of } \\
\text { impurity samples }\end{array}$ & $7 / 98$ & & & $\bullet$ & \\
\hline \multirow[t]{2}{*}{ FY99 } & Initiate drip tests with ${ }^{238} \mathrm{Pu}$ ceramic. & $6 / 99$ & & & $\bullet$ & \\
\hline & $\begin{array}{l}\text { Issue data package on PUFT results for TSPA } \\
\text { licensing application }\end{array}$ & $6 / 99$ & & & & $\bullet$ \\
\hline \multirow[t]{2}{*}{ FY00 } & $\begin{array}{l}\text { Update data package with results from radiation- } \\
\text { damaged samples and samples with impurities }\end{array}$ & $6 / 00$ & & & & $\bullet$ \\
\hline & $\begin{array}{l}\text { Issue report on status of drip tests and VHT } \\
\text { interaction tests }\end{array}$ & $9 / 00$ & & & $\bullet$ & \\
\hline \multirow[t]{2}{*}{ FY01 } & $\begin{array}{l}\text { Update data package with results from radiation- } \\
\text { damaged samples and samples with impurities }\end{array}$ & $6 / 01$ & & & & - \\
\hline & $\begin{array}{l}\text { Issue report on status of drip tests and VHT } \\
\text { interaction tests }\end{array}$ & $9 / 01$ & & & $\bullet$ & \\
\hline \multirow[t]{2}{*}{ FY02 } & $\begin{array}{l}\text { Update data package with results from radiation } \\
\text { damaged samples and samples with impurities }\end{array}$ & $6 / 02$ & & & & $\bullet$ \\
\hline & $\begin{array}{l}\text { Issue report on status of drip tests and VHT } \\
\text { interaction tests }\end{array}$ & $9 / 02$ & & & $\bullet$ & \\
\hline
\end{tabular}


Integrated Corrosion Tests: Total Budget (\$K)

\begin{tabular}{lrrrrrrrr}
\hline Site/Yr & FY98 & FY99 & FY00 & FY01 & FY02 & FY03 & FY04 & TOTAL \\
\hline LLNL & 0 & 0 & 0 & 0 & 0 & 0 & 0 & 0 \\
\hline WSRC & 0 & 0 & 0 & 0 & 0 & 0 & 0 & 0 \\
\hline ANL & 430 & 560 & 590 & 620 & 650 & 685 & 720 & 4255 \\
\hline PNNL & 515 & 610 & 510 & 410 & 360 & 270 & 285 & 2960 \\
\hline LANL & 0 & 0 & 0 & 0 & 0 & 0 & 0 & 0 \\
\hline Total & 945 & $\mathbf{1 1 7 0}$ & $\mathbf{1 1 0 0}$ & $\mathbf{1 0 3 0}$ & $\mathbf{1 0 1 0}$ & $\mathbf{9 5 5}$ & $\mathbf{1 0 0 5}$ & $\mathbf{7 2 1 5}$ \\
\hline
\end{tabular}

\subsubsection{Single-Pass Flow-Through Tests}

A parameterized dissolution rate law is needed for waste package performance assessment (PA) modeling to be conducted by RW or the Yucca Mountain management and operating contractor. This task is designed to supply the key rate constants used in PA modeling as functions of $\mathrm{pH}$ and temperature.

Single-pass flow-through experiments will be used to develop an understanding of the dissolution kinetics of the ceramic form as a function of temperature and solution $\mathrm{pH}$. Initial experiments will be focused on the primary single phases that host the plutonium, including pyrochlore, zirconolite, and brannerite. Results from the testing of the single phases will be used to verify and interpret tests with the multiphase ceramic. Finally, a selected set of experiments will be performed to evaluate changes, if any, in dissolution kinetic properties of samples that have been subjected to accelerated radiation damage. These samples will contain short half-life isotopes such as ${ }^{238} \mathrm{Pu}$. If found practicable, samples that have been damaged by exposure to intense bremsstrahlung-induced- $(\gamma, \mathrm{n})$ damage will also be tested.

The bulk of the experimental studies on pure phase materials is expected to be completed in FY98 and FY99. Testing of radiation-damaged samples is expected to continue throughout the duration of the project.

\section{Single-Pass Flow-Through Tests: Milestones}

\begin{tabular}{|c|c|c|c|c|c|}
\hline \multicolumn{2}{|c|}{ Milestone } & \multirow{2}{*}{$\frac{\text { Date }}{10 / 97}$} & \multirow{2}{*}{$\frac{\text { LLNL }}{\bullet}$} & \multirow[t]{2}{*}{ WSRC ANL } & \multirow[t]{2}{*}{ PNNL } \\
\hline FY98 & Issue data package on SPFT results for TSPA-VA & & & & \\
\hline FY99 & $\begin{array}{l}\text { Issue data package on SPFT results for TSPA } \\
\text { licensing application }\end{array}$ & $5 / 99$ & $\bullet$ & & O \\
\hline FY00 & $\begin{array}{l}\text { Update data package with results from } \\
\text { radiation-damaged samples }\end{array}$ & $5 / 00$ & $\bullet$ & & O \\
\hline FY01 & $\begin{array}{l}\text { Update data package with results from } \\
\text { radiation-damaged samples }\end{array}$ & $5 / 01$ & O & & $\bullet$ \\
\hline FY02 & $\begin{array}{l}\text { Update data package with results from } \\
\text { radiation-damaged samples }\end{array}$ & $5 / 02$ & O & & ○ \\
\hline
\end{tabular}


Single-Pass Flow-Through Tests: Total Budget (\$K)

\begin{tabular}{lrrrrrrrr} 
Site/Yr & FY98 & FY99 & FY00 & FY01 & FY02 & FY03 & FY04 & TOTAL \\
\hline LLNL & 565 & 310 & 210 & 170 & 110 & 115 & 120 & 1600 \\
\hline WSRC & 0 & 0 & 0 & 0 & 0 & 0 & 0 & 0 \\
\hline ANL & 0 & 0 & 0 & 0 & 0 & 0 & 0 & 0 \\
\hline PNNL & 400 & 460 & 310 & 250 & 160 & 165 & 175 & 1920 \\
\hline LANL & 0 & 0 & 0 & 0 & 0 & 0 & 0 & 0 \\
\hline Total & $\mathbf{9 6 5}$ & $\mathbf{7 7 0}$ & $\mathbf{5 2 0}$ & $\mathbf{4 2 0}$ & $\mathbf{2 7 0}$ & $\mathbf{2 8 0}$ & $\mathbf{2 9 5}$ & $\mathbf{3 5 2 0}$ \\
\hline
\end{tabular}

\subsubsection{Dissolution Model Development}

A parameterized mechanistic model for ceramic dissolution rates is needed for waste package performance assessment modeling of the ceramic waste form in a repository.

The purpose of this task is to develop a defensible mechanistic rate model for ceramic reaction with ground water under repository conditions. The model should identify the rate-limiting processes (e.g., surface reaction control, transport control through a surface alteration layer, or formation of gel layers) and the conditions under which they are ratelimiting, and provide all necessary parameters to implement the model in calculations of waste form behavior in the repository. Although ideally the model would be based entirely on sound theory, it may be based on some combination of theoretically based and empirical functional relationships.

The model will be developed by examining data collected in the ceramic degradation testing tasks of this project, and identifying the dependence of corrosion rates on parameters such as temperature, $\mathrm{pH}$, and solution concentrations. The nature of these dependencies, coupled with identification of alteration layers and secondary phases, should provide key information on the rate-limiting processes. Ideally, the model should be developed from one set of test results, and model validation from another. In this case, we will use mainly SPFT and selected MCC-1, PUFT and PCT test results for generating model parameters, and other MCC-1, PCT, and PUFT tests for validation.

This task will use rate data provided by all the other testing activities (SPFT, MCC-1, PCT, VHT, PUFT, unsaturated, and potentially others) to synthesize a consistent model for ceramic dissolution behavior. The task also relies on our ability to calculate element and mineral solubilities in the test solutions, to determine whether steady-state or solubility-controlled elemental concentrations are being measured. Data from the thermodynamic data development task will also be used. Additionally, both calorimetric and dissolution-rate data on single phase materials are needed to interpret leach data from multi-phase ceramics, and to define the saturation state of each mineral for determining saturation effects on dissolution rates (a key term in the rate equation).

This task will continue throughout the duration of experimental work on ceramic durabilities and will couple intimately with testing activities to provide guidance for these activities. Initial effort will be limited because of the limited amount of test data currently available. More effort will be needed late in FY99 and in succeeding years. Effort in outyears, after a satisfactory model is developed, will focus on abstracting the model for incorporation into repository performance assessment models. 
Dissolution Model Development: Milestones

\begin{tabular}{llcccc} 
Milestone & Date & LLNL & WSRC & ANL & PNNL \\
\hline FY98 & Issue detailed model development work plan & $4 / 98$ & $\bullet$ & O \\
\hline FY99 & $\begin{array}{l}\text { Issue interim report on model development } \\
\text { for repository licensing application }\end{array}$ & $6 / 99$ & $\bullet$ & 0 \\
\hline FY00 & Issue final report on model development & $6 / 00$ & $\bullet$ & 0 \\
\hline FY01 & Issue report on model abstraction for PA & $6 / 01$ & $\bullet$ & 0 \\
\hline
\end{tabular}

Dissolution Model Development: Total Budget (\$K)

\begin{tabular}{lrrrrrrrr} 
Site/Yr & FY98 & FY99 & FY00 & FY01 & FY02 & FY03 & FY04 & TOTAL \\
\hline LLNL & 120 & 240 & 220 & 175 & 175 & 125 & 125 & 1180 \\
\hline WSRC & 0 & 0 & 0 & 0 & 0 & 0 & 0 & 0 \\
\hline ANL & 0 & 0 & 0 & 0 & 0 & 0 & 0 & 0 \\
\hline PNNL & 60 & 80 & 80 & 80 & 80 & 80 & 80 & 540 \\
\hline LANL & 0 & 0 & 0 & 0 & 0 & 0 & 0 & 0 \\
\hline Total & $\mathbf{1 8 0}$ & $\mathbf{3 2 0}$ & $\mathbf{3 0 0}$ & $\mathbf{2 5 5}$ & $\mathbf{2 5 5}$ & $\mathbf{2 0 5}$ & $\mathbf{2 0 5}$ & $\mathbf{1 7 2 0}$ \\
\hline
\end{tabular}

\subsubsection{Physical Property Measurements}

Various physical properties need to be determined for use in DWPF pour modeling, repository performance assessments, and dispersion models of design-basis events in processing, storage, and transportation.

Properties to be measured include, but are not necessarily limited to, thermal conductivity, heat capacity, fracture toughness, thermal expansion, and open/closed porosity. It is expected that most of these measurements will be performed on non-plutonium-containing samples and will be subcontracted by LLNL.

\section{Physical Property Measurements: Milestones}

\begin{tabular}{|c|c|c|c|c|c|c|}
\hline Milest & & Date & LLNL & WSRC & ANL & PNNL \\
\hline FY98 & $\begin{array}{l}\text { Determine heat capacity, thermal conductivity, } \\
\text { and open porosity on ceramic pellet and } \\
\text { issue report }\end{array}$ & $4 / 98$ & ○ & & & \\
\hline FY99 & $\begin{array}{l}\text { Determine particle size distribution for } \\
\text { DBE analyses }\end{array}$ & $3 / 99$ & $\bullet$ & & & \\
\hline & Determine connected porosity of ceramic & $5 / 99$ & ○ & & & \\
\hline FY00 & To be determined (TBD) & TBD & - & & & \\
\hline FY01 & TBD & TBD & & & & \\
\hline
\end{tabular}


Physical Property Measurements: Total Budget (\$K)

\begin{tabular}{lrrrrrrrr} 
Site/Yr & FY98 & FY99 & FY00 & FY01 & FY02 & FY03 & FY04 & TOTAL \\
\hline LLNL & 50 & 50 & 20 & 0 & 0 & 0 & 0 & 120 \\
\hline WSRC & 0 & 0 & 0 & 0 & 0 & 0 & 0 & 0 \\
\hline ANL & 0 & 0 & 0 & 0 & 0 & 0 & 0 & 0 \\
\hline PNNL & 0 & 0 & 0 & 0 & 0 & 0 & 0 & 0 \\
\hline LANL & 0 & 0 & 0 & 0 & 0 & 0 & 0 & 0 \\
\hline Total & 50 & $\mathbf{5 0}$ & $\mathbf{2 0}$ & $\mathbf{0}$ & $\mathbf{0}$ & $\mathbf{0}$ & $\mathbf{0}$ & $\mathbf{1 2 0}$ \\
\hline
\end{tabular}

\subsubsection{Thermodynamic Data Determination and Validation}

\subsubsection{Aqueous Solubility/Speciation Measurements}

A successful safety argument at the time of licensing application requires the development of defensible bounds on the radionuclide source term. These bounds are developed by evaluating and determining solubility limits and chemical speciation for actinides, fission products, and neutron absorbers. Solubility limits provide an understanding of the controls on release rates of radionuclides in aqueous solution; in the absence of colloid transport, they represent the upper limit of waterborne radionuclide concentrations. Chemical thermodynamic data are needed to model the changes in solubility limits and speciation as functions of temperature, $\mathrm{pH}, \mathrm{Eh}$, and water composition. Two types of data are needed:

- Solubility and speciation of individual radionuclides, neutron-absorbers, and key elemental constituents of the form matrix (plutonium, uranium, hafnium, gadolini$\mathrm{um}$, and titanium and their mixtures as functions of temperature for selected water compositions).

- Thermodynamic constants (i.e., solubility products and complexion constants) for the formation of solid and aqueous species as functions of temperature.

Significant data gaps have been identified in the solubility database. Of particular importance is the likelihood of solid phases forming in repository water chemistries that have not been previously observed or characterized in terms of chemical composition or thermochemical properties. Attempts will be made to synthesize or isolate these secondary phases so that their solubility properties can be determined. Silica and phosphate have been identified as being important components present under repository conditions that may affect the solubility of plutonium. Silica is an important constituent of the HLW glass surrounding the immobilized plutonium, and is present in groundwater. Phosphate is also present in the groundwater. Interactions between these components and plutonium in all of its oxidation states are expected to have significant impact on the types of the stable plutonium compounds and potential impact on the dominant plutonium aqueous species; however, a limited quantity of reliable thermodynamic data is available for ascertaining their impact on the solubility of plutonium.

Development of the Nuclear Energy Agency volume, Thermochemical Properties of Plutonium, will be monitored and selected data will be incorporated into the data base. These data will be qualified for use in the repository licensing application. 
Determination of hafnium carbonate and hafnium hydroxide thermodynamic constants and examination of plutonium silicate complexes will be performed. The hafnium studies will be a continuation of work initiated in FY97. Solubility constants and stability constants are evaluated from solubility experiments. By fitting equations that express the solubility and stability to the hafnium solution concentration, one can determine the thermodynamic constants. Data-fitting of $\mathrm{pH}$ titrations can be used to evaluate the hydrolysis and carbonate constants. Solvent extraction and competition experiments will be performed to determine constants in critical ranges. The amount of hafnium in solution will be determined using ICP-MS, neutron activation, indicators, or tracer hafnium produced in the Massachusetts Institute of Technology research reactor.

The ceramics to be used for plutonium disposition are titania based, but there are not sufficient thermodynamic and kinetic data to use titanium oxide minerals for differentiating between solubility and kinetic control of titanium concentrations measured in solutions obtained during ceramic waste form corrosion experiments. These data will be obtained using measurements of the solubility of anatase $\left(\mathrm{TiO}_{2}\right)$. The solubility measurements as a function of $\mathrm{pH}$ provide the data needed to determine the hydrolysis constants for titanium (e.g., formation constants for $\mathrm{TiOH}_{3}+$ and $\mathrm{Ti}(\mathrm{OH})_{2}{ }^{2+}$ ). Sequential samples will be taken over time in the solubility experiments to determine rates of approach to saturation. These data can be used to determine the dissolution rate of anatase and the parametric effect of the saturation state on the dissolution rate. Once the hydrolysis constants are determined, other titanium complex formation constants will be determined by adding relevant ligands (e.g., those present in $\mathrm{J}-13$ water, such as $\mathrm{HCO}_{3}^{-}, \mathrm{Cl}^{-}$, and $\mathrm{PO}_{4}^{3-}$ ) to the solubility experiments. These data can be used to determine the stoichiometries and association constants for these aqueous titanium complexes necessary to calculate titanium solubilities in repository groundwaters. The measurements of $\mathrm{TiO}_{2}$ solubility needed to generate the hydrolysis constants for titanium can be completed in the first year. Followup work will generate data for important aqueous complexes of titanium. The actual ligands studied will be determined based on a literature review of aqueous titanium species.

Validation of the thermodynamic database will consist of forecasting the solubility and speciation of actinides or other radionuclides in a predetermined water chemistry. Experiments will be conducted using the established water composition, and experimental results will be compared with predictions. Confidence will be gained in the thermodynamic database by conducting a series of oversaturation experiments. Plutonium (V) will be added to a solution of some simulated groundwater composition. The anticipated solution species and solubility controlling solid phase will be forecast before the experiment is conducted. Experimental results will be compared to the forecast results to determine if the database is adequate to describe the systems that we anticipate in the repository.

The possible role of radionuclide transport via colloidal material will be explored. This phenomenon is complex and not well understood. Recent results from water wells located near underground nuclear test cavities have shown migration of plutonium from the source terms for some distance, and colloid transport has been identified as the likely mechanism. Experiments will be designed to help advance the understanding of the phenomenon and its possible role in the migration of actinides and fission products from a geologic repository. 
Aqueous Solubility/Speciation Measurements: Milestones

\begin{tabular}{|c|c|c|c|c|c|c|}
\hline \multicolumn{2}{|c|}{ Milestone } & \multirow{2}{*}{$\begin{array}{l}\text { Date } \\
3 / 98\end{array}$} & \multirow[t]{2}{*}{ LLNL } & \multirow[t]{2}{*}{ WSRC } & \multirow[t]{2}{*}{ ANL } & \multirow{2}{*}{$\begin{array}{c}\text { PNNL } \\
0\end{array}$} \\
\hline FY98 & Complete gadolinium carbonate speciation report & & & & & \\
\hline & Issue annual report summarizing FY activities & $9 / 98$ & & & & - \\
\hline \multirow[t]{3}{*}{ FY99 } & $\begin{array}{l}\text { Update thermodynamic database for } \\
\text { licensing application }\end{array}$ & $5 / 99$ & - & & & O \\
\hline & Issue report on $\mathrm{TiO}_{2}$ solubility study & $5 / 99$ & - & & & \\
\hline & Issue report on plutonium phosphate solubility & $5 / 99$ & & & & $\bullet$ \\
\hline \multirow[t]{2}{*}{ FY00 } & Issue annual report summarizing FY activities & $9 / 00$ & ? & & & \\
\hline & Issue annual report - plutonium compounds in waste & $9 / 00$ & & & & • \\
\hline FY01 & Issue annual report summarizing FY activities & $9 / 01$ & - & & & $\mathrm{O}$ \\
\hline \multirow[t]{2}{*}{ FY02 } & Issue annual report summarizing FY activities & $9 / 02$ & - & & & \\
\hline & Issue annual report summarizing FY activities & 9/02 & & & & ○ \\
\hline
\end{tabular}

Aqueous Solubility/Speciation Measurements: Total Budget (\$K)

\begin{tabular}{lrrrrrrrr} 
Site/Yr & FY98 & FY99 & FY00 & FY01 & FY02 & FY03 & FY04 & TOTAL \\
\hline LLNL & 680 & 625 & 615 & 265 & 265 & 0 & 0 & 2450 \\
\hline WSRC & 0 & 0 & 0 & 0 & 0 & 0 & 0 & 0 \\
\hline ANL & 0 & 0 & 0 & 0 & 0 & 0 & 0 & 0 \\
\hline PNNL & 360 & 270 & 300 & 200 & 200 & 0 & 0 & 1330 \\
\hline LANL & 0 & 0 & 0 & 0 & 0 & 0 & 0 & 0 \\
\hline Total & 1040 & 895 & 915 & 465 & 465 & 0 & 0 & 3780 \\
\hline
\end{tabular}

\subsubsection{Solid-Phase Enthalpy and Entropy Measurements}

Thermodynamic data for crystalline and metamict materials are needed for repository dissolution models. Thermodynamic data are also needed to aid development of the model used to relate input composition and processing conditions to output mineralogy and composition during processing. Information on stored energy for metamict phases is needed to assess the effects of radiation damage.

Work in FY98 will include the determination of the standard enthalpy of formation and absolute entropy of non-radioactive crystalline and metamict pyrochlores $\left(\mathrm{CaCeTi}_{2} \mathrm{O}_{7}\right.$ and/or $\left.\mathrm{Gd}_{2} \mathrm{Ti}_{2} \mathrm{O}_{7}\right)$, zirconolites $\left(\mathrm{CaHfTi}_{2} \mathrm{O}_{7}\right.$ and/or $\left.\mathrm{CaZrTi}_{2} \mathrm{O}_{7}\right)$, and brannerites $\left(\mathrm{CeTi}_{2} \mathrm{O}_{6}\right)$. Single-phase crystalline minerals will be prepared at LLNL (and ANSTO) as part of a separate task (see above). The standard enthalpies of formation will be determined at UC Davis and the standard entropies will be determined at Brigham Young University (BYU). Small quantities of metamict minerals will be prepared by ion beam irradiation. Work in later years will focus on uranium and plutonium bearing samples, both endmember phases and solid solutions. (Note that some of the plutonium calorimetry work performed at LANL may be covered under separate EMSP funding.) 
Solid-Phase Enthalpy and Entropy Measurements: Milestones

\begin{tabular}{|c|c|c|c|c|c|c|}
\hline \multicolumn{2}{|c|}{ Milestone } & \multirow{2}{*}{$\begin{array}{l}\text { Date } \\
\text { 9/98 }\end{array}$} & \multirow{2}{*}{$\begin{array}{c}\text { LLNL } \\
\qquad\end{array}$} & \multirow[t]{2}{*}{ WSRC } & \multirow[t]{2}{*}{ ANL } & \multirow[t]{2}{*}{ PNNL } \\
\hline FY98 & $\begin{array}{l}\text { Issue report on enthalpy and entropy } \\
\text { measurements of cerium endmembers }\end{array}$ & & & & & \\
\hline \multirow[t]{2}{*}{ FY99 } & $\begin{array}{l}\text { Issue report on enthalpy and entropy of uranium } \\
\text { and plutonium endmembers }\end{array}$ & $6 / 99$ & $\bullet$ & & & \\
\hline & $\begin{array}{l}\text { Issue report on enthalpy and entropy of cerium } \\
\text { solid solution phases }\end{array}$ & $9 / 99$ & 0 & & & \\
\hline FY00 & $\begin{array}{l}\text { Issue report on enthalpy and entropy of uranium } \\
\text { and plutonium solid solution phases }\end{array}$ & $9 / 00$ & 0 & & & \\
\hline
\end{tabular}

Solid-Phase Entropy and Enthalpy Measurements: Total Budget (\$K)

\begin{tabular}{lrrrrrrrr} 
Site/Yr & FY98 & FY99 & FY00 & FY01 & FY02 & FY03 & FY04 & TOTAL \\
\hline LLNL & 260 & 80 & 60 & 0 & 0 & 0 & 0 & 400 \\
\hline WSRC & 0 & 0 & 0 & 0 & 0 & 0 & 0 & 0 \\
\hline ANL & 0 & 0 & 0 & 0 & 0 & 0 & 0 & 0 \\
\hline PNNL & 0 & 0 & 0 & 0 & 0 & 0 & 0 & 0 \\
\hline LANL & 0 & 0 & 0 & 0 & 0 & 0 & 0 & 0 \\
\hline Total & $\mathbf{2 6 0}$ & $\mathbf{8 0}$ & $\mathbf{6 0}$ & $\mathbf{0}$ & $\mathbf{0}$ & $\mathbf{0}$ & $\mathbf{0}$ & $\mathbf{4 0 0}$ \\
\hline
\end{tabular}

\subsubsection{Form Qualification and Repository Interactions}

As discussed in Section 1.3.2, qualification of the immobilized waste form for acceptance into the Civilian Radioactive Waste Management System requires a waste form qualification strategy and implementing program. In addition, documentation of expected performance of the waste form under repository conditions must be prepared for use in the repository licensing process. This task performs the various interface activities needed to be performed by MD to get the ceramic can-in-canister immobilization form accepted for repository disposal.

The previous tasks associated with immobilization form performance testing, thermodynamic data determination dissolution modeling, will provide the necessary data needed in the repository licensing process. These data will be reported in numerous topical and annual reports associated with the individual tasks. In addition, the data and analyses will be integrated into at least two reports that support the RW licensing application. The first of these will be provided to RW in 7/99.

The waste form qualification program must develop the acceptance specifications for the product, show how compliance with these specifications will be met, and then demonstrate compliance. An important element of this program is developing a measure to demonstrate product consistency. For the can-in-canister disposition program, waste form qualification is needed not only for the immobilized form but also for HLW glass canister containing the plutonium waste form. In addition, it must be shown that deleterious interactions between the ceramic form and HLW glass do not occur. The latter two items will require close interaction and coordination among EM, RW, and the producer of the HLW form (DWPF at SRS). 
In FY98, preliminary PIPS, defining the criteria that a waste form must meet to be accepted by the Civilian Radioactive Waste Management System, will be drafted for the plutonium ceramic form. Concurrence of these initial specifications is expected to be obtained by RW in FY98. Additionally, a product acceptance strategy will be developed with an integrated schedule. Concurrence with the strategy and schedule is expected to be obtained from $\mathrm{MD}, \mathrm{RW}$, and EM before additional product acceptance activities proceed.

In the same fiscal year, the development of a measure to demonstrate product consistency in the immobilization production process will be initiated. An ad hoc committee with members from the immobilization team will be assembled to consult on this effort.

In FY99, the PIPS will be finalized. The PICP will be drafted in FY99. This document will show the methodologies that will be used in the demonstration to ensure compliance with the plutonium immobilization product. Revisions and augmentation to the Waste Compliance Plan (WCP) for DWPF will also be initiated in FY99. Also, efforts will be coordinated with the formulation team to validate the production product consistency measure. This will likely require a significant test effort.

In FY00, the PICP and augmentation to the WCP will be finalized. In FY00 and later years, efforts will concentrate on the development of PIQRs that demonstrate compliance with the PIPS. The methodology to demonstrate product consistency will be integrated into the production process flowsheets.

This task will require close interaction with the ongoing repository testing at ANL, PNNL, and LLNL. Because LLNL is coordinating these testing activities, coordination with the LLNL performance testing lead is required. It is anticipated that WSRC and LLNL will jointly develop the waste acceptance documentation under direction of WSRC because of their experience in this area with DWPF. The development of the product consistency measure will require close coupling with the formulation development and process development teams.

Form Qualification and Repository Interactions: Milestones

\begin{tabular}{|c|c|c|c|c|c|c|}
\hline \multicolumn{2}{|c|}{ Milestone } & \multirow{2}{*}{$\begin{array}{l}\text { Date } \\
11 / 97\end{array}$} & \multirow{2}{*}{$\frac{\text { LLNL }}{\bullet}$} & \multirow[t]{2}{*}{ WSRC } & \multirow{2}{*}{$\frac{\text { ANL }}{0}$} & \multirow{2}{*}{$\frac{\text { PNNL }}{0}$} \\
\hline FY98 & Input data to RW for repository EIS & & & & & \\
\hline & Input data to RW for repository VA TSPA & $11 / 97$ & 0 & & 0 & $\mathrm{O}$ \\
\hline & Issue draft PIPS & $8 / 98$ & O & $\bullet$ & O & O \\
\hline FY99 & $\begin{array}{l}\text { Issue preliminary integrated data report for } \\
\text { licensing application }\end{array}$ & $7 / 99$ & $\mathbf{0}$ & 0 & O & O \\
\hline & Provide final PIPS & $8 / 99$ & 0 & ○ & $\mathrm{O}$ & $\mathrm{O}$ \\
\hline \multirow[t]{2}{*}{ FY00 } & Provide final PICP & $8 / 00$ & $\mathrm{O}$ & $\bullet$ & $\mathrm{O}$ & $\mathrm{O}$ \\
\hline & $\begin{array}{l}\text { Issue updated integrated data report for } \\
\text { licensing application }\end{array}$ & $8 / 00$ & ○ & 0 & 0 & O \\
\hline FY01 & $\begin{array}{l}\text { Issue updated integrated data report } \\
\text { for licensing application }\end{array}$ & $8 / 01$ & $\bullet$ & 0 & & \\
\hline \multirow[t]{2}{*}{ FY02 } & Initiate development of PIQR & $10 / 01$ & O & - & & \\
\hline & $\begin{array}{l}\text { Issue updated integrated data report } \\
\text { for licensing application }\end{array}$ & $8 / 02$ & $\mathbf{0}$ & 0 & & \\
\hline FY03 & Provide preliminary PIQR & $8 / 03$ & 0 & ○ & & \\
\hline
\end{tabular}


Form Qualification and Repository Interactions: Total Budget (\$K)

\begin{tabular}{lrrrrrrrr} 
Site/Yr & FY98 & FY99 & FY00 & FY01 & FY02 & FY03 & FY04 & TOTAL \\
\hline LLNL & 145 & 150 & 100 & 100 & 100 & 55 & 55 & 705 \\
\hline WSRC & 100 & 350 & 250 & 250 & 250 & 270 & 270 & 1740 \\
\hline ANL & 50 & 95 & 100 & 105 & 110 & 115 & 120 & 695 \\
\hline PNNL & 25 & 25 & 25 & 25 & 25 & 0 & 0 & 125 \\
\hline LANL & 0 & 0 & 0 & 0 & 0 & 0 & 0 & 0 \\
\hline Total & $\mathbf{3 2 0}$ & $\mathbf{6 2 0}$ & $\mathbf{4 7 5}$ & $\mathbf{4 8 0}$ & $\mathbf{4 8 5}$ & $\mathbf{4 4 0}$ & $\mathbf{4 4 5}$ & $\mathbf{3 2 6 5}$ \\
\hline
\end{tabular}




\subsection{PLUTONIUM CONVERSION PROCESS/EQUIPMENT DEVELOPMENT}

Plutonium conversion is the first major element in the immobilization process. This activity encompasses material receipt, storage, and processing of the feed materials into oxide forms. These oxides are the input feeds for the first-stage immobilization process. The plutonium conversion portion of the immobilization plant, shown in the process flow diagram in Figure 2-3, consists of the following functional modules or subsystems:

- Material Receipt and Storage (Module 5.1)

- Oxide Fuel Feed Prep (Module 5.2)

- Material Size Reduction (Module 5.3)

- Material Unpacking and Sorting (Module 5.4)

- Metal Fuel Feed Prep (Module 5.5)

- Metal Conversion (Module 5.6)

- Impure Oxide Feed Prep (Module 5.7)

- Materials Characterization (Module 5.8)

- MC\&A (Module 5.9)

- In-Process Storage Vault (Module 5.10)

The equipment subsystems for conversion processes must be fully automated because of the high radiation levels of the plutonium feed materials. The plutonium conversion activity area provides process equipment definition, equipment development when needed, and testing of unit operations and complete modules as required. Each module consists of one or more unit operations, which are at various levels of technical maturity.

The plutonium conversion process flow diagram is color-coded to indicate the degree of D\&T required for the various modules. Some modules require no special D\&T (e.g., areas of truck and container unloading, and shipping and receiving). Although these modules require special automated equipment for material unpackaging, measurement, and storage, these systems will be designed and built using commercially available equipment. In order to specify the information needed for the final design, it is necessary to define the problem, determine equipment specifications, and perform engineering analysis and design as required for the module.

Some modules require concept demonstration with plutonium but do not require the equipment to be prototyped. For example, the crushing and grinding operation in material size reduction must be demonstrated and the product incorporated into the first-stage immobilization feed stream to determine compatibility of the material with the ceramic 


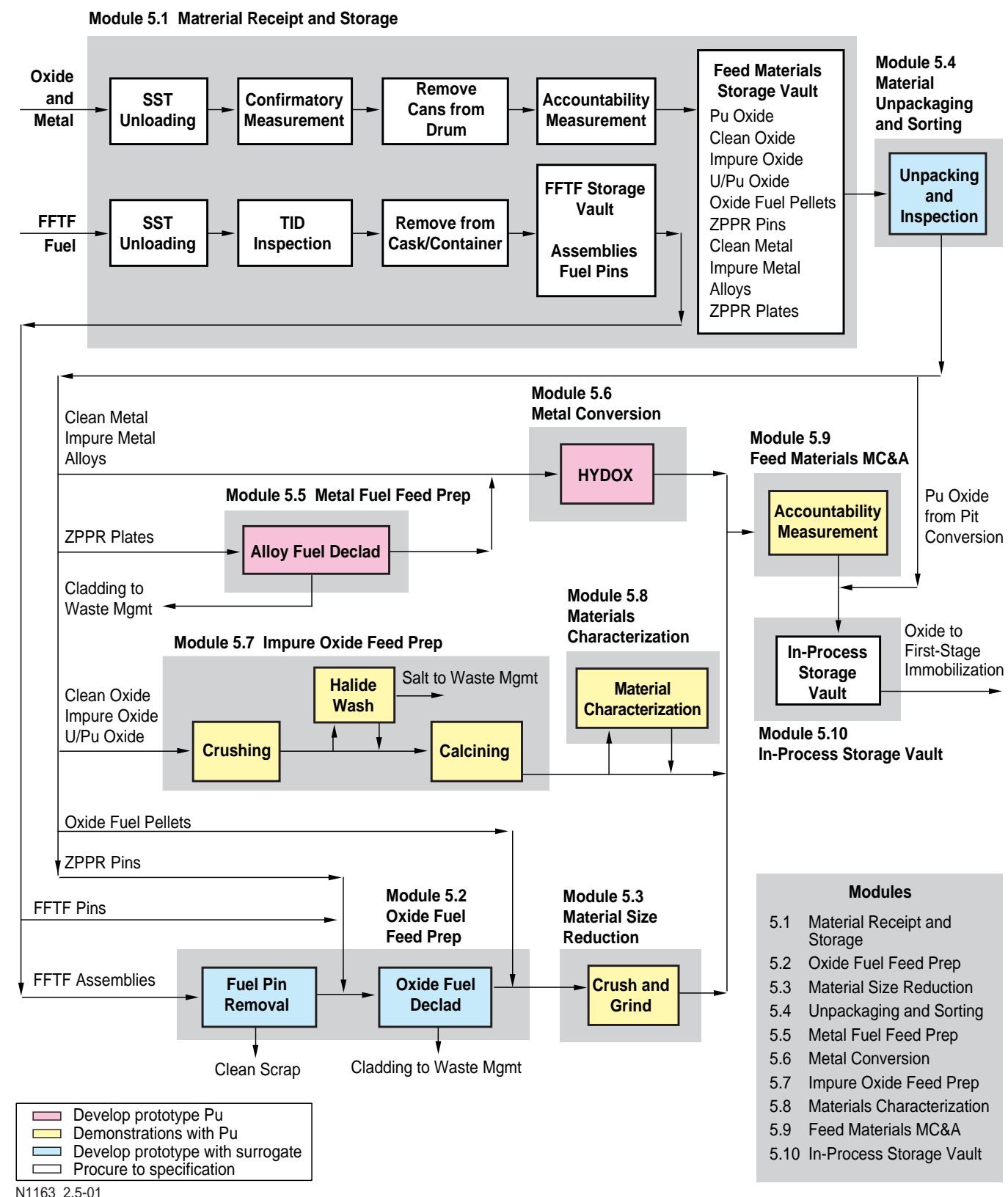

Figure 2-3. Process flow diagram.

formation process. The demonstration must be done using plutonium oxide material from either Zero Power Physics Reactor (ZPPR) or FFTF fuel pins. However, the demonstration does not have to be done at full scale, nor does it require prototypic equipment. The equipment in these modules can be specified once the operating parameters have been determined in the concept tests.

Other modules, such as oxide fuel feed preparation, require concept testing using plutonium feed materials but use surrogate materials for the prototype equipment testing. Tests using plutonium will establish process operational parameters and will provide representative material for first-stage immobilization process equipment testing. Tests using surrogate materials will validate the remote handling features of the prototype equipment and equipment reliability. 
The most challenging modules are those that require prototype equipment tests using actual plutonium feed materials. For example, the metal conversion process requires verification using the full assortment of plutonium metal alloys slated for immobilization. The initial feasibility demonstrations must be followed by tests of plant-scale prototypic equipment using plutonium feed materials to verify the fully automated features of the module. These prototype tests include the full range of feed materials, including variations in size and chemical makeup.

In general, equipment development activities for plutonium conversion modules requiring testing with actual feed materials will be performed at LLNL with WSRC support. Development of modules not requiring testing with plutonium will be performed by WSRC at SRS.

The following sections describe the tasks, milestones, and budgets associated with each module.

\subsubsection{Material Receipt and Storage}

The Immobilization Facility will receive FFTF fuel (as assemblies, pins and pellets), ZPPR fuel plates, clean and dirty oxides, pit conversion oxides, and clean and impure metals/alloys. Receipt, handling, MC\&A, unpacking, and storage of these items will be provided at the head end of the Immobilization Facility. Key operations in this module are illustrated in Module 5.1 below.

No R\&D program will be required for the generally commercially available material handling system. However, it is necessary that a baseline concept, functional requirements, and storage capability be defined as input to the design effort. The material handling features will be largely automatic, without personnel intervention, to provide for a safe and low exposure environment for the workers. An important objective in defining this system is to review the incoming storage drums/containers for the various types of material receipts so that material handling systems are adequate. An assessment of the MC\&A requirements for the various receipts will be performed. Once completed, the recommended techniques and equipment will be identified/specified in the TDR to the $\mathrm{A} / \mathrm{E}$ for this module.

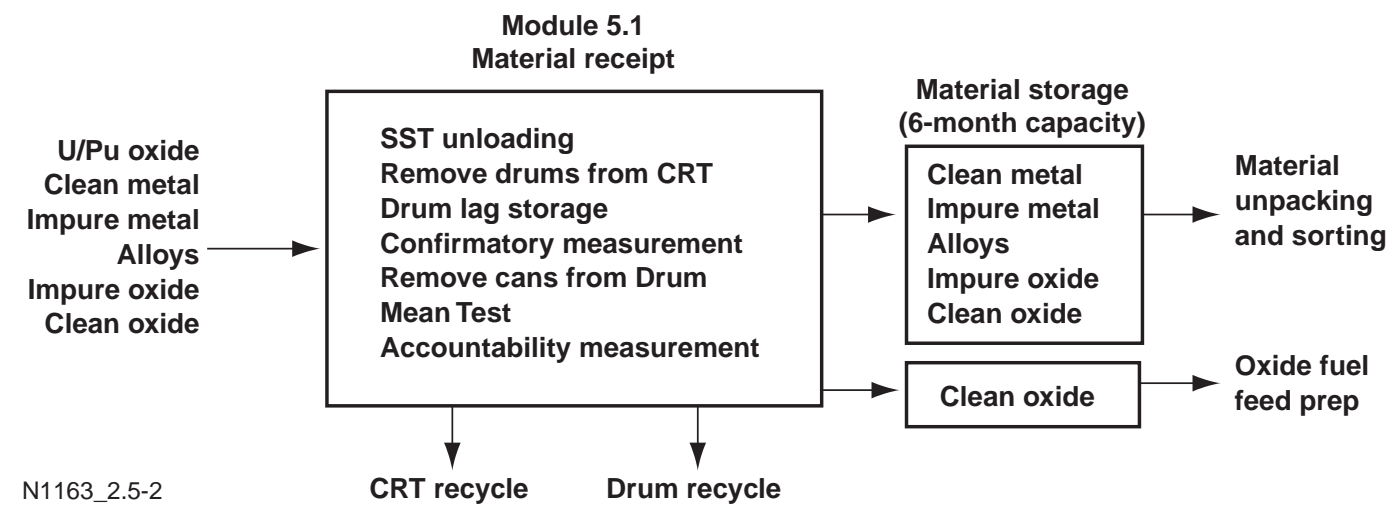


Material Receipt and Storage: Milestones

\begin{tabular}{|c|c|c|c|c|c|c|}
\hline Miles & & Date & LLNL & WSRC & ANL & PNNL \\
\hline FY98 & & & & & & \\
\hline FY99 & $\begin{array}{l}\text { Review \& define receipt shipping container } \\
\text { and can storage requirements }\end{array}$ & $3 / 99$ & & 0 & & \\
\hline & $\begin{array}{l}\text { Develop concept and layouts for material } \\
\text { receipt MC\&A and storage }\end{array}$ & $9 / 99$ & & 0 & & \\
\hline FY00 & $\begin{array}{l}\text { Complete equipment specifications for material } \\
\text { receipt MC\&A and storage }\end{array}$ & $9 / 00$ & & & & \\
\hline & Provide TDR for plant design & $9 / 00$ & & ○ & & \\
\hline
\end{tabular}

Primary Responsibility

O Support Responsibility

Material Receipt and Storage: Total Budget (\$K)

\begin{tabular}{lrrrrrrrr} 
Site/Yr & FY98 & FY99 & FY00 & FY01 & FY02 & FY03 & FY04 & TOTAL \\
\hline LLNL & 0 & 0 & 0 & 0 & 0 & 0 & 0 & 0 \\
\hline WSRC & 0 & 50 & 50 & 20 & 20 & 0 & 0 & 140 \\
\hline ANL & 0 & 0 & 0 & 0 & 0 & 0 & 0 & 0 \\
\hline PNNL & 0 & 0 & 0 & 0 & 0 & 0 & 0 & 0 \\
\hline LANL & 0 & 0 & 0 & 0 & 0 & 0 & 0 & 0 \\
\hline Total & 0 & $\mathbf{5 0}$ & $\mathbf{5 0}$ & $\mathbf{2 0}$ & $\mathbf{2 0}$ & $\mathbf{0}$ & $\mathbf{0}$ & $\mathbf{1 4 0}$ \\
\hline
\end{tabular}

\subsubsection{Oxide Fuel Feed Preparation}

The plant will receive FFTF fuel assemblies and pins and ZPPR fuel pins (Figure 2-4) that contain plutonium and uranium oxide pellets. A remotely operated method of removing the cladding surrounding the oxide fuel for both the FFTF and ZPPR pins has to be designed, built, and tested. Remote operations will be required because of the high radiation levels and the large number of fuel pins slated for immobilization. Module 5.2 below illustrates the major operations associated with oxide fuel feed preparation.

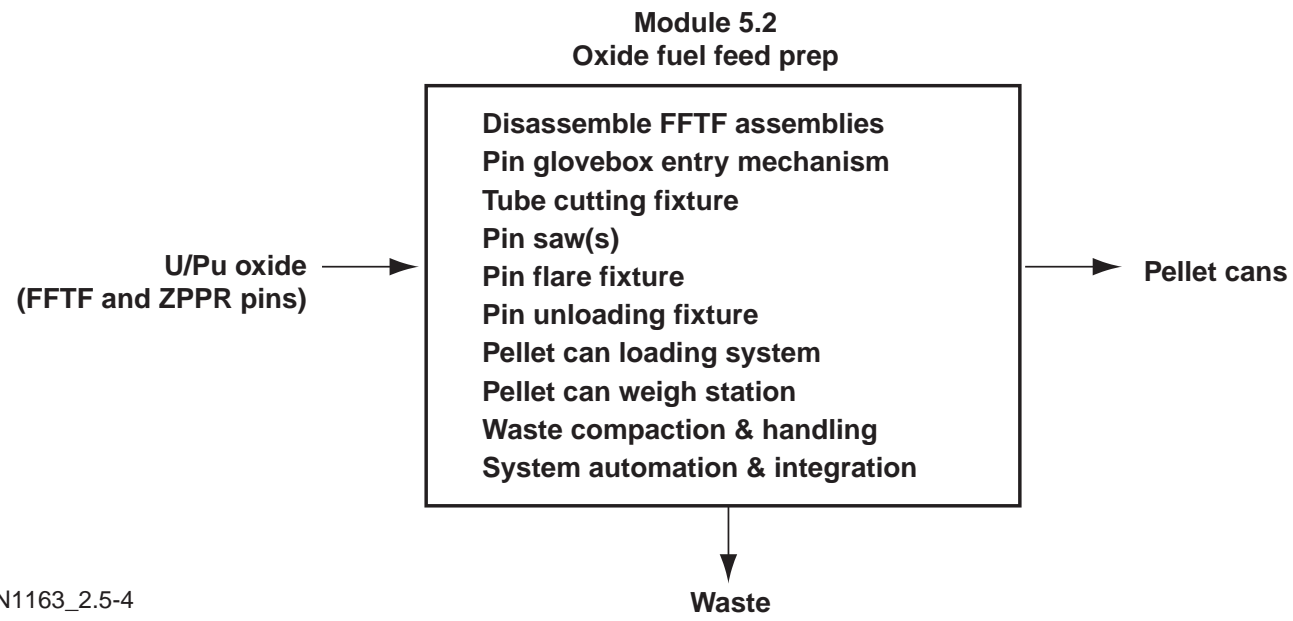


(a)

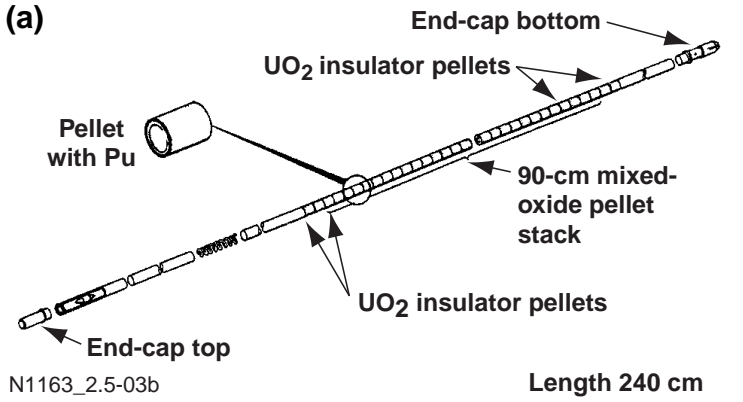

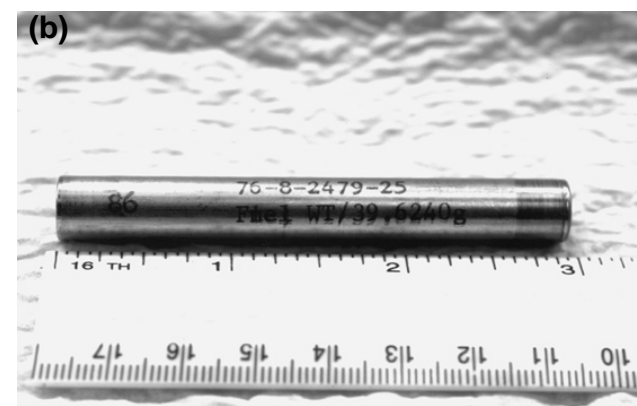

Figure 2-4. Fuel pins: (a) FFTF fuel pin, (b) ZPPR fuel pin.

The first task will be to identify the assembly and pin configurations. After the oxide fuel materials are identified and quantified, the process steps will be defined for material handling and decladding operations. A prototype system, using automatic handling and decladding operations will be designed, built, and tested by means of surrogate fuel pin assemblies. Tests of prototype equipment are necessary to verify process parameters, identify maintenance issues, and demonstrate equipment reliability. It is not necessary to test this module with actual fuel materials.

Oxide Fuel Feed Preparation: Milestones

\begin{tabular}{|c|c|c|c|c|c|c|}
\hline Miles & & Date & LLNL & WSRC & ANL & PNNL \\
\hline FY98 & Identify oxide fuel disassembly requirements & $4 / 98$ & & $\bullet$ & & \\
\hline & $\begin{array}{l}\text { Develop concept for disassembly, declad, } \\
\text { and material transfer }\end{array}$ & $9 / 98$ & & $\bullet$ & & \\
\hline FY99 & Define equipment specs. & $3 / 99$ & $\mathrm{O}$ & 0 & & \\
\hline & Procure major equipment system & $8 / 99$ & & • & & \\
\hline FY00 & Assemble test module & $12 / 99$ & & $\bullet$ & & \\
\hline & Complete module test program and provide TDR & $9 / 00$ & $\mathrm{O}$ & - & & \\
\hline
\end{tabular}

Oxide Fuel Feed Preparation: Total Budget (\$K)

\begin{tabular}{lrrrrrrrr} 
Site/Yr & FY98 & FY99 & FY00 & FY01 & FY02 & FY03 & FY04 & TOTAL \\
\hline LLNL & 0 & 100 & 100 & 20 & 0 & 0 & 0 & 220 \\
\hline WSRC & 100 & 800 & 500 & 50 & 25 & 0 & 0 & 1475 \\
\hline ANL & 0 & 0 & 0 & 0 & 0 & 0 & 0 & 0 \\
\hline PNNL & 0 & 0 & 0 & 0 & 0 & 0 & 0 & 0 \\
\hline LANL & 0 & 0 & 0 & 0 & 0 & 0 & 0 & 0 \\
\hline Total & $\mathbf{1 0 0}$ & $\mathbf{9 0 0}$ & $\mathbf{6 0 0}$ & $\mathbf{7 0}$ & $\mathbf{2 5}$ & $\mathbf{0}$ & $\mathbf{0}$ & $\mathbf{1 6 9 5}$ \\
\hline
\end{tabular}


Oxide Fuel Feed Preparation: Equipment Budget (included above)

\begin{tabular}{lrrrrrrrr} 
Site/Yr & FY98 & FY99 & FY00 & FY01 & FY02 & FY03 & FY04 & TOTAL \\
\hline LLNL & 0 & 0 & 0 & 0 & 0 & 0 & 0 & 0 \\
\hline WSRC & 0 & 500 & 100 & 0 & 0 & 0 & 0 & 600 \\
\hline ANL & 0 & 0 & 0 & 0 & 0 & 0 & 0 & 0 \\
\hline PNNL & 0 & 0 & 0 & 0 & 0 & 0 & 0 & 0 \\
\hline LANL & 0 & 0 & 0 & 0 & 0 & 0 & 0 & 0 \\
\hline Total & $\mathbf{0}$ & $\mathbf{5 0 0}$ & $\mathbf{1 0 0}$ & $\mathbf{0}$ & $\mathbf{0}$ & $\mathbf{0}$ & $\mathbf{0}$ & $\mathbf{6 0 0}$ \\
\hline
\end{tabular}

\subsubsection{Material Size Reduction}

Following decladding, oxide fuel pellets must be size-reduced to provide powder feed to first-stage immobilization. Module 5.3 below shows the major operations associated with material size reduction.

Grinding the pellets into powders can be done using equipment available in industry. A feasibility demonstration is required to show compatibility of the powders as an oxide feed stream to first-stage immobilization processes. A small number of fuel pellets must be ground into powder using techniques similar to industry standards and this powder used in the first-stage immobilization process. The result of this demonstration will be a TDR that specifies the grinding/crushing equipment required in the material size-reduction glove box. No prototype testing is required.

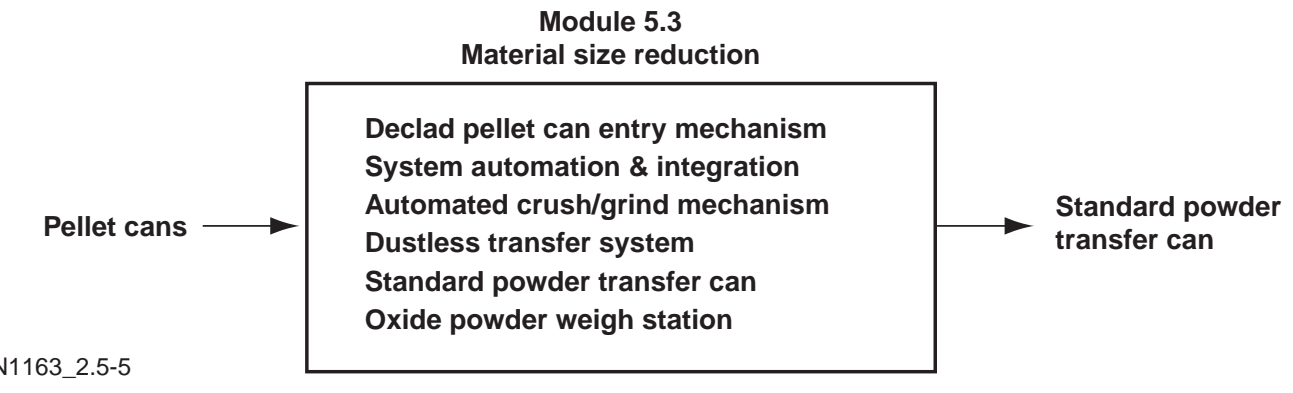

The three subtasks required in this effort are:

- Evaluate present industry capabilities and processes for grinding/crushing oxide fuel pellets into powders.

- Procure a material reduction system that is typical of industry standards. Mount this unit in an existing glove box at LLNL, then generate oxide powder from oxide fuel pins and impure oxides. Use this powder in the first-stage immobilization equipment.

- Generate the TDR for the material size-reduction equipment. 
Material Size Reduction: Milestones

\begin{tabular}{|c|c|c|c|c|c|c|}
\hline Milest & & Date & LLNL & WSRC & ANL & PNNL \\
\hline FY98 & & & & & & \\
\hline FY99 & Evaluate industry capabilities & $12 / 98$ & ○ & & & \\
\hline & $\begin{array}{l}\text { Demonstrate capability to use oxide } \\
\text { powder in immobilization }\end{array}$ & 9/99 & $\bullet$ & & & \\
\hline & Provide input for preliminary TDR & 9/99 & $\bullet$ & & & \\
\hline FY00 & Provide input for TDR & $9 / 00$ & ○ & & & \\
\hline
\end{tabular}

Material Size Reduction: Total Budget (\$K)

\begin{tabular}{lrrrrrrrr} 
Site/Yr & FY98 & FY99 & FY00 & FY01 & FY02 & FY03 & FY04 & TOTAL \\
\hline LLNL & 0 & 260 & 25 & 20 & 20 & 0 & 0 & 325 \\
\hline WSRC & 0 & 0 & 0 & 0 & 0 & 0 & 0 & 0 \\
\hline ANL & 0 & 0 & 0 & 0 & 0 & 0 & 0 & 0 \\
\hline PNNL & 0 & 0 & 0 & 0 & 0 & 0 & 0 & 0 \\
\hline LANL & 0 & 0 & 0 & 0 & 0 & 0 & 0 & 0 \\
\hline Total & $\mathbf{0}$ & $\mathbf{2 6 0}$ & $\mathbf{2 5}$ & $\mathbf{2 0}$ & $\mathbf{2 0}$ & $\mathbf{0}$ & $\mathbf{0}$ & $\mathbf{3 2 5}$ \\
\hline
\end{tabular}

\subsubsection{Material Unpackaging and Sorting}

Material will be received from off-site in a variety of shapes and forms and in various containers. Primary containment containers will be stored in the feed materials vault, then transferred to the material unpackaging and sorting glove box. The key steps associated with the unpackaging and sorting module are shown in Module 5.4 below.

Module 5.4

Material unpacking and sorting

N1163_2.5-6

Clean metal Impure metal Alloys Impure oxide Clean oxide

A methodology and related equipment handling system must be developed to transfer the various canisters into this glove box for processing. The first process within the glove box is the removal of the outer or primary containment containers. The next process within the glove box is to put the various materials into a common transfer can. A common transfer container will be selected to move the various materials throughout the Immobilization 
Facility. Also, design and testing of standard material handling systems will be required. Designing and testing prototype can removal and material handling systems using surrogate materials will be performed to ensure reliable and efficient plant operations.

This task will develop various material unpackaging, transfer, and sorting concepts. The concept will be prototyped and cold-tested to develop plant equipment specifications. The data generated from this task will be used to develop the TDR package.

Material Unpackaging and Sorting: Milestones

\begin{tabular}{|c|c|c|c|c|c|c|}
\hline \multicolumn{2}{|c|}{ Milestone } & \multirow{2}{*}{$\begin{array}{l}\text { Date } \\
4 / 98\end{array}$} & \multirow[t]{2}{*}{ LLNL } & \multirow{2}{*}{$\begin{array}{c}\text { WSRC } \\
0\end{array}$} & \multirow[t]{2}{*}{ ANL } & \multirow[t]{2}{*}{ PNNL } \\
\hline FY98 & $\begin{array}{l}\text { Define the various feed containers coming } \\
\text { from receipts vault }\end{array}$ & & & & & \\
\hline & Develop standard transfer can configuration & $5 / 98$ & & $\bullet$ & & \\
\hline & Develop concept for handling various feed containers & $6 / 98$ & & $\bullet$ & & \\
\hline & $\begin{array}{l}\text { Complete specification of feed material } \\
\text { handling systems }\end{array}$ & 9/98 & & $\bullet$ & & \\
\hline & $\begin{array}{l}\text { Complete specification for transfer cans } \\
\text { and handling systems }\end{array}$ & 9/98 & & $\bullet$ & & \\
\hline & $\begin{array}{l}\text { Define testing program for the material } \\
\text { handling system }\end{array}$ & 9/98 & & $\bullet$ & & \\
\hline FY99 & Procure material handling components for testing & $3 / 99$ & $\mathrm{O}$ & • & & \\
\hline FY00 & Complete testing and provide TDR & $9 / 00$ & O & 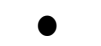 & & \\
\hline
\end{tabular}

Material Unpackaging and Sorting: Total Budget (\$K)

\begin{tabular}{lrrrrrrrr} 
Site/Yr & FY98 & FY99 & FY00 & FY01 & FY02 & FY03 & FY04 & TOTAL \\
\hline LLNL & 0 & 125 & 125 & 20 & 0 & 0 & 0 & 270 \\
\hline WSRC & 100 & 650 & 350 & 35 & 25 & 0 & 0 & 1160 \\
\hline ANL & 0 & 0 & 0 & 0 & 0 & 0 & 0 & 0 \\
\hline PNNL & 0 & 0 & 0 & 0 & 0 & 0 & 0 & 0 \\
\hline LANL & 0 & 0 & 0 & 0 & 0 & 0 & 0 & 0 \\
\hline Total & $\mathbf{1 0 0}$ & $\mathbf{7 7 5}$ & $\mathbf{4 7 5}$ & $\mathbf{5 5}$ & $\mathbf{2 5}$ & $\mathbf{0}$ & $\mathbf{0}$ & $\mathbf{1 4 3 0}$ \\
\hline
\end{tabular}

Material Unpackaging and Sorting: Equipment Budget (included above)

\begin{tabular}{lrrrrrrrr} 
Site/Yr & FY98 & FY99 & FY00 & FY01 & FY02 & FY03 & FY04 & TOTAL \\
\hline LLNL & 0 & 0 & 0 & 0 & 0 & 0 & 0 & 0 \\
\hline WSRC & 0 & 400 & 100 & 0 & 0 & 0 & 0 & 500 \\
\hline ANL & 0 & 0 & 0 & 0 & 0 & 0 & 0 & 0 \\
\hline PNNL & 0 & 0 & 0 & 0 & 0 & 0 & 0 & 0 \\
\hline LANL & 0 & 0 & 0 & 0 & 0 & 0 & 0 & 0 \\
\hline Total & $\mathbf{0}$ & $\mathbf{4 0 0}$ & $\mathbf{1 0 0}$ & $\mathbf{0}$ & $\mathbf{0}$ & $\mathbf{0}$ & $\mathbf{0}$ & $\mathbf{5 0 0}$ \\
\hline
\end{tabular}




\subsubsection{Metal Fuel Feed Preparation}

The ZPPR metal alloy fuel contains a significant fraction of the total amount of plutonium and uranium identified as feed for the immobilization process. The ZPPR fuel is a combination of varying weight percents of uranium and plutonium, alloyed with either aluminum or molybdenum to make a material that is resistant to oxidation. In some cases, the fuel plates have been nickel-plated to enhance oxidation resistance. The fuel plates also vary in size and cladding design. Figure 2-5 illustrates one of these plates.

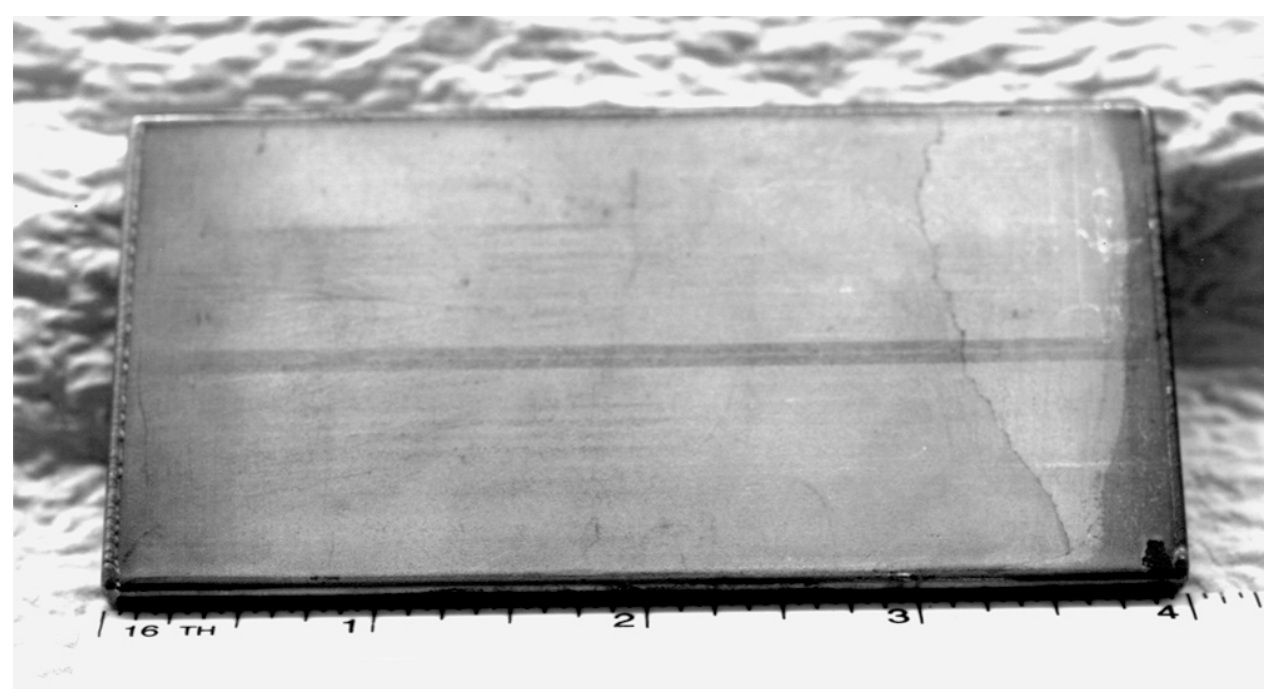

Figure 2-5. ZPPR fuel plate.

The physical steps required to immobilize the fuel, shown in Module 5.5 below, are first a decladding operation, followed by a metal-to-oxide conversion process, and then incorporation of the oxide in the final immobilized form. The isotopic contents of the fuel make it highly radioactive. An automated fuel feed preparation system, which eliminates human handling of the fuel plates, will be required to declad the 22,000 ZPPR fuel plates. A ZPPR decladding process does not currently exist. The decladding operation must expose clean metal on all fuel types for the hydride process step in the metal conversion process. The nickel on the plated fuel must be penetrated before hydriding.

Although clad removal can be demonstrated using surrogate materials, a significant effort would be required to manufacture the appropriate number of surrogate ZPPR plates with cladding to adequately test the fuel feed preparation system. Also, actual fuel material is required to support metal to oxide conversion development. Therefore, a pro-

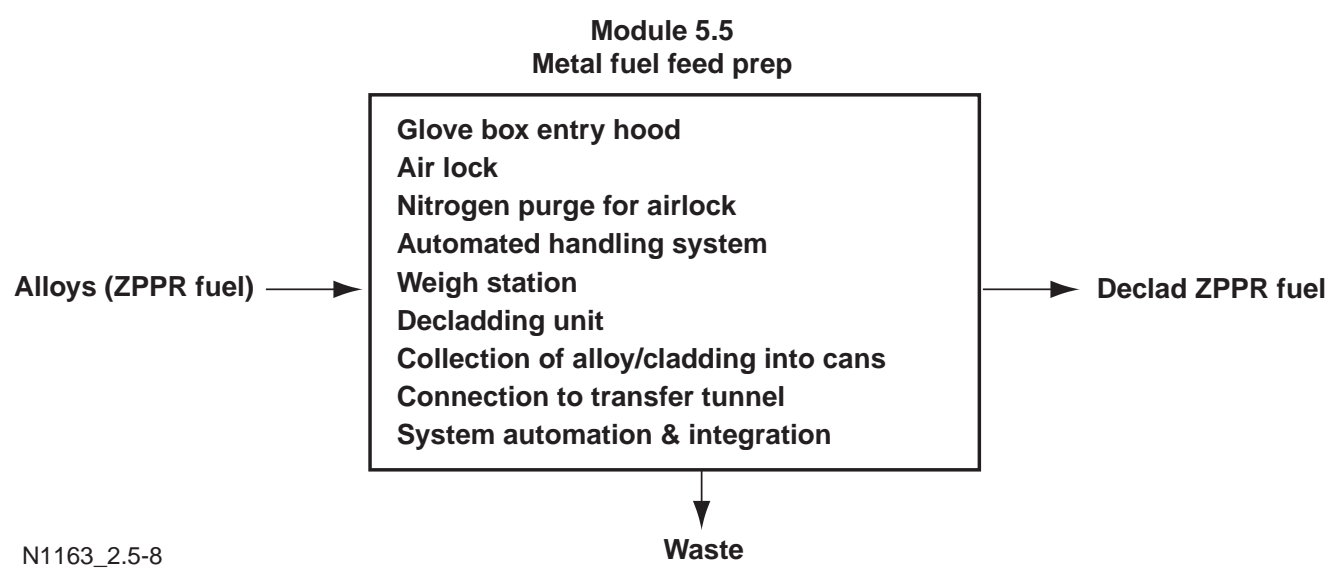


totypic ZPPR fuel feed preparation unit is needed for equipment testing. The prototype will test the operability and reliability of the system components and provide prepared ZPPR plates to the metal conversion module (see Section 2.5.6). Using ZPPR fuel elements in actual demonstrations will provide information on radiation levels and on the ability of the system to adequately prepare the fuel for the metal conversion process.

Also implied in this process is a transfer system that will automatically transfer the ZPPR materials into and out of the fuel feed prep and metal-to-oxide conversion systems. This automated transfer system is required because of radiation exposure concerns when testing the two systems under plant-like conditions.

A remotely operated prototype ZPPR fuel feed preparation system will be developed, designed, and tested-initially using surrogate materials and later with actual ZPPR fuel elements-to demonstrate operating capabilities to input design of plant equipment. The following subtasks are associated with this effort:

- Performing feasibility tests on surrogate and actual ZPPR plates.

- Designing and procuring an automated ZPPR fuel feed prep system. This includes an automated transfer system outside of the glove box that moves the fuel from a staging area into and out of the fuel feed prep system. A transfer system inside the glove box will move the fuel to any work station in the box. Other processes inside the box include a weigh station, a decladding unit, and a storage area.

- Building and testing the feed prep and the external transfer system using surrogate materials to verify process capabilities.

- Moving the fuel feed prep system to the transfer system, coupling this with the metal conversion system in the plutonium facility at LLNL, and testing both systems using ZPPR fuel plates.

- Generating the TDR for the external transfer system and the fuel feed preparation system.

Metal Fuel Feed Preparation: Milestones

\begin{tabular}{|c|c|c|c|c|c|c|}
\hline \multicolumn{2}{|c|}{ Milestone } & \multirow{2}{*}{$\frac{\text { Date }}{1 / 98}$} & \multirow{2}{*}{$\frac{\text { LLNL }}{\bullet}$} & \multirow[t]{2}{*}{ WSRC } & \multirow[t]{2}{*}{ ANL } & \multirow[t]{2}{*}{ PNNL } \\
\hline FY98 & Develop system design and demonstration criteria & & & & & \\
\hline & $\begin{array}{l}\text { Complete feasibility demonstration of selected } \\
\text { ZPPR fuel decladding technology }\end{array}$ & $4 / 98$ & $\bullet$ & & & \\
\hline & $\begin{array}{l}\text { Design ZPPR fuel decladding system and } \\
\text { begin procurement }\end{array}$ & 9/98 & ○ & $\mathrm{O}$ & & \\
\hline \multirow[t]{3}{*}{ FY99 } & Procure mechanical systems and electronic controls & $1 / 99$ & ○ & & & \\
\hline & Assemble design and test cold & $6 / 99$ & $\bullet$ & 0 & & \\
\hline & Provide input for preliminary TDR & $8 / 99$ & - & 0 & & \\
\hline \multirow[t]{4}{*}{ FY00 } & $\begin{array}{l}\text { Move system into Radiation Materials } \\
\text { Management Area (RMMA) }\end{array}$ & $1 / 00$ & • & & & \\
\hline & Perform hot tests & $5 / 00$ & $\bullet$ & 0 & & \\
\hline & Demonstrate decladding consolidation & $6 / 00$ & - & & & \\
\hline & Provide TDR & $8 / 00$ & $\bullet$ & 0 & & \\
\hline FY01 & Provide input for supplemental TDR & $9 / 01$ & ? & 0 & & \\
\hline
\end{tabular}


Metal Fuel Feed Preparation: Total Budget (\$K)

\begin{tabular}{lrrrrrrrr} 
Site/Yr & FY98 & FY99 & FY00 & FY01 & FY02 & FY03 & FY04 & TOTAL \\
\hline LLNL & 2010 & 2090 & 800 & 150 & 25 & 0 & 0 & 5075 \\
\hline WSRC & 150 & 150 & 100 & 500 & 0 & 0 & 0 & 900 \\
\hline ANL & 0 & 0 & 0 & 0 & 0 & 0 & 0 & 0 \\
\hline PNNL & 0 & 0 & 0 & 0 & 0 & 0 & 0 & 0 \\
\hline LANL & 0 & 0 & 0 & 0 & 0 & 0 & 0 & 0 \\
\hline Total & $\mathbf{2 1 6 0}$ & $\mathbf{2 2 4 0}$ & $\mathbf{9 0 0}$ & $\mathbf{6 5 0}$ & $\mathbf{2 5}$ & $\mathbf{0}$ & $\mathbf{0}$ & $\mathbf{5 9 7 5}$ \\
\hline
\end{tabular}

Metal Fuel Feed Preparation: Equipment Budget (included above)

\begin{tabular}{lrrrrrrrr} 
Site/Yr & FY98 & FY99 & FY00 & FY01 & FY02 & FY03 & FY04 & TOTAL \\
\hline LLNL & 700 & 500 & 0 & 0 & 0 & 0 & 0 & 1200 \\
\hline WSRC & 0 & 0 & 0 & 0 & 0 & 0 & 0 & 0 \\
\hline ANL & 0 & 0 & 0 & 0 & 0 & 0 & 0 & 0 \\
\hline PNNL & 0 & 0 & 0 & 0 & 0 & 0 & 0 & 0 \\
\hline LANL & 0 & 0 & 0 & 0 & 0 & 0 & 0 & 0 \\
\hline Total & 700 & $\mathbf{5 0 0}$ & $\mathbf{0}$ & $\mathbf{0}$ & $\mathbf{0}$ & $\mathbf{0}$ & $\mathbf{0}$ & $\mathbf{1 2 0 0}$ \\
\hline
\end{tabular}

\subsubsection{Metal Conversion}

The plutonium and uranium in the metal alloy ZPPR fuel must be converted into an oxide for immobilization. This will be done by adapting the hydriding and oxidation (HYDOX) process (being developed for Pit Disassembly and Conversion) and tailoring it to the ZPPR fuel elements. Key steps in the HYDOX processing system are illustrated in Module 5.6 below. The hydriding-nitriding stage of the HYDOX concept for ZPPR fuel plates is shown in Figure 2-6.

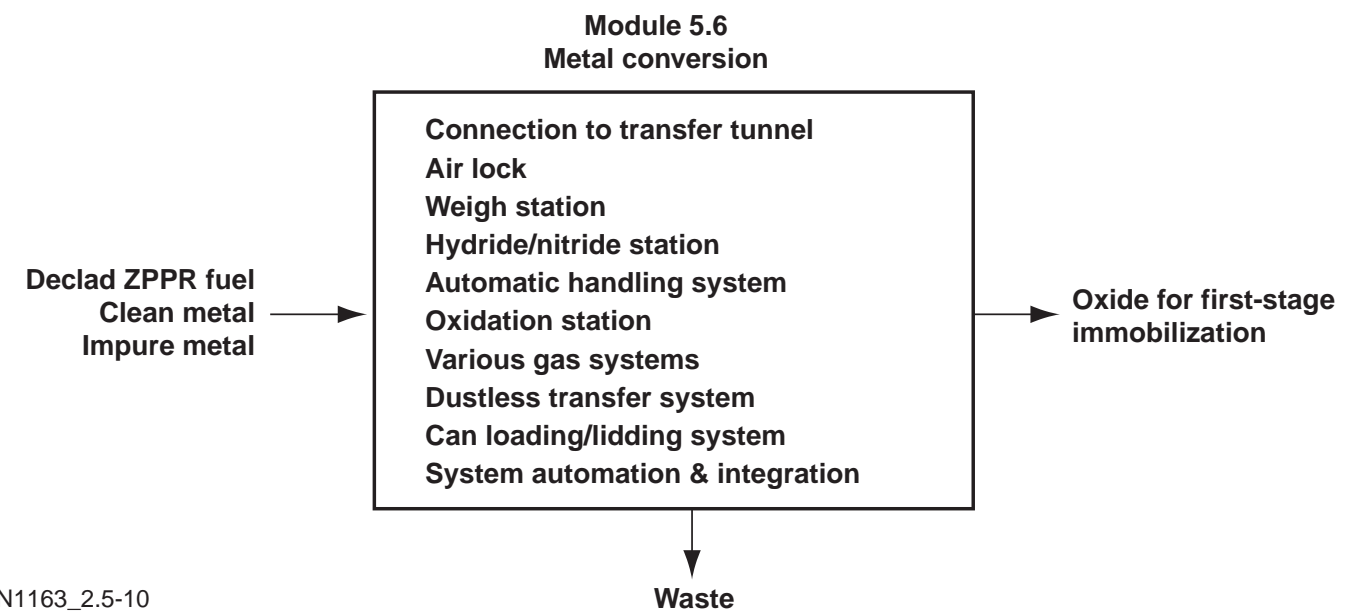

A very limited number of ZPPR fuel plates have been tested with the HYDOX process. These tests demonstrated feasibility, but provided limited data for plant operation.

Furthermore, the sample preparation was not prototypic of plant operation. Tests using 


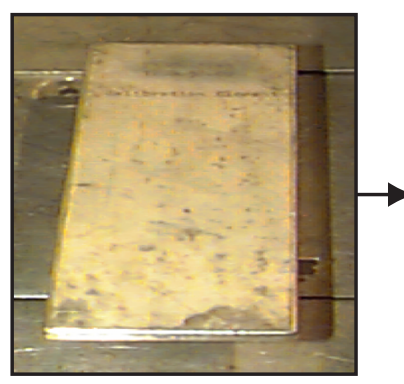

ZPPR Fuel Plate N1163_2.5-9

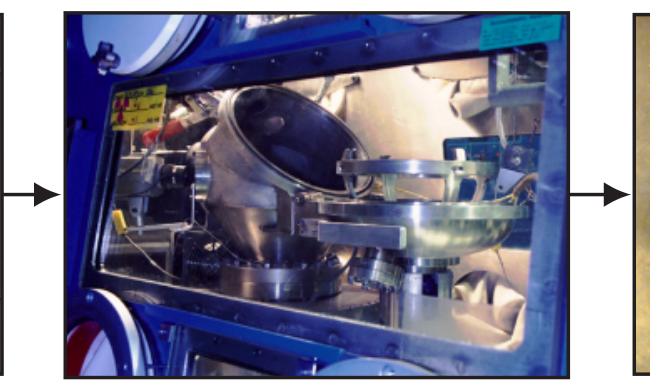

Experimental HYDOX System

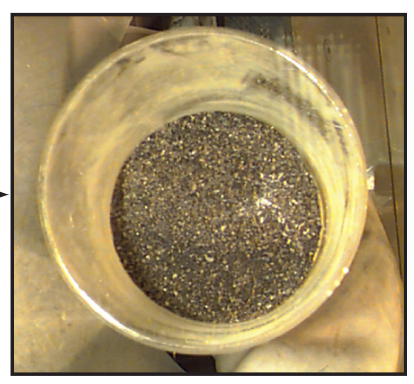

Oxide Powder

Figure 2-6. The hydriding-nitriding stage of the HYDOX concept for ZPPR fuel plate.

prototypic plant processes are needed to adequately demonstrate plant capabilities and also to provide feed material for the development and testing of ceramification equipment in the first-stage immobilization (Section 2.6).

Varying uranium and plutonium mixtures in ZPPR fuel may require slight changes in the HYDOX process parameters to ensure complete fuel oxidation and to optimize production throughput capabilities. These parameters will be determined after prototype testing using ZPPR alloy fuels. The aluminum and molybdenum are contaminants in the oxide powder. Ceramification tests indicate that the level of these contaminants in the ZPPR alloy fuel is not detrimental to the final immobilized product form.

The isotopic contents of the fuel materials make them highly radioactive. This requires that a reliable automated HYDOX system be designed and prototyped prior to specifying final design of the plant system. The present HYDOX experimental units are not automated. They require human interface between process steps. This will not be possible in the plant design because of the radiation from ZPPR fuels. Automating the HYDOX design and testing this system for equipment reliability is required before final design of the plant system. Adequately testing the automated system using ZPPR fuels is required to demonstrate the HYDOX process in handling all of ZPPR fuel alloys; measure radiation levels; and establish equipment operability, maintainability, and reliability.

A remotely operated metal conversion system will be developed, designed, and tested using ZPPR fuel plates to demonstrate plant operating capabilities. The following subtasks are associated with this effort:

- Performing feasibility tests using ZPPR fuel plates. This testing will verify applicability and set process parameters for the HYDOX operation in the metal conversion system.

- Designing and procuring an automated metal conversion system. This includes an automated transfer system inside the glove box, a weigh station, the HYDOX unit, a dustless powder removal system, and a storage area.

- Building and testing the metal conversion system using surrogate materials to verify process capabilities.

- Moving the metal conversion system into the plutonium facility at LLNL, coupling this with the transfer system and the ZPPR fuel feed system, and testing these systems using ZPPR fuel plates.

- Generating the TDR for the metal conversion system. 
Metal Conversion: Milestones

\begin{tabular}{|c|c|c|c|c|c|c|}
\hline Milest & & Date & LLNL & WSRC & ANL & PNNL \\
\hline FY98 & $\begin{array}{l}\text { Perform feasibility demonstrations on Pu-Al alloys } \\
\text { (expected receival date } 7 / 1 / 98 \text {; test schedule } \\
\text { is dependent on facility operation) }\end{array}$ & 9/98 & ○ & & & \\
\hline & $\begin{array}{l}\text { Design and begin procurement of glove box, } \\
\text { mechanical systems, and electronic controls }\end{array}$ & $9 / 98$ & ○ & & & \\
\hline FY99 & Procure remaining mechanical systems and electronic & s $1 / 99$ & - & & & \\
\hline & Assemble and test cold & $6 / 99$ & $\bullet$ & $\mathrm{O}$ & & \\
\hline & Provide input for preliminary TDR & $8 / 99$ & - & $\mathrm{O}$ & & \\
\hline & Prepare area in Bldg 332 at LLNL & $9 / 99$ & ○ & & & \\
\hline FY00 & Move system into RMMA & $1 / 00$ & $\bullet$ & & & \\
\hline & Perform hot tests & $7 / 00$ & ○ & $\mathrm{O}$ & & \\
\hline & Provide TDR & $9 / 00$ & - & O & & \\
\hline FY01 & $\begin{array}{l}\text { Install auxiliary support systems for immobilization } \\
\text { glove boxes in Bldg } 332\end{array}$ & $12 / 00$ & ○ & & & \\
\hline & Provide input to supplemental TDR & $9 / 01$ & ○ & 0 & & \\
\hline
\end{tabular}

Metal Conversion: Total Budget (\$K)

\begin{tabular}{lrrrrrrrr} 
Site/Yr & FY98 & FY99 & FY00 & FY01 & FY02 & FY03 & FY04 & TOTAL \\
\hline LLNL & 1910 & 2100 & 950 & 430 & 50 & 0 & 0 & 5440 \\
\hline WSRC & 100 & 100 & 100 & 100 & 0 & 0 & 0 & 400 \\
\hline ANL & 0 & 0 & 0 & 0 & 0 & 0 & 0 & 0 \\
\hline PNNL & 0 & 0 & 0 & 0 & 0 & 0 & 0 & 0 \\
\hline LANL & 0 & 0 & 0 & 0 & 0 & 0 & 0 & 0 \\
\hline Total & $\mathbf{2 0 1 0}$ & $\mathbf{2 2 0 0}$ & $\mathbf{1 0 5 0}$ & $\mathbf{5 3 0}$ & $\mathbf{5 0}$ & $\mathbf{0}$ & $\mathbf{0}$ & $\mathbf{5 8 4 0}$ \\
\hline
\end{tabular}

Metal Conversion: Equipment Budget (included above)

\begin{tabular}{lrrrrrrrr} 
Site/Yr & FY98 & FY99 & FY00 & FY01 & FY02 & FY03 & FY04 & TOTAL \\
\hline LLNL & 700 & 100 & 0 & 0 & 0 & 0 & 0 & 800 \\
\hline WSRC & 0 & 0 & 0 & 0 & 0 & 0 & 0 & 0 \\
\hline ANL & 0 & 0 & 0 & 0 & 0 & 0 & 0 & 0 \\
\hline PNNL & 0 & 0 & 0 & 0 & 0 & 0 & 0 & 0 \\
\hline LANL & 0 & 0 & 0 & 0 & 0 & 0 & 0 & 0 \\
\hline Total & $\mathbf{7 0 0}$ & $\mathbf{1 0 0}$ & $\mathbf{0}$ & $\mathbf{0}$ & $\mathbf{0}$ & $\mathbf{0}$ & $\mathbf{0}$ & $\mathbf{8 0 0}$ \\
\hline
\end{tabular}




\subsubsection{Impure Oxide Feed Preparation}

The list of feed materials that are currently slated for the Immobilization Facility includes impure oxides that contain halides. Removal of these halides is desirable prior to first-stage immobilization due to the volatilization of the halides in the sintering furnace. A simple washing operation followed by calcination is the baseline process to remove the halides from the impure plutonium oxide material. Key steps in the impure oxide feed preparation module are shown in Module 5.7 below.

Module 5.7

Impure oxide feed prep

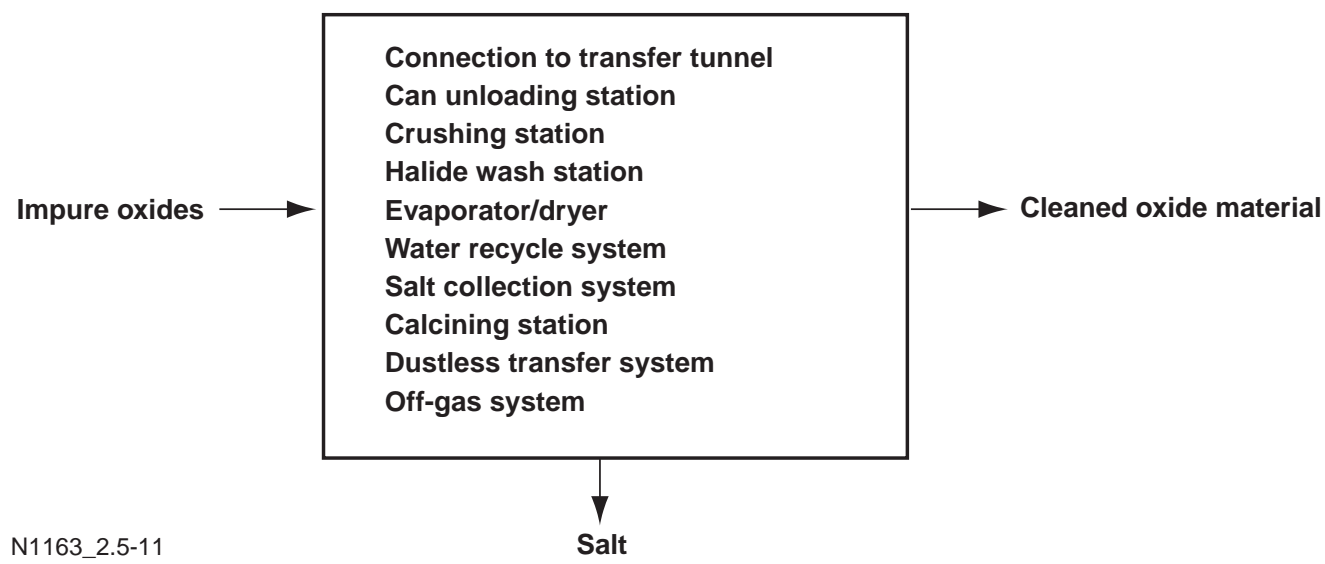

Equipment for this type of operation is common in the DOE complex and extensive development is not considered necessary. However, due to the high temperature treatment of this oxide to meet DOE safe storage standards, a feasibility demonstration of the washing and calcining process is deemed necessary.

This task involves LLNL obtaining several batches of halide-containing oxides from Hanford, where they are currently being stored, and demonstrating that a simple wash and calcination process will remove the halides to an acceptable level for the immobilization process. This feasibility study will be performed to assure that the baseline plan is adequate and that more extensive development is not required. A TDR will be provided to outline process equipment specifications and operational parameters for plant operation.

Impure Oxide Feed Preparation: Milestones

\begin{tabular}{|c|c|c|c|c|c|c|}
\hline Milest & & Date & LLNL & WSRC & ANL & PNNL \\
\hline FY98 & Develop demonstration criteria & $1 / 98$ & - & & & \\
\hline & $\begin{array}{l}\text { Perform feasibility demonstration of halide wash } \\
\text { (demonstration is dependent on facility operations) }\end{array}$ & $9 / 98$ & 0 & & & \\
\hline FY99 & Provide preliminary TDR input & $3 / 99$ & $\bullet$ & & & \\
\hline FY00 & Provide input to TDR & $8 / 00$ & • & & & \\
\hline
\end{tabular}


Impure Oxide Feed Preparation: Total Budget (\$K)

\begin{tabular}{lrrrrrrrr} 
Site/Yr & FY98 & FY99 & FY00 & FY01 & FY02 & FY03 & FY04 & TOTAL \\
\hline LLNL & 175 & 50 & 20 & 20 & 20 & 0 & 0 & 285 \\
\hline WSRC & 0 & 0 & 0 & 0 & 0 & 0 & 0 & 0 \\
\hline ANL & 0 & 0 & 0 & 0 & 0 & 0 & 0 & 0 \\
\hline PNNL & 0 & 0 & 0 & 0 & 0 & 0 & 0 & 0 \\
\hline LANL & 0 & 0 & 0 & 0 & 0 & 0 & 0 & 0 \\
\hline Total & $\mathbf{1 7 5}$ & $\mathbf{5 0}$ & $\mathbf{2 0}$ & $\mathbf{2 0}$ & $\mathbf{2 0}$ & $\mathbf{0}$ & $\mathbf{0}$ & $\mathbf{2 8 5}$ \\
\hline
\end{tabular}

\subsubsection{Materials Characterization}

The materials exiting the impure oxide feed preparation process will have to be analyzed for elemental content and to provide material composition data for determining batch sequencing in the feed (blending) batching step at the beginning of first-stage immobilization. This characterization does not have to provide exact compositional data, but must identify problematic components to within a few percent. Key steps in the materials characterization module are shown in Module 5.8 below.

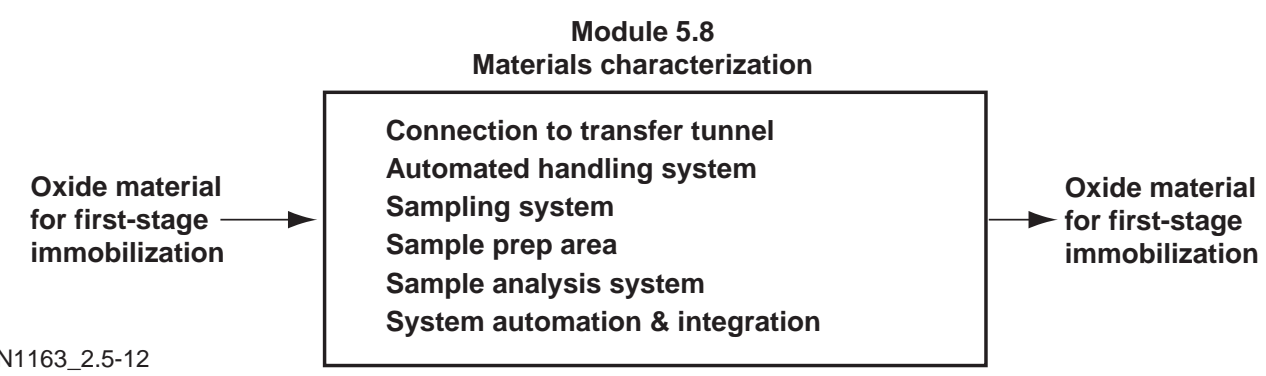

A survey of potential analytical equipment will be made. This will include techniques such as XRF, spectroscopic techniques (such as laser-induced breakdown spectroscopy [LIBS]), chemical digestion techniques, etc. Once the most applicable systems are identified, testing of anticipated feeds spiked with impurities will be analyzed to identify the most suitable technique or techniques. Relative accuracy, flexibility, and analysis time will be used to judge the various systems.

Once a characterization method is chosen, then the development of a production type system(s) will begin. The system(s) will be used in conjunction with the "hot" materials conversion testing being performed at LLNL on actual plutonium feeds. Modification and improvement of the systems will continue in outyears to integrate them into the production process. 
Materials Characterization: Milestones

\begin{tabular}{|c|c|c|c|c|c|c|}
\hline Milest & & Date & LLNL & WSRC & ANL & PNNL \\
\hline FY99 & $\begin{array}{l}\text { Identify candidate techniques and complete } \\
\text { scoping test }\end{array}$ & $1 / 99$ & $\bullet$ & 0 & & \\
\hline & Procure test systems & $5 / 99$ & $\bullet$ & $\mathrm{O}$ & & \\
\hline & Provide input to preliminary TDR & 9/99 & 0 & 0 & & \\
\hline & Complete feed characterization testing at LLNL & 9/99 & - & & & \\
\hline FY00 & Provide TDR & $9 / 00$ & - & 0 & & \\
\hline
\end{tabular}

Materials Characterization: Total Budget (\$K)

\begin{tabular}{lrrrrrrrr} 
Site/Yr & FY98 & FY99 & FY00 & FY01 & FY02 & FY03 & FY04 & TOTAL \\
\hline LLNL & 0 & 750 & 200 & 25 & 0 & 0 & 0 & 975 \\
\hline WSRC & 0 & 350 & 350 & 50 & 30 & 0 & 0 & 780 \\
\hline ANL & 0 & 0 & 0 & 0 & 0 & 0 & 0 & 0 \\
\hline PNNL & 0 & 0 & 0 & 0 & 0 & 0 & 0 & 0 \\
\hline LANL & 0 & 0 & 0 & 0 & 0 & 0 & 0 & 0 \\
\hline Total & $\mathbf{0}$ & $\mathbf{1 1 0 0}$ & $\mathbf{5 5 0}$ & $\mathbf{7 5}$ & $\mathbf{3 0}$ & $\mathbf{0}$ & $\mathbf{0}$ & $\mathbf{1 7 5 5}$ \\
\hline
\end{tabular}

Materials Characterization: Equipment Budget for (included above)

\begin{tabular}{lrrrrrrrr} 
Site/Yr & FY98 & FY99 & FY00 & FY01 & FY02 & FY03 & FY04 & TOTAL \\
\hline LLNL & 0 & 0 & 0 & 0 & 0 & 0 & 0 & 0 \\
\hline WSRC & 0 & 150 & 200 & 0 & 0 & 0 & 0 & 350 \\
\hline ANL & 0 & 0 & 0 & 0 & 0 & 0 & 0 & 0 \\
\hline PNNL & 0 & 0 & 0 & 0 & 0 & 0 & 0 & 0 \\
\hline LANL & 0 & 0 & 0 & 0 & 0 & 0 & 0 & 0 \\
\hline Total & $\mathbf{0}$ & $\mathbf{1 5 0}$ & $\mathbf{2 0 0}$ & $\mathbf{0}$ & $\mathbf{0}$ & $\mathbf{0}$ & $\mathbf{0}$ & $\mathbf{3 5 0}$ \\
\hline
\end{tabular}

\subsubsection{Material Control and Accountability}

Special nuclear material leaving the plutonium conversion unit operations may be changed in form and concentration and will be packaged as an oxide. Therefore, this material will require assaying prior to entering the in-process vault. Steps in the MC\&A module are shown in Module 5.9 below.

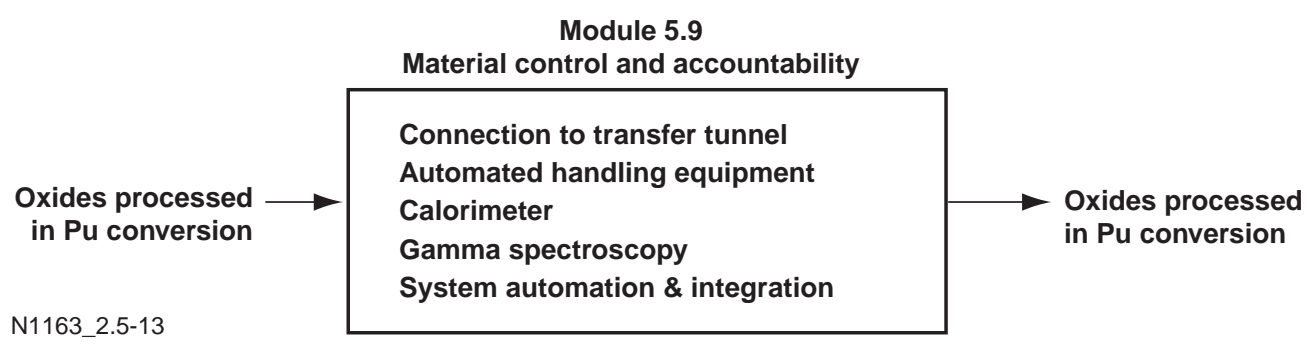


Nondestructive assay (NDA) of product oxide cans leaving plutonium conversion will be accomplished without operator assist in a glove box containing an automated overhead gantry and vertical top-loaded NDA equipment systems. LANL has developed an automated NDA system to support pit disassembly and conversion, and this technology can be applied to this task. Immobilization feed material samples can be prepared and sent to LANL for demonstration in FY00.

Material Control and Accountability: Milestones

\begin{tabular}{|c|c|c|c|c|c|c|}
\hline \multicolumn{2}{|c|}{ Milestone } & \multirow{2}{*}{$\frac{\text { Date }}{1 / 99}$} & \multirow[t]{2}{*}{ LLNL } & \multirow{2}{*}{$\frac{\text { WSRC }}{\bullet}$} & \multirow[t]{2}{*}{ ANL } & \multirow[t]{2}{*}{ PNNL } \\
\hline FY99 & Develop NDA equipment options & & & & & \\
\hline & $\begin{array}{l}\text { Develop concept/layouts for material handling } \\
\text { system and identify any mock-up requirements }\end{array}$ & $6 / 99$ & & ○ & & \\
\hline & $\begin{array}{l}\text { Issue equipment system specification and testing } \\
\text { plan in TDR for plant design }\end{array}$ & $9 / 99$ & & 0 & & \\
\hline FY00 & Perform LANL demonstration tests & $9 / 00$ & & $\bullet$ & & \\
\hline
\end{tabular}

Material Control and Accountability: Total Budget (\$K)

\begin{tabular}{lrrrrrrrr} 
Site/Yr & FY98 & FY99 & FY00 & FY01 & FY02 & FY03 & FY04 & TOTAL \\
\hline LLNL & 0 & 0 & 0 & 0 & 0 & 0 & 0 & 0 \\
\hline WSRC & 0 & 100 & 20 & 20 & 20 & 0 & 0 & 160 \\
\hline ANL & 0 & 0 & 0 & 0 & 0 & 0 & 0 & 0 \\
\hline PNNL & 0 & 0 & 0 & 0 & 0 & 0 & 0 & 0 \\
\hline LANL & 0 & 0 & 80 & 0 & 0 & 0 & 0 & 80 \\
\hline Total & $\mathbf{0}$ & $\mathbf{1 0 0}$ & $\mathbf{1 0 0}$ & $\mathbf{2 0}$ & $\mathbf{2 0}$ & $\mathbf{0}$ & $\mathbf{0}$ & $\mathbf{2 4 0}$ \\
\hline
\end{tabular}

\subsubsection{In-Process Storage Vault}

An in-process storage vault is required to store materials between plutonium conversion and first-stage immobilization. This vault provides temporary storage of material for downstream blending of the feed batches prior to their movement into the ceramification process. Batch operation of first-stage immobilization will require a two- to fourmonth backlog of feed material to operate efficiently. Key operations are shown in the Module 5.10 below.

Module 5.10

In-Process Storage Vault

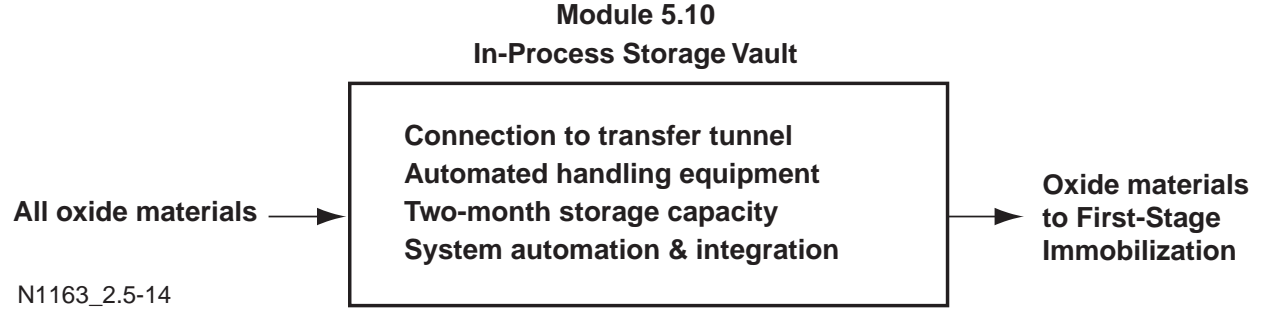


Concepts will be developed to receive standard transfer cans and store a minimum of 2 months' supply of plutonium and uranium feed materials in an automatically operated stacker/retriever vault configuration. Material transfer operations entering and leaving the vault will be conducted without operator assist.

In-Process Storage Vault: Milestones

\begin{tabular}{|c|c|c|c|c|c|c|}
\hline Milest & & Date & LLNL & WSRC & ANL & PNNL \\
\hline FY98 & & & & & & \\
\hline FY99 & Complete vault configuration study & $3 / 99$ & & $\bullet$ & & \\
\hline & $\begin{array}{l}\text { Complete concept for material handling and } \\
\text { recommendations for cold testing requirements }\end{array}$ & $9 / 99$ & & 0 & & \\
\hline & Provide TDR for storage vault & $8 / 00$ & & $\bullet$ & & \\
\hline
\end{tabular}

\section{In-Process Storage Vault: Total Budget (\$K)}

\begin{tabular}{lrrrrrrrr} 
Site/Yr & FY98 & FY99 & FY00 & FY01 & FY02 & FY03 & FY04 & TOTAL \\
\hline LLNL & 0 & 0 & 0 & 0 & 0 & 0 & 0 & 0 \\
\hline WSRC & 0 & 75 & 0 & 0 & 0 & 0 & 0 & 75 \\
\hline ANL & 0 & 0 & 0 & 0 & 0 & 0 & 0 & 0 \\
\hline PNNL & 0 & 0 & 0 & 0 & 0 & 0 & 0 & 0 \\
\hline LANL & 0 & 0 & 0 & 0 & 0 & 0 & 0 & 0 \\
\hline Total & $\mathbf{0}$ & $\mathbf{7 5}$ & $\mathbf{0}$ & $\mathbf{0}$ & $\mathbf{0}$ & $\mathbf{0}$ & $\mathbf{0}$ & $\mathbf{7 5}$ \\
\hline
\end{tabular}




\subsection{FIRST-STAGE IMMOBILIZATION PROCESS/EQUIPMENT DEVELOPMENT}

First-stage immobilization is the second step in the overall immobilization process. This activity receives oxide feed from plutonium conversion, conditions and blends this feed with uranium oxide and ceramic precursors, presses the green pucks, and sinters them into a ceramic. A number of pucks, are then loaded into a metal can, which is then sealed. The first-stage immobilization portion of the immobilization plant, shown in the process flow diagram in Figure 2-7, consists of the following functional modules:

- Ceramic Feed Batching (Module 6.1)

- Ceramification Subsystem Development and Testing (Module 6.2)

- Ceramic Puck Handling (Module 6.3)

- Puck NDE for Process Control (Module 6.4)

- SNM (Special Nuclear Material) Material Accountability (Module 6.5)

- Sintering (Module 6.6)

- Recycle of Unacceptable Materials (Module 6.7)

- Can Loading (Module 6.8)

- Can NDE and MC\&A (Module 6.9)

- Can Storage Vault (Module 6.10)

The equipment subsystems for first-stage immobilization must be automated because of the high radiation levels of the oxide materials and because of the large number of repetitive processes involved in puck production. The first-stage immobilization activity area provides process equipment definition, equipment development when needed, and testing of unit operations and complete modules as required. Each module consists of one or more unit operations, which are at various levels of technical maturity.

The first-stage immobilization process flow diagram is color-coded to indicate the degree of D\&T required for the various modules. Some modules (e.g., sintering) require no special D\&T. These modules will be designed and built using commercially available equipment. In order to specify the information for the TDR, it is necessary to define the problem, determine equipment specifications, and perform engineering analysis and design as required for the module.

Other modules require concept testing using plutonium feed materials and or prototype testing using surrogate materials. Tests using plutonium will establish key equipment and process operational parameters. Tests using surrogate materials will validate the remote handling features of the prototype equipment and equipment reliability. 


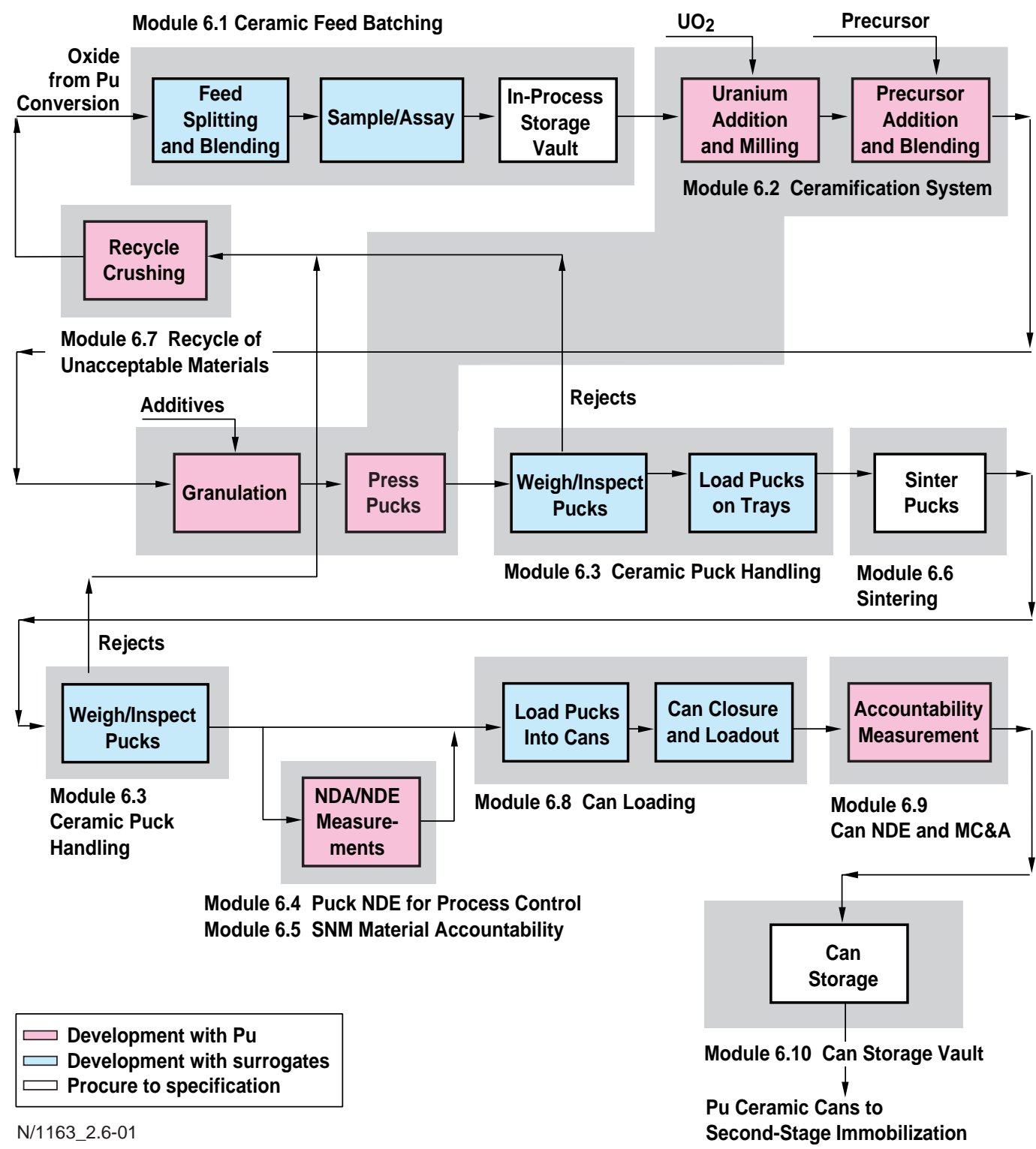

Figure 2-7. First-stage immobilization process flow diagram.

The most challenging modules are those that involve the preparation and conditioning of the oxide powders that will form the finished ceramic product. The powder preparation and conditioning operations are key to the formation of a final ceramic product that must meet repository requirements. Development of these modules involves initial feasibility demonstrations followed by tests of prototypic equipment using the actual plutonium feed materials.

In general, development activities for modules requiring testing with actual plutonium feed materials will be performed at LLNL with WSRC support. Development of modules not requiring testing with plutonium will in general be performed by WSRC at SRS.

The following sections describe the tasks, milestones, and budgets associated with each module. 


\subsubsection{Ceramic Feed Batching}

Feed batch preparation involves blending the various oxide feed-stocks to achieve leveling of the plutonium isotopic content and dilution of impurities. Batching is done to improve process control, levelize radiation exposure, and achieve acceptable product consistency.

As currently conceptualized, the batch blending operation feeds individual cans of plutonium oxide to a riffle sample splitter. The riffle splitter is a vertical, rotary device that uniformly distributes the oxide in a single feed can into a number of receipt cans. The process is repeated with successive feed cans until each receipt can contains sufficient material for subsequent processing. After blending, the splitter cans are weighed, assayed, and placed in an in-line process vault for temporary storage prior to introduction to the ceramification process line. The operations involved in feed batching are indicated in Module 6.1 below.

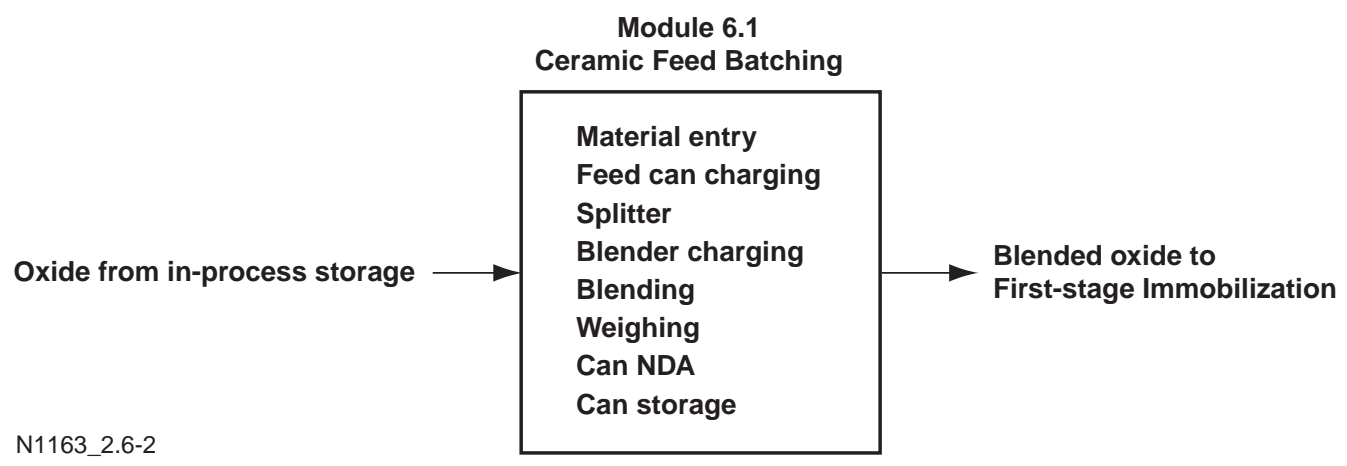

Although commercially available technology and equipment exist for powder splitting operations, the proposed plutonium process application imposes additional performance requirements, including remote control of equipment, control of dusting, criticality spacing, and automated material movement within close tolerances. A successful design solution requires a systems engineering approach that relies on integration of nuclear experience in both engineering and operations.

The task will specifically involve a conceptual design, specification of test system components, and procurement of these components for testing. These components will then be tested for their performance in the blending of surrogate feed materials representative of the $\mathrm{PuO}_{2}$ feed entering the first-stage immobilization process. The specific subtasks to be completed include:

- Blend/batch system conceptual design and specification

- Construction and testing of subsystem with surrogates

- Development and modeling of concepts for in-line storage and material flow

- Subsystem radiation dose analysis

- Preparation of detailed design input. 
Ceramic Feed Batching: Milestones

\begin{tabular}{|c|c|c|c|c|c|c|}
\hline \multicolumn{2}{|c|}{ Milestone } & \multirow{2}{*}{$\frac{\text { Date }}{9 / 98}$} & \multirow[t]{2}{*}{ LLNL } & \multirow{2}{*}{$\frac{\text { WSRC }}{}$} & \multirow[t]{2}{*}{ ANL } & \multirow[t]{2}{*}{ PNNL } \\
\hline FY98 & Complete design concepts and specifications & & & & & \\
\hline \multirow[t]{3}{*}{ FY99 } & Complete acquisition and installation of test system & $5 / 99$ & & ○ & & \\
\hline & Complete evaluation of test system & $7 / 99$ & & ○ & & \\
\hline & Provide input to preliminary TDR & $8 / 99$ & & $\mathbf{0}$ & & \\
\hline \multirow[t]{2}{*}{ FYOO } & $\begin{array}{l}\text { Complete system modeling and dose } \\
\text { analysis }\end{array}$ & $3 / 00$ & & $\mathbf{0}$ & & \\
\hline & Provide detailed design input for TDR & $6 / 00$ & & 0 & & \\
\hline
\end{tabular}

- Primary Responsibility

O Support Responsibility

Ceramic Feed Batching: Total Budget (\$K)

\begin{tabular}{lrrrrrrrr} 
Site/Yr & FY98 & FY99 & FY00 & FY01 & FY02 & FY03 & FY04 & TOTAL \\
\hline LLNL & 0 & 0 & 0 & 0 & 0 & 0 & 0 & 0 \\
\hline WSRC & 180 & 740 & 300 & 0 & 0 & 0 & 0 & 1220 \\
\hline ANL & 0 & 0 & 0 & 0 & 0 & 0 & 0 & 0 \\
\hline PNNL & 0 & 0 & 0 & 0 & 0 & 0 & 0 & 0 \\
\hline LANL & 0 & 0 & 0 & 0 & 0 & 0 & 0 & 0 \\
\hline Total & $\mathbf{1 8 0}$ & $\mathbf{7 4 0}$ & $\mathbf{3 0 0}$ & $\mathbf{0}$ & $\mathbf{0}$ & $\mathbf{0}$ & $\mathbf{0}$ & $\mathbf{1 2 2 0}$ \\
\hline
\end{tabular}

Ceramic Feed Batching: Equipment Budget (included above)

\begin{tabular}{lrrrrrrrr} 
Site/Yr & FY98 & FY99 & FY00 & FY01 & FY02 & FY03 & FY04 & TOTAL \\
\hline LLNL & 70 & 0 & 0 & 0 & 0 & 0 & 0 & 70 \\
\hline WSRC & 0 & 0 & 0 & 0 & 0 & 0 & 0 & 0 \\
\hline ANL & 0 & 0 & 0 & 0 & 0 & 0 & 0 & 0 \\
\hline PNNL & 0 & 0 & 0 & 0 & 0 & 0 & 0 & 0 \\
\hline LANL & 0 & 0 & 0 & 0 & 0 & 0 & 0 & 0 \\
\hline Total & 70 & $\mathbf{0}$ & $\mathbf{0}$ & $\mathbf{0}$ & $\mathbf{0}$ & $\mathbf{0}$ & $\mathbf{0}$ & $\mathbf{7 0}$ \\
\hline
\end{tabular}

\subsubsection{Ceramification Subsystem Development and Testing}

Critical process and equipment concepts for the ceramification system must be developed and tested. This development and testing includes important overall ceramic processing parameters and the equipment for the critical unit operations in the ceramic fabrication process. These process operations include milling, blending, granulation, pressing, and sintering: steps that are critical to the production of a qualified plutonium disposition form. Key factors to be evaluated include the ability to consistently produce a qualified product, system operability and maintainability, process flow, material accountability, process and product quality control, and operator radiation exposure minimization. 
Development will be performed-initially with surrogate materials and uranium, and subsequently with plutonium - to determine the correlation of product performance with variations in the feed stream types and concentrations, operating characteristics, material holdup, accountability, powder transfer, and dusting control conditions.

\subsubsection{Ceramification Process Development}

This task develops the essential process techniques and processing data for the ceramic formation operations, with emphasis on the adaptation of techniques and equipment from the MOX fuel and related powder handling industries. The major deliverables will include: 1) determination of the specific plant processing technologies, and 2) detailed flow-sheets with process descriptions and process data for all product-critical unit operations necessary for the first-stage immobilization. These form-critical operations include precursor preparation, feed and precursor conditioning, blending of the actinides with the precursor materials, granulation, pressing, and sintering.

The ceramic feed preparation operations that are form-critical are discussed in more detail below. These processes mill the actinides to an acceptable size ( $<20$ microns), blend the milled actinides with the ceramic precursors and neutron absorbers on a scale sufficient to ensure adequate sintering interaction and incorporation of the actinides into the mineral matrix, and press the blended material into a pellet for sintering. Such micro-blended products tend to agglomerate and clump in adverse ways, and the resulting blend must undergo conditioning to obtain a flowable and dustless powder form for feeding to the pressing operation. Various additives may be required to assure flowability, provide die lubrication, and assure pellet integrity prior to sintering. These processing requirements must be understood, and processing parameter ranges must be established to assure consistent production of a qualified product form.

The unit process operations of milling, blending, and granulation are interactive and may be performed in a variety of ways. Work in this task will focus on understanding the individual processes, investigating a combination of ways for accomplishing feed preparation, and assessing the combination of process operations to minimize operating equipment and processing.

The following subtasks will be performed in carrying out this task:

- Procure and install production scale, high-speed attritor mills at both LLNL and SRS (including Clemson) for surrogate milling operations, including uranium milling. Process parameters to be evaluated include milling time, mill speed, batch size, and initial feed. The optimum size, material, and quantity of grinding media will be determined experimentally. Use of milling aids, variations in milling conditions, and feed pretreatment will be evaluated. If grinding aids (organic additives) are required to prevent packing, it must be demonstrated that organic burnout does not affect the disposal form.

- Evaluate the milling of actinide feeds to specified size using an attritor mill in cold facilities and uranium and representative feed materials. In the "baseline" process, the plutonia and urania feed will be dry-milled. However, dry milling of the feed material has not been demonstrated. The micron particle size distribution for plutonia and urania that will dissolve in the matrix, and the milling parameters to achieve this size distribution, must be determined. The primary objective of the milling studies will be to demonstrate dry grinding and optimize the grinding parameters in an attritor mill for these feeds. The effect of impurities introduced during milling will also be evaluated to provide a basis for the selection of materials for the mill and grinding media. 
- Evaluate mill wear and the effects of impurities introduced from the mill for different types of materials (e.g., ceramic, steel) and for a range of milling parameters.

- Evaluate the milling of actinide feed to specified size using a wet ball mill as reference process.

- Evaluate the blending of milled actinide feeds with ceramic precursors using an attritor mill in order to determine the degree of micro-blending that can be achieved for various actinide and precursor feed pre-treatments. The impact on the sintered products will be evaluated in terms of degree of reaction and formation of clumping. Experimental work will be performed using surrogates for plutonium in the cold ceramic facilities at LLNL and WSRC.

- Evaluate the blending of milled actinide feed with ceramic precursors using a wet ball mill as an alternative to the attritor mill discussed above. The experimental approach will parallel that described in the item above for the attritor mill.

- Establish limits on the pre-sintering of the precursors and precursor purchase specifications. Validate with experimental surrogate testing and plutonium confirmatory testing.

- Develop granulation of the micro-blended feed to facilitate press feeding. The granulation process is still evolving, and final selection of commercial granulation equipment will be made. Granulation parameters must be optimized for feed flowability and to minimize fines. The granulation process may require the addition of binders, lubricants, and/or controlled water content. The granulated feed will be characterized using size analyses, SEM observations, flowability tests, and compaction tests. Choice of granulation approach will depend on the milling and blending results above.

- Evaluate batching and blending of various feed stream forms with varying impurity contents, using materials produced by the plutonium conversion program as specified by the feed materials definition study.

\section{Ceramification Process Development: Milestones}

\begin{tabular}{llcccc} 
Milestone & Date & LLNL & WSRC & ANL & PNNL \\
\hline FY98 & Perform preliminary assessment of MOX industry & $12 / 97$ & $\bullet$ & 0 & \\
\hline & Complete installation of uranium line at LLNL & $2 / 98$ & $\bullet$ & 0 & \\
\hline $\begin{array}{l}\text { Identify preferred techniques/equipment } \\
\text { for feed preparation }\end{array}$ & $9 / 98$ & $\bullet$ & 0 \\
\hline FY99 & Provide process specifications for preliminary TDR & $6 / 99$ & $\bullet$ & 0 \\
\hline FY00 & Provide process design criteria for TDR & $6 / 00$ & $\bullet$ & 0
\end{tabular}

Ceramification Process Development: Total Budget (\$K)

\begin{tabular}{lrrrrrrrr} 
Site/Yr & FY98 & FY99 & FY00 & FY01 & FY02 & FY03 & FY04 & TOTAL \\
\hline LLNL & 1970 & 1200 & 500 & 50 & 50 & 0 & 0 & 3770 \\
\hline WSRC & 555 & 455 & 340 & 95 & 75 & 0 & 0 & 1520 \\
\hline ANL & 0 & 0 & 0 & 0 & 0 & 0 & 0 & 0 \\
\hline PNNL & 0 & 0 & 0 & 0 & 0 & 0 & 0 & 0 \\
\hline LANL & 0 & 0 & 0 & 0 & 0 & 0 & 0 & 0 \\
\hline Total & $\mathbf{2 5 2 5}$ & $\mathbf{1 6 5 5}$ & $\mathbf{8 4 0}$ & $\mathbf{1 4 5}$ & $\mathbf{1 2 5}$ & $\mathbf{0}$ & $\mathbf{0}$ & $\mathbf{5 2 9 0}$ \\
\hline
\end{tabular}


Ceramification Process Development: Equipment Budget (included above)

\begin{tabular}{lrrrrrrrr} 
Site/Yr & FY98 & FY99 & FY00 & FY01 & FY02 & FY03 & FY04 & TOTAL \\
\hline LLNL & 0 & 0 & 0 & 0 & 0 & 0 & 0 & 0 \\
\hline WSRC & 25 & 325 & 0 & 0 & 0 & 0 & 0 & 350 \\
\hline ANL & 0 & 0 & 0 & 0 & 0 & 0 & 0 & 0 \\
\hline PNNL & 0 & 0 & 0 & 0 & 0 & 0 & 0 & 0 \\
\hline LANL & 0 & 0 & 0 & 0 & 0 & 0 & 0 & 0 \\
\hline Total & $\mathbf{2 5}$ & $\mathbf{3 2 5}$ & $\mathbf{0}$ & $\mathbf{0}$ & $\mathbf{0}$ & $\mathbf{0}$ & $\mathbf{0}$ & $\mathbf{3 5 0}$ \\
\hline
\end{tabular}

\subsubsection{Ceramification Equipment Development}

This task is undertaken to assure that the key process operations and equipment design specifications produce a qualifiable ceramic product with the actual range of feed streams characteristic of those expected for the plant. In this task, the critical ceramification steps will be integrated and demonstrated with plutonium feed materials using equipment that contains the essential design features of plant equipment, but that is not plant prototypic in size or throughput. The operations included in the ceramification subsystem are indicated in Module 6.2 below.

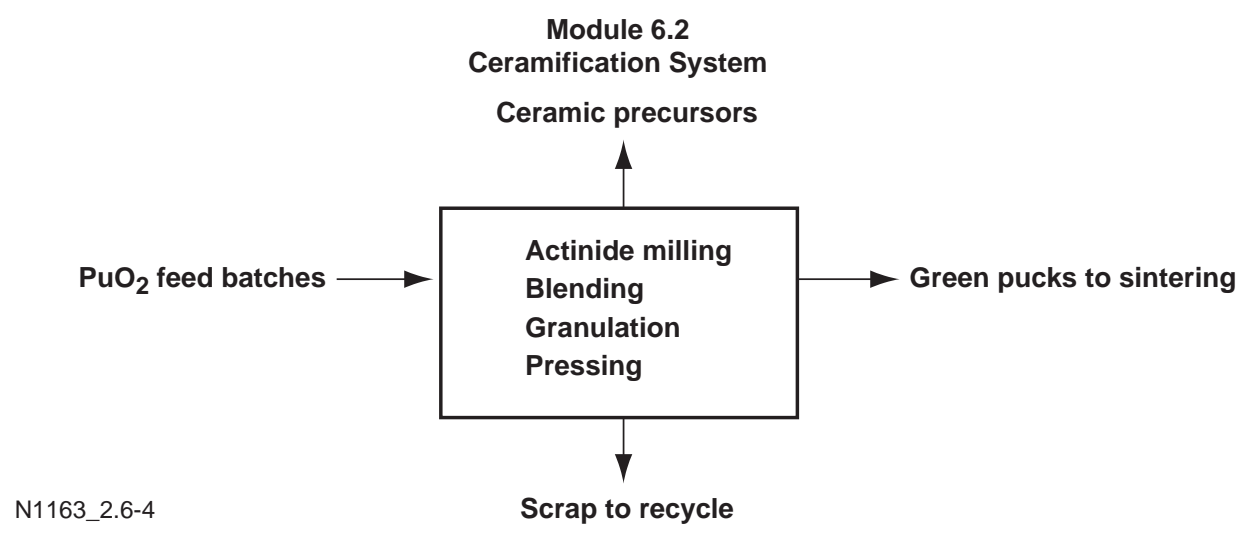

The ceramification subsystem test equipment, illustrated in Figure 2-8, will initially operate for a three-month period to verify key plant equipment features prior to providing equipment size requirements, utility specifications, and design specifications to the $\mathrm{A} / \mathrm{E}$ for plant design. Following this, the system will continue to operate for two years using various materials from feed conversion that are representative of the range of feeds expected for the operating plant.

In the testing configuration, the ceramification subsystem will couple sub-scale milling, blending, and granulation equipment for the actinide milling and blending operations with an automated press and a laboratory-scale sintering furnace. Full-size ceramic pellets will be fabricated under the range of processing conditions expected in the plant and for the expected range of plutonium feed materials. This proof test will:

- Provide equipment design guidance and specifications for the ceramification subsystem in the plant

- Generate the final product and process specifications for plant operation

- Provide a platform for evaluation of the product control model 


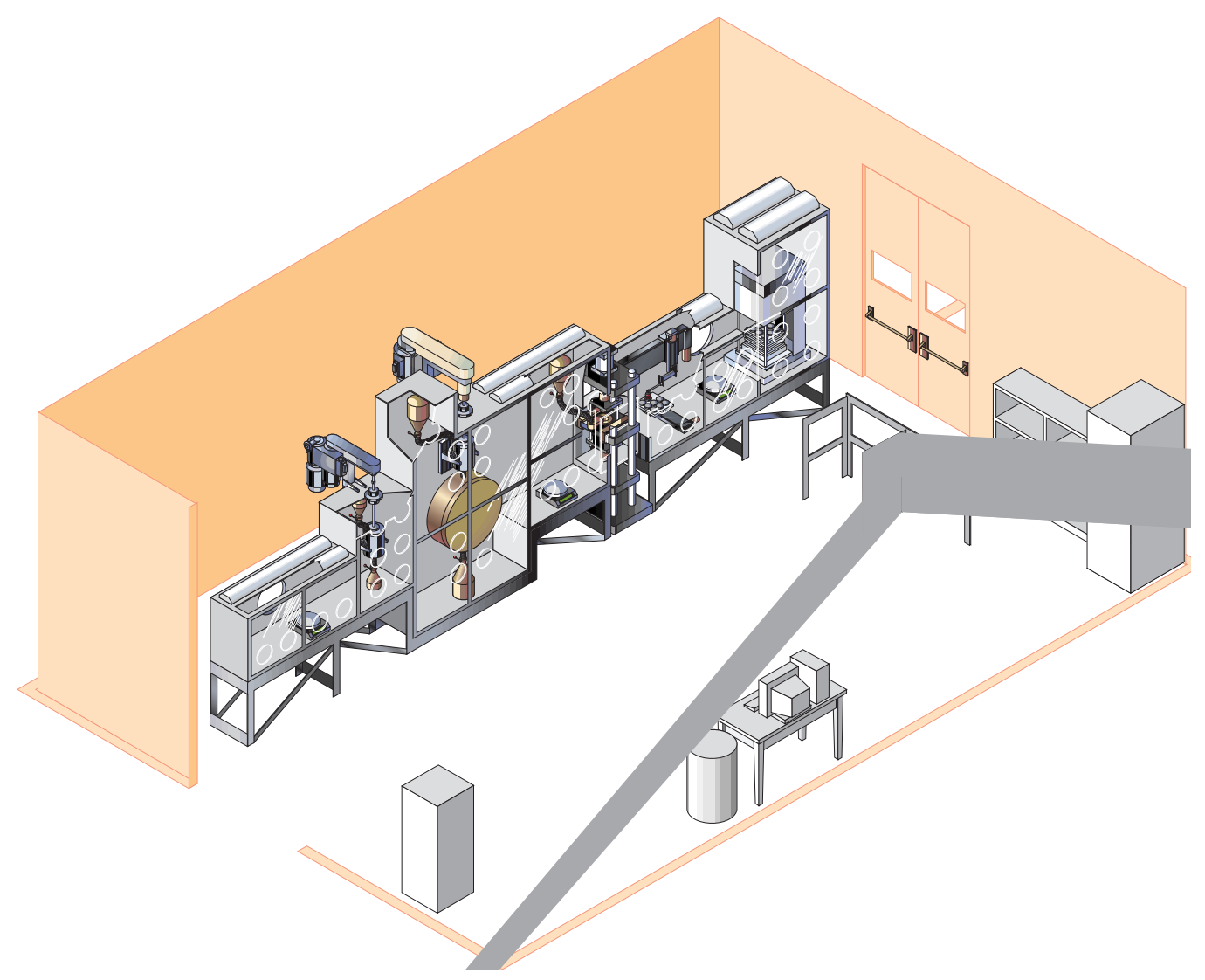


Phase 2: Acquisition and installation of the subsystem in the LLNL plutonium facility. Facility modifications will be required for this installation. Subtasks include:

- Procuring integrated subsystem components

- Cleaning out and preparing plutonium facility for installation

- Assembling and testing the subsystem in Building 241 with surrogate materials prior to transfer to the plutonium facility

- Installing integrated subsystem in the LLNL plutonium facility, including all necessary documentation and reviews

- Starting plutonium subsystem operation with surrogate materials followed by plutonium operations.

Phase 3: Operation of the ceramification subsystem with plutonium feed streams characteristic of those planned for the plant. Feed materials will be obtained from plutonium conversion operations, which convert the candidate immobilization feeds. Subtasks include:

- Conducting performance validation testing with regard to operability, product quality and product control, and operator radiation dose

- Verifying performance using the range of plutonium feed materials expected by MD and prepared by the plutonium conversion operation

- Conducting dose analysis and correlate with operations experience

- Preparing TDR for plant design

- Preparing final equipment design and specification packages for the project.

- Testing and refining the PCM initially developed by the form development task (Section 2.3.4). The testing will involve full-scale samples with near-production scale equipment. The input composition, process conditions, and other variables of the PCM will be refined based on the results of these tests. Validation and final optimization of the PCM will be performed subsequently in the PPSL at SRS (Section 2.8.2). 
Ceramification Equipment Development: Milestones

\begin{tabular}{|c|c|c|c|c|c|c|}
\hline \multicolumn{2}{|c|}{ Milestone } & \multirow{2}{*}{$\frac{\text { Date }}{5 / 98}$} & \multirow{2}{*}{$\frac{\text { LLNL }}{\bullet}$} & \multirow{2}{*}{$\begin{array}{c}\text { WSRC } \\
0\end{array}$} & \multirow[t]{2}{*}{ ANL } & \multirow[t]{2}{*}{ PNNL } \\
\hline FY98 & Develop plant concepts & & & & & \\
\hline & Complete experimental system conceptual design & $9 / 98$ & ○ & $\mathrm{O}$ & & \\
\hline & Initiate long-lead procurements & $9 / 98$ & - & $\mathrm{O}$ & & \\
\hline \multirow[t]{4}{*}{ FY99 } & Complete subsystem design package & $1 / 99$ & ○ & $\mathrm{O}$ & & \\
\hline & Begin subsystem assembly for testing in Bldg. 241 & $4 / 99$ & - & O & & \\
\hline & Provide input to preliminary TDR & $8 / 99$ & - & $\mathrm{O}$ & & \\
\hline & Prepare Pu facility for installation & $9 / 99$ & - & $\mathrm{O}$ & & \\
\hline \multirow[t]{4}{*}{ FY00 } & Test subsystem tested in Bldg. 241 w/surrogates & $12 / 99$ & ○ & $\mathrm{O}$ & & \\
\hline & Install operational subsystem in plutonium building & $6 / 00$ & $\bullet$ & 0 & & \\
\hline & Verify ceramic formation subsystem performance & $8 / 00$ & - & $\mathrm{O}$ & & \\
\hline & Provide TDR & $9 / 00$ & - & $\mathrm{O}$ & & \\
\hline \multirow[t]{2}{*}{ FY01 } & Provide update for the supplemental TDR & $9 / 01$ & - & $\mathrm{O}$ & & \\
\hline & Provide PCM and report to SRS & $9 / 02$ & ○ & $\mathrm{O}$ & & \\
\hline
\end{tabular}

Ceramification Equipment Development: Total Budget (\$K)

\begin{tabular}{lrrrrrrrr} 
Site/Yr & FY98 & FY99 & FY00 & FY01 & FY02 & FY03 & FY04 & TOTAL \\
\hline LLNL & 3007 & 4360 & 3100 & 1300 & 1050 & 0 & 0 & 12817 \\
\hline WSRC & 800 & 800 & 650 & 400 & 250 & 0 & 0 & 2900 \\
\hline ANL & 0 & 0 & 0 & 0 & 0 & 0 & 0 & 0 \\
\hline PNNL & 0 & 0 & 0 & 0 & 0 & 0 & 0 & 0 \\
\hline LANL & 0 & 0 & 0 & 0 & 0 & 0 & 0 & 0 \\
\hline Total & $\mathbf{3 8 0 7}$ & $\mathbf{5 1 6 0}$ & $\mathbf{3 7 5 0}$ & $\mathbf{1 7 0 0}$ & $\mathbf{1 3 0 0}$ & $\mathbf{0}$ & $\mathbf{0}$ & $\mathbf{1 5 7 1 7}$ \\
\hline
\end{tabular}

\section{Ceramification Equipment Development: Equipment Budget (included above)}

\begin{tabular}{lrrrrrrrr} 
Site/Yr & FY98 & FY99 & FY00 & FY01 & FY02 & FY03 & FY04 & TOTAL \\
\hline LLNL & 2000 & 1500 & 0 & 0 & 0 & 0 & 0 & 3500 \\
\hline WSRC & 0 & 0 & 0 & 0 & 0 & 0 & 0 & 0 \\
\hline ANL & 0 & 0 & 0 & 0 & 0 & 0 & 0 & 0 \\
\hline PNNL & 0 & 0 & 0 & 0 & 0 & 0 & 0 & 0 \\
\hline LANL & 0 & 0 & 0 & 0 & 0 & 0 & 0 & 0 \\
\hline Total & 2000 & $\mathbf{1 5 0 0}$ & $\mathbf{0}$ & $\mathbf{0}$ & $\mathbf{0}$ & $\mathbf{0}$ & $\mathbf{0}$ & $\mathbf{3 5 0 0}$ \\
\hline
\end{tabular}




\subsubsection{Ceramic Puck Handling}

This task develops automated ceramic puck handling systems to limit operator radiation dose and to transport the large number of pucks efficiently among many unit operations, from pressing to can loading. Systems to perform these tasks will be defined in FY98 and specifications prepared for prototype system procurement and testing in late FY98, FY99 and FY00.

Development of puck handling is required because of the many one-of-a-kind remote handling operations that must be performed on individual green and sintered pucks and trays of pucks. Due to the large number and high radiation level of pucks to be handled in ceramification process, it will be necessary to develop automated material handling systems to essentially eliminate hands-on operation. In addition, the equipment must function in an inerted, contaminated, radioactive environment and where equipment must be designed for dustless operation. The operations involved in puck handling are illustrated in Module 6.3 below.

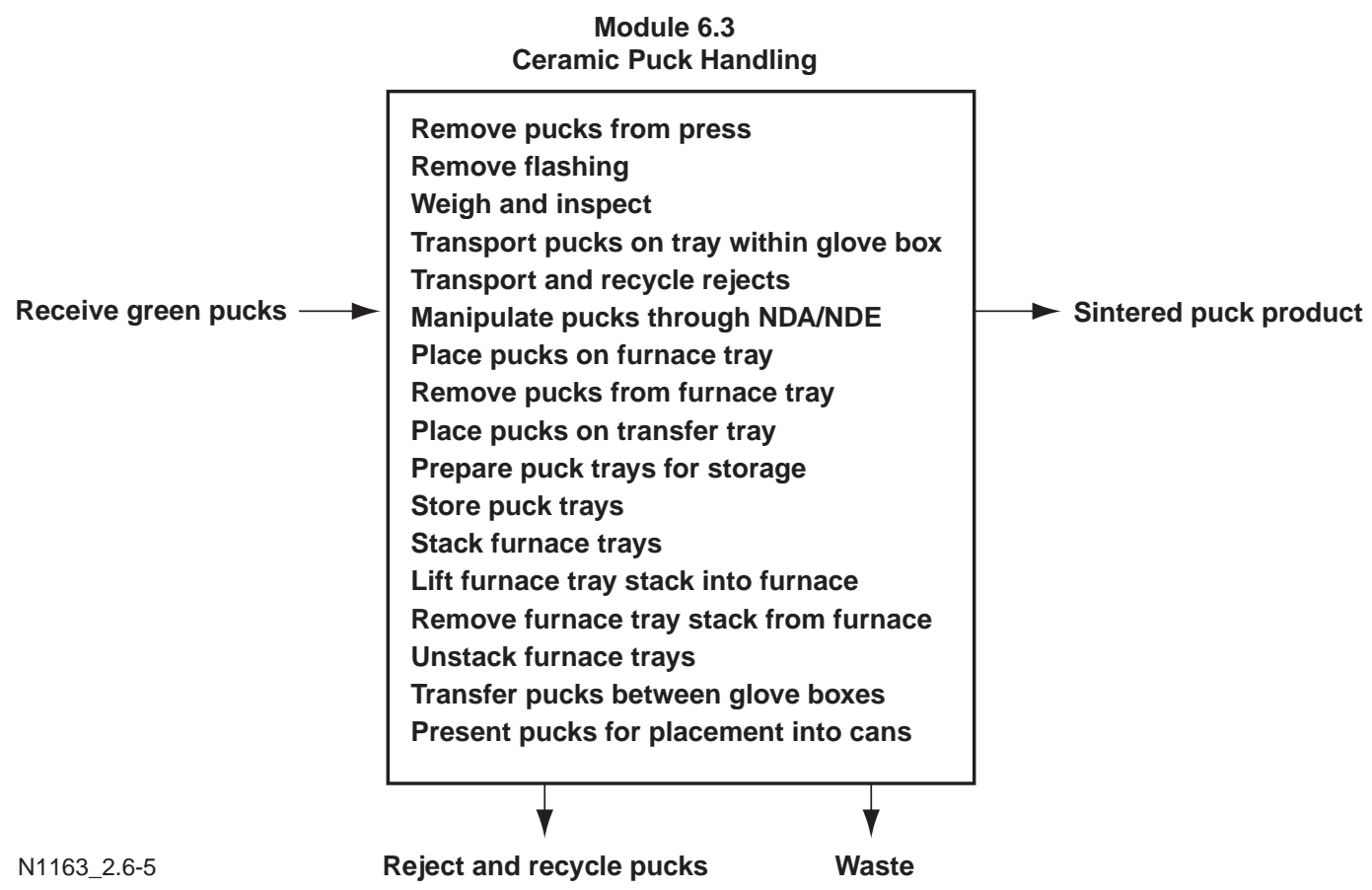

The green pucks are about 3-1/2 inches in diameter by 1-3/8 inches thick. Green pucks may be fragile and must be handled with special care through the initial inspection, cleanup, weighing, and delivery on furnace trays to the sintering furnace. Furnace trays must be stacked such that an entire batch of pucks is placed into the furnace. Sintered pucks may leave the furnace at an elevated temperature, which could introduce additional complexity for the material handling systems. In addition, the sintering cycle shrinks the pucks to approximately 2-1/2 inches by $1 \mathrm{inch}$. After cooling and reloading on transfer trays, a random number of pucks must be evaluated and assayed before transferring the entire lot to temporary storage and the canning operation. 
This task will be conducted by first conceptualizing, designing, and specifying the major handling system components of the system. These elements will then be procured for further integration and testing with surrogate materials. Some equipment can be purchased from commercial vendors, but adaptation must be done to meet the specific handling requirements of each operation. This equipment must be mocked-up and tested to allow the iterative process of engineered equipment development to accomplish the goal of confirmed equipment specifications ahead of detailed design. To ensure that all requirements have been met, these tests will prove the feasibility of the proposed design and demonstrate that the systems interface properly with other equipment elements in the process.

Subtasks to be performed include:

- Designing press unloading automated handling system to include puck weighing and visual and dimensional inspection

- Designing furnace loading and unloading automated handling system

- Designing puck tray transfer system

- Constructing and demonstrating surrogate pellet handling systems

- Performing subsystem radiation dose analysis

- Preparing formal input to A/E documentation.

\section{Ceramic Puck Handling: Milestones}

\begin{tabular}{|c|c|c|c|c|c|c|}
\hline Miles & & Date & LLNL & WSRC & ANL & PNNL \\
\hline FY98 & Identify puck handling concepts & $5 / 98$ & & ○ & & \\
\hline & Determine system specifications & $8 / 98$ & & ○ & & \\
\hline FY99 & Fabricate mock-up system & $6 / 99$ & & • & & \\
\hline & Provide input to preliminary TDR & $9 / 99$ & & $\bullet$ & & \\
\hline FY00 & Complete final system testing and provide TDR & $9 / 00$ & & ○ & & \\
\hline FY01 & Provide input for supplemental TDR & $6 / 01$ & & ○ & & \\
\hline FY02 & Provide input for supplemental TDR & $6 / 02$ & & 0 & & \\
\hline
\end{tabular}

Ceramic Puck Handling: Total Budget (\$K)

\begin{tabular}{lrrrrrrrr} 
Site/Yr & FY98 & FY99 & FY00 & FY01 & FY02 & FY03 & FY04 & TOTAL \\
\hline LLNL & 0 & 0 & 0 & 0 & 0 & 0 & 0 & 0 \\
\hline WSRC & 590 & 890 & 525 & 100 & 50 & 0 & 0 & 2155 \\
\hline ANL & 0 & 0 & 0 & 0 & 0 & 0 & 0 & 0 \\
\hline PNNL & 0 & 0 & 0 & 0 & 0 & 0 & 0 & 0 \\
\hline LANL & 0 & 0 & 0 & 0 & 0 & 0 & 0 & 0 \\
\hline Total & $\mathbf{5 9 0}$ & $\mathbf{8 9 0}$ & $\mathbf{5 2 5}$ & $\mathbf{1 0 0}$ & $\mathbf{5 0}$ & $\mathbf{0}$ & $\mathbf{0}$ & $\mathbf{2 1 5 5}$ \\
\hline
\end{tabular}


Ceramic Puck Handling: Equipment Budget (included above)

\begin{tabular}{lrrrrrrrr} 
Site/Yr & FY98 & FY99 & FY00 & FY01 & FY02 & FY03 & FY04 & TOTAL \\
\hline LLNL & 0 & 0 & 0 & 0 & 0 & 0 & 0 & 0 \\
\hline WSRC & 200 & 500 & 100 & 0 & 0 & 0 & 0 & 800 \\
\hline ANL & 0 & 0 & 0 & 0 & 0 & 0 & 0 & 0 \\
\hline PNNL & 0 & 0 & 0 & 0 & 0 & 0 & 0 & 0 \\
\hline LANL & 0 & 0 & 0 & 0 & 0 & 0 & 0 & 0 \\
\hline Total & $\mathbf{2 0 0}$ & $\mathbf{5 0 0}$ & $\mathbf{1 0 0}$ & $\mathbf{0}$ & $\mathbf{0}$ & $\mathbf{0}$ & $\mathbf{0}$ & $\mathbf{8 0 0}$ \\
\hline
\end{tabular}

\subsubsection{Puck NDE for Process Control}

Nondestructive evaluation techniques must be developed to ensure adequate quality of the final ceramic product. This task has a significant impact on both form qualification and plant design for first-stage immobilization. Techniques under consideration include XRF and XRD. In FY98, exploratory work will be done on both techniques, and specifications will be prepared for an experimental NDE system to be installed and evaluated during the ceramification module testing. The operations involved in the NDE process are shown in Module 6.4 below.

Ideally, the primary product characterization equipment in the immobilization plant will be nondestructive and in-line to the process, thus preserving the integrity of the ceramic products and minimizing or eliminating the number of processing steps (namely, destructive analytical steps) outside of the main process line. The in-line product characterization equipment will be used to determine mineral abundance, overall composition, and product density. It is anticipated that these data can be used in conjunction with phase equilibria and impurity partitioning data to determine compositions of the individual minerals and residual porosity.

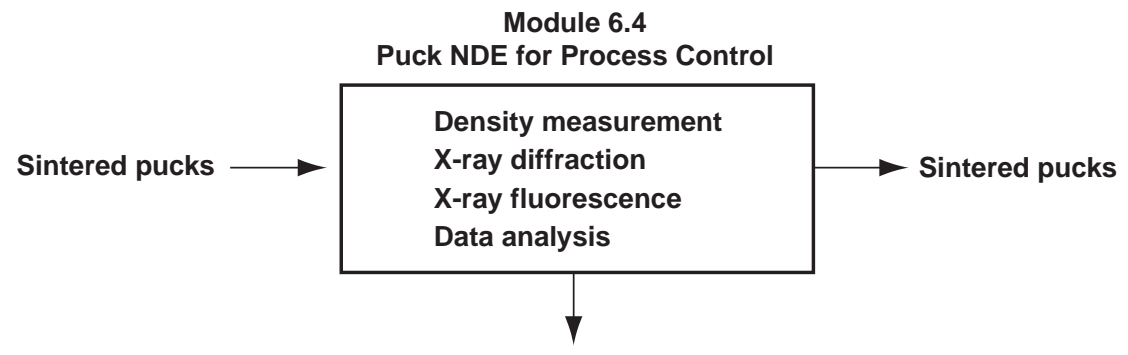

N1163_2.6-6

Reject pucks

The whole system is expected to be an important part of demonstrating or confirming product consistency. At this time, the measurement devices expected to be used are: XRD units for determining mineral abundance, XRF for determining overall composition, and laser densitometers. These devices are available off the shelf: however, they will need to be modified for the in-line process operation. Some development is desirable to maximize accuracy with minimal or no impact on the product or the product operations. In addition, there are some technical issues that need to be worked out for the XRD system to demonstrate that it can actually be used for this ceramic form to determine mineral abundance. In addition, options with potential significant advantages for standard XRF units need to be explored. No technical issues are anticipated for the laser dilatometers. 
In performing this task, a review will be conducted to determine the appropriate analytical techniques to use for the in-line ceramic product NDE system. Unless significantly more advantageous technologies are discovered, it is assumed that mineralogical abundance will be determined by quantitative $\mathrm{XRD}$, the overall compositions will be determined by $\mathrm{XRF}$, and the densities will be determined by laser dilatometers.

The suitability of the self-induced XRF technique patented at Lawrence Berkeley Laboratory will be examined. The advantage of this technique is that only a detector is required for the measurements, and it can be located external to the glove box system. Technical work at LLNL and SRS will focus on XRD of ceramic samples to show that XRD patterns of the sample surface are the same as or can be related to XRD patterns of the bulk powder. The XRD patterns will be analyzed by Reitfield analysis to show that quantitative information about the mineralogical abundance can be obtained. This is expected to be relatively difficult for zirconolite and pyrochlore since their x-ray patterns are so similar.

A preliminary NDE unit (probably with XRF capability only) will be installed and tested in the LLNL plutonium facility to evaluate the applicability of this technique to plutoniumcontaining materials. Work at LLNL and SRS will continue to develop a database of XRD, $\mathrm{XRF}$, and density measurements. These characterization data will be used in combination with phase equilibria data and impurity partitioning data to show that not only abundance, but also compositions of the constituent phases can be obtained. Testing of the system concepts at LLNL will be used to help design a prototype system for testing at SRS.

The prototype system will be purchased, installed, and tested at SRS with non-radioactive materials. Experience obtained from the prototype system will be used to determine the final design of the ceramic product NDE system.

A small effort will continue at WSRC beyond FY00 to demonstrate the link between the NDE analysis and the product consistency methodology. Ceramic products will continue to be tested routinely in the prototype system to verify that they meet the defined product acceptance criteria.

Specific subtasks include:

- Conceptualizing and quantifying process control measures

- Evaluating process control measurement techniques

- Developing specifications for a sintered puck NDE inspection system

- Installing and testing an NDE glove box for sintered plutonium pellet analysis in conjunction with the ceramification subsystem at LLNL

- Providing technical data to plant design

- Designing and installing a separate test system at SRS based on the experimental results obtained at LLNL, and operating this NDE system at WSRC and verifying operation with surrogates. 
Puck NDE for Process Control: Milestones

\begin{tabular}{|c|c|c|c|c|c|c|}
\hline \multicolumn{2}{|c|}{ Milestone } & \multirow{2}{*}{$\begin{array}{l}\text { Date } \\
9 / 98\end{array}$} & \multirow{2}{*}{$\frac{\text { LLNL }}{\bullet}$} & \multirow[t]{2}{*}{ WSRC } & \multirow[t]{2}{*}{ ANL } & \multirow[t]{2}{*}{ PNNL } \\
\hline FY98 & Evaluate X-ray fluorescence for NDE & & & & & \\
\hline \multirow[t]{2}{*}{ FY99 } & Complete preliminary NDE system design & $7 / 99$ & ○ & O & & \\
\hline & Provide input to preliminary TDR & $8 / 99$ & - & O & & \\
\hline \multirow[t]{2}{*}{ FY00 } & Install NDE (XRF only) equipment at LLNL & $12 / 99$ & $\bullet$ & & & \\
\hline & $\begin{array}{l}\text { Complete NDE evaluation and provide input to } \\
\text { plant TDR }\end{array}$ & $9 / 00$ & $\bullet$ & O & & \\
\hline FY01 & $\begin{array}{l}\text { Install prototype NDE (XRF \& XRD) } \\
\text { system at WSRC }\end{array}$ & $3 / 01$ & & $\bullet$ & & \\
\hline \multirow[t]{2}{*}{ FY02 } & Complete final prototype system testing & $9 / 02$ & & $\bullet$ & & \\
\hline & Complete final system designs and specifications & $9 / 02$ & & ○ & & \\
\hline
\end{tabular}

Puck NDE for Process Control: Total Budget (\$K)

\begin{tabular}{lrrrrrrrr} 
Site/Yr & FY98 & FY99 & FY00 & FY01 & FY02 & FY03 & FY04 & TOTAL \\
\hline LLNL & 300 & 750 & 450 & 100 & 0 & 0 & 0 & 1600 \\
\hline WSRC & 110 & 160 & 680 & 300 & 170 & 0 & 0 & 1420 \\
\hline ANL & 0 & 0 & 0 & 0 & 0 & 0 & 0 & 0 \\
\hline PNNL & 0 & 0 & 0 & 0 & 0 & 0 & 0 & 0 \\
\hline LANL & 0 & 0 & 0 & 0 & 0 & 0 & 0 & 0 \\
\hline Total & $\mathbf{4 1 0}$ & $\mathbf{9 1 0}$ & $\mathbf{1 1 3 0}$ & $\mathbf{4 0 0}$ & $\mathbf{1 7 0}$ & $\mathbf{0}$ & $\mathbf{0}$ & $\mathbf{3 0 2 0}$ \\
\hline
\end{tabular}

Puck NDE for Process Control: Equipment Budget (included above)

\begin{tabular}{lrrrrrrrr} 
Site/Yr & FY98 & FY99 & FY00 & FY01 & FY02 & FY03 & FY04 & TOTAL \\
\hline LLNL & 0 & 350 & 0 & 0 & 0 & 0 & 0 & 350 \\
\hline WSRC & 0 & 0 & 300 & 0 & 0 & 0 & 0 & 300 \\
\hline ANL & 0 & 0 & 0 & 0 & 0 & 0 & 0 & 0 \\
\hline PNNL & 0 & 0 & 0 & 0 & 0 & 0 & 0 & 0 \\
\hline LANL & 0 & 0 & 0 & 0 & 0 & 0 & 0 & 0 \\
\hline Total & $\mathbf{0}$ & $\mathbf{3 5 0}$ & $\mathbf{3 0 0}$ & $\mathbf{0}$ & $\mathbf{0}$ & $\mathbf{0}$ & $\mathbf{0}$ & $\mathbf{6 5 0}$ \\
\hline
\end{tabular}

\subsubsection{SNM Material Accountability}

Special nuclear material safeguards and accountability functions are essential in the immobilization plant and can have significant impact on plant operating efficiency. The uniformity of the ceramic product offers the promise of accurate SNM accountability measurements using NDA techniques for MC\&A. This task will evaluate different measurement approaches and operating scenarios to select an efficient approach for the plant with minimum process delay and uncertainty. The operations involved in material accountability are shown in Module 6.5 below. 


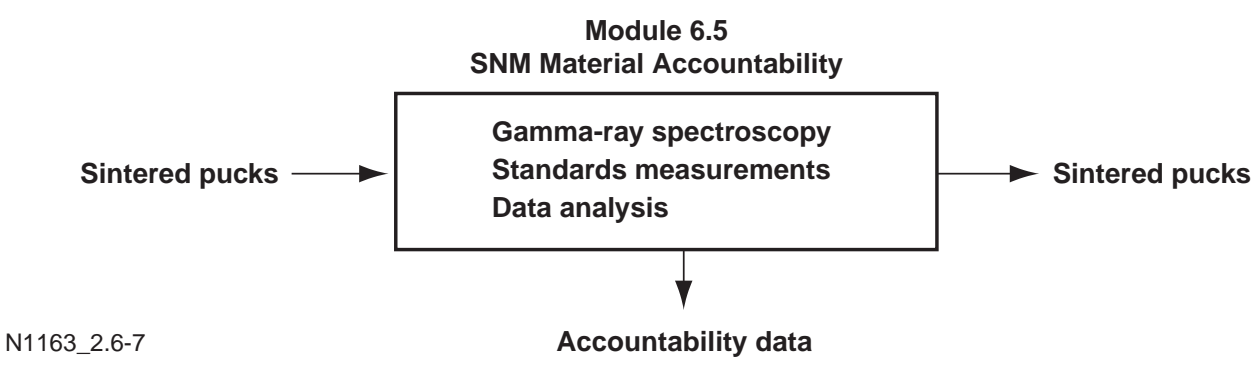

Experimental verification of the SNM measurement approaches must be made using product pellets formed from the full range of plutonium feed streams planned for the plant. Material accountability depends on the accurate measurement of plutonium quantity in the various stages of the immobilization processing and handling. Once the final form is sintered, it should be possible to make measurements of plutonium inventory, which would then allow a part-counting MC\&A approach. Several assay techniques will be considered and evaluated, including gamma ray spectroscopy, calorimetry, and sampling and analytic chemistry for total plutonium as well as weighing. The uniformity of the product and the use of plutonium batching make accurate assay measurements feasible. These measurements will be conceptually and compositionally evaluated in order to determine equipment requirements.

The chosen SNM assay equipment will be installed in a glove box in the LLNL plutonium facility as part of the ceramification module test. A series of standard samples will be made and calibrated as part of this effort. Measurements will be made of the full range of products produced with the various feed sources and impurity loadings by the ceramification module, and separate measurements will be used to determine assay accuracy. Applicability of this measurement approach will be used to specify plant assay equipment and as input for developing the plant MC\&A plan.

Specific subtasks to be performed include:

- Conceptualizing and specifying NDA measurements for MC\&A

- Developing specifications for a puck NDA system for MC\&A for testing at LLNL with plutonium

- Constructing and installing the NDA system for MC\&A analysis of plutonium ceramic pucks

- Validating system accountability performance for the range of plutonium feed materials expected for the plant

- Establishing and correlating operator radiation dose

- Providing TDR for plant design

- Providing TDR updates based on the continuing validation runs planned for the ceramification module. 
SNM Material Accountability: Milestones

\begin{tabular}{|c|c|c|c|c|c|c|}
\hline \multicolumn{2}{|c|}{ Milestone } & \multirow{2}{*}{$\begin{array}{l}\text { Date } \\
8 / 99\end{array}$} & \multirow{2}{*}{$\begin{array}{c}\text { LLNL } \\
0\end{array}$} & \multirow{2}{*}{$\begin{array}{c}\text { WSRC } \\
0\end{array}$} & \multirow[t]{2}{*}{ ANL } & \multirow[t]{2}{*}{ PNNL } \\
\hline FY99 & $\begin{array}{l}\text { Determine MC\&A system } \\
\text { specifications for acquisition }\end{array}$ & & & & & \\
\hline & Provide input to preliminary TDR & $8 / 99$ & $\bullet$ & O & & \\
\hline \multirow[t]{4}{*}{ FY00 } & Complete glove box procurement & $12 / 99$ & 0 & & & \\
\hline & Install system & $3 / 00$ & $\bullet$ & & & \\
\hline & Complete assay evaluation & $7 / 00$ & $\bullet$ & 0 & & \\
\hline & Provide TDR input & $9 / 00$ & • & 0 & & \\
\hline FY01 & Provide supplemental TDR & $9 / 01$ & 0 & ○ & & \\
\hline
\end{tabular}

SNM Material Accountability: Total Budget (\$K)

\begin{tabular}{lrrrrrrrr} 
Site/Yr & FY98 & FY99 & FY00 & FY01 & FY02 & FY03 & FY04 & TOTAL \\
\hline LLNL & 0 & 450 & 450 & 100 & 0 & 0 & 0 & 1000 \\
\hline WSRC & 0 & 100 & 100 & 150 & 0 & 0 & 0 & 350 \\
\hline ANL & 0 & 0 & 0 & 0 & 0 & 0 & 0 & 0 \\
\hline PNNL & 0 & 0 & 0 & 0 & 0 & 0 & 0 & 0 \\
\hline LANL & 0 & 0 & 0 & 0 & 0 & 0 & 0 & 0 \\
\hline Total & $\mathbf{0}$ & $\mathbf{5 5 0}$ & $\mathbf{5 5 0}$ & $\mathbf{2 5 0}$ & $\mathbf{0}$ & $\mathbf{0}$ & $\mathbf{0}$ & $\mathbf{1 3 5 0}$ \\
\hline
\end{tabular}

SNM Material Accountability: Equipment Budget (included above)

\begin{tabular}{lrrrrrrrr} 
Site/Yr & FY98 & FY99 & FY00 & FY01 & FY02 & FY03 & FY04 & TOTAL \\
\hline LLNL & 0 & 300 & 0 & 0 & 0 & 0 & 0 & 300 \\
\hline WSRC & 0 & 0 & 0 & 0 & 0 & 0 & 0 & 0 \\
\hline ANL & 0 & 0 & 0 & 0 & 0 & 0 & 0 & 0 \\
\hline PNNL & 0 & 0 & 0 & 0 & 0 & 0 & 0 & 0 \\
\hline LANL & 0 & 0 & 0 & 0 & 0 & 0 & 0 & 0 \\
\hline Total & $\mathbf{0}$ & $\mathbf{3 0 0}$ & $\mathbf{0}$ & $\mathbf{0}$ & $\mathbf{0}$ & $\mathbf{0}$ & $\mathbf{0}$ & $\mathbf{3 0 0}$ \\
\hline
\end{tabular}

\subsubsection{Sintering}

The sintering process involves the operations shown in Module 6.6 below. Product quality depends on the sintering furnace atmosphere control and temperature-time cycle. Operation outside of an acceptable processing envelope will result in off-spec, unacceptable products. Acceptable processing bounds must be determined and specified. 


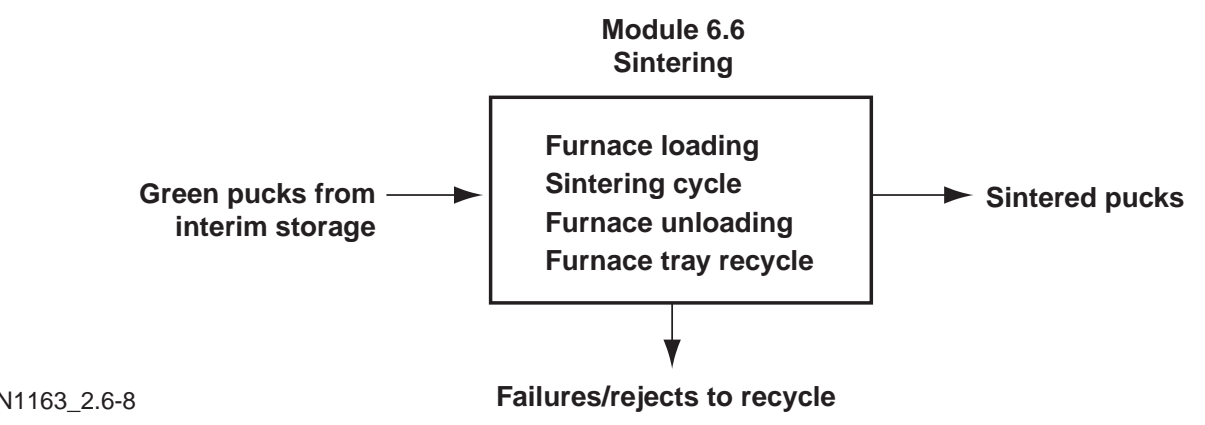

Parametric studies of material prepared for sintering include control of moisture in the granulated feed, use of binders and lubricants, and behavior and consistency of the feed material during the sintering operation. In addition, it is essential to determine what impact the inclusion of various impurities in the feed stream has on the sintering operation and product quality.

The sintering operation will be sensitive to reduction oxidation (redox) conditions during the burnout and sintering phases. Time/temperature effects on the product sintering, diffusion, and solubility of the actinides and neutron absorbers must be determined. In addition, the addition of impurities will alter the sintering characteristics, and could result in ceramic melting or slumping as well as open porosity, out-of-size products, and low-density ceramics unless the correct sintering conditions are known.

Preliminary work on sintering in FY98 will be performed as part of ceramification process development (Task 2.6.2.1). Limited parametric studies of sintering conditions will be performed in FY99, and specifications will be prepared for the plant sintering system.

Sintering experiments using surrogates for the plutonium will be performed in conjunction with feed preparation and pressing in the cold facilities at LLNL and WSRC. Impurity effects will be determined on an individual basis and in combinations that are likely to be encountered as well as those that may be more problematic. Confirmatory pressing and sintering operations using plutonium and selected impurity combinations will be performed with the baseline formulation at existing facilities in the LLNL plutonium building. This sintering capability will not be plant prototypic in scale or design, but will provide essential process data to allow specification of the sintering furnace functional requirements for the $\mathrm{A} / \mathrm{E}$.

\section{Sintering: Milestones}

\begin{tabular}{|c|c|c|c|c|c|c|}
\hline Milest & & Date & LLNL & WSRC & ANL & PNNL \\
\hline FY99 & Develop sintering process specifications & 9/99 & ○ & $\mathrm{O}$ & & \\
\hline & Provide input to preliminary TDR & 9/99 & $\bullet$ & O & & \\
\hline FY00 & $\begin{array}{l}\text { Complete documentation and confirmation } \\
\text { of process specifications }\end{array}$ & $6 / 00$ & & $\bullet$ & & \\
\hline & Provide TDR input & $9 / 00$ & & $\bullet$ & & \\
\hline FY01 & Provide supplemental TDR & $9 / 01$ & & ○ & & \\
\hline
\end{tabular}


Sintering: Total Budget (\$K)

\begin{tabular}{lrrrrrrrr} 
Site/Yr & FY98 & FY99 & FY00 & FY01 & FY02 & FY03 & FY04 & TOTAL \\
\hline LLNL & 0 & 50 & 0 & 0 & 0 & 0 & 0 & 50 \\
\hline WSRC & 0 & 120 & 50 & 25 & 20 & 0 & 0 & 215 \\
\hline ANL & 0 & 0 & 0 & 0 & 0 & 0 & 0 & 0 \\
\hline PNNL & 0 & 0 & 0 & 0 & 0 & 0 & 0 & 0 \\
\hline LANL & 0 & 0 & 0 & 0 & 0 & 0 & 0 & 0 \\
\hline Total & $\mathbf{0}$ & $\mathbf{1 7 0}$ & $\mathbf{5 0}$ & $\mathbf{2 5}$ & $\mathbf{2 0}$ & $\mathbf{0}$ & $\mathbf{0}$ & $\mathbf{2 6 5}$ \\
\hline
\end{tabular}

Sintering: Equipment Budget (included above)

\begin{tabular}{lrrrrrrrr} 
Site/Yr & FY98 & FY99 & FY00 & FY01 & FY02 & FY03 & FY04 & TOTAL \\
\hline LLNL & 0 & 0 & 0 & 0 & 0 & 0 & 0 & 0 \\
\hline WSRC & 0 & 120 & 0 & 0 & 0 & 0 & 0 & 120 \\
\hline ANL & 0 & 0 & 0 & 0 & 0 & 0 & 0 & 0 \\
\hline PNNL & 0 & 0 & 0 & 0 & 0 & 0 & 0 & 0 \\
\hline LANL & 0 & 0 & 0 & 0 & 0 & 0 & 0 & 0 \\
\hline Total & $\mathbf{0}$ & $\mathbf{1 2 0}$ & $\mathbf{0}$ & $\mathbf{0}$ & $\mathbf{0}$ & $\mathbf{0}$ & $\mathbf{0}$ & $\mathbf{1 2 0}$ \\
\hline
\end{tabular}

\subsubsection{Recycle of Unacceptable Materials}

Off-spec materials generated in the immobilization process will be recycled back into the main feed stream. A small portion of granules, the as-pressed green pucks, and sintered pucks may have to be recycled due to out-of-specification conditions, mishandling, or other process upsets. The equipment and processing conditions required to recycle material from various stages of the process need to be established for plant design. To define the acceptable processing envelope for repository acceptance, the maximum percentage of these recycled materials that can be formulated into the ceramic product will also need to be determined. The operations involved in recycling are shown in Module 6.7 below.

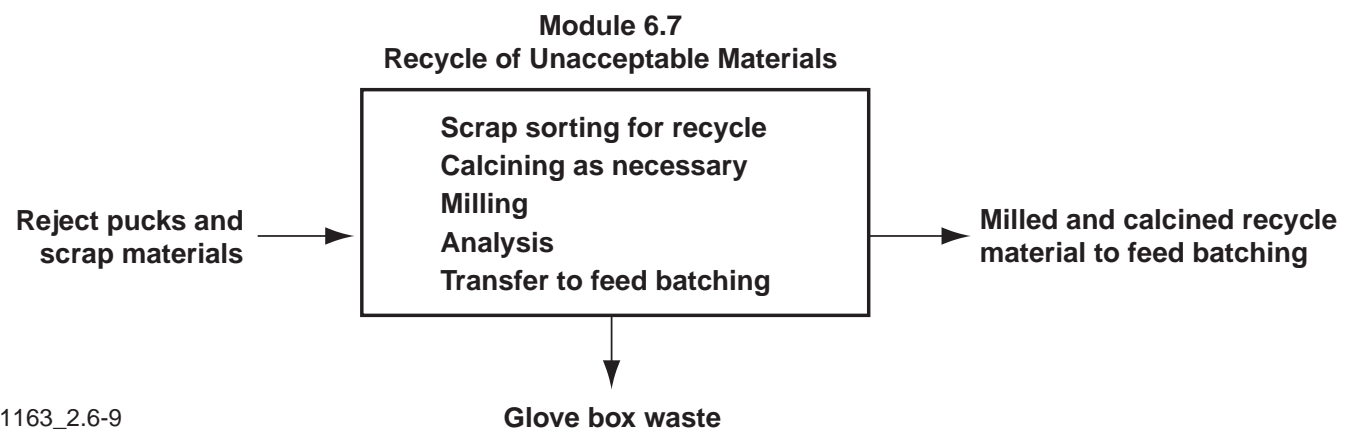

At both SRS and LLNL, the uranium/cerium surrogate baseline mixture will be processed to produce granulated feed, as-pressed (unsintered) pellets, and sintered (including overand under-fired) pellets. Equipment will be selected and purchased to crush sintered pellets into pieces fine enough to be fed into the attritor mill. The optimum grinding 
parameters to reprocess the sintered and crushed material will also be determined. Puck fabrication tests from the recycled materials will be performed to establish the maximum concentration of recycled material that can be added. Confirmatory tests will be performed with "full-scale" uranium/plutonium pellets at LLNL.

The bulk of the experimental work will be performed during FY98 and FY99. Work in FY00 will focus on design of the recycle process for the plant. Work in outyears will demonstrate the recycle process on an as-needed basis for form qualification.

Recycle of Unacceptable Materials: Milestones

\begin{tabular}{|c|c|c|c|c|c|c|}
\hline \multicolumn{2}{|c|}{ Milestone } & \multirow{2}{*}{$\begin{array}{l}\text { Date } \\
9 / 98\end{array}$} & \multirow{2}{*}{$\begin{array}{c}\text { LLNL } \\
\qquad \\
\bullet\end{array}$} & \multirow{2}{*}{$\begin{array}{c}\text { WSRC } \\
0\end{array}$} & \multirow[t]{2}{*}{ ANL } & \multirow[t]{2}{*}{ PNNL } \\
\hline FY98 & $\begin{array}{l}\text { Complete initial evaluation of ceramic } \\
\text { recycling impacts }\end{array}$ & & & & & \\
\hline FY99 & $\begin{array}{l}\text { Determine processing limiting parameters } \\
\text { in recycle process }\end{array}$ & $5 / 99$ & $\bullet$ & 0 & & \\
\hline & Provide input to preliminary TDR & $8 / 99$ & $\bullet$ & $\mathrm{O}$ & & \\
\hline FY00 & $\begin{array}{l}\text { Complete final design of recycle system } \\
\text { and provide TDR }\end{array}$ & $9 / 00$ & $\bullet$ & 0 & & \\
\hline \multicolumn{7}{|l|}{ FY01 } \\
\hline FY02 & $\begin{array}{l}\text { Complete testing and demonstration } \\
\text { of recycle process }\end{array}$ & $9 / 02$ & & 0 & & \\
\hline
\end{tabular}

Recycle of Unacceptable Materials: Total Budget (\$K)

\begin{tabular}{lrrrrrrrr} 
Site/Yr & FY98 & FY99 & FY00 & FY01 & FY02 & FY03 & FY04 & TOTAL \\
\hline LLNL & 270 & 110 & 50 & 0 & 0 & 0 & 0 & 430 \\
\hline WSRC & 130 & 160 & 95 & 30 & 30 & 0 & 0 & 445 \\
\hline ANL & 0 & 0 & 0 & 0 & 0 & 0 & 0 & 0 \\
\hline PNNL & 0 & 0 & 0 & 0 & 0 & 0 & 0 & 0 \\
\hline LANL & 0 & 0 & 0 & 0 & 0 & 0 & 0 & 0 \\
\hline Total & $\mathbf{4 0 0}$ & $\mathbf{2 7 0}$ & $\mathbf{1 4 5}$ & $\mathbf{3 0}$ & $\mathbf{3 0}$ & $\mathbf{0}$ & $\mathbf{0}$ & $\mathbf{8 7 5}$ \\
\hline
\end{tabular}

\section{Recycle of Unacceptable Materials: Equipment Budget (included above)}

\begin{tabular}{lrrrrrrrr} 
Site/Yr & FY98 & FY99 & FY00 & FY01 & FY02 & FY03 & FY04 & TOTAL \\
\hline LLNL & 30 & 0 & 0 & 0 & 0 & 0 & 0 & 30 \\
\hline WSRC & 30 & 0 & 0 & 0 & 0 & 0 & 0 & 30 \\
\hline ANL & 0 & 0 & 0 & 0 & 0 & 0 & 0 & 0 \\
\hline PNNL & 0 & 0 & 0 & 0 & 0 & 0 & 0 & 0 \\
\hline LANL & 0 & 0 & 0 & 0 & 0 & 0 & 0 & 0 \\
\hline Total & $\mathbf{6 0}$ & $\mathbf{0}$ & $\mathbf{0}$ & $\mathbf{0}$ & $\mathbf{0}$ & $\mathbf{0}$ & $\mathbf{0}$ & $\mathbf{6 0}$ \\
\hline
\end{tabular}




\subsubsection{Can Loading}

In this module, the sintered pucks are removed from glove box containment and loaded into an uncontaminated can. This system, whose operations are shown in Module 6.8 below, will load ceramic pucks into a product can, weld a top on the can, and perform a leak-and-smear test on the can. Since the unshielded puck contact dose rate may be as high as $1 \mathrm{R} / \mathrm{hr}$, all operations should be automated in a glove box to ensure achieving operator exposure under $0.5 \mathrm{R} / \mathrm{yr}$. The finished cans are verified to be free of contamination, and then sent to final accountability assay measurements prior to loading into magazines.

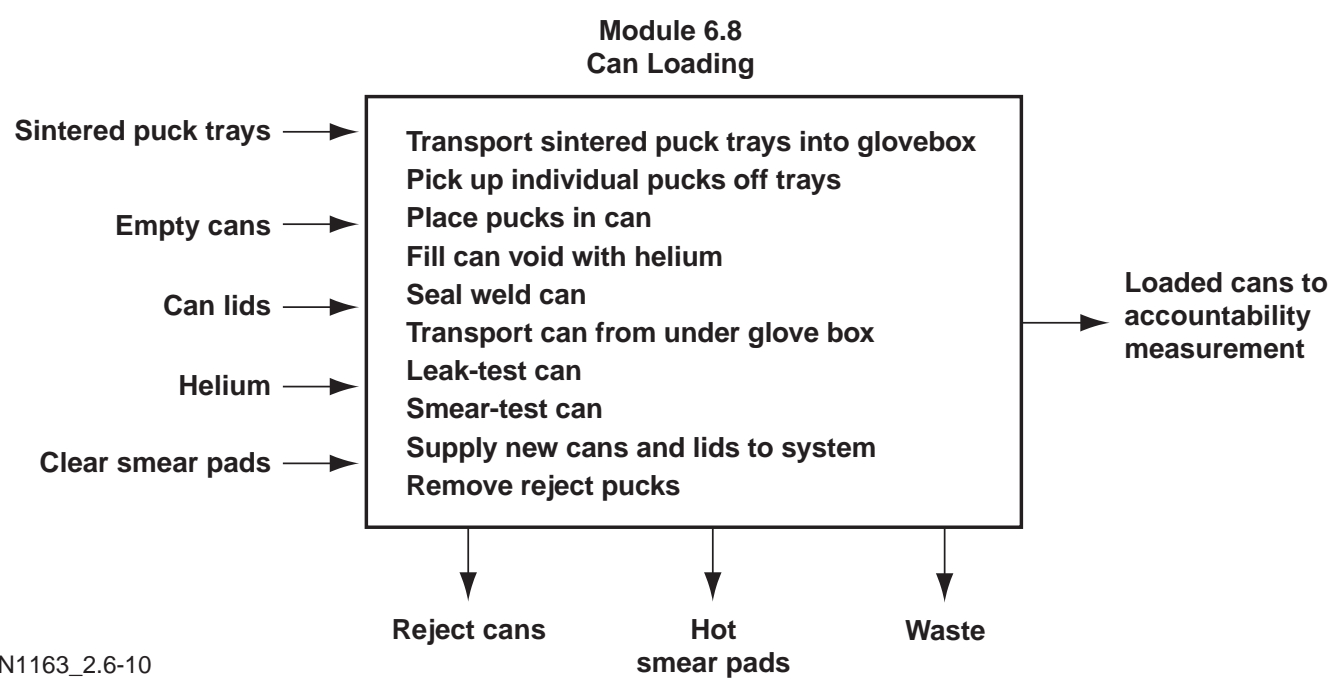

This one-of-kind automated can loading system must be developed in order to have confirmed equipment specifications before detailed design begins. Some of the equipment components can be purchased from commercial vendors, but modifications will be required in order to meet the specific requirements of each operation. Approximately $50 \%$ of the automation and unit operation system will be new or modified commercial designs requiring further development. Design development, equipment mock-up, and testing will ensure that the equipment provided to the new facility is operator-accessible, maintainable, and will perform reliably as intended, thereby minimizing cost, schedule, and overall project risk.

This task will modify the existing SRS bagless transfer system and ensure the feasibility of loading the ceramic pucks into the product can, filling the void space with helium, installing and welding the lid, separating the upper and lower can portions by cutting and removing the uncontaminated product can (bottom portion) from the glove box. This task also includes remote handling of the completed product can through testing and any reject can handling.

\section{Can Loading: Milestones}

\begin{tabular}{|c|c|c|c|c|c|c|}
\hline \multicolumn{2}{|c|}{ Milestone } & \multirow{2}{*}{$\frac{\text { Date }}{5 / 98}$} & \multirow[t]{2}{*}{ LLNL } & \multirow{2}{*}{$\frac{\text { WSRC }}{0}$} & \multirow[t]{2}{*}{ ANL } & \multirow[t]{2}{*}{ PNNL } \\
\hline FY98 & Identify design concepts & & & & & \\
\hline & Complete concept design & $8 / 98$ & & ○ & & \\
\hline \multirow[t]{2}{*}{ FY99 } & Procure and install cold test system & $2 / 99$ & & $\mathbf{0}$ & & \\
\hline & Complete cold system test report for preliminary TDR & $9 / 99$ & & 0 & & \\
\hline \multirow[t]{2}{*}{ FYOO } & Complete integrated testing of can loading & $8 / 00$ & & 0 & & \\
\hline & Provide TDR & $9 / 00$ & & ○ & & \\
\hline FY01 & $\begin{array}{l}\text { Provide detailed designs and specifications } \\
\text { to the project }\end{array}$ & $9 / 01$ & & ○ & & \\
\hline
\end{tabular}


Can Loading: Total Budget (\$K)

\begin{tabular}{lrrrrrrrr} 
Site/Yr & FY98 & FY99 & FY00 & FY01 & FY02 & FY03 & FY04 & TOTAL \\
\hline LLNL & 0 & 0 & 0 & 0 & 0 & 0 & 0 & 0 \\
\hline WSRC & 595 & 825 & 425 & 50 & 50 & 0 & 0 & 1945 \\
\hline ANL & 0 & 0 & 0 & 0 & 0 & 0 & 0 & 0 \\
\hline PNNL & 0 & 0 & 0 & 0 & 0 & 0 & 0 & 0 \\
\hline LANL & 0 & 0 & 0 & 0 & 0 & 0 & 0 & 0 \\
\hline Total & $\mathbf{5 9 5}$ & $\mathbf{8 2 5}$ & $\mathbf{4 2 5}$ & $\mathbf{5 0}$ & $\mathbf{5 0}$ & $\mathbf{0}$ & $\mathbf{0}$ & $\mathbf{1 9 4 5}$ \\
\hline
\end{tabular}

Can Loading: Equipment Budget (included above)

\begin{tabular}{lrrrrrrrr} 
Site/Yr & FY98 & FY99 & FY00 & FY01 & FY02 & FY03 & FY04 & TOTAL \\
\hline LLNL & 0 & 0 & 0 & 0 & 0 & 0 & 0 & 0 \\
\hline WSRC & 240 & 500 & 100 & 0 & 0 & 0 & 0 & 840 \\
\hline ANL & 0 & 0 & 0 & 0 & 0 & 0 & 0 & 0 \\
\hline PNNL & 0 & 0 & 0 & 0 & 0 & 0 & 0 & 0 \\
\hline LANL & 0 & 0 & 0 & 0 & 0 & 0 & 0 & 0 \\
\hline Total & 240 & $\mathbf{5 0 0}$ & $\mathbf{1 0 0}$ & $\mathbf{0}$ & $\mathbf{0}$ & $\mathbf{0}$ & $\mathbf{0}$ & $\mathbf{8 4 0}$ \\
\hline
\end{tabular}

\subsubsection{Can NDE and MC\&A}

This module performs the necessary measurements to confirm plutonium inventories in the can for material balance closure and the integrity of the can seal, as illustrated in Module 6.9 below. Assay of the product cans from the immobilization process will be required to maintain $M C \& A$ of the cans and their contents downstream of the can loading process. This task will investigate the applicability of existing systems for use with the ceramic product cans and establish requirements for the plant systems. The goal of the task will be to minimize the amount of assay required and still meet MC\&A requirements. The ultimate objective of the task is to move can MC\&A toward item count and confirmatory pellet loading only.

The equipment requirements for an automated, remote MC\&A system will have a significant impact on facility layout. The space to house the NDA instruments and their support equipment must be located within the material access area (hardened facility) to meet safeguards and physical security requirements. Minimization of the usual high cost of hardened building construction can be realized by developing a system with optimum throughput.

Module 6.9

Can NDE and MC\&A

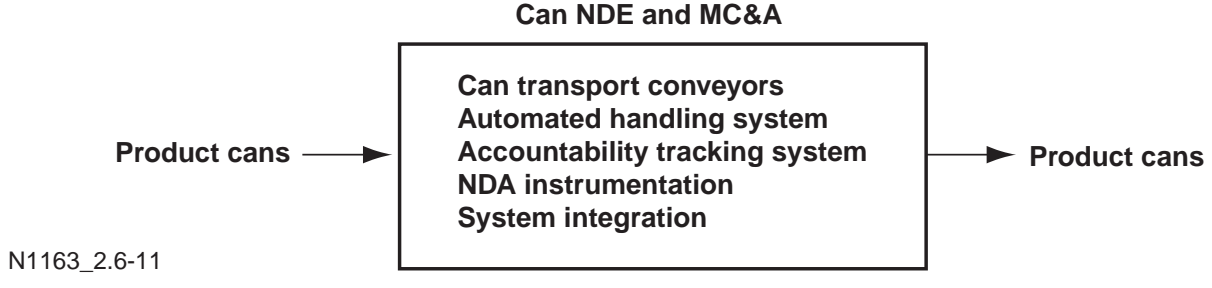


In FY99, WSRC will survey potential analytical equipment for can assay and NDE as well as other inspection techniques. These will include gamma-ray spectrometers, neutron coincidence counters, neutron multiplication counters, and calorimeters. These devices may vary in both the analytical precision as well as the time required for analysis (i.e., the higher the resolution, the longer the analytical time required). Simpler accountability techniques (e.g., piece counting) will be investigated for their ability to meet accountability requirements.

To facilitate selection of the most appropriate NDA approaches for MC\&A, an assessment of requirements for the can assay will also be performed. Once this assessment has been completed and the MC\&A requirements are defined, selection of the most suitable technique will be made and pursued in later project years.

In FY00, development of production type can assay systems will begin. These systems will be used in conjunction with the plutonium ceramification module and the MC\&A module testing at LLNL on actual plutonium feeds. Modification and improvement of these systems will continue in outyears as they are integrated into the production process.

\section{Can NDE and MC\&A: Milestones}

\begin{tabular}{|c|c|c|c|c|c|c|}
\hline \multicolumn{2}{|c|}{ Milestone } & \multirow{2}{*}{$\begin{array}{l}\text { Date } \\
8 / 99\end{array}$} & \multirow{2}{*}{ LLNL } & \multirow{2}{*}{$\begin{array}{c}\text { WSRC } \\
\bullet\end{array}$} & \multirow[t]{2}{*}{ ANL } & \multirow[t]{2}{*}{ PNNL } \\
\hline FY99 & $\begin{array}{l}\text { Determine preliminary MC\&A requirements and } \\
\text { identify candidate analytical techniques }\end{array}$ & & & & & \\
\hline & Provide preliminary TDR input & $9 / 99$ & & $\bullet$ & & \\
\hline \multirow[t]{2}{*}{ FY00 } & Procure test systems & $4 / 00$ & & $\bullet$ & & \\
\hline & $\begin{array}{l}\text { Complete testing on analytical test systems } \\
\text { and provide TDR }\end{array}$ & $9 / 00$ & & $\bullet$ & & \\
\hline FY01 & $\begin{array}{l}\text { Deliver production characterization system } \\
\text { design specifications }\end{array}$ & $9 / 01$ & & $\bullet$ & & \\
\hline
\end{tabular}

\section{Can NDE and MC\&A: Total Budget (\$K)}

\begin{tabular}{lrrrrrrrr} 
Site/Yr & FY98 & FY99 & FY00 & FY01 & FY02 & FY03 & FY04 & TOTAL \\
\hline LLNL & 0 & 0 & 0 & 0 & 0 & 0 & 0 & 0 \\
\hline WSRC & 0 & 30 & 425 & 100 & 50 & 0 & 0 & 605 \\
\hline ANL & 0 & 0 & 0 & 0 & 0 & 0 & 0 & 0 \\
\hline PNNL & 0 & 0 & 0 & 0 & 0 & 0 & 0 & 0 \\
\hline LANL & 0 & 0 & 0 & 0 & 0 & 0 & 0 & 0 \\
\hline Total & $\mathbf{0}$ & $\mathbf{3 0}$ & $\mathbf{4 2 5}$ & $\mathbf{1 0 0}$ & $\mathbf{5 0}$ & $\mathbf{0}$ & $\mathbf{0}$ & $\mathbf{6 0 5}$ \\
\hline
\end{tabular}


Can NDE and MC\&A: Equipment Budget (included above)

\begin{tabular}{lrrrrrrrr} 
Site/Yr & FY98 & FY99 & FY00 & FY01 & FY02 & FY03 & FY04 & TOTAL \\
\hline LLNL & & & & & & & \\
\hline WSRC & 0 & 0 & 150 & 0 & 0 & 0 & 0 & 150 \\
\hline ANL & & & & & & & \\
\hline PNNL & & & & & & & 0 \\
\hline LANL & & & & & & & 0 \\
\hline Total & $\mathbf{0}$ & $\mathbf{0}$ & $\mathbf{1 5 0}$ & $\mathbf{0}$ & $\mathbf{0}$ & $\mathbf{0}$ & $\mathbf{0}$ & $\mathbf{1 5 0}$ \\
\hline
\end{tabular}

\subsubsection{Can Storage Vault}

A storage vault is required for the interim storage of the ceramic product in the form of cans and/or magazines. This product storage vault will provide space for the necessary storage and staging prior to loading the canisters (see Module 6.10 below). The storage vault will provide 30-day-capacity storage, including an automated vault storage system and transport system to move cans in and out of the vault. Normal operation will directly load product cans into magazines for shielded storage; however, limited space will be provided for shielded storage of individual product cans, if necessary. Can storage and loading operations will be automated. An assessment of existing storage and handling concepts will be made. The best concept for the immobilization system will be identified.

Module 6.10

In-Process Storage Vault

\begin{tabular}{|c|c|c|}
\hline $\begin{array}{l}\text { Cans or } \\
\text { can loaded } \longrightarrow \\
\text { magazines }\end{array}$ & $\begin{array}{l}\text { Automated conveyance to vault } \\
\text { Automated vault handling equipment } \\
\text { One-month storage capacity } \\
\text { System automation \& integration }\end{array}$ & $\begin{array}{l}\text { Cans to } \\
\text { magazine loading } \\
\text { or } \\
\text { magazines to }\end{array}$ \\
\hline N1163_2.6-12 & & \\
\hline
\end{tabular}

Can Storage Vault: Milestones

\begin{tabular}{|c|c|c|c|c|c|c|}
\hline Milest & & Date & LLNL & WSRC & ANL & PNNL \\
\hline FY99 & Identify storage and can handling concept & $12 / 98$ & & - & & \\
\hline FY00 & Provide TDR input & $5 / 99$ & & • & & \\
\hline FY01 & Provide supplemental TDR & $9 / 01$ & & - & & \\
\hline
\end{tabular}

Can Storage Vault: Total Budget (\$K)

\begin{tabular}{lrrrrrrrr} 
Site/Yr & FY98 & FY99 & FY00 & FY01 & FY02 & FY03 & FY04 & TOTAL \\
\hline LLNL & 0 & 0 & 0 & 0 & 0 & 0 & 0 & 0 \\
\hline WSRC & 0 & 50 & 50 & 20 & 20 & 0 & 0 & 140 \\
\hline ANL & 0 & 0 & 0 & 0 & 0 & 0 & 0 & 0 \\
\hline PNNL & 0 & 0 & 0 & 0 & 0 & 0 & 0 & 0 \\
\hline LANL & 0 & 0 & 0 & 0 & 0 & 0 & 0 & 0 \\
\hline Total & $\mathbf{0}$ & $\mathbf{5 0}$ & $\mathbf{5 0}$ & $\mathbf{2 0}$ & $\mathbf{2 0}$ & $\mathbf{0}$ & $\mathbf{0}$ & $\mathbf{1 4 0}$ \\
\hline
\end{tabular}




\subsection{SECOND-STAGE IMMOBILIZATION PROCESS/EQUIPMENT DEVELOPMENT}

Second-stage immobilization, shown in the process flow diagram in Figure 2-9 is the third and final part of the integrated immobilization plant process flowsheet. This portion of the integrated flowsheet receives cans containing plutonium-bearing ceramic from first-stage immobilization and produces finished canisters filled with HLW glass. A completed immobilization canister has been shown in Figure 1-1. The second stage immobilization flowsheet consists of three functional modules:

- Can-in-Canister Design and Assembly (Module 7.1)

- Canister Transport System (Module 7.2)

- DWPF Receipt and Handling (Module 7.3)

These modules accomplish the following operations: assembly of the ceramic containing cans into magazines, which are placed into an empty canister; transport of the canisters to DWPF; and pouring of HLW glass into the canisters. In addition to tasks in each of these three functional modules, the D\&T plan includes a precursor activity, canister pour analysis and testing, which is required to determine the appropriate canister internal configuration.
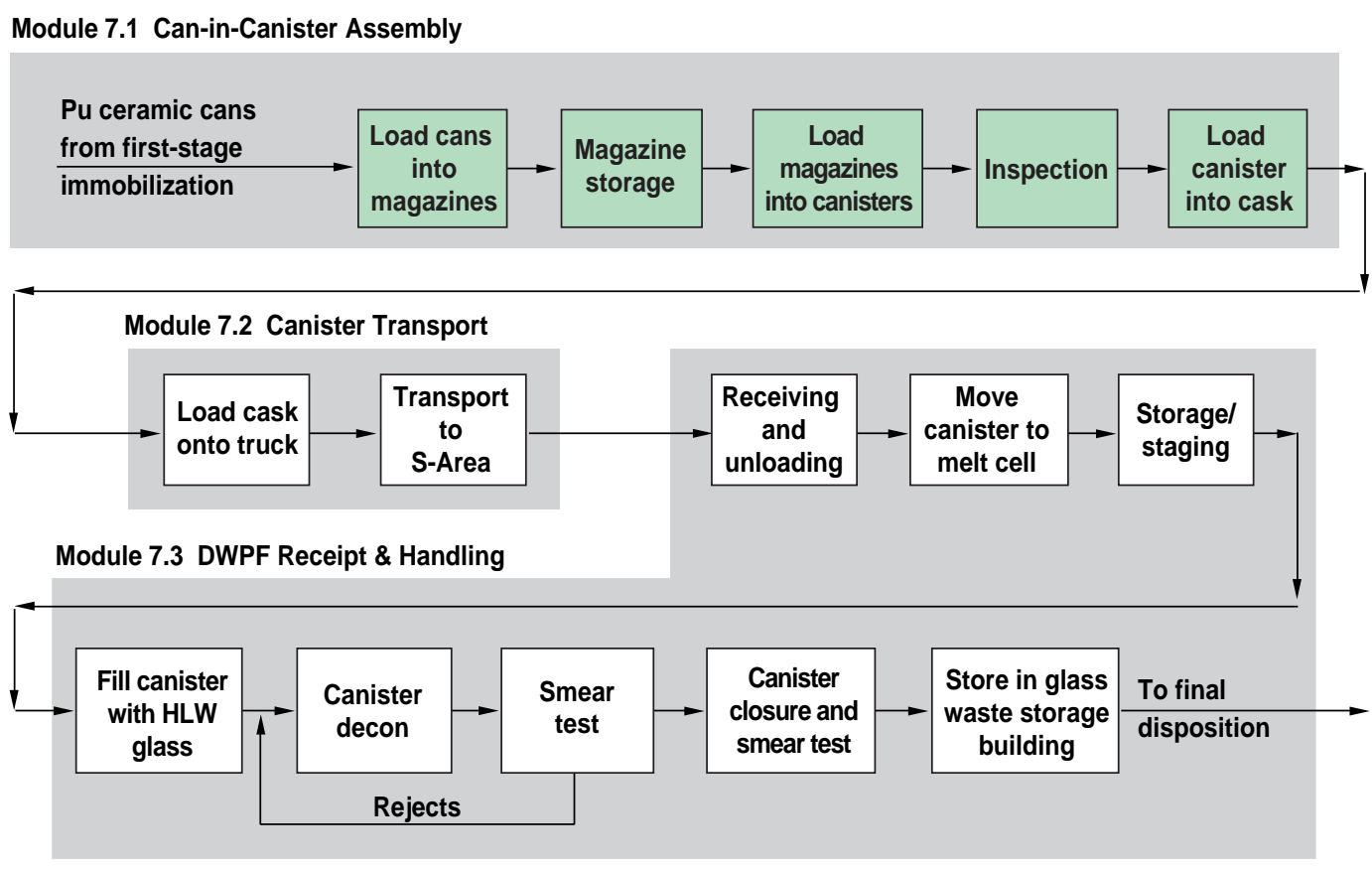

$$
\square \text { Prototype components }
$$

Conceptual design only

Figure 2-9. Second-stage immobilization process flow diagram. 
This internal configuration in turn determines the quantity of plutonium (number of cans) in each canister. The canister design must allow for the unhindered pouring of the HLW glass to completely encapsulate the cans so that an adequate radiation barrier is created.

\subsubsection{Can-in-Canister System}

\subsubsection{Can-in-Canister Design and Assembly}

This task will develop and demonstrate the design and remote assembly of the can-incanister assemblies prior to the pouring of HLW glass. Automation of the assembly steps in a remote environment is required to minimize personnel radiation exposure. A can-incanister assembly is shown in Figure 2-10 and the unit operations involved in its production are shown in Module 7.1 below. The assembly process will place ceramic product cans into magazines that will subsequently be loaded into the DWPF canister. The magazines will be restrained in the canister by a support rack installed by the canister vendor during manufacture.

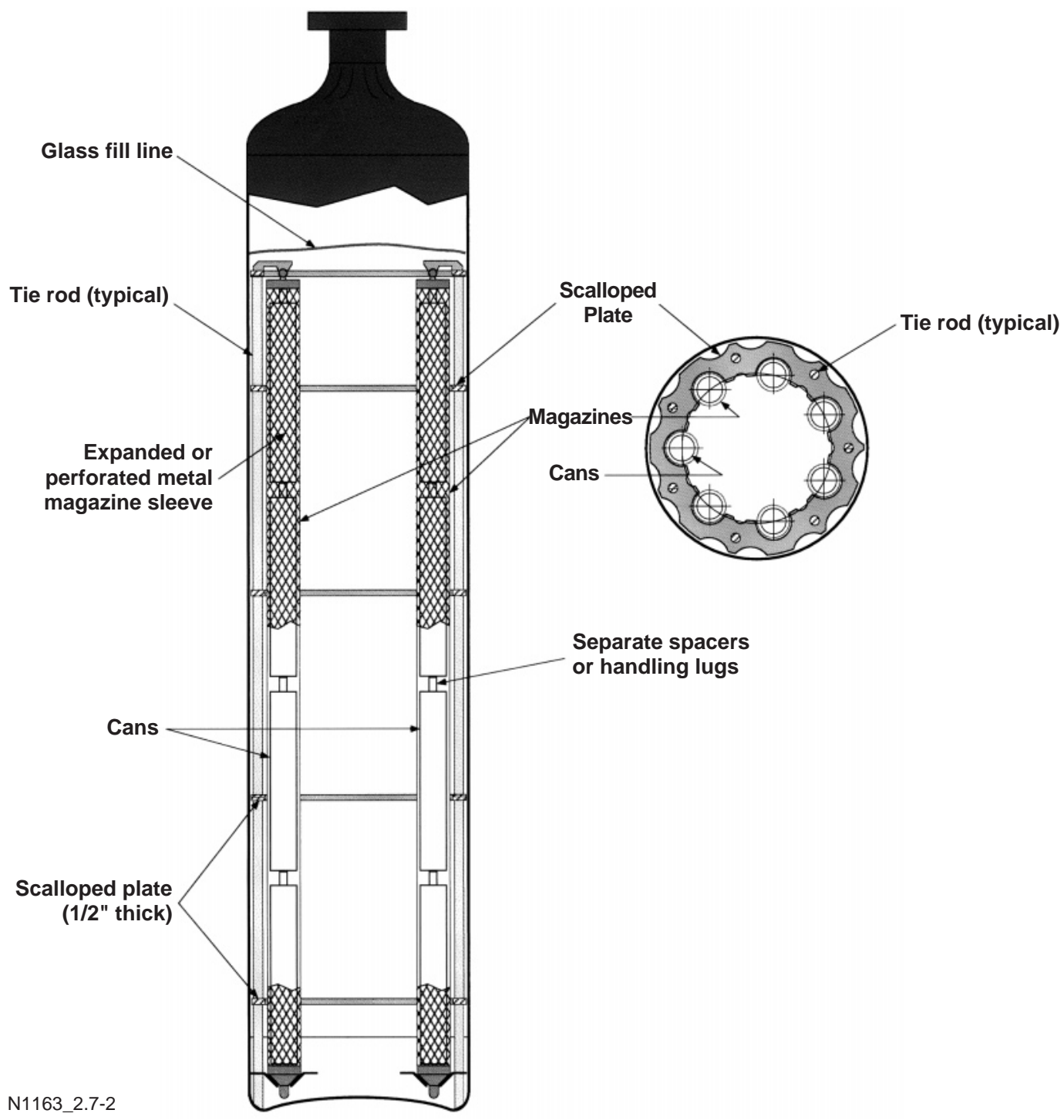

Figure 2-10. Can-in-canister assembly. 
Module 7.1

Can-in-Canister Assembly

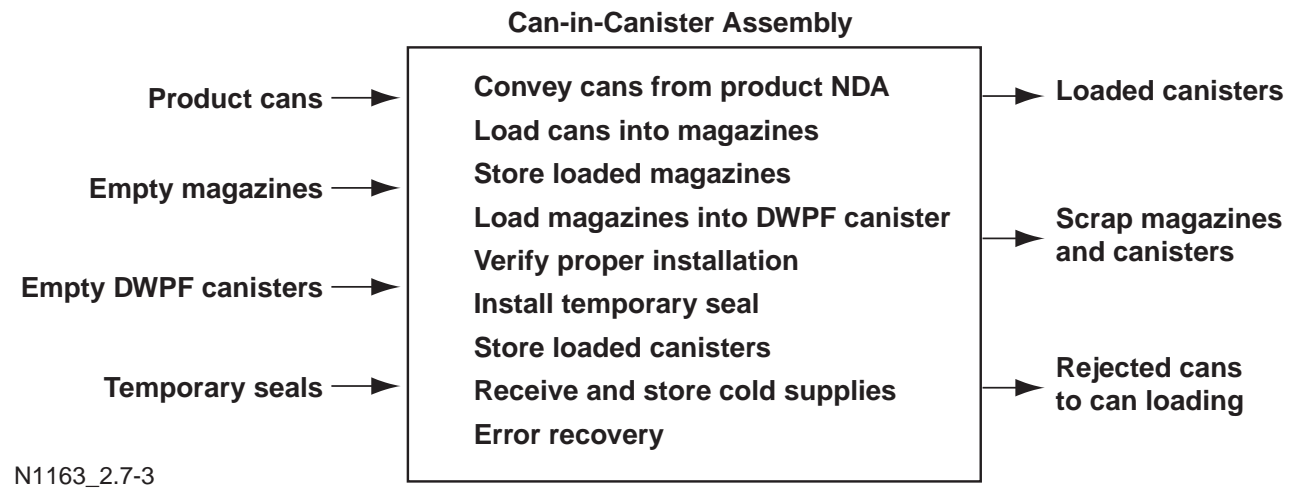

The ceramic product cans will be approximately 3 inches in diameter and 20 inches long. Each magazine will accommodate four of the product cans and will be sized to fit through the opening in top of the DWPF canister (approximately 4.25 inches in diameter). An acceptable magazine should be simple, reliable, and relatively inexpensive to manufacture. At least three magazine loading concepts will be investigated.

The internal support rack within the DWPF canister will be designed to automatically latch or otherwise secure the magazines. The rack must be designed to adequately support the magazines during assembly, storage, and transportation to the DWPF and during filling of HLW glass.

This task will be performed in two phases. Phase 1 will concentrate on the development of the can/magazine-rack design baseline to be tested with simulated HLW glass pour experiments in FY99. In FY00, Phase 2 of this task will complete component testing for the canister loading system to provide final specifications for fabrication to be completed by an external vendor.

\section{Can-in-Canister Design and Assembly: Milestones}

\begin{tabular}{|c|c|c|c|c|c|c|}
\hline Miles & & Date & LLNL & WSRC & ANL & PNNL \\
\hline FY98 & Complete concept design & $4 / 98$ & & $\bullet$ & & \\
\hline & $\begin{array}{l}\text { Verify critical unit operations } \\
\text { requiring concentrated developmental effort }\end{array}$ & $4 / 98$ & & ○ & & \\
\hline & $\begin{array}{l}\text { Complete preliminary specifications for can/ } \\
\text { magazine and rack baseline design and initiate } \\
\text { equipment procurement }\end{array}$ & $9 / 98$ & & ○ & & \\
\hline FY99 & $\begin{array}{l}\text { Demonstrate rack/canister preliminary } \\
\text { (cold pours) and provide preliminary TDR }\end{array}$ & $7 / 99$ & & ○ & & \\
\hline FY00 & Procure and test plant scale systems & $9 / 00$ & & $\bullet$ & & \\
\hline & $\begin{array}{l}\text { Complete specifications for canister loading system } \\
\text { and provide TDR }\end{array}$ & $9 / 00$ & & 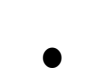 & & \\
\hline
\end{tabular}


Can-in-Canister Design and Assembly: Total Budget (\$K)

\begin{tabular}{lrrrrrrrr} 
Site/Yr & FY98 & FY99 & FY00 & FY01 & FY02 & FY03 & FY04 & TOTAL \\
\hline LLNL & 0 & 0 & 0 & 0 & 0 & 0 & 0 & 0 \\
\hline WSRC & 1010 & 980 & 1720 & 0 & 0 & 0 & 0 & 3710 \\
\hline ANL & 0 & 0 & 0 & 0 & 0 & 0 & 0 & 0 \\
\hline PNNL & 0 & 0 & 0 & 0 & 0 & 0 & 0 & 0 \\
\hline LANL & 0 & 0 & 0 & 0 & 0 & 0 & 0 & 0 \\
\hline Total & 1010 & $\mathbf{9 8 0}$ & $\mathbf{1 7 2 0}$ & $\mathbf{0}$ & $\mathbf{0}$ & $\mathbf{0}$ & $\mathbf{0}$ & $\mathbf{3 7 1 0}$ \\
\hline
\end{tabular}

Can-in-Canister Design and Assembly: Equipment Budget (included above)

\begin{tabular}{lrrrrrrrr} 
Site/Yr & FY98 & FY99 & FY00 & FY01 & FY02 & FY03 & FY04 & TOTAL \\
\hline LLNL & 0 & 0 & 0 & 0 & 0 & 0 & 0 & 0 \\
\hline WSRC & 200 & 340 & 1000 & 0 & 0 & 0 & 1540 \\
\hline ANL & 0 & 0 & 0 & 0 & 0 & 0 & 0 & 0 \\
\hline PNNL & 0 & 0 & 0 & 0 & 0 & 0 & 0 & 0 \\
\hline LANL & 0 & 0 & 0 & 0 & 0 & 0 & 0 & 0 \\
\hline Total & 200 & $\mathbf{3 4 0}$ & $\mathbf{1 0 0 0}$ & $\mathbf{0}$ & $\mathbf{0}$ & $\mathbf{0}$ & $\mathbf{0}$ & $\mathbf{1 5 4 0}$ \\
\hline
\end{tabular}

\subsubsection{Canister Pour Analysis and Testing}

The objective of the canister pour analysis and testing task is to assist in the development of and verify a baseline design concept for the immobilization canister. This activity will provide input to the technical requirements for the canister subsystem, which must be established to start the detailed design for the plant.

In FY98, the ProCAST code will be used to computationally evaluate the pour characteristics of HLW glass into canisters so that the optimum internal configuration of the cans, magazine and fixturing assembly can be determined. These analyses will also help to establish design parameters for the cans, magazine, and rack assembly. Designs and plans for full scale surrogate HLW glass pour experiments will be developed to demonstrate the viability of the canister design in FY99.

Several surrogate HLW glass test pours into full-scale canisters will be conducted in FY99 using prototypic DWPF pour rates (batch and continuous) and pour volumes. In these full-scale tests, each canister will contain an array of surrogate plutonium cans using canister internal configurations developed in FY98 and early FY99. The canisters will be instrumented to measure heating and cooling schedules. Glass filling behavior will be evaluated using both nondestructive analysis (e.g., radiography) and destructive analysis techniques. The FY99 scope includes procurement of rack and canister assembly components, fabrication of the canister assemblies, procurement of glass frit, instrumentation of the canisters, canister pours, nondestructive and destructive analysis of the canisters, data analysis and reporting.

In outyears, fabrication and testing of final canister configurations will be performed to support repository qualification activities. 
Canister Pour Analysis and Testing: Milestones

\begin{tabular}{|c|c|c|c|c|c|c|}
\hline \multicolumn{2}{|c|}{ Milestone } & \multirow{2}{*}{$\begin{array}{l}\text { Date } \\
7 / 98 \\
\end{array}$} & \multirow{2}{*}{$\begin{array}{c}\text { LLNL } \\
\bullet\end{array}$} & \multirow{2}{*}{$\begin{array}{c}\text { WSRC } \\
0\end{array}$} & \multirow[t]{2}{*}{ ANL } & \multirow[t]{2}{*}{ PNNL } \\
\hline FY98 & $\begin{array}{l}\text { Place preliminary limits on can number } \\
\text { and configurations }\end{array}$ & & & & & \\
\hline & $\begin{array}{l}\text { Complete design and plans for full-scale } \\
\text { canister experiments }\end{array}$ & $7 / 98$ & ○ & O & & \\
\hline & Make thermal evaluation of rack design & $9 / 98$ & ○ & & & \\
\hline \multirow[t]{2}{*}{ FY99 } & Complete test pours on can-in-canister assemblies & $6 / 99$ & O & - & & $\mathrm{O}$ \\
\hline & $\begin{array}{l}\text { Complete analysis of canisters/data reduction } \\
\text { and provide TDR input }\end{array}$ & $9 / 99$ & 0 & 0 & & \\
\hline
\end{tabular}

- Primary Responsibility

O Support Responsibility

Canister Pour Analysis and Testing: Total Budget (\$K)

\begin{tabular}{lrrrrrrrr} 
Site/Yr & FY98 & FY99 & FY00 & FY01 & FY02 & FY03 & FY04 & TOTAL \\
\hline LLNL & 195 & 200 & 100 & 100 & 0 & 0 & 0 & 595 \\
\hline WSRC & 10 & 670 & 100 & 800 & 0 & 0 & 0 & 1580 \\
\hline ANL & 0 & 0 & 0 & 0 & 0 & 0 & 0 & 0 \\
\hline PNNL & 0 & 50 & 25 & 25 & 0 & 0 & 0 & 100 \\
\hline LANL & 0 & 0 & 0 & 0 & 0 & 0 & 0 & 0 \\
\hline Total & $\mathbf{2 0 5}$ & $\mathbf{9 2 0}$ & $\mathbf{2 2 5}$ & $\mathbf{9 2 5}$ & $\mathbf{0}$ & $\mathbf{0}$ & $\mathbf{0}$ & $\mathbf{2 2 7 5}$ \\
\hline
\end{tabular}

\subsubsection{Canister Transport System}

Assembled canisters containing the immobilized plutonium cans require on-site transportation from the immobilization plant to the DWPF. It is envisioned that several assembled canisters will be shipped at a time to the DWPF. A transportation container will be required during shipment to provide physical protection and to meet site transportation requirements. Such a container does not currently exist.

This task will generate a concept and specifications for a system to transport the assembled canisters. This information will be transferred to the A/E for completion of the development followed by procurement of the transport vehicle. The transport system will consist primarily of the transportation container, although other supporting system peripherals are required. A preliminary safety analysis report and procedures may be required. 
Canister Transport System: Milestones

\begin{tabular}{lccccc} 
Milestone & Date & LLNL & WSRC & ANL & PNNL \\
\hline FY98 & & & & & \\
\hline FY99 & Provide concept design report and specifications & $9 / 99$ & & & \\
\hline
\end{tabular}

Canister Transport System: Total Budget (\$K)

\begin{tabular}{lrrrrrrrr} 
Site/Yr & FY98 & FY99 & FY00 & FY01 & FY02 & FY03 & FY04 & TOTAL \\
\hline LLNL & 0 & 0 & 0 & 0 & 0 & 0 & 0 & 0 \\
\hline WSRC & 0 & 50 & 0 & 0 & 0 & 0 & 0 & 50 \\
\hline ANL & 0 & 0 & 0 & 0 & 0 & 0 & 0 & 0 \\
\hline PNNL & 0 & 0 & 0 & 0 & 0 & 0 & 0 & 0 \\
\hline LANL & 0 & 0 & 0 & 0 & 0 & 0 & 0 & 0 \\
\hline Total & $\mathbf{0}$ & $\mathbf{5 0}$ & $\mathbf{0}$ & $\mathbf{0}$ & $\mathbf{0}$ & $\mathbf{0}$ & $\mathbf{0}$ & $\mathbf{5 0}$ \\
\hline
\end{tabular}

\subsubsection{DWPF Receipt and Handling}

This task will develop a concept for receiving and handling can-in-canister assemblies at the DWPF and for introducing these canisters to the DWPF melt cell. It will provide specifications for a system to safely remove the canisters from the transportation cask, handle the assembled canisters, and introduce the canisters to the DWPF melt cell.

DWPF Receipt and Handling: Milestones

\begin{tabular}{lccccc} 
Milestone & Date & LLNL & WSRC & ANL & PNNL \\
\hline FY98 & & & & \\
\hline FY99 & Provide concept design report and specifications & $9 / 99$ & & $\bullet$ & \\
\hline
\end{tabular}

DWPF Receipt and Handling: Total Budget (\$K)

\begin{tabular}{lrrrrrrrr} 
Site/Yr & FY98 & FY99 & FY00 & FY01 & FY02 & FY03 & FY04 & TOTAL \\
\hline LLNL & 0 & 0 & 0 & 0 & 0 & 0 & 0 & 0 \\
\hline WSRC & 0 & 100 & 0 & 0 & 0 & 0 & 0 & 100 \\
\hline ANL & 0 & 0 & 0 & 0 & 0 & 0 & 0 & 0 \\
\hline PNNL & 0 & 0 & 0 & 0 & 0 & 0 & 0 & 0 \\
\hline LANL & 0 & 0 & 0 & 0 & 0 & 0 & 0 & 0 \\
\hline Total & $\mathbf{0}$ & $\mathbf{1 0 0}$ & $\mathbf{0}$ & $\mathbf{0}$ & $\mathbf{0}$ & $\mathbf{0}$ & $\mathbf{0}$ & $\mathbf{1 0 0}$ \\
\hline
\end{tabular}




\subsection{PLANT EQUIPMENT TESTING AND DEMONSTRATIONS}

The successful completion of process and equipment development for the Plutonium Immobilization Project requires a well-planned integration of a number of stages of development and testing to support the design, acceptance, and operation of the new plant. This section of the report describes a ceramic process test facility to be built at Clemson University and the Integrated Plutonium Immobilization Test Facilities required at SRS to support the project.

The initial research and development activities for this project are being conducted at LLNL and SRTC laboratories. The objective is to obtain a thorough understanding of the ceramic form and the selection of suitable subscale and full-scale test equipment to evaluate the necessary process operations for making a qualified ceramic product. This work will culminate in fabrication tests of full-scale ceramic plutonium forms (pucks) using anticipated production process parameters in the Superblock Facility at LLNL in FY00/01. The test data resulting from this work is expected to provide the information necessary to form a firm baseline data package for the A/E performing the Title I and Title II design function in FY00/02.

As a necessary and logical follow-on to the hot ceramic form and process testing with sub-scale equipment in the Superblock, a ceramic process test facility will be established at the Clemson Environmental Technologies Laboratory (CETL) to perform full-scale testing of the ceramic system using surrogate materials and uranium to confirm and optimize the physical process operations.

Early in FY99, the record of decision will be made establishing a location for the Plutonium Immobilization Plant (presumably SRS, which is the preferred site). The Plutonium Immobilization Test Facilities (PITFs) at SRS will be reinitiated in FY00 to provide a smooth path for technology transfer to the Immobilization Plant. The SRS PITFs have two major elements: plutonium process chemistry (in 773-A) and equipment integration (in 246-F).

The 773-A PPSL will initiate an interface testing program for EM acceptance, validate the plutonium process chemistry and the product control model, and provide the downstream chemistry verification capability to support the operating facility. This lab will contain processing equipment to fabricate prototypic ceramic pucks as well as facilities and equipment to provide analytical support for materials characterization of the pucks.

The second major element of this capability is the IETF in 246-F. This facility will provide for pre-plant installation testing and automation/cycle testing and will evaluate the reliability, maintainability, and containment features to be installed in the operating facility. In addition, this facility will provide for operator training, operating procedure development, and operating plant process equipment verification and modification prior to installation during the production years. 


\subsubsection{Ceramic Process Test Facility}

This task will establish a full-scale ceramic system test capability at CETL to test integrated unit operations of powder feeding through pelletizing. This capability is needed to ensure that the as-designed plant equipment will effectively condition and press the actinide and precursor oxide powders in the configuration intended for the immobilization plant. Funding for work at CETL can readily be provided by subcontracts through the South Carolina Universities Research and Education Foundation (SCUREF). Past experiences with SCUREF contracts at Clemson have been very successful with rapid installation and start-up of facilities similar to that proposed here. Installation and operation at the CETL will be a cost-effective means of achieving full-scale confirmation of the ceramic formation system. Clemson Environmental Technologies Laboratory is an excellent facility with space available in a high bay area to locate the proposed vertical ceramic process line: it already has the necessary services. It is also licensed to handle sufficient quantities radioactive materials to perform this task and is staffed with a full-time health physicist. This facility, readily accessible to the public and the press, could be used to demonstrate the successful conversion of powder into sintered pucks.

Initial testing will be done with surrogates, followed by testing with uranium dioxide. Like the plant configuration, the ceramic process equipment development modules (e.g., powder feeding, milling, blending, granulating and pressing) will be interconnected into a prototypic ceramic test stack to validate many critical process/equipment design concepts developed at LLNL. Validation testing with full-scale prototypic ceramic equipment will confirm the physical process operations and greatly reduce schedule risk.

Incorporation of a full-scale uranium dioxide ceramic test stack from powder feeding through pelletizing will provide key data on equipment performance, feed handling, and product uniformity.

Feed handling will include the transfer of material between unit operations as well as an assessment of the quantity of material retained in the equipment. The retention of material in unit operations is a concern for accountability, criticality, and radiation dose assessments. The effects of feed variability on handling and product quality will also be evaluated. The operation of this facility for extended periods will provide a basis for predicting throughputs, product recycle requirements, and routine operating requirements (e.g., the lifetime of the grinding media and cold press dies). The module development tasks described previously will define, procure, and initially test key engineering-scale equipment for unit process operations based on initial lab-scale data in FY98-99. Funding for testing of the individual modules is included within module tasks. Only additional funding for the integration activities (e.g., facility preparation, equipment installation, and operations staffing) is included in this task.

In FY01 testing will be performed with surrogates. After the installation of containment, full-scale testing with uranium dioxide will begin in FY02.

The schedule and milestones for the Ceramic Process Test Facility at Clemson can be accelerated by six months if additional funding is made available in FY99. 
Ceramic Process Test Facility: Milestones

\begin{tabular}{llll} 
Milestone & Date & WSRC \\
\hline FY99 & Develop plan for Ceramic Process Test Facility & $9 / 99$ & \\
\hline FY00 & Modify Clemson facility & $1 / 00$ & \\
\hline & Procure processing equipment & $5 / 00$ & \\
\hline & Install processing equipment at Clemson & $9 / 00$ & \\
\hline FY01 & Design containment for processing equipment & $4 / 01$ & \\
\hline & Complete testing with surrogates & $9 / 01$ & \\
\hline & Input design modifications & $9 / 01$ & \\
\hline FY02 & Procure containment for Clemson & $10 / 01$ & \\
\hline & Install Clemson containment & $1 / 02$ & \\
\hline & Validate design and input design modifications & $3 / 02$ & \\
\hline & Complete testing with UO ${ }_{2}$ at Clemson & $9 / 02$ &
\end{tabular}

Primary Responsibility

O Support Responsibility

Ceramic Process Test Facility: Total Budget (\$K)

\begin{tabular}{lrrrrrrrr} 
Site/Yr & FY98 & FY99 & FY00 & FY01 & FY02 & FY03 & FY04 & TOTAL \\
\hline LLNL & 0 & 0 & 0 & 0 & 0 & 0 & 0 & 0 \\
\hline WSRC & 0 & 150 & 3900 & 1900 & 1500 & 0 & 0 & 7450 \\
\hline ANL & 0 & 0 & 0 & 0 & 0 & 0 & 0 & 0 \\
\hline PNNL & 0 & 0 & 0 & 0 & 0 & 0 & 0 & 0 \\
\hline LANL & 0 & 0 & 0 & 0 & 0 & 0 & 0 & 0 \\
\hline Total & $\mathbf{0}$ & $\mathbf{1 5 0}$ & $\mathbf{3 9 0 0}$ & $\mathbf{1 9 0 0}$ & $\mathbf{1 5 0 0}$ & $\mathbf{0}$ & $\mathbf{0}$ & $\mathbf{7 4 5 0}$ \\
\hline
\end{tabular}

Ceramic Process Test Facility: Equipment Budget (included above)

\begin{tabular}{lrrrrrrrr} 
Site/Yr & FY98 & FY99 & FY00 & FY01 & FY02 & FY03 & FY04 & TOTAL \\
\hline LLNL & 0 & 0 & 0 & 0 & 0 & 0 & 0 & 0 \\
\hline WSRC & 0 & 0 & 1300 & 800 & 0 & 0 & 0 & 2100 \\
\hline ANL & 0 & 0 & 0 & 0 & 0 & 0 & 0 & 0 \\
\hline PNNL & 0 & 0 & 0 & 0 & 0 & 0 & 0 & 0 \\
\hline LANL & 0 & 0 & 0 & 0 & 0 & 0 & 0 & 0 \\
\hline Total & $\mathbf{0}$ & $\mathbf{0}$ & $\mathbf{1 3 0 0}$ & $\mathbf{8 0 0}$ & $\mathbf{0}$ & $\mathbf{0}$ & $\mathbf{0}$ & $\mathbf{2 1 0 0}$ \\
\hline
\end{tabular}

If approved, the add-ons to the FY98 funding for glove box installation ( $\$ 225 \mathrm{~K}$ ) and process equipment procurement $(\$ 800 \mathrm{~K})$ will be removed from the FY00 budget. 


\subsubsection{Plutonium Process Support Laboratory}

The PPSL at SRS will demonstrate and validate the can-in-canister form/process by successfully producing repository qualifiable plutonium ceramic forms at SRS in advance of demonstration at the Immobilization Plant. The confidence of project stakeholders and regulators will be obtained through the demonstration of product control and repository qualification strategies. This demonstration will also facilitate technology transfer from LLNL to the SRS operating contractor for the product-critical ceramic process system. The PPSL will generate valuable operational data on first-stage immobilization for the production plant in the areas of process and product controls, plutonium process chemistry, radiation dose assessments, material accountability, and quality assurance. The PPSL may also be used in the future for feed variability testing, plant operations support and technical issue troubleshooting. Additionally, by taking the prototypic product through canister pouring in the DWPF, operational data on second-stage immobilization will be obtained in areas of safeguards and security, radiological controls, can-in-canister assembly handling, and canister glass pouring.

An important function of the PPSL will be to validate the PCM. Validation of the PCM is a requirement to qualify the process for hot start-up and operation in the plant. The form development activity (Section 2.3.4) will have provided the initial input to the PCM. Subsequently, the first-stage immobilization activity (Section 2.6.2) will have tested and refined the PCM using larger scale equipment. This validation in the PPSL at SRS will consist of fabrication tests of full-size ceramic forms using the feed and ceramic precursor input compositions and process conditions developed by the form development and first-stage development activities. The data from these product qualification tests will be used to set the technical specifications for plant operation and to provide validated data to SRS for the waste form qualification process; i.e., for the PIQR (Sections 1.3.2 and 2.4.3).

The fabrication of a prototypic plutonium loaded can-in-canister assembly and subsequent filling with high-level waste glass is planned to facilitate the resolution of several technical and institutional issues. Repository qualification and acceptance of plutonium loaded can-in-canister assemblies will be facilitated through an early can-in-canister demonstration by driving the waste acceptance process and resolving technical issues among MD, EM, and RW. Moreover, this early demonstration will provide the necessary confidence to EM and DWPF operations personnel that the plutonium immobilization mission will not adversely impact EM missions or DWPF operations. Safeguard and security issues regarding handling of the plutonium loaded can-in-canister assemblies, as well as the repository qualification of the plutonium ceramic forms, are important issues affecting the implementation of the can-in-canister concept. Use of prototypic plutonium ceramic forms in the can-in-canister demonstration will help resolve these technical issues and provide value to the immobilization program.

Work begun in FY98 on the PPSL will be brought to orderly closure and continued efforts will be deferred until FY00, after the ceramic process flowsheet and equipment are defined. In FY98, a shielded glove box to contain the process equipment was identified and removed for modification. This glove box will be placed in a secured location until the project is resumed. Several safety analyses (criticality, radiological shielding, environmental and process hazards) were initiated in FY98. These activities will be brought to closure to ensure that all data generated are documented and that the tasks can be readily resumed in FY00. 
In FY00, the safety analyses will be resumed and completed. Through a cooperative effort with LLNL personnel, the first-stage immobilization processing equipment and analytical support equipment will be specified and procured. The design for the process equipment glove box modifications will be finalized and the glove box modifications will be initiated. The analytical capability in the PPSL will consist of other glove boxes (containing equipment to section pucks), grind and polish metallographic samples, a metallograph (for microstructural characterization), and other sample preparation equipment. Once prepared, additional samples will be sent to existing SRTC facilities, such as the contained XRD and contained SEM. A metallograph bought for a discontinued project will be used in the PPSL, providing a cost-savings for the project.

In FY01 and outyears, cold testing of the first-stage immobilization processing equipment and qualification runs (i.e., demonstration of the product control methodology) will be completed, leading to hot start-up of the facility. It is anticipated that the prototypic plutonium ceramic forms will be produced in FY02 and the high level waste glass pour will be completed in the DWPF in late FY03.

\section{Plutonium Process Support Laboratory: Milestones}

\begin{tabular}{llll}
\multicolumn{2}{l}{ Milestone } & Date & WSRC \\
\hline FY00 & Complete process equipment specifications & $11 / 99$ & $\bullet$ \\
\hline & Complete glove box modification design & $1 / 00$ & $\bullet$ \\
\hline FY01 & Complete cold testing process equipment & $9 / 01$ & $\bullet$ \\
\hline FY02 & Complete qualification runs with surrogates & $2 / 02$ & $\bullet$ \\
\hline & Validate product control model with surrogates & $3 / 02$ & $\bullet$ \\
\hline & Complete plutonium ceramic processing for & $9 / 02$ & $\bullet$ \\
\hline FY03 & Provide input data to PIQR & $8 / 03$ & $\bullet$ \\
\hline & Complete DWPF can-in-canister pour & $9 / 03$ & $\bullet$ \\
\hline FY04 & Complete validation of PCM with plutonium & Provide final data to PIQR & $8 / 04$ \\
\hline
\end{tabular}

Plutonium Process Support Laboratory: Total Budget (\$K)

\begin{tabular}{lrrrrrrrr} 
Site/Yr & FY98 & FY99 & FY00 & FY01 & FY02 & FY03 & FY04 & TOTAL \\
\hline LLNL & 0 & 0 & 0 & 0 & 0 & 0 & 0 & 0 \\
\hline WSRC & 780 & 0 & 4500 & 5300 & 5500 & 1500 & 700 & 18280 \\
\hline ANL & 0 & 0 & 0 & 0 & 0 & 0 & 0 & 0 \\
\hline PNNL & 0 & 0 & 0 & 0 & 0 & 0 & 0 & 0 \\
\hline LANL & 0 & 0 & 0 & 0 & 0 & 0 & 0 & 0 \\
\hline Total & $\mathbf{7 8 0}$ & $\mathbf{0}$ & $\mathbf{4 5 0 0}$ & $\mathbf{5 3 0 0}$ & $\mathbf{5 5 0 0}$ & $\mathbf{1 5 0 0}$ & $\mathbf{7 0 0}$ & $\mathbf{1 8 2 8 0}$ \\
\hline
\end{tabular}


Plutonium Process Support Laboratory: Equipment Budget (included above)

\begin{tabular}{lrrrrrrrr} 
Site/Yr & FY98 & FY99 & FY00 & FY01 & FY02 & FY03 & FY04 & TOTAL \\
\hline LLNL & 0 & 0 & 0 & 0 & 0 & 0 & 0 & 0 \\
\hline WSRC & 0 & 0 & 2500 & 1800 & 2000 & 300 & 0 & 6600 \\
\hline ANL & 0 & 0 & 0 & 0 & 0 & 0 & 0 & 0 \\
\hline PNNL & 0 & 0 & 0 & 0 & 0 & 0 & 0 & 0 \\
\hline LANL & 0 & 0 & 0 & 0 & 0 & 0 & 0 & 0 \\
\hline Total & $\mathbf{0}$ & $\mathbf{0}$ & $\mathbf{2 5 0 0}$ & $\mathbf{1 8 0 0}$ & $\mathbf{2 0 0 0}$ & $\mathbf{3 0 0}$ & $\mathbf{0}$ & $\mathbf{6 6 0 0}$ \\
\hline
\end{tabular}

\subsubsection{Integrated Equipment Test Facility}

The IETF will provide several of the major capabilities that are necessary steps in the development of a first-of-kind, fully automated plutonium production facility. Initially, it will focus on pre-plant equipment integration and installation testing. This includes the integration of key unit operations fabricated at various vendor locations, but requiring a site location for full integration. Key systems will be tested. In the plutonium conversion area, the oxide fuel disassembly and decladding system and its material handling operation will undergo integration testing. The splitting and blending system, the puck handling system (from the press to can loading), and the can loading system in first-stage immobilization are also key systems requiring integration. These systems combine a need for unit operation development at the site with vendor fabrication/testing as available and, finally, integration in this test facility. These tests will validate the material handling automation design and/or provide extended cycle evaluation to confirm reliability of components prior to installation in the operating facility.

It has been the experience in commercial industry and at SRS and other DOE operating facilities that integrated mock-ups of plant scale systems have identified issues that could be revised/improved in a more cost-effective manner prior to initial installation in the operating plant. As with most equipment development, the initial work for each unit operation concentrates or focuses on development of a specific need. Integration brings into focus the entire system of equipment, glove boxes, and support systems, where many issues can be resolved by integrated tests and operator hands-on review. Moving from the designer view of necessary work station functionality to the more practical view of the plant operator and engineer delivers the most workable system and leaves fewer surprises at startup and greater reliability during operation.

The second important role of the IETF is the evaluation of system maintainability relative to applied automation and nuclear material containment. Plant equipment systems will be set up as designed and tests will be conducted by skilled operating and maintenance technicians to determine the feasibility of equipment repair and replacement. Enhancements to produce cost-effective modifications and minimize exposure to personnel will be recommended and implemented. 
A third feature or capability of the facility addresses the post-startup replacement of process equipment systems. Test cells will be built into the IETF to simulate important features (i.e., containment, support interface/ mating process unit interface) of the operating facility. With this feature, the IETF can duplicate the exact equipment replacement requirements both functionally and physically to demonstrate compatibility with the operating plant, make modifications as required, and plan the actual installation.

In FY00, an existing facility (246-F at SRS) will be modified to include the features necessary for conversion to the IETF capability.

In FY01 and FY02, integrated testing will commence, focusing on the key modules described above. For these modules, subsystems must be interfaced to determine full functionality and to validate automation and reliability. Valuable design input resulting from integration tests will provide verification and/or modification information to the final plant procured equipment system. In addition, the uranium dioxide ceramic stack undergoing manual process performance testing at Clemson will be evaluated for complete automation and cycle testing at the IETF. The IETF has a large open bay area suitable for testing of systems requiring extensive overhead space. One particular section includes a pit and would provide 80 feet of clear vertical space for testing the full-scale ceramic stack to be installed in the operating facility.

From FY03 until startup, integrated testing of process equipment systems delivered to the site for plant installation will commence. Validation data, including extended cycle tests where required, will provide any final changes necessary before installation in the operating facility. Operator interface with plant systems, including training and developing procedures for operation and maintenance, will be conducted.

In FY06 and beyond, the IETF will become a production support facility. The test facility will now provide for checkout/modifications for replacement equipment to be installed in the operating facility after startup. The IETF will serve the Plutonium Immobilization Plant just as the 717-F Facility has served the Canyons and DWPF for many years in checkout of equipment before installation. Exact physical plant features of key automated process systems will be built into the test facility so that pre-installation checkout and confirmation of critical physical features as well as operability of the unit operation can be verified prior to installation. Funds are budgeted in FY04 to procure and install these mock-up features. Key systems, where pre-testing would reduce the risk of extended downtime, are the oxide and metal feed preparation system, the ceramic process system, and the puck handling system. Details on the design features to be built into the test facility will be developed in late FY03. In addition, operator training and procedure development will be conducted with the goal of continuous enhancement of the operability of the facility. 
Integrated Equipment Test Facility: Milestones

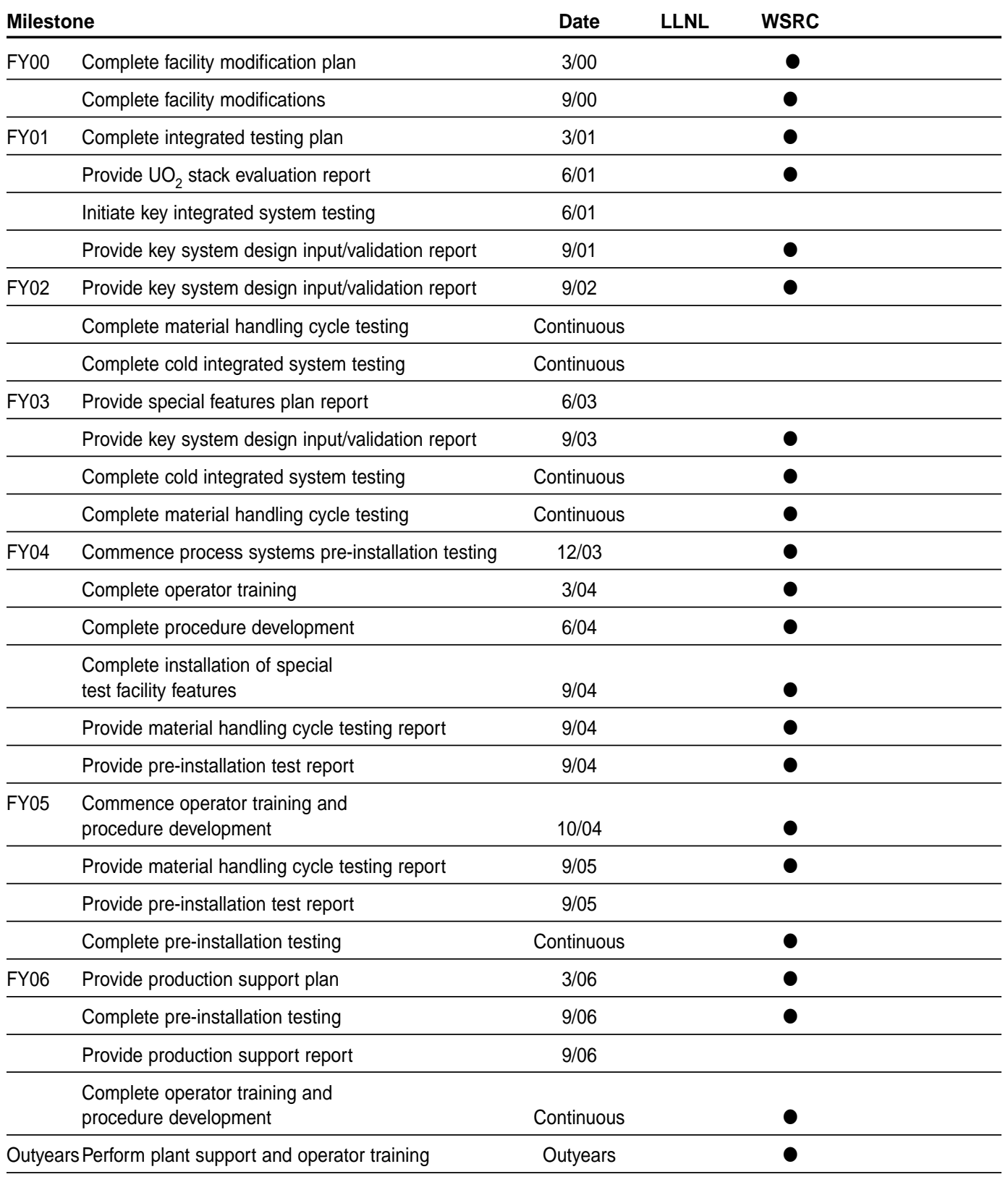


Integrated Equipment Test Facility: Total Budget (\$K)

\begin{tabular}{lrrrrrrrr} 
Site/Yr & FY98 & FY99 & FY00 & FY01 & FY02 & FY03 & FY04 & TOTAL \\
\hline LLNL & 0 & 0 & 0 & 0 & 0 & 0 & 0 & 0 \\
\hline WSRC & 0 & 0 & 800 & 2800 & 1800 & 1800 & 3700 & 10900 \\
\hline ANL & 0 & 0 & 0 & 0 & 0 & 0 & 0 & 0 \\
\hline PNNL & 0 & 0 & 0 & 0 & 0 & 0 & 0 & 0 \\
\hline LANL & 0 & 0 & 0 & 0 & 0 & 0 & 0 & 0 \\
\hline Total & $\mathbf{0}$ & $\mathbf{0}$ & $\mathbf{8 0 0}$ & $\mathbf{2 8 0 0}$ & $\mathbf{1 8 0 0}$ & $\mathbf{1 8 0 0}$ & $\mathbf{3 7 0 0}$ & $\mathbf{1 0 9 0 0}$ \\
\hline
\end{tabular}

Integrated Equipment Test Facility: Equipment Budget (included above)

\begin{tabular}{lrrrrrrrr} 
Site/Yr & FY98 & FY99 & FY00 & FY01 & FY02 & FY03 & FY04 & TOTAL \\
\hline LLNL & 0 & 0 & 0 & 0 & 0 & 0 & 0 & 0 \\
\hline WSRC & 0 & 0 & 500 & 1000 & 600 & 600 & 2500 & 5200 \\
\hline ANL & 0 & 0 & 0 & 0 & 0 & 0 & 0 & 0 \\
\hline PNNL & 0 & 0 & 0 & 0 & 0 & 0 & 0 & 0 \\
\hline LANL & 0 & 0 & 0 & 0 & 0 & 0 & 0 & 0 \\
\hline Total & $\mathbf{0}$ & $\mathbf{0}$ & $\mathbf{5 0 0}$ & $\mathbf{1 0 0 0}$ & $\mathbf{6 0 0}$ & $\mathbf{6 0 0}$ & $\mathbf{2 5 0 0}$ & $\mathbf{5 2 0 0}$ \\
\hline
\end{tabular}




\subsection{NATIONAL ENVIRONMENT POLICY ACT SUPPORT}

In FY98, the NEPA activity will provide a continuation of ongoing technical support for EIS and EIS ROM cost estimates. The ROM cost estimates (capital and operating) for constructing and operating immobilization plants at Hanford and SRS will support MD's ROD for site selection. Nine separate cost estimates are required: five estimates at Hanford, including co-location with MOX and PD\&C in the FMEF, and four estimates at SRS involving new and existing facilities. In addition, the EIS data call reports will be completed and support for DOE in completing the EIS and ROD will be continued.

National Environment Policy Act Support: Milestone

\begin{tabular}{lccccc} 
Milestone & Date & LLNL & WSRC & ANL & PNNL \\
\hline FY98 Complete ElS cost estimates & 2/98 & $\bullet$ & 0 & & \\
\hline
\end{tabular}

Primary Responsibility

O Support Responsibility

National Environment Policy Act Support: Total Budget (K\$)

\begin{tabular}{lrrrrrrrr} 
Site/Yr & FY98 & FY99 & FY00 & FY01 & FY02 & FY03 & FY04 & TOTAL \\
\hline LLNL & 350 & 0 & 0 & 0 & 0 & 0 & 0 & 350 \\
\hline WSRC & 25 & 0 & 0 & 0 & 0 & 0 & 0 & 25 \\
\hline ANL & 0 & 0 & 0 & 0 & 0 & 0 & 0 & 0 \\
\hline PNNL & 0 & 0 & 0 & 0 & 0 & 0 & 0 & 0 \\
\hline LANL & 0 & 0 & 0 & 0 & 0 & 0 & 0 & 0 \\
\hline Total & $\mathbf{3 7 5}$ & $\mathbf{0}$ & $\mathbf{0}$ & $\mathbf{0}$ & $\mathbf{0}$ & $\mathbf{0}$ & $\mathbf{0}$ & $\mathbf{3 7 5}$ \\
\hline
\end{tabular}




\subsection{DESIGN-ONLY CONCEPTUAL DESIGN REPORT}

The DOCDR subtask will provide a conceptual design of the immobilization plant and cost estimates for the preliminary and final design phases of the plant project. Also, an ROM estimate of the capital and operating costs for the plant will be developed. The basis of this conceptual design is an end-to-end process flowsheet. A nominal set of parameters covering material flows, balances, cycle times, and waste streams for all unit operations must be generated to determine the equipment list and appropriate sizing of equipment. A first-order equipment layout is developed using this information. These data, together with assessments of building/site utilities and services, provide the bases for estimating a schedule and cost for preliminary and detailed design. This task also provides for development of selected engineering and design data subsequent to the DOCDR. These data, identified but not developed in the DOCDR, will supplement the DOCDR information and be used to support the procurement package for the A/E selection.

\section{Design-Only Conceptual Design Report: Milestones}

\begin{tabular}{|c|c|c|c|c|c|}
\hline Miles & & Date & LLNL & WSRC & ANL \\
\hline FY98 & Provide DOCDR draft & $7 / 98$ & 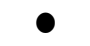 & 0 & \\
\hline & Provide final DOCDR & $9 / 98$ & 0 & $\mathrm{O}$ & \\
\hline FY99 & Provide supplemental $A / E$ procurement data & $3 / 99$ & - & 0 & \\
\hline
\end{tabular}

- Primary Responsibility

O Support Responsibility

\section{Design-Only Conceptual Design Report: Total Budget (\$K)}

\begin{tabular}{lrrrrrrrr} 
Site/Yr & FY98 & FY99 & FY00 & FY01 & FY02 & FY03 & FY04 & TOTAL \\
\hline LLNL & 725 & 200 & 0 & 0 & 0 & 0 & 0 & 925 \\
\hline WSRC & 500 & 200 & 0 & 0 & 0 & 0 & 0 & 700 \\
\hline ANL & 0 & 0 & 0 & 0 & 0 & 0 & 0 & 0 \\
\hline PNNL & 0 & 0 & 0 & 0 & 0 & 0 & 0 & 0 \\
\hline LANL & 0 & 0 & 0 & 0 & 0 & 0 & 0 & 0 \\
\hline Total & $\mathbf{1 2 2 5}$ & $\mathbf{4 0 0}$ & $\mathbf{0}$ & $\mathbf{0}$ & $\mathbf{0}$ & $\mathbf{0}$ & $\mathbf{0}$ & $\mathbf{1 6 2 5}$ \\
\hline
\end{tabular}


Appendix A

D\&T PROGRAM INTEGRATED SCHEDULE 


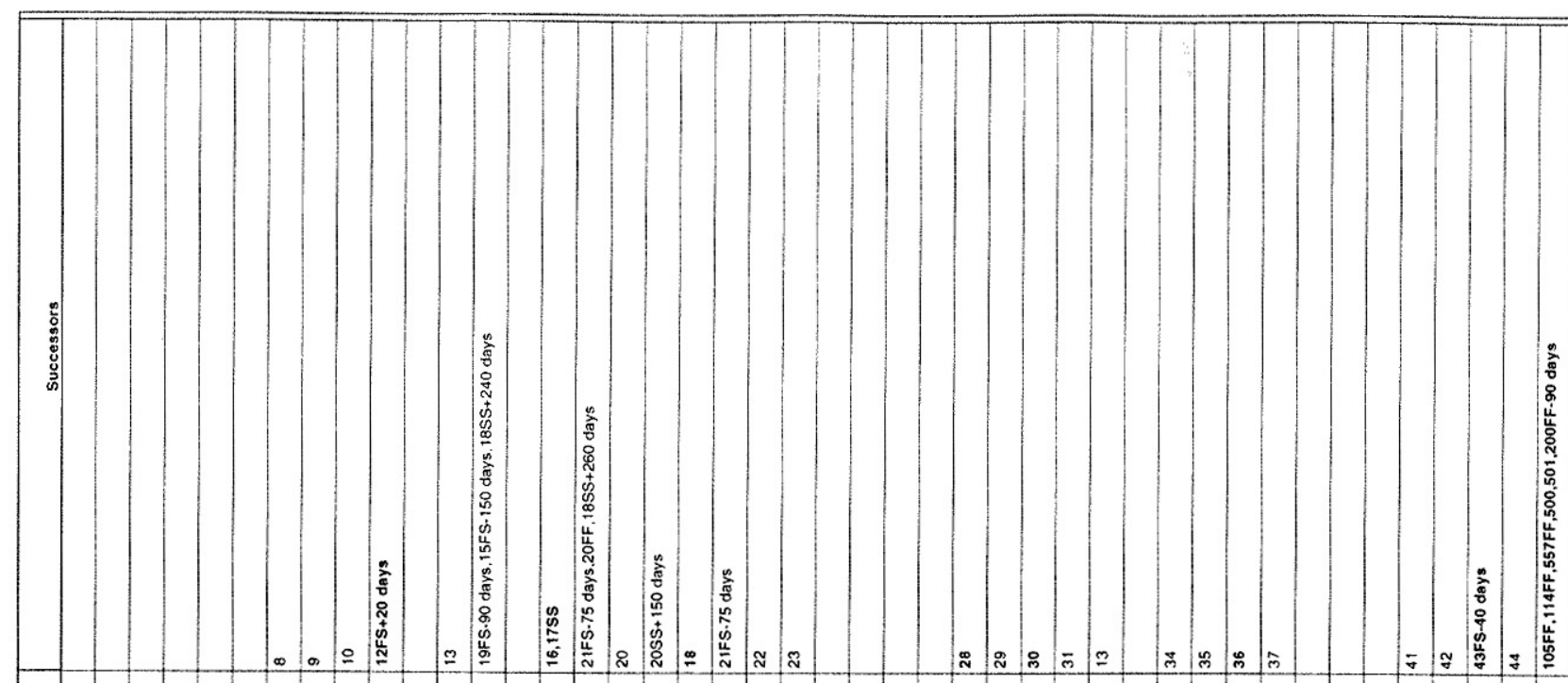

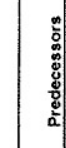

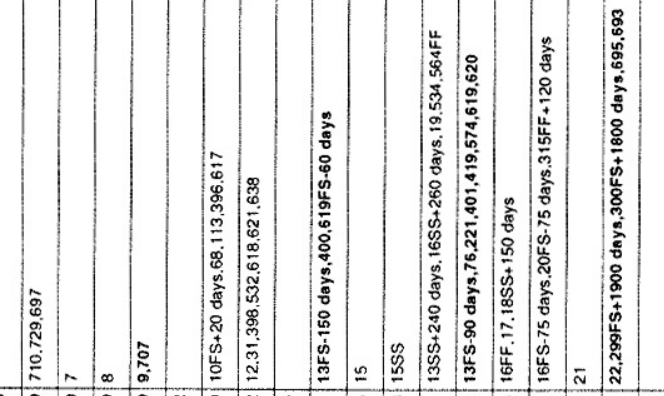

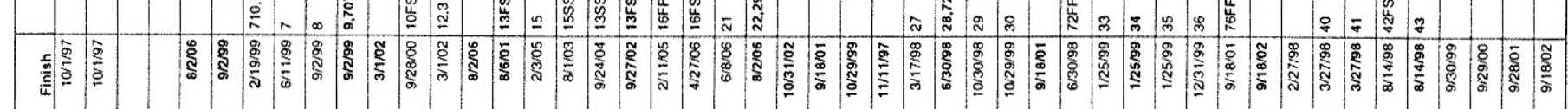

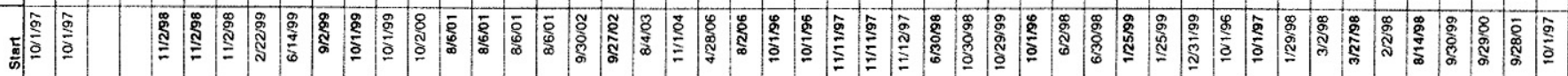

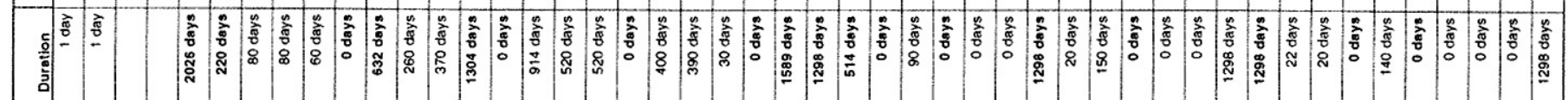
toun

:

(2)

:

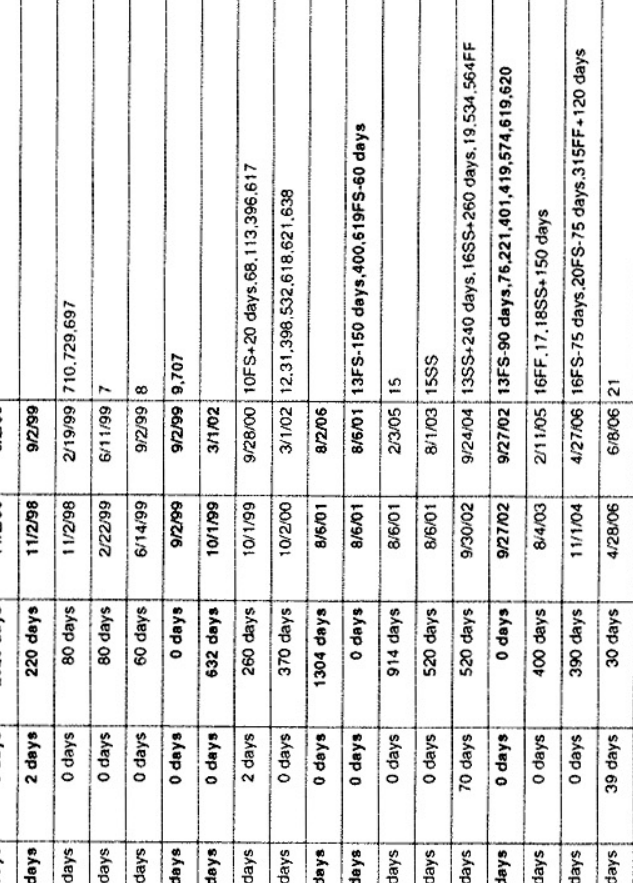

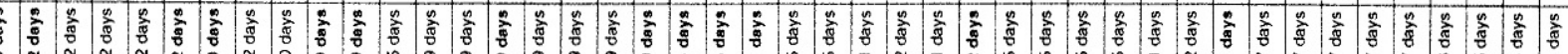
票 J

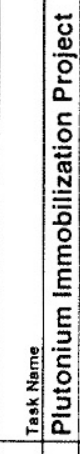
要
$\frac{2}{2}$

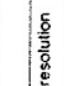

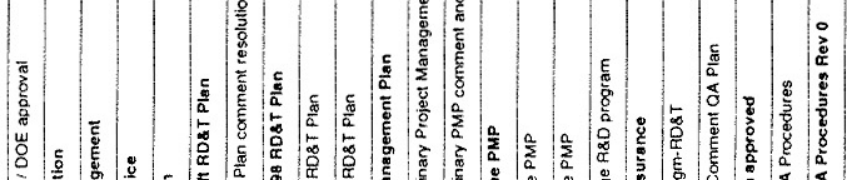

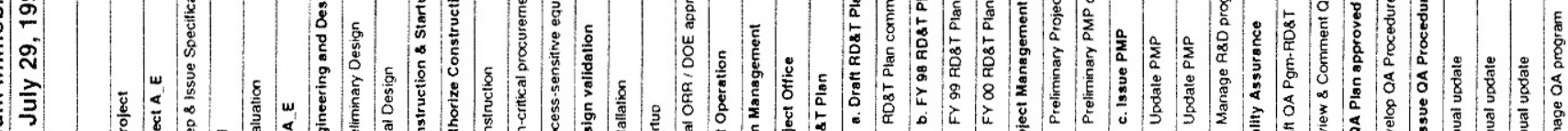

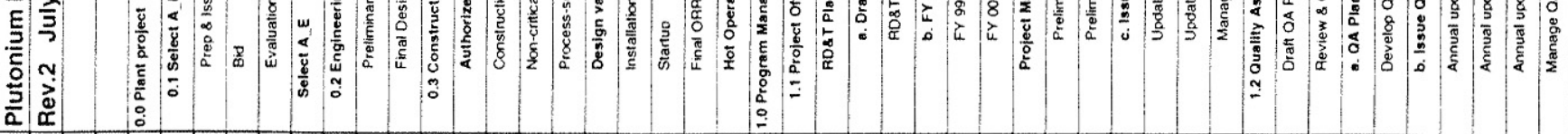

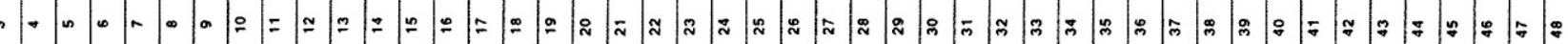

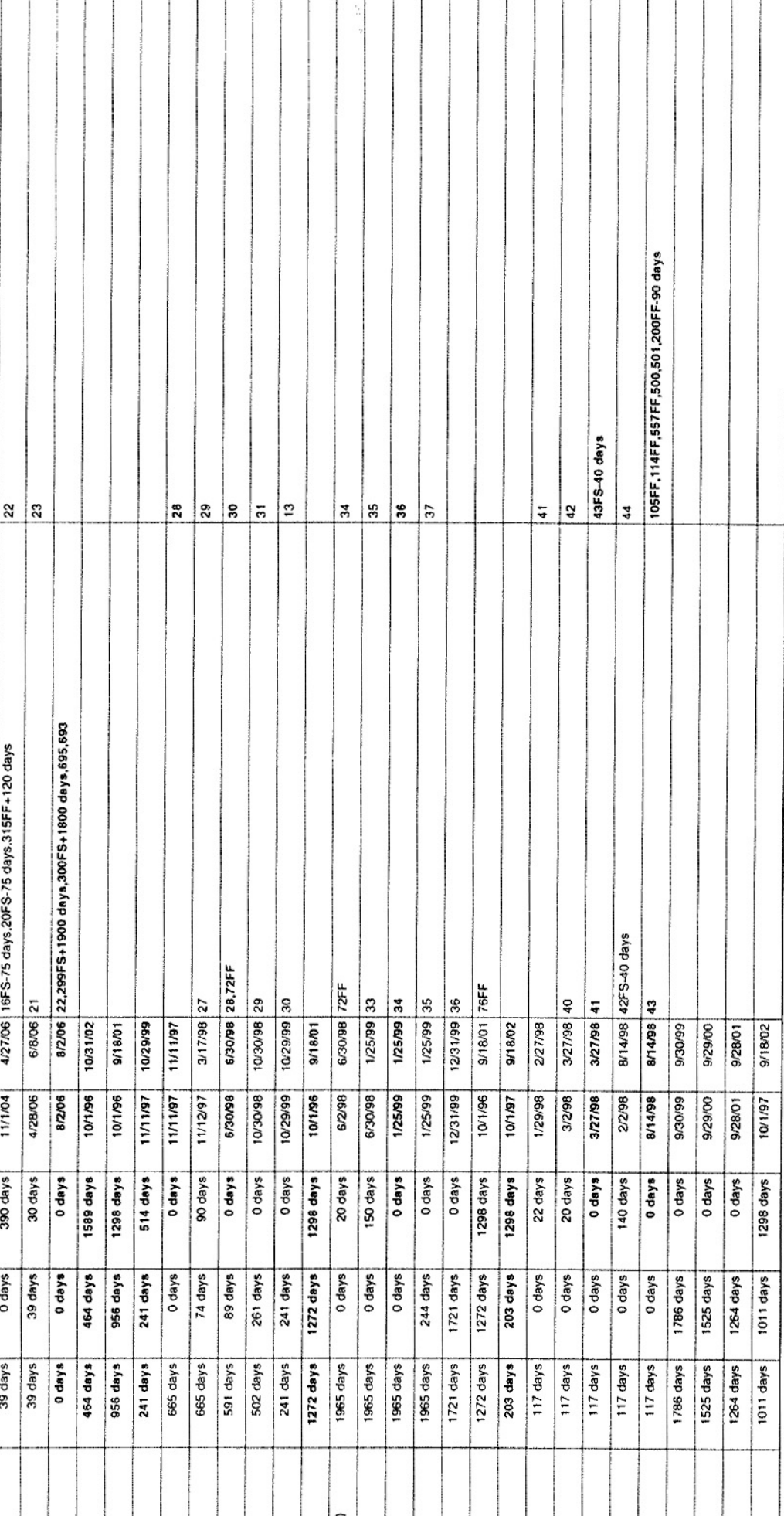




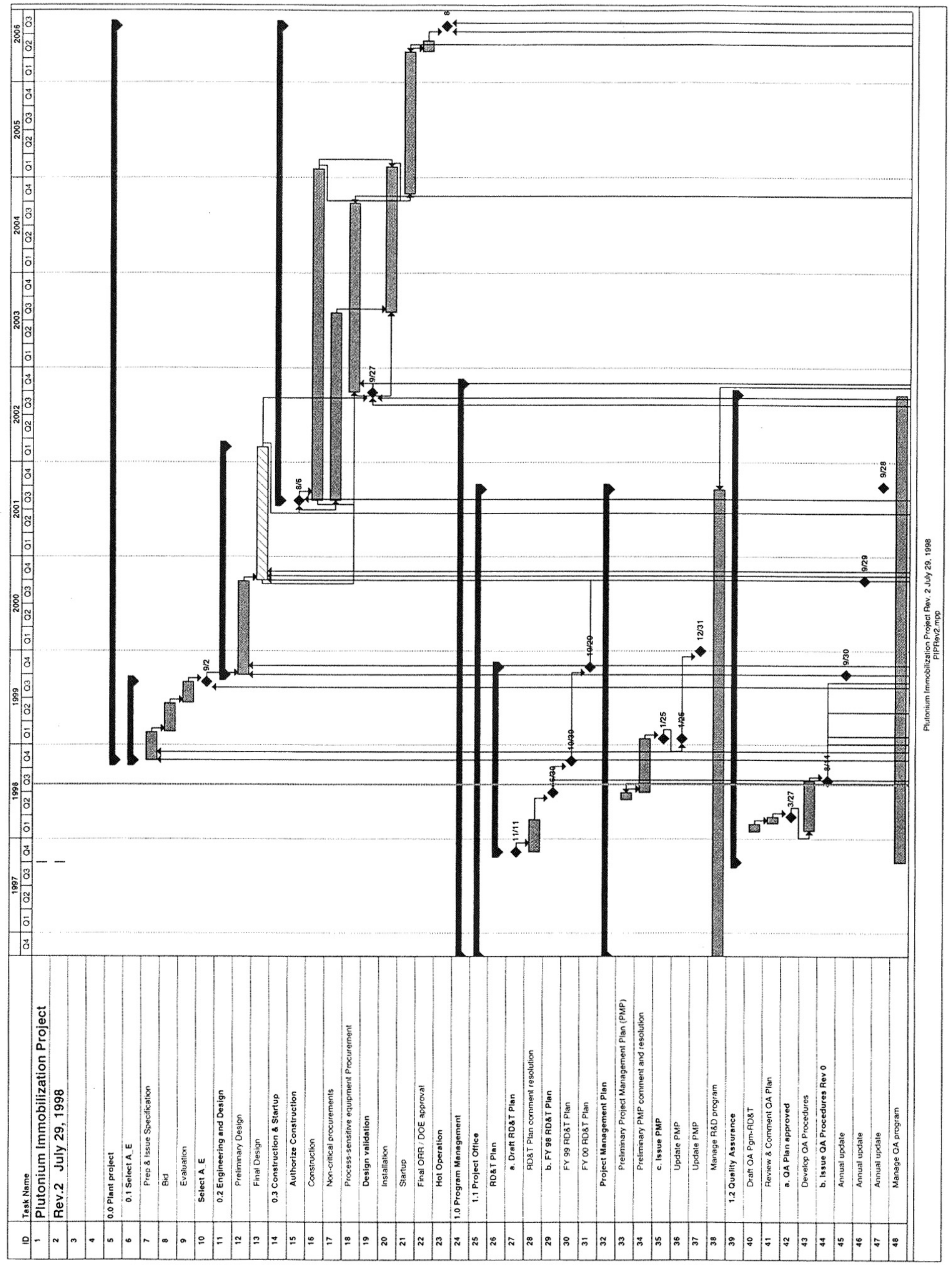


. . $2 \%$ $\mathscr{\infty}$ \begin{tabular}{|l|l|l}
$\infty$ & 8 \\
\hline
\end{tabular}

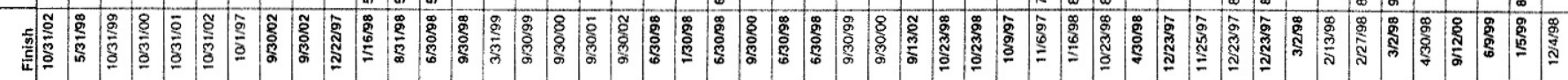

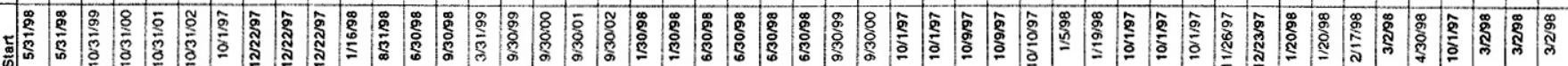

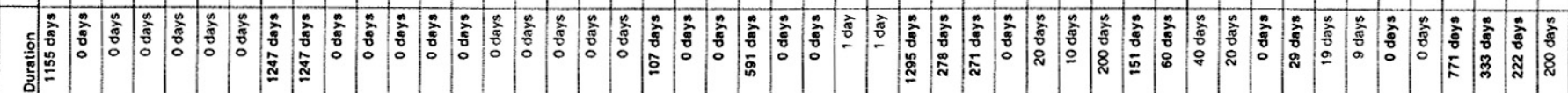

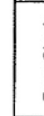

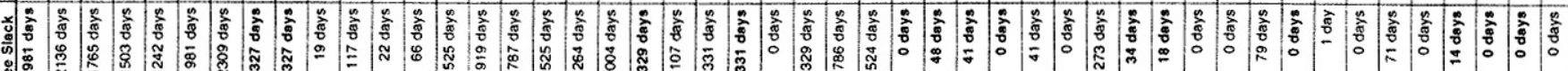

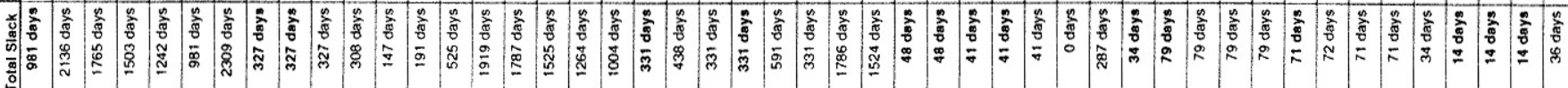

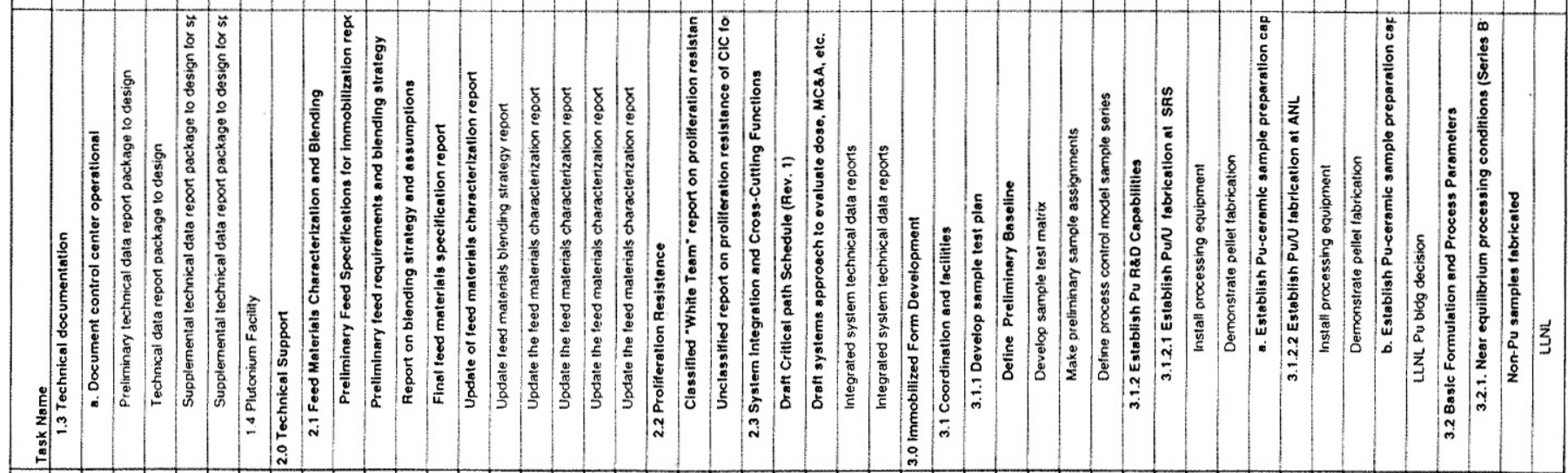




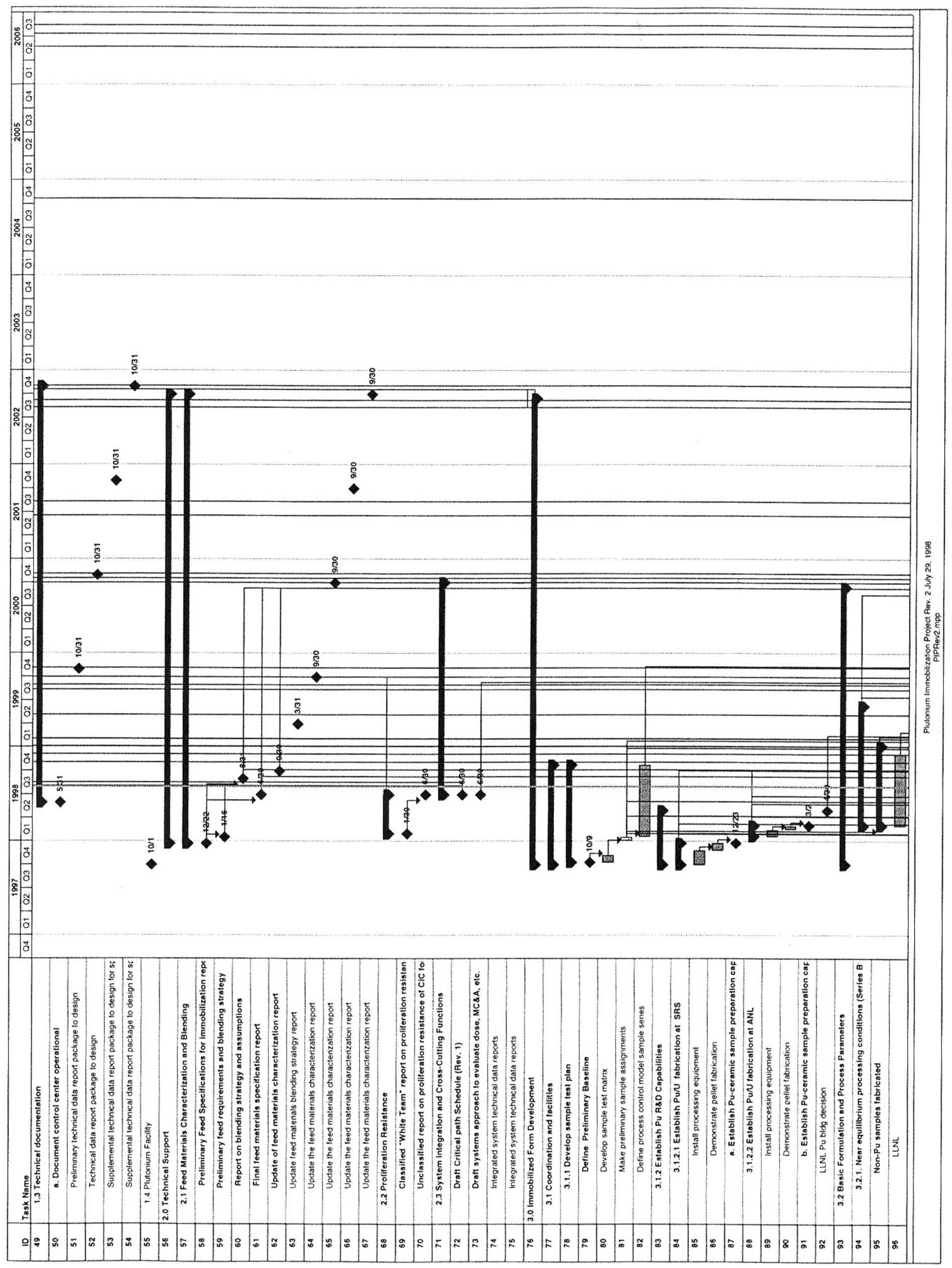




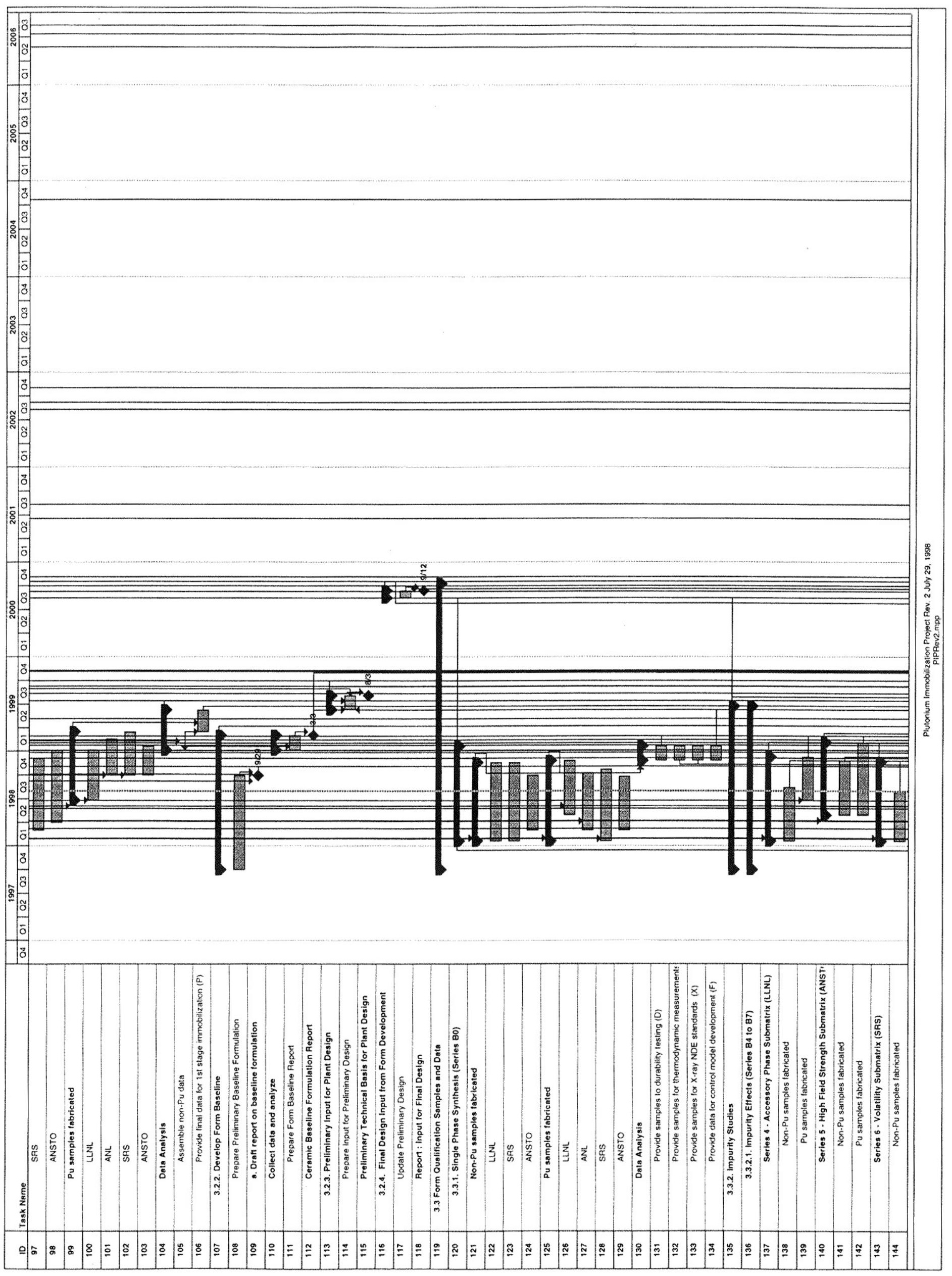




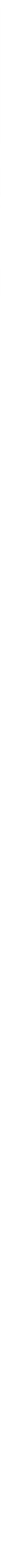





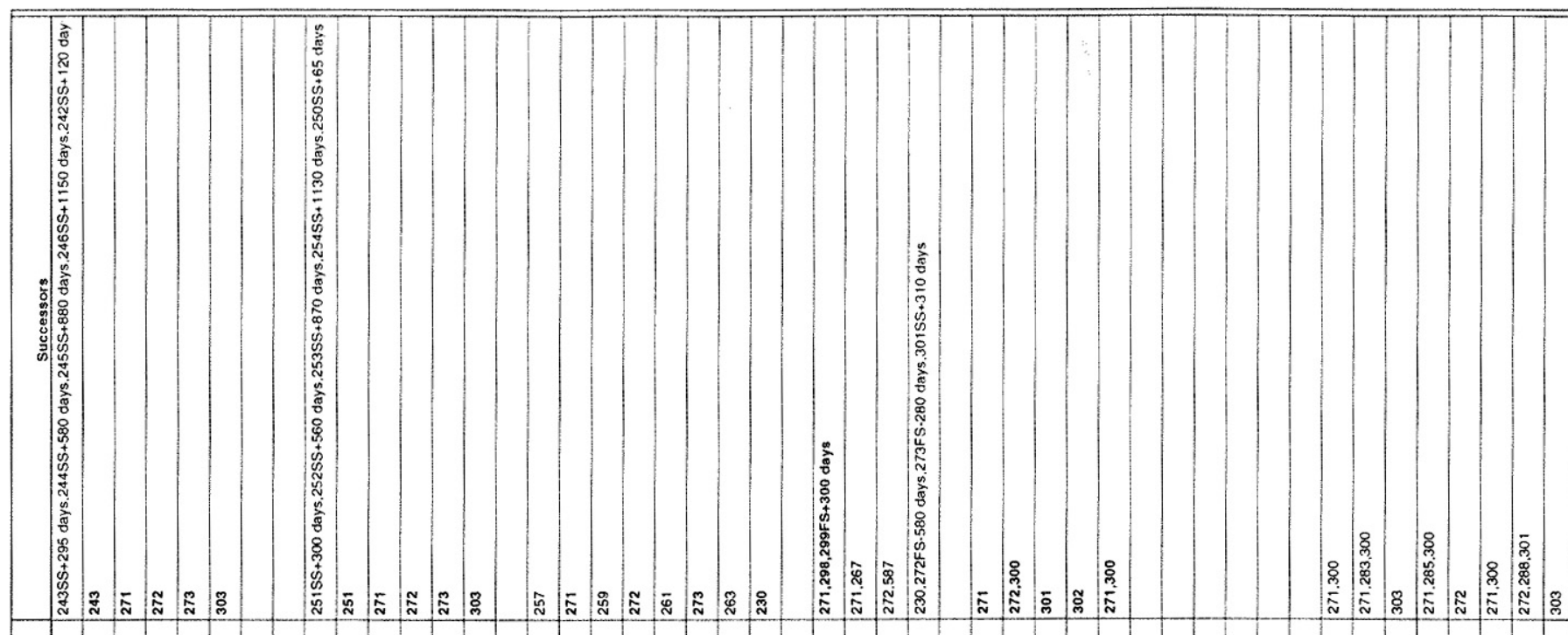




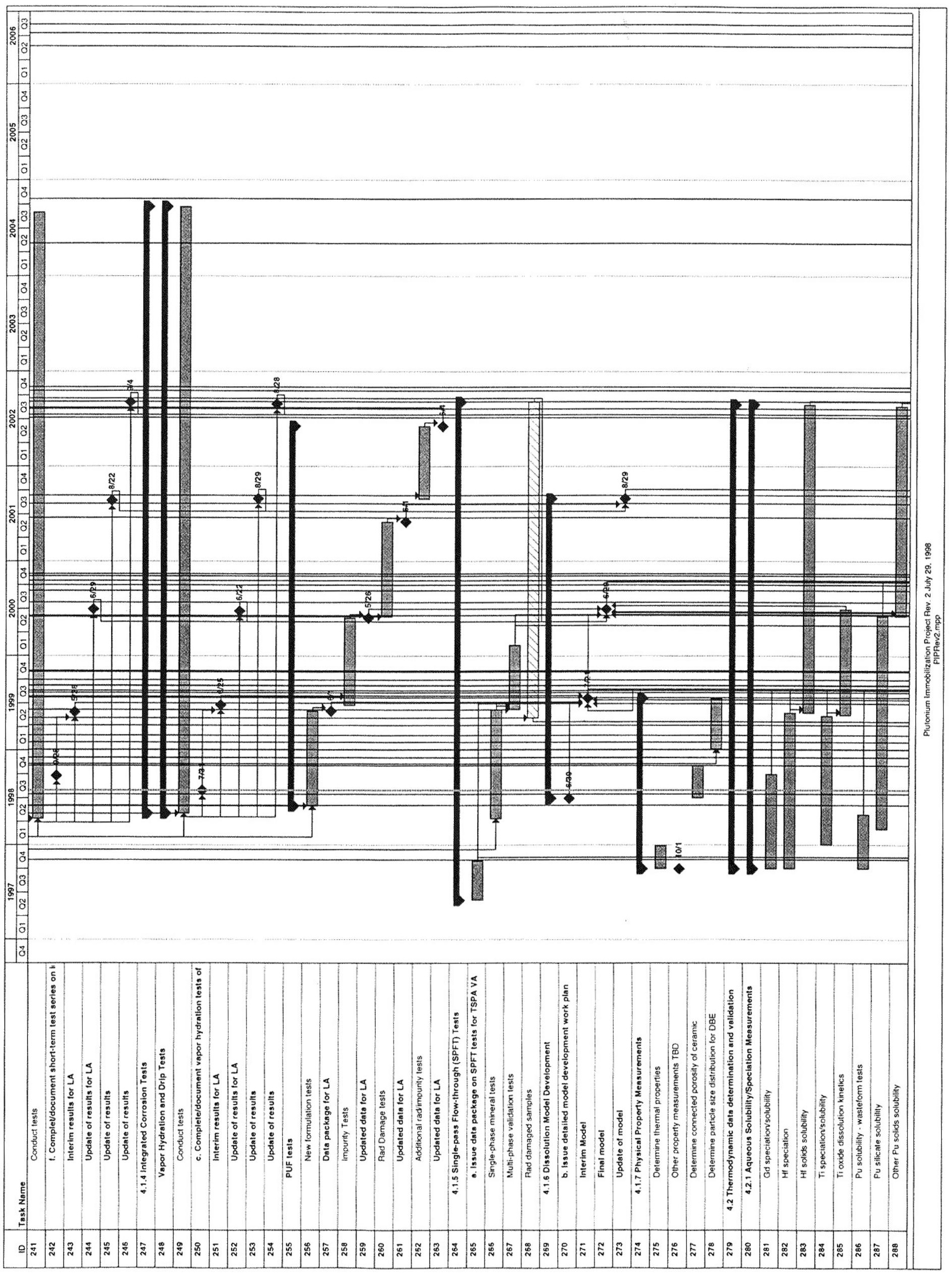




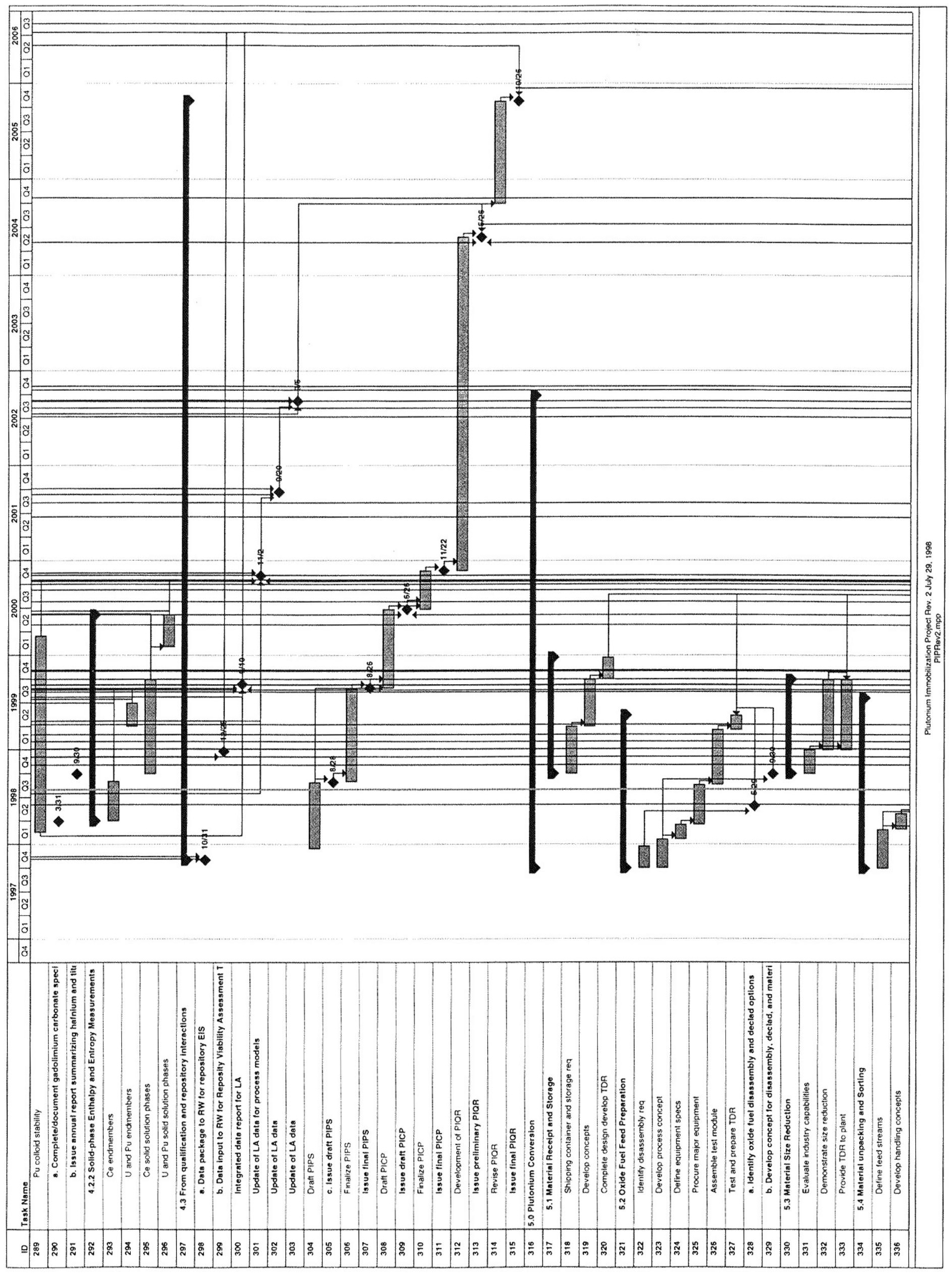




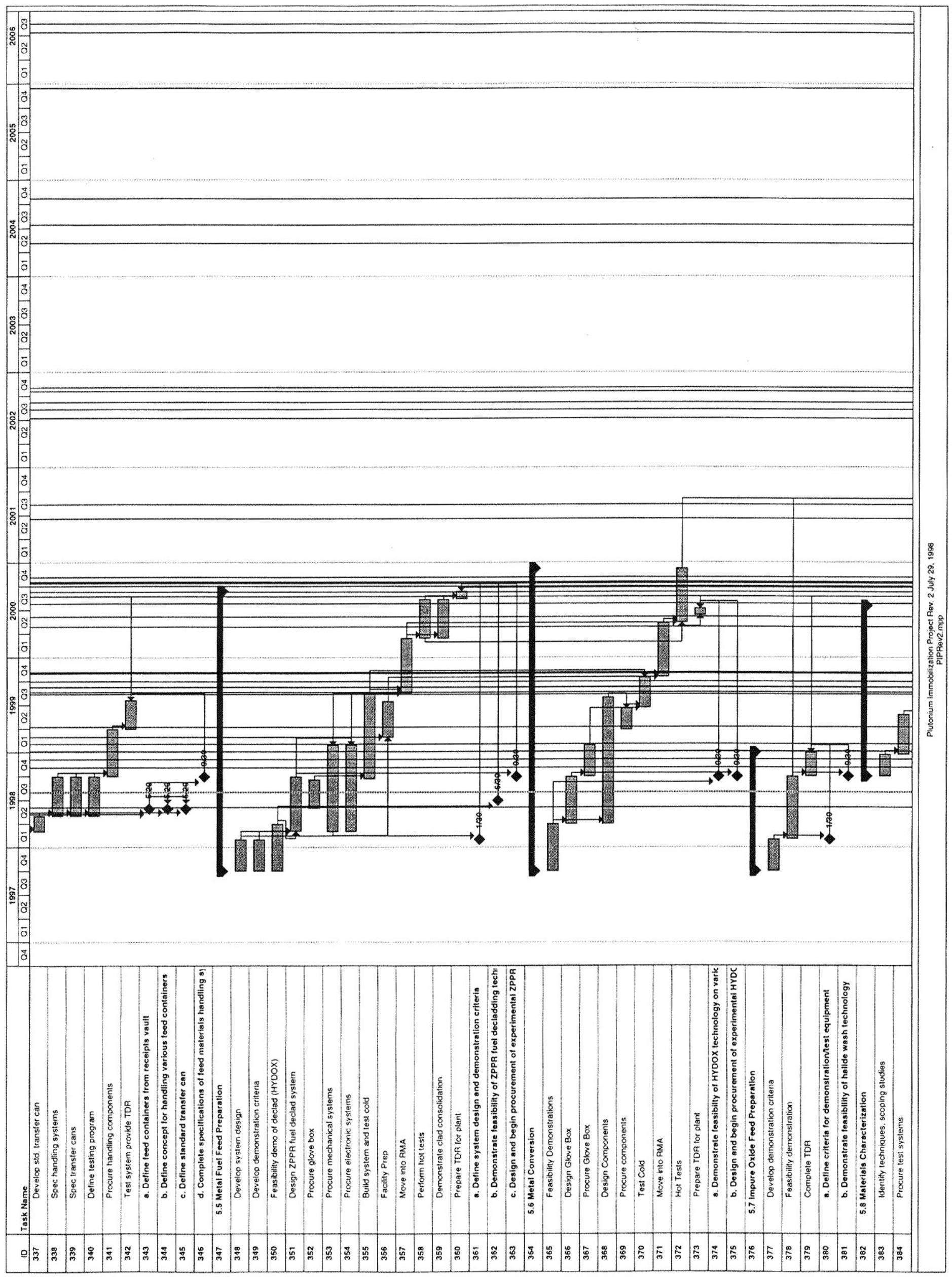




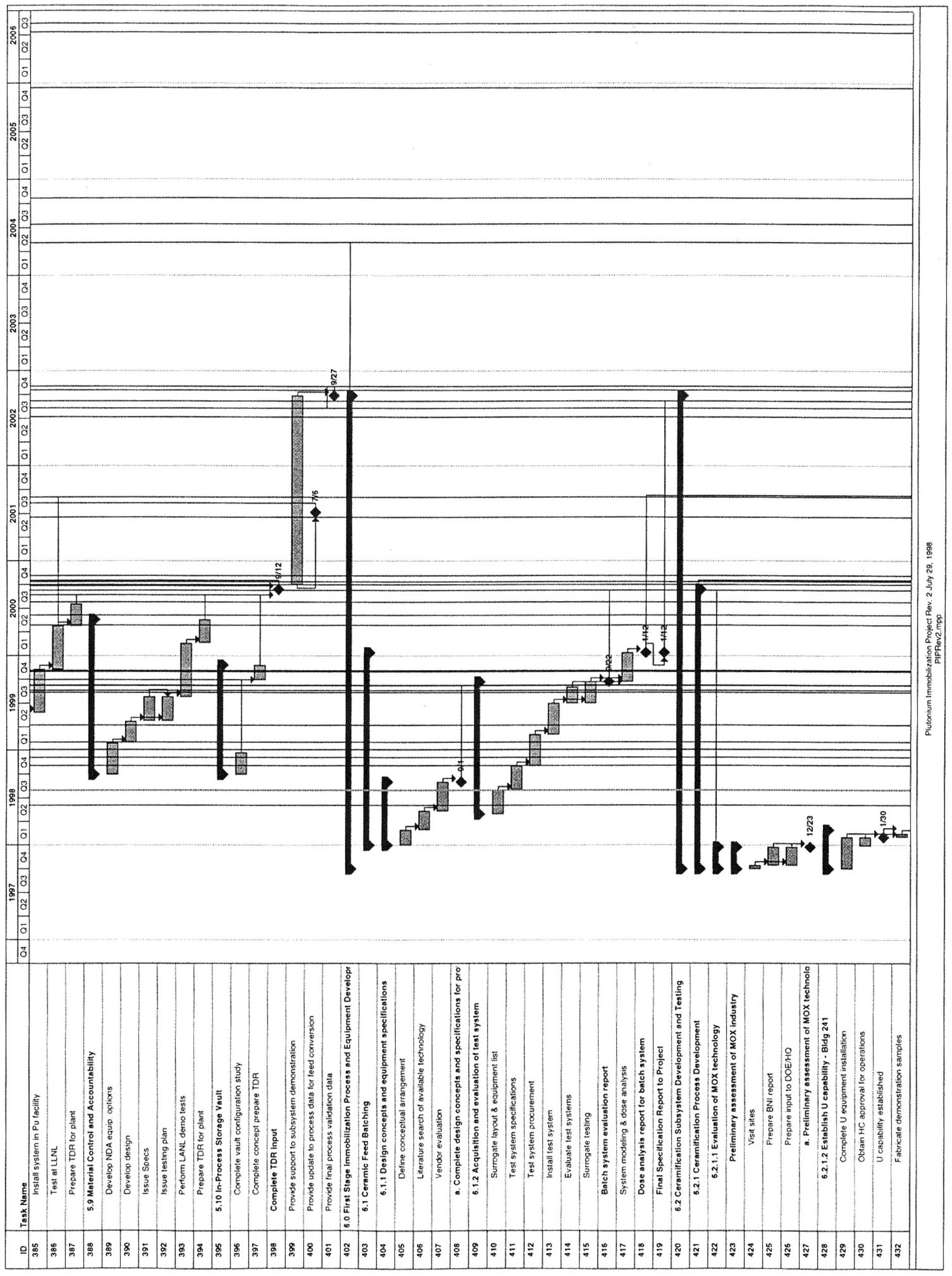




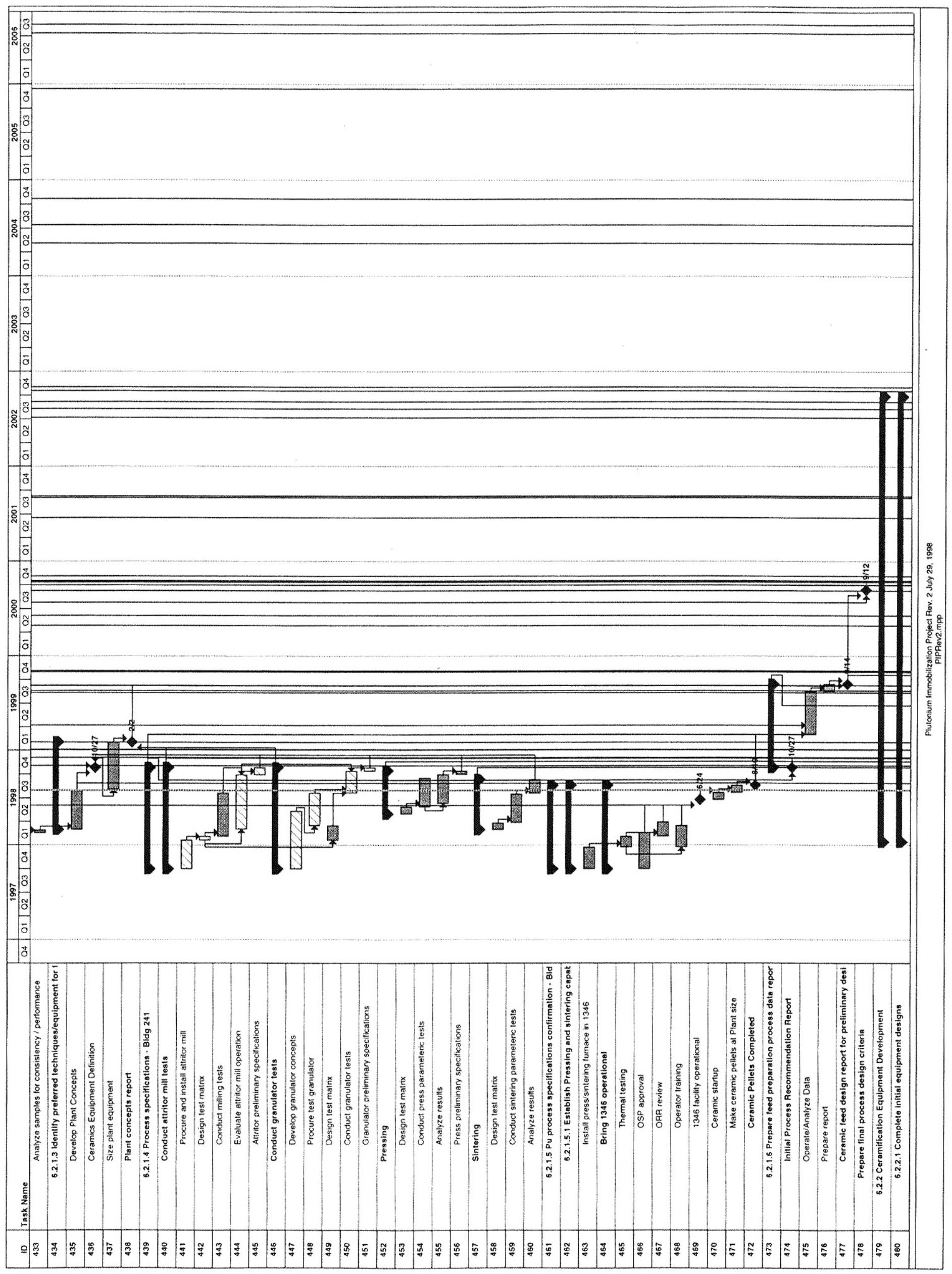




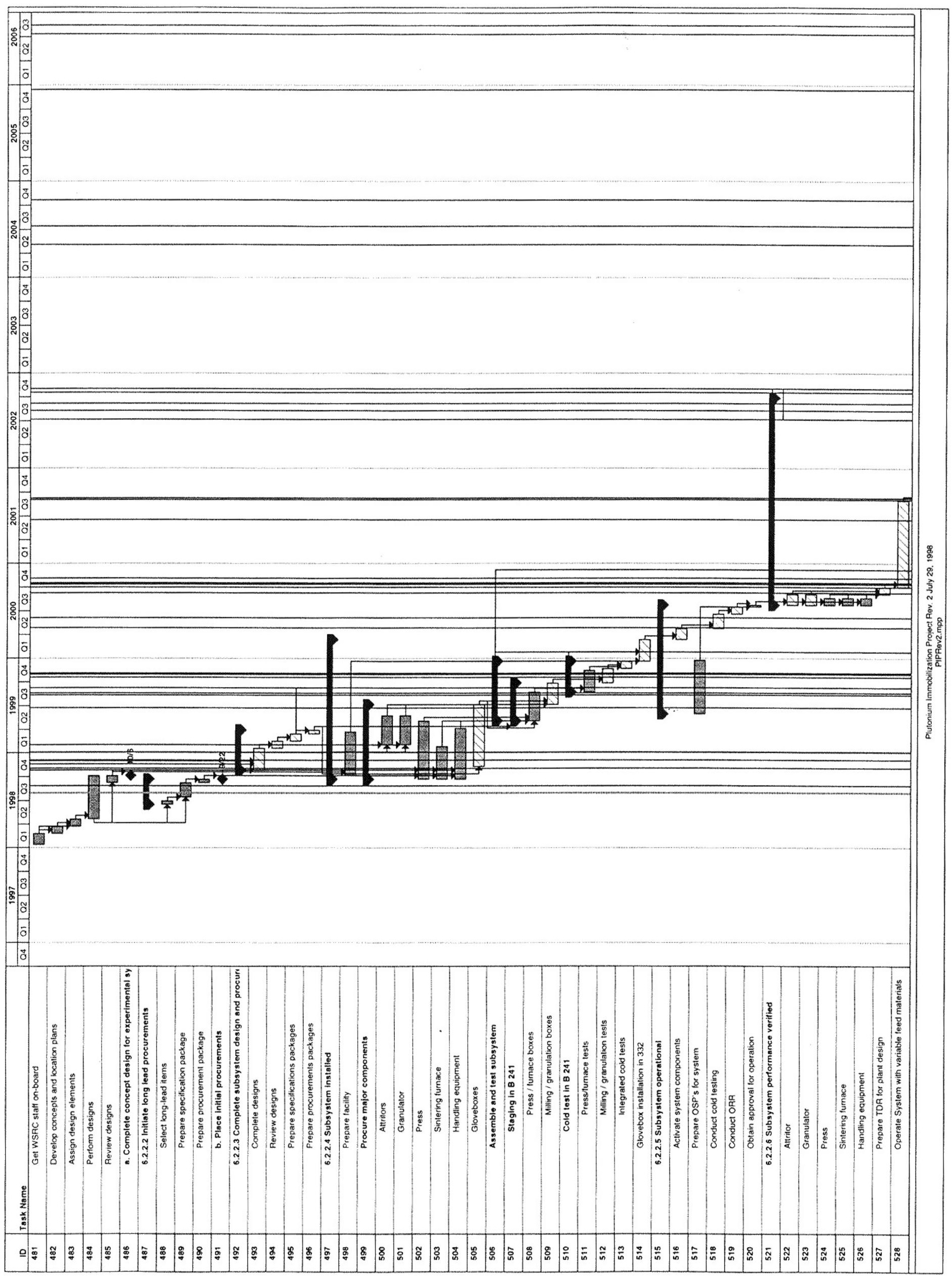





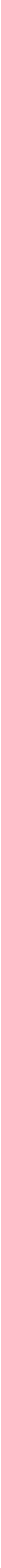




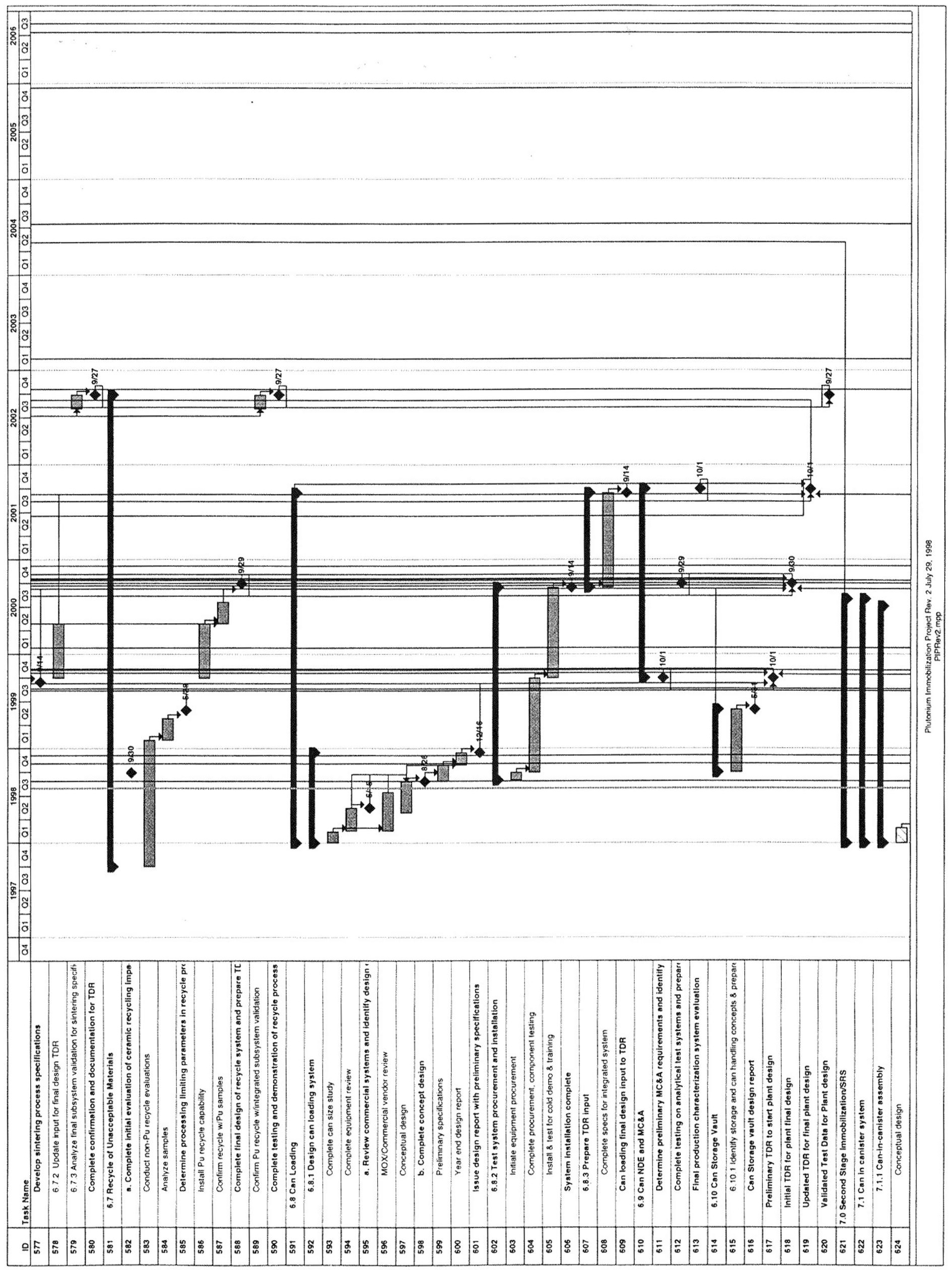





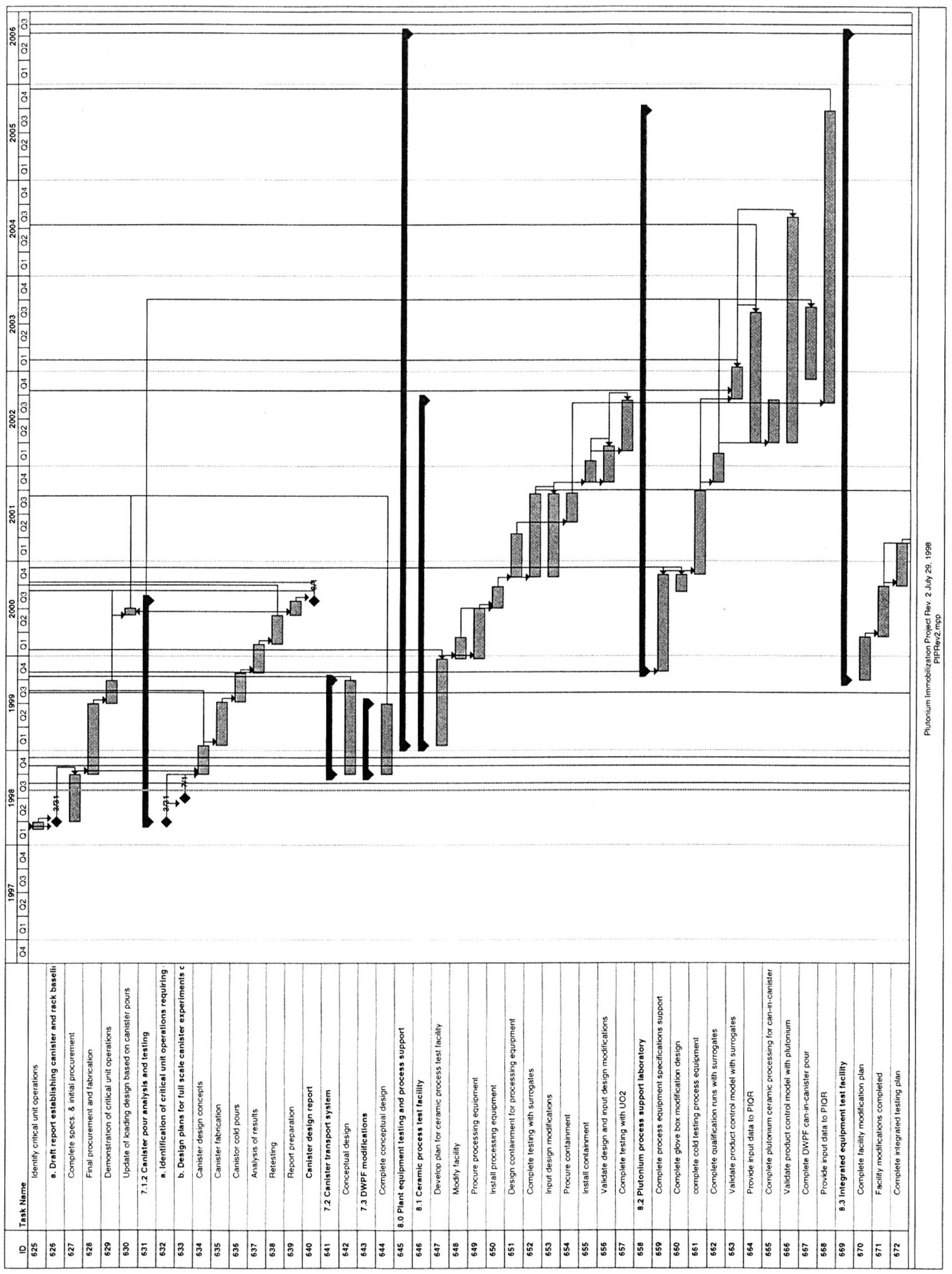




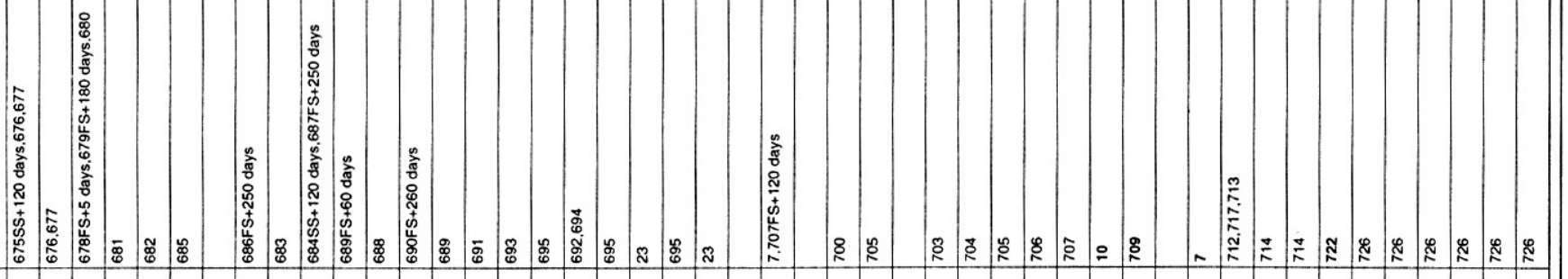

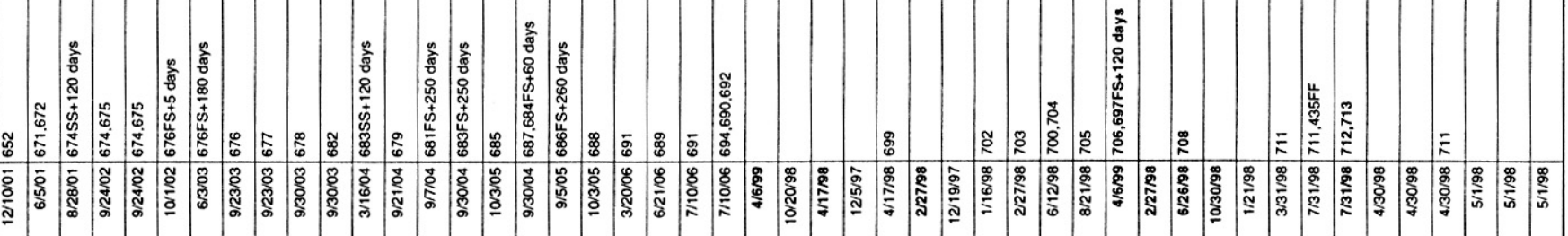

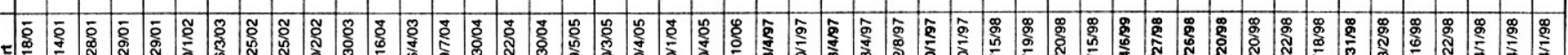

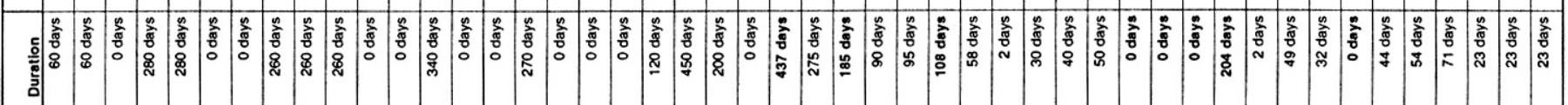
\begin{tabular}{|c} 
\\
\hline$\underline{a}$ \\
\hline$\underline{w}$
\end{tabular}

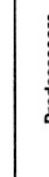
:

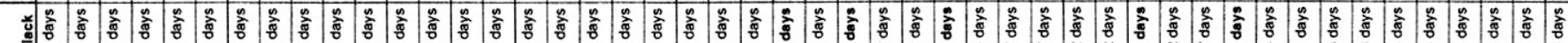

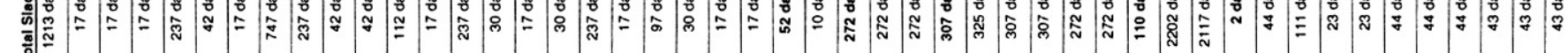

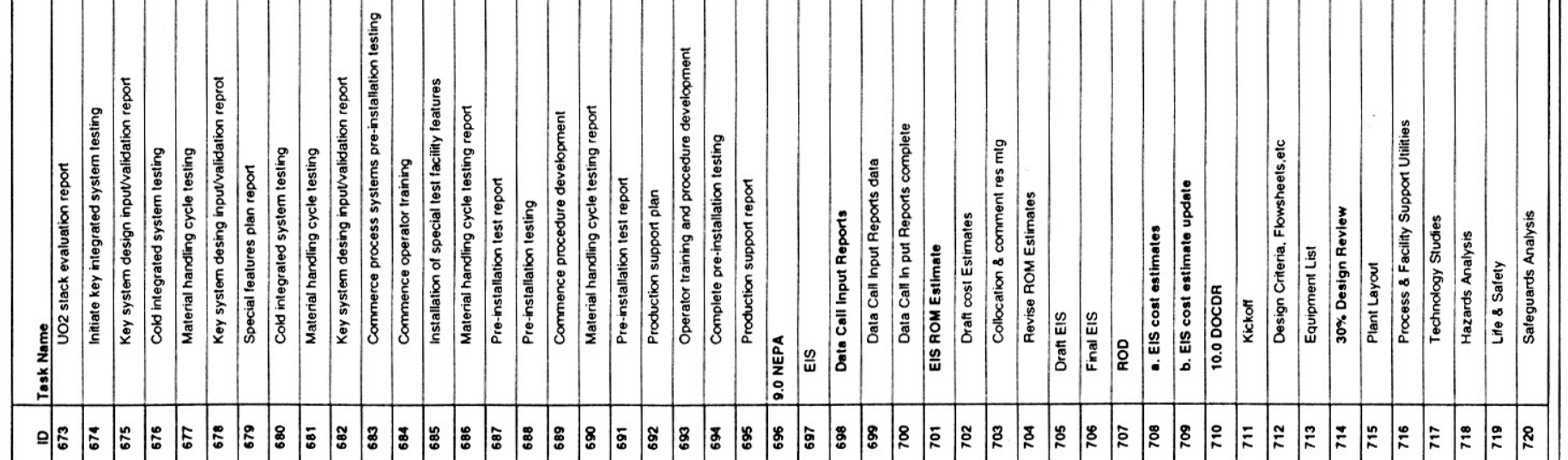




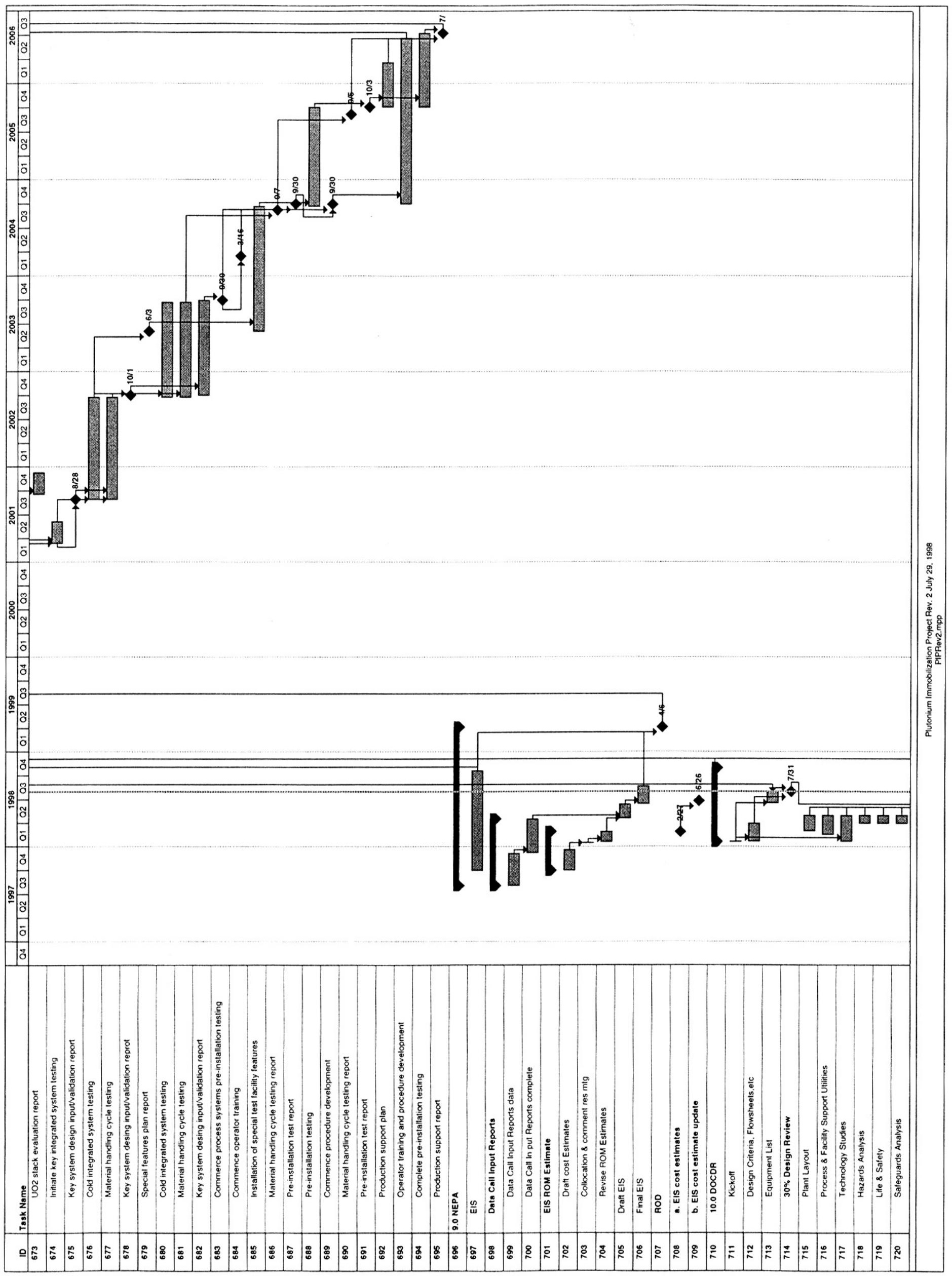




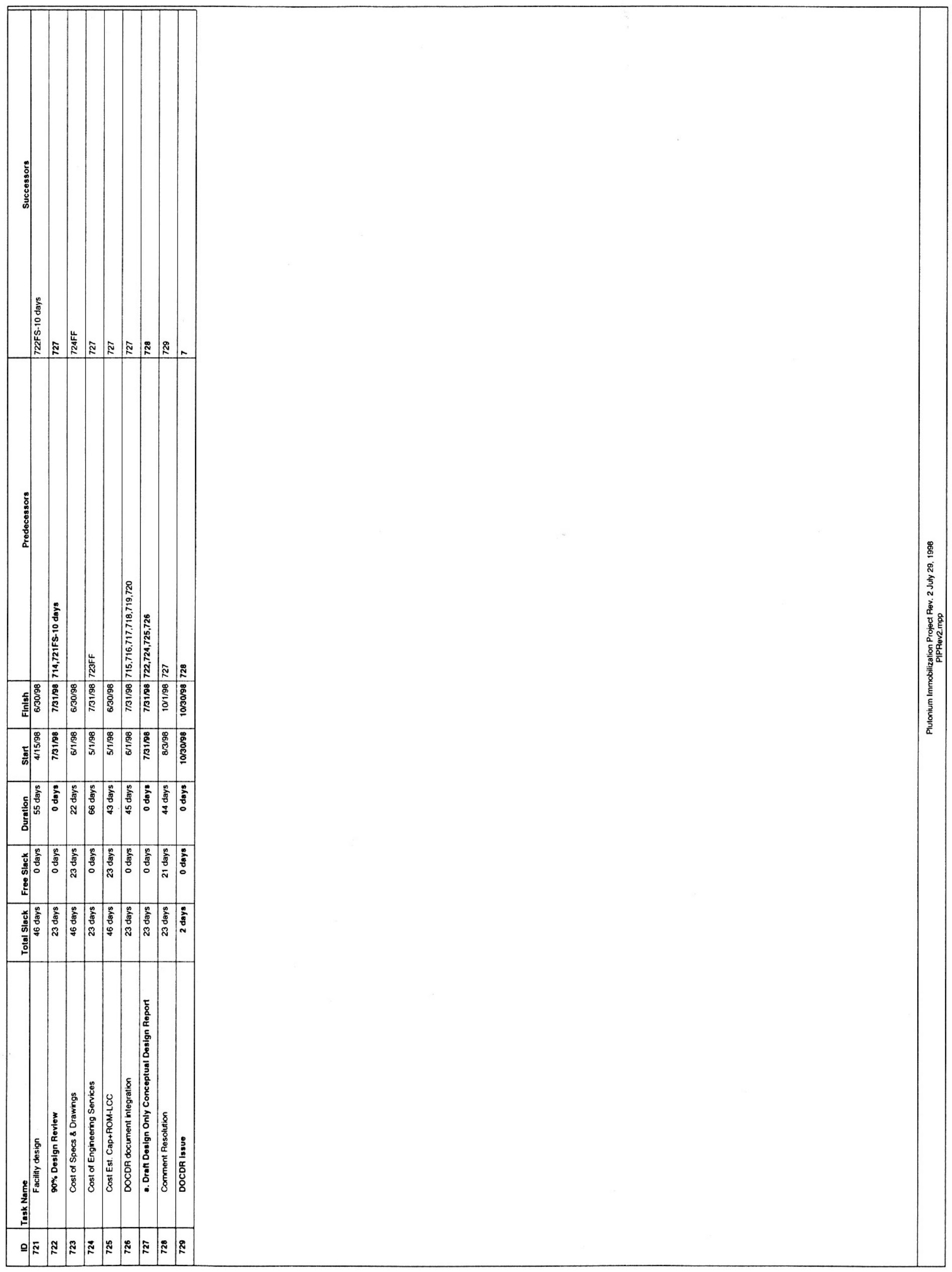




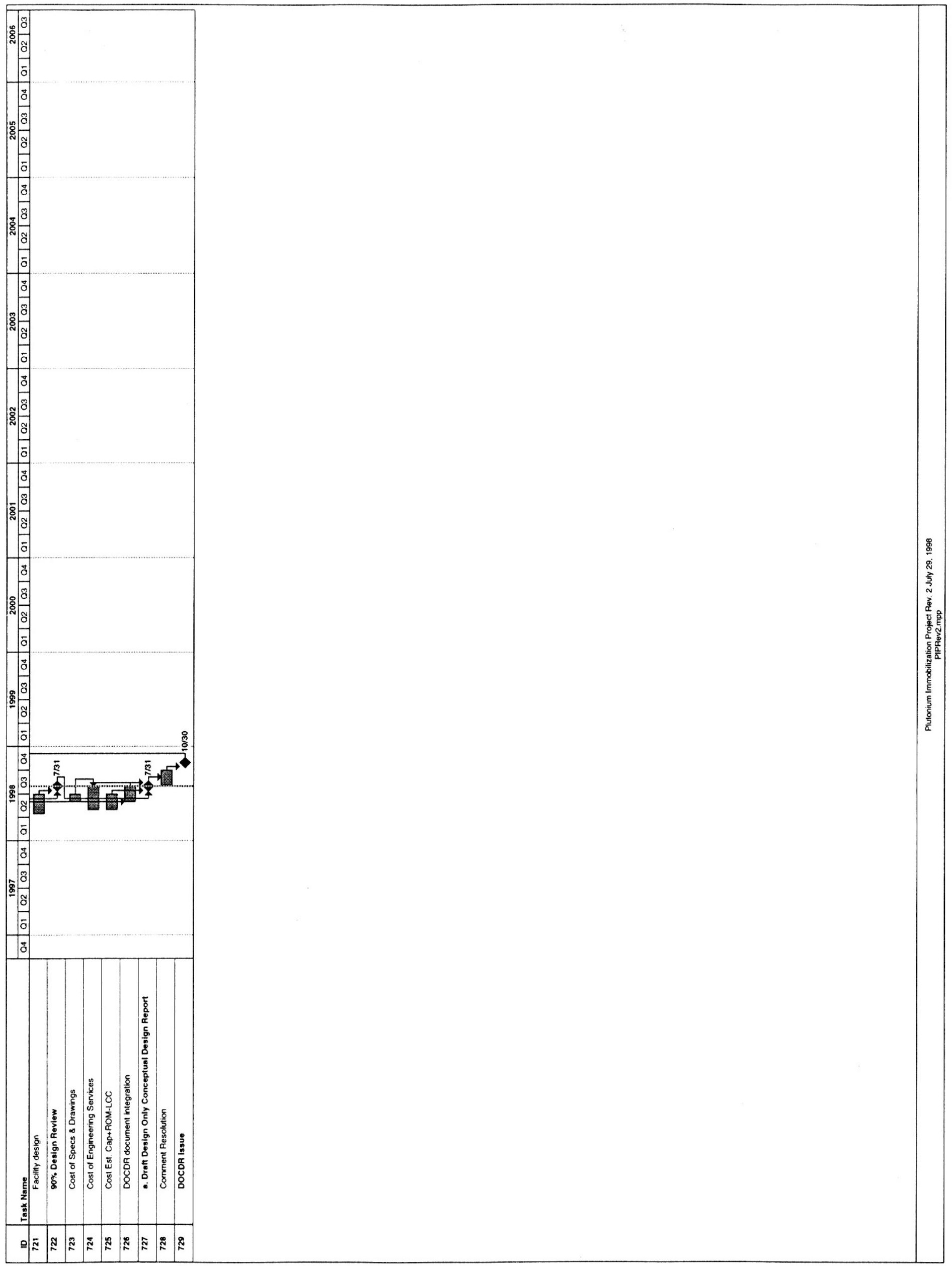


Appendix B

ACRONYMS \& ABBREVIATIONS 


\section{ACRONYMS \& ABBREVATIONS}

\begin{tabular}{ll} 
A/E & architect-engineer \\
Al & aluminum \\
Am & americium \\
ANL & Argonne National Laboratory \\
ANSTO & Australian National Science and Technology Organization \\
Ar & argon \\
ASTM & American Society for Testing and Materials, Philadelphia, Pennsylvania \\
BCP & baseline change proposal \\
BYU & Brigham Young University \\
Ca & calcium \\
Ce & cerium \\
CETL & the Clemson Environmental Technologies Laboratory \\
CIC & can-in-canister \\
C1 & chlorine \\
Cr & chromium \\
CRT & container restraint transport \\
CSNF & commercial spent nuclear fuel \\
D\&T & development and testing \\
DBE & design basis event \\
DIS & disposal interface specification \\
DNFSB & Defense Nuclear Facilities Safety Board \\
DOCDR & design-only conceptual design report \\
DOE & U.S. Department of Energy \\
DWPF & Defense Waste Processing Facility (at SRS) \\
EDS & energy dispersive spectrometry \\
EIS & Experimental Impact Statement \\
EM & Environmental Management \\
EMSP & Environmental Management Science Program \\
F & fluorine \\
Fe & iron \\
FFTF & Fast Flux Test Facility \\
\hline DE
\end{tabular}


FMEF Fuels and Materials Examination Facility

FSAR final safety analysis report

Ga gallium

GC General Council

Gd gadolinium

H hydrogen

Hf hafnium

HLW high level waste

HYDOX hydriding and oxidation

ICP/MS inductively coupled plasma-atomic emission spectroscopy

IETF Integrated Equipment Test Facility

K potassium

LA licensing application

LANL Los Alamos National Laboratory

LIBS laser-induced breakdown spectroscopy

LLNL Lawrence Livermore National Laboratory

MC\&A material control and accountability

MD DOE Office of Fissile Materials Disposition

Mg magnessium

MOA mem+orandum of agreement

MOX mixed oxide (fuel)

MT tonne (metric ton)

MTHM metric ton heavy metal

$\mathrm{Na} \quad$ sodium

NDA nondestructive assay

NDE nondestructive evaluation

NE Nuclear Energy

NEPA National Environmental Policy Act

NRC Nuclear Regulatory Commission

O oxygen

OCRWM Office of Civilian Radioactive Waste Management (RW)

ORR operational readiness review

PA performance assessment

PCM product control model

PCT product consistency test

PD\&C pit disassembly and conversion

PICP plutonium immobilization compliance plan

PIPS plutonium immobilization product specification

PIQR plutonium immobilization qualification report 


\begin{tabular}{|c|c|}
\hline PNNL & Pacific Northwest National Laboratory \\
\hline PPSL & Plutonium Process Support Laboratory (at SRS) \\
\hline PSAR & preliminary safety analysis report \\
\hline $\mathbf{P u}$ & plutonium \\
\hline PUF & pressurized unsaturated flow \\
\hline PUFT & pressurized unsaturated flow through \\
\hline QA & quality assurance \\
\hline QARD & quality assurance requirements and description \\
\hline $\mathbf{R}$ & roentgen \\
\hline redox & reduction oxidation \\
\hline RFETS & Rocky Flats Environmental Testing Site \\
\hline RMMA & Radiation Materials Management Area \\
\hline ROD & record of decision \\
\hline ROM & rough order of magnitude \\
\hline RW & Office of Civilian Radioactive Waste Management \\
\hline SAR & safety analysis report \\
\hline SCUREF & South Carolina Universities Research and Education Foundation \\
\hline SEM & scanning electron microscope \\
\hline SNF & spent nuclear fuel \\
\hline SNM & special nuclear material \\
\hline SPFT & single phase flow through \\
\hline SRS & Savannah River Site \\
\hline SRTC & Westinghouse Savannah River Company Technology Center \\
\hline SST & secure safe transport \\
\hline TBD & to be determined \\
\hline TDR & technical data report \\
\hline Ti & titanium \\
\hline TSPA & total system performance assessment \\
\hline TSPA-VA & total system performance assessment-viability assessment \\
\hline $\mathbf{U}$ & uranium \\
\hline $\mathrm{UO}_{2}$ & uranium dioxide \\
\hline $\mathbf{V}$ & vanadium \\
\hline VA & viability assessment \\
\hline VHT & vapor hydration test \\
\hline WAC & waste acceptance criteria \\
\hline WASRD & Waste Acceptance Systems Requirement Document \\
\hline WCP & waste compliance plan \\
\hline WF & waste form \\
\hline WP & waste package \\
\hline
\end{tabular}




$\begin{array}{ll}\text { WSRC } & \text { Westinghouse Savannah River Company } \\ \text { XRD } & \text { x-ray diffraction } \\ \text { XRF } & \text { x-ray fluorescence } \\ \text { YM } & \text { Yucca Mountain } \\ \text { Zn } & \text { zinc } \\ \text { Zr } & \text { zirconium } \\ \text { ZPPR } & \text { Zero Power Physics Reactor }\end{array}$

